January 2005 - NREL/SR-500-36336

\title{
Effects of Airfoil Thickness and Maximum Lift Coefficient on Roughness Sensitivity
}

\section{Period of Performance: 1997 - 1998}

\author{
D.M. Somers
}

Airfoils, Inc.

State College, Pennsylvania

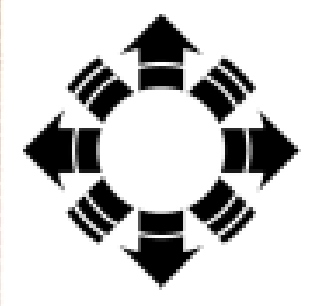

\section{NPEI}

National Renewable Energy Laboratory 1617 Cole Boulevard, Golden, Colorado 80401-3393 303-275-3000 • www.nrel.gov

Operated for the U.S. Department of Energy Office of Energy Efficiency and Renewable Energy by Midwest Research Institute • Battelle 


\section{Effects of Airfoil Thickness and Maximum Lift Coefficient on Roughness Sensitivity}

\section{Period of Performance: 1997 - 1998}

D.M. Somers

Airfoils, Inc.

State College, Pennsylvania

NREL Technical Monitor: Jim Tangler

Prepared under Subcontract No. AAM-7-16479-01
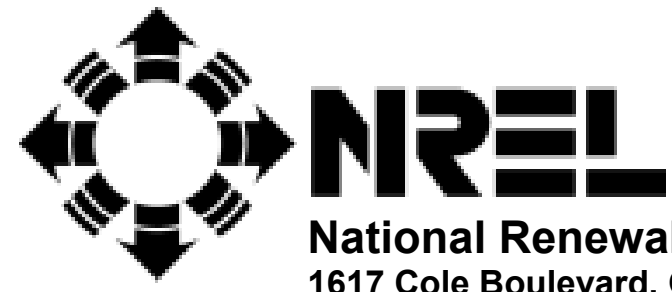

National Renewable Energy Laboratory

1617 Cole Boulevard, Golden, Colorado 80401-3393

303-275-3000 • www.nrel.gov

Operated for the U.S. Department of Energy

Office of Energy Efficiency and Renewable Energy

by Midwest Research Institute $\bullet$ Battelle

Contract No. DE-AC36-99-G010337 


\section{This publication was reproduced from the best available copy submitted by the subcontractor and received no editorial review at NREL}

\section{NOTICE}

This report was prepared as an account of work sponsored by an agency of the United States government. Neither the United States government nor any agency thereof, nor any of their employees, makes any warranty, express or implied, or assumes any legal liability or responsibility for the accuracy, completeness, or usefulness of any information, apparatus, product, or process disclosed, or represents that its use would not infringe privately owned rights. Reference herein to any specific commercial product, process, or service by trade name, trademark, manufacturer, or otherwise does not necessarily constitute or imply its endorsement, recommendation, or favoring by the United States government or any agency thereof. The views and opinions of authors expressed herein do not necessarily state or reflect those of the United States government or any agency thereof.

Available electronically at http://www.osti.gov/bridge

Available for a processing fee to U.S. Department of Energy and its contractors, in paper, from:

U.S. Department of Energy

Office of Scientific and Technical Information

P.O. Box 62

Oak Ridge, TN 37831-0062

phone: 865.576 .8401

fax: 865.576 .5728

email: mailto:reports@adonis.osti.gov

Available for sale to the public, in paper, from:

U.S. Department of Commerce

National Technical Information Service

5285 Port Royal Road

Springfield, VA 22161

phone: 800.553 .6847

fax: 703.605.6900

email: orders@ntis.fedworld.gov

online ordering: http://www.ntis.gov/ordering.htm 


\section{Table of Contents}

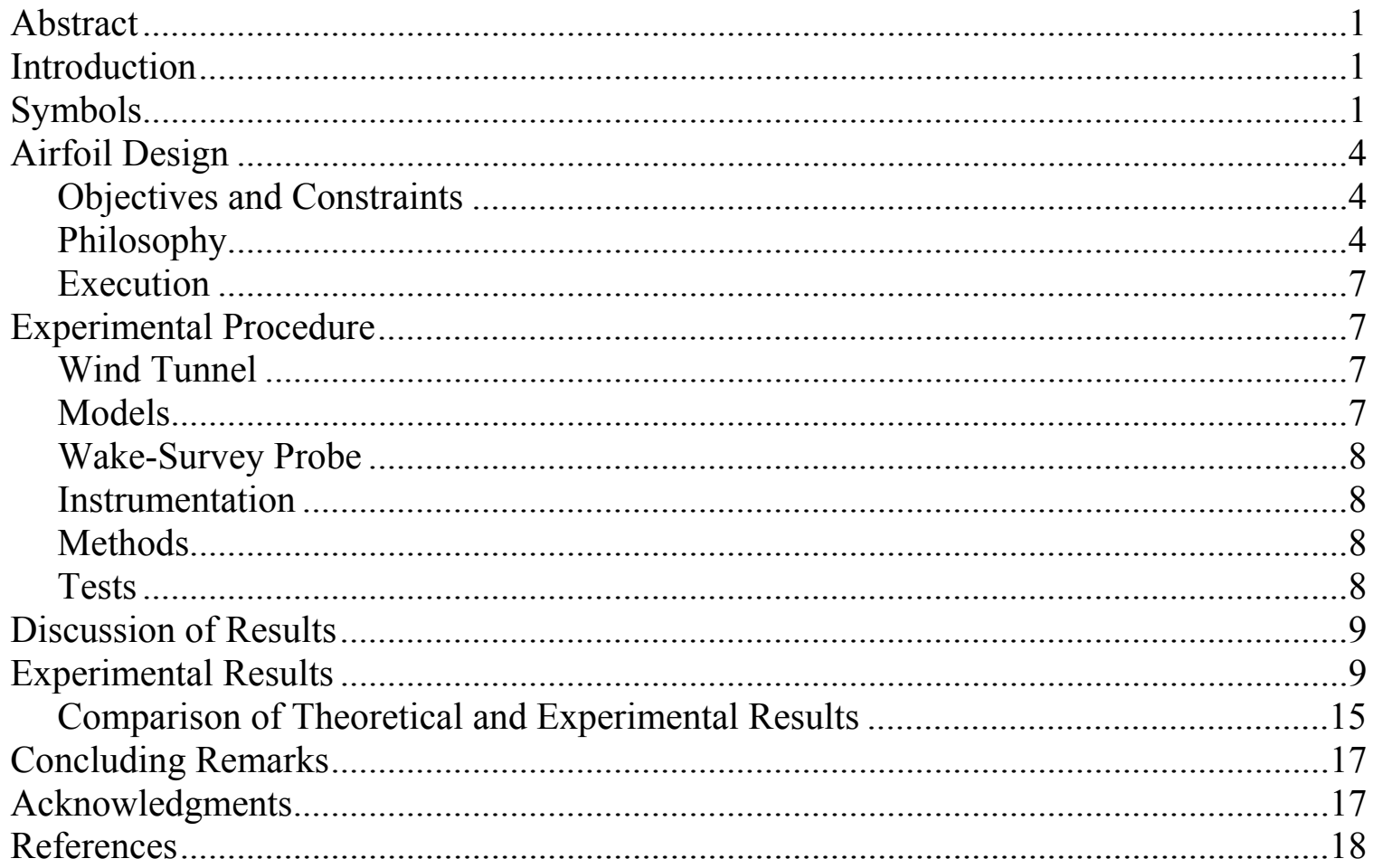

\section{List of Tables}

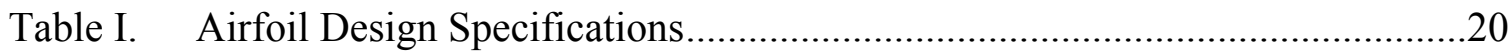

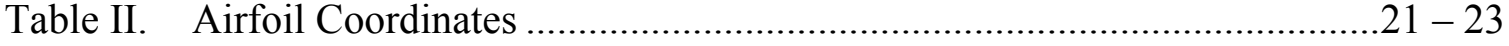

Table III. Model Orifice Locations …………………........................................... 24

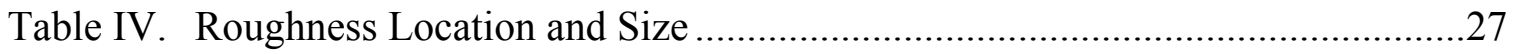

\section{List of Figures}

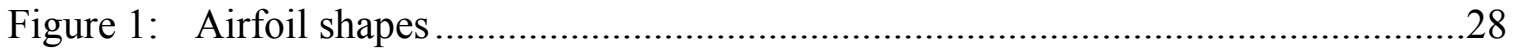

Figure 2: The Pennsylvania State University low-speed, low-

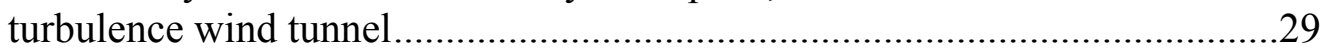

Figure 3: Model and wake-survey probe mounted in test section...................................30

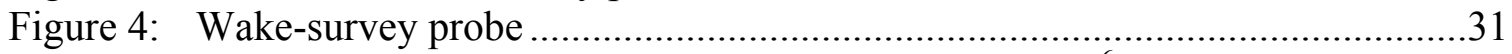

Figure 5: Pressure distributions for S901 airfoil for $\mathrm{R}=1.0 \times 10^{6}$ and

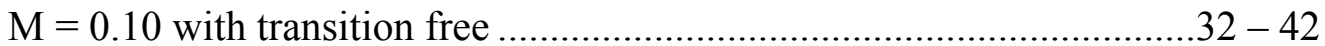

Figure 6: Pressure distributions for S902 airfoil for $\mathrm{R}=1.0 \times 10^{6}$ and $\mathrm{M}=0.10$ with transition free ...

Figure 7: Pressure distributions for $\mathrm{S} 903$ airfoil for $\mathrm{R}=1.0 \times 10^{6}$, and $\mathrm{M}=0.10$ with transition free ........................................................... 67

Figure 8: Section characteristics of S901 airfoil with transition free, transition fixed, and rough $68-71$ 
Figure 9: Effects of Reynold number on section characteristics

of S901 airfoil $72-74$

Figure 10: Section characteristics of S902 airfoil with transition free, transition fixed, and rough $75-78$

Figure 11: Effects of Reynolds number on section characteristics of S902 airfoil $79-81$

Figure 12: Section characteristics of S903 airfoil with transition free, transition fixed, and rough $82-85$

Figure 13: Effects of Reynolds number on section characteristics of S903 airfoil $86-88$

Figure 14: Variation of maximum lift coefficient of S901, S902, and S903 airfoils with Reynolds number.

Figure 15: Variation of minimum profile-drag coefficient of S901, S902, and S903 airfoils with Reynolds number. .90

Figure 16: Variation of change in maximum lift coefficient due to roughness with Reynolds number for S901, S902, and S903 airfoils

Figure 17: Effect of airfoil thickness on change in maximum lift coefficient due to scaled, NACA standard roughness

Figure 18: Effect of maximum lift coefficient on change in maximum lift coefficient due to scaled, NACA standard roughness

Figure 19: Comparison of theoretical and experimental pressure distribution for S901 airfoil $.94-96$

Figure 20: Comparison of theoretical and experimental pressure distribution for S902 airfoil $97-99$

Figure 21: Comparison of theoretical and experimental pressure distributions for S903 airfoil $100-102$

Figure 22: Comparison of theoretical and experimental section characteristics of S901 airfoil with transition free. $103-106$

Figure 23: Comparison of theoretical and experimental section characteristics of S902 airfoil with transition free $107-109$

Figure 24: Comparison of theoretical and experimental section characteristics of S903 airfoil with transition free $110-113$

Figure 25: Comparison of theoretical and experimental section characteristics of S901 airfoil with transition fixed.... $114-117$

Figure 26: Comparison of theoretical and experimental section characteristics of S902 airfoil with transition fixed. $118-120$

Figure 27: Comparison of theoretical and experimental section characteristics of S903 airfoil with transition fixed. $121-124$ 


\begin{abstract}
A matrix of airfoils has been developed to determine the effects of airfoil thickness and maximum lift on the sensitivity of the maximum lift to leading-edge roughness. The matrix consists of three natural-laminar-flow airfoils, the S901, S902, and S903, for windturbine applications. The airfoils have been designed and analyzed theoretically and verified experimentally in The Pennsylvania State University low-speed, low-turbulence wind tunnel. The effect of roughness on the maximum lift increases with increasing airfoil thickness and decreases slightly with increasing maximum lift. Comparisons of the theoretical and experimental results generally show good agreement.
\end{abstract}

\title{
$\underline{\text { INTRODUCTION }}$
}

The results of three recent experimental investigations (refs. 1-3) of wind-turbine airfoils exhibit effects of airfoil thickness and maximum lift coefficient on the sensitivity of the maximum lift coefficient to leading-edge roughness. Because the design specifications for these airfoils are not consistent, however, the results cannot be used to conclusively determine these effects. Accordingly, a matrix of three natural-laminar-flow airfoils has been designed and analyzed theoretically and verified experimentally to quantify these effects.

The airfoils designed under the present study are not intended for a specific class of wind turbines but, instead, are only representative of recent, horizontal-axis wind-turbine airfoils. The specific tasks performed under this study are described in National Renewable Energy Laboratory (NREL) Subcontract Number AAM-7-16479-01. The design specifications for the airfoils are outlined in the Statement of Work. These specifications were later refined during discussions with James L. Tangler of NREL.

To more accurately quantify the effects of airfoil thickness and maximum lift coefficient on roughness sensitivity, an experimental investigation was conducted in The Pennsylvania State University low-speed, low-turbulence wind tunnel (ref. 4) to obtain the basic, lowspeed, two-dimensional aerodynamic characteristics of the airfoils. The results have been compared with predictions from the method of references 5 and 6 .

\section{$\underline{\text { SYMBOLS }}$}

Values are given in both SI and U.S. Customary Units. Measurements and calculations were made in U.S. Customary Units.

$$
\begin{array}{ll}
\mathrm{C}_{\mathrm{p}} & \text { pressure coefficient, } \frac{\mathrm{p}_{l}-\mathrm{p}_{\infty}}{\mathrm{q}_{\infty}} \\
\mathrm{c} & \text { airfoil chord, } \mathrm{mm} \text { (in.) }
\end{array}
$$


$c_{c}$

$c_{d}$

$\mathrm{c}_{\mathrm{d}}{ }^{\prime}$

$\mathrm{c}_{l}$

$c_{m}$

$\mathrm{c}_{\mathrm{n}}$

h

L.

$\mathrm{M}$

$\mathrm{p}$

q

$\mathrm{R}$

S.

$\mathrm{T}$.

t

U.

$\mathrm{X}$

y

$\mathrm{Z}$

section chord-force coefficient, $\oint C_{p} d\left(\frac{z}{c}\right)$

section profile-drag coefficient, $\int_{\text {Wake }} c_{d}{ }^{\prime} d\left(\frac{h}{c}\right)$

point drag coefficient (ref. 7)

section lift coefficient, $c_{n} \cos \alpha-c_{c} \sin \alpha$

section pitching-moment coefficient about quarter-chord point,

$-\oint C_{p}\left(\frac{x}{c}-0.25\right) d\left(\frac{x}{c}\right)+\oint C_{p}\left(\frac{z}{c}\right) d\left(\frac{z}{c}\right)$

section normal-force coefficient, $-\oint C_{p} d\left(\frac{x}{c}\right)$

horizontal width in wake profile, $\mathrm{mm}$ (in.)

lower surface

free-stream Mach number

static pressure, $\mathrm{Pa}\left(\mathrm{lbf} / \mathrm{ft}^{2}\right)$

dynamic pressure, $\mathrm{Pa}\left(\mathrm{lbf} / \mathrm{ft}^{2}\right)$

Reynolds number based on free-stream conditions and airfoil chord

boundary-layer separation location, $\mathrm{x}_{\mathrm{S}} / \mathrm{c}$

boundary-layer transition location, $\mathrm{x}_{\mathrm{T}} / \mathrm{c}$

airfoil thickness, $\mathrm{mm}$ (in.)

upper surface

airfoil abscissa, $\mathrm{mm}$ (in.)

model span station, $y=0$ at midspan, positive downward, $\mathrm{mm}$ (in.)

airfoil ordinate, $\mathrm{mm}$ (in.) 
$\alpha$

$\Delta \mathrm{c}_{\mathrm{d}}$

$\Delta \mathrm{c}_{l, \max }$

$$
\frac{\left(\mathrm{c}_{l, \mathrm{max}}\right)_{\text {free }}-\left(\mathrm{c}_{l, \text { max }}\right)_{\text {fixed or } \text { rough }}}{\left(\mathrm{c}_{l, \text { max }}\right)_{\text {free }}} \text {, percent }
$$

Subscripts:

$\begin{array}{ll}\text { fixed } & \text { transition fixed } \\ l & \text { transition free } \\ \text { last } & \text { local point on airfoil } \\ \text { Il } & \text { last measured wake profile } \\ \text { max } & \text { lower limit of low-drag range } \\ \text { min } & \text { maximum } \\ \text { rough } & \text { minimum } \\ \mathrm{S} & \text { rough } \\ \mathrm{T} & \text { separation } \\ \mathrm{ul} & \text { transition } \\ 0 & \text { upper limit of low-drag range } \\ \infty & \text { zero lift } \\ \end{array}$

Abbreviation:

NACA National Advisory Committee for Aeronautics 


\section{AIRFOIL DESIGN}

\section{OBJECTIVES AND CONSTRAINTS}

The results presented in references 1 through 3 suggest that the effect of leading-edge roughness on the maximum lift coefficient is a function of airfoil thickness and maximum lift coefficient. One of the key goals for wind-turbine airfoils, however, is to achieve a maximum lift coefficient that is relatively insensitive to leading-edge roughness. Therefore, the maximum lift coefficient of the airfoils designed under the present study should be insensitive to roughness to determine if the effects implied by the previous results must occur.

The design specifications for the airfoils, designated the S901, S902, and S903, are contained in table I. To separate the effects of airfoil thickness and maximum lift coefficient, two of the airfoils (S901 and S902) have a common maximum lift coefficient and two (S902 and S903) have a common airfoil thickness. For all three airfoils, a primary goal is to achieve a maximum lift coefficient that does not decrease significantly with transition fixed near the leading edge on both surfaces for a Reynolds number of $1.0 \times 10^{6}$. (The Reynolds number was determined by the wind-tunnel testing capabilities.)

One major constraint, in addition to the airfoil-thickness constraint, was placed on the design of the airfoils: the zero-lift pitching-moment coefficient must be no more negative than the value given in table I. Several additional goals were set to ensure that the airfoils would be representative of recent, horizontal-axis wind-turbine airfoils.

\section{PHILOSOPHY}

Given the above objectives and constraints, certain characteristics of the design are apparent. The following sketch illustrates a drag polar that meets the goals for this design. (The S902 airfoil design specifications are used for this example.)

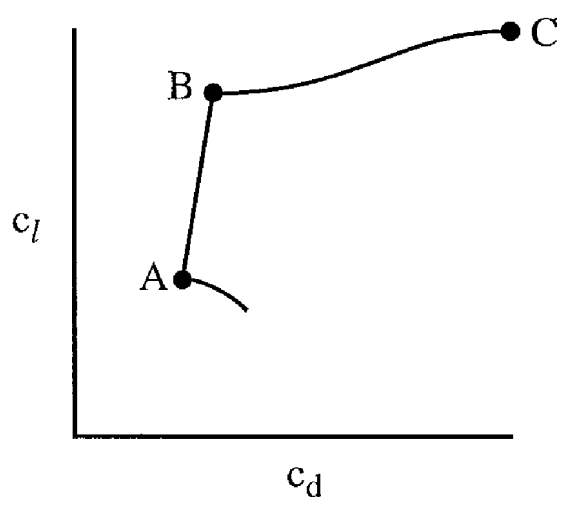

Sketch 1 
The desired airfoil shape can be traced to the pressure distributions that occur at the various points in sketch 1. Point $A$ is the lower limit of the low-drag, lift-coefficient range and point $B$, the upper limit. The drag increases very rapidly outside the low-drag range because boundary-layer transition moves quickly toward the leading edge with increasing (or decreasing) lift coefficient. This feature results in a leading edge that produces a suction peak at higher lift coefficients, which ensures that transition on the upper surface will occur near the leading edge. Thus, the maximum lift coefficient, point $\mathrm{C}$, occurs with turbulent flow along the entire upper surface and, therefore, should be relatively insensitive to roughness at the leading edge.

From the preceding discussion, the pressure distributions along the polar can be deduced. The pressure distribution at point A should look something like sketch 2, again using the $\mathrm{S} 902$ airfoil as the example.

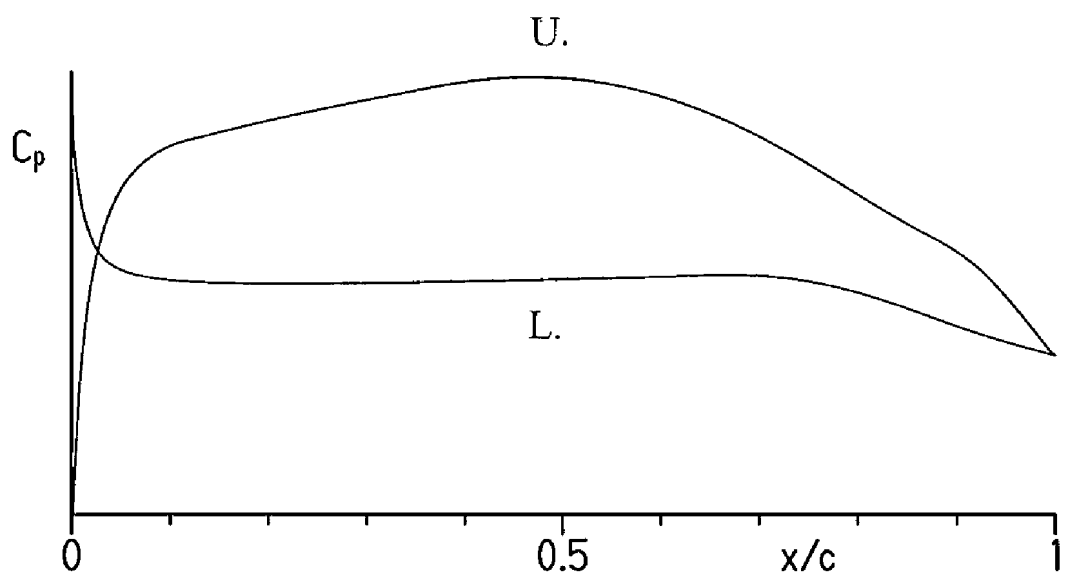

Sketch 2

To achieve low drag, a favorable pressure gradient is desirable along the upper surface to about 45-percent chord. Aft of this point, a region having a shallow, adverse pressure gradient ("transition ramp") promotes the efficient transition from laminar to turbulent flow (ref. 8). The curved transition ramp (ref. 9) is followed by a nearly linear pressure recovery. The specific pressure recovery employed represents a compromise between maximum lift, drag, pitching moment, and stall characteristics. The steep, adverse pressure gradient aft of about 90-percent chord is a "separation ramp," originally proposed by F. X. Wortmann, ${ }^{1}$ which confines turbulent separation to a small region near the trailing edge. By constraining the movement of the separation point at high angles of attack, high lift coefficients can be achieved with little drag penalty. This feature has the added benefit of promoting docile stall characteristics. (See ref. 10.)

\footnotetext{
${ }^{1}$ Director, Institute for Aerodynamics and Gas Dynamics, University of Stuttgart, Germany.
} 
Along the lower surface, the pressure gradient is initially adverse, then zero, and then favorable to about 65-percent chord. Thus, transition is imminent over the entire forward portion of the lower surface. (See ref. 11.) This concept allows a wide low-drag range to be achieved and increases the amount of camber in the leading-edge region. The forward camber serves to balance, with respect to the pitching-moment constraint, the aft camber, both of which contribute to the achievement of a high maximum lift coefficient and low profile-drag coefficients. This region is followed by a curved transition ramp. The ramp is followed by a concave pressure recovery, which exhibits lower drag and has less tendency to separate than the corresponding linear or convex pressure recovery (ref. 8).

The amounts of pressure recovery on the upper and lower surfaces are determined by the airfoil-thickness and pitching-moment constraints.

At point B, the pressure distribution should look like sketch 3 .

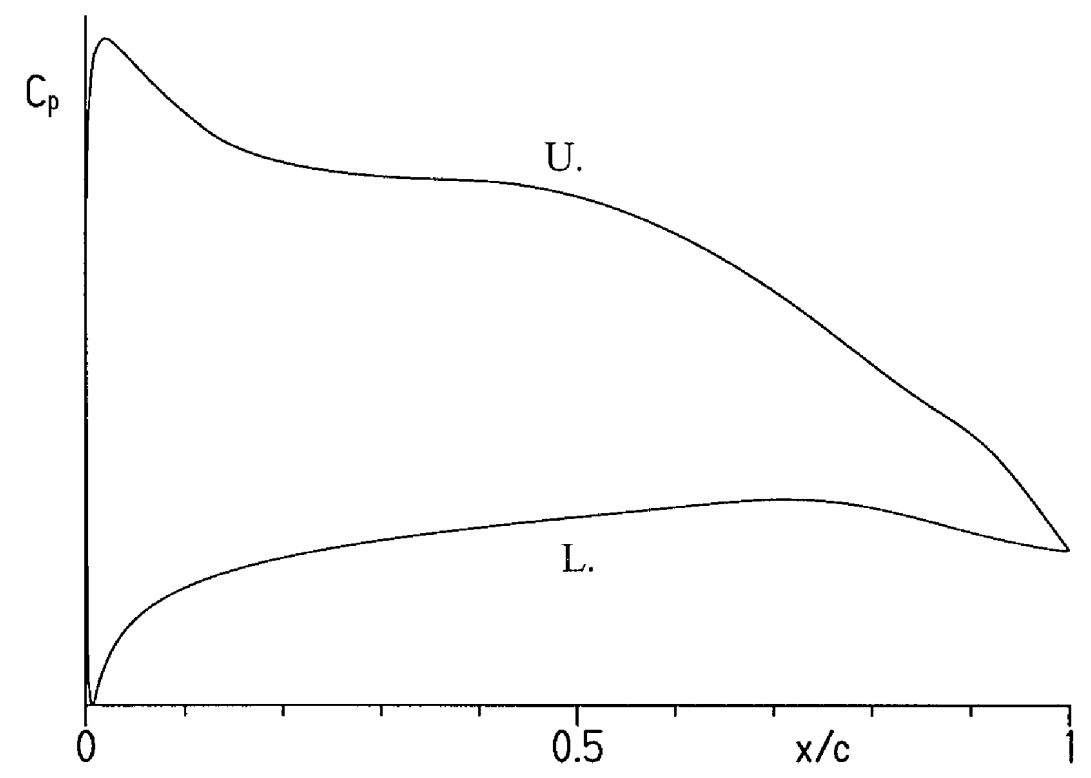

Sketch 3

No suction spike exists at the leading edge. Instead, a gently rounded peak occurs aft of the leading edge. This feature allows higher lift coefficients to be reached without significant separation. At higher angles of attack, the peak becomes sharper and moves rapidly forward to the leading edge. This feature causes transition to move quickly toward the leading edge with increasing lift coefficient, which leads to the roughness insensitivity of the maximum lift coefficient. 
The transition movement in the vicinity of the maximum lift coefficient should be essentially identical for all three airfoils. This common characteristic is intended to produce the same roughness insensitivity for all three airfoils.

\section{EXECUTION}

Given the pressure distributions previously discussed, the design of the airfoils is reduced to the inverse problem of transforming the pressure distributions into airfoil shapes. The Eppler Airfoil Design and Analysis Code (refs. 5 and 6) was used because of its unique capability for multipoint design and because of confidence gained during the design, analysis, and experimental verification of many other airfoils. (See refs. 1-3 and 12, for example.)

The shapes of the S901, S902, and S903 airfoils are shown in figure 1 and the coordinates are contained in table II. The airfoil thicknesses are 17.99-, 11.99-, and 11.99-percent chord, respectively, which satisfy the design constraints.

\section{EXPERIMENTAL PROCEDURE}

\section{WIND TUNNEL}

The Pennsylvania State University low-speed, low-turbulence wind tunnel (ref. 4) is a closed-throat, single-return, atmospheric tunnel (fig. 2). The test section is $148 \mathrm{~cm}(58.1 \mathrm{in}$.) wide by $101 \mathrm{~cm}$ (39.9 in.) high (fig. 3). Electrically actuated turntables provide positioning and attachment for the two-dimensional model. The turntables are flush with the top and bottom tunnel walls and rotate with the model. The axis of rotation coincided with the midchord of the model which was mounted vertically between the turntables. The gaps between the model and the turntables were sealed. The turbulence intensity in the test section is approximately 0.045 percent at $46 \mathrm{~m} / \mathrm{s}(150 \mathrm{ft} / \mathrm{s})$.

\section{MODELS}

The composite, wind-tunnel models were constructed by Skytop Aerospace, Bellefonte, Pennsylvania, using plastic molds cut by a numerically controlled milling machine. Each model consisted of a pseudo spar, two end ribs, and an upper and a lower shell. All the models had a chord of $457.20 \mathrm{~mm}$ (18.000 in.) and a span of about $100 \mathrm{~cm}$ (40 in.). Upperand lower-surface orifices were located to one side of the midspan at the staggered positions listed in table III. All the orifices were $0.51 \mathrm{~mm}(0.020 \mathrm{in}$.) in diameter with their axes perpendicular to the surface. The surface of the models consisted of polyester gelcoat that had been sanded and polished to ensure an aerodynamically smooth finish. The measured model contours were within $0.38 \mathrm{~mm}$ ( $0.015 \mathrm{in}$.) of the prescribed shapes. 


\section{WAKE-SURVEY PROBE}

A total- and static-pressure, wake-survey probe (fig. 4) was mounted from the top tunnel wall (fig. 3). The probe was positioned spanwise at the tunnel centerline and automatically aligned with the local flow. A traverse mechanism incrementally positioned the probe in the wake. The tip of the probe was located 0.8 chord downstream of the trailing edge of the model.

\section{INSTRUMENTATION}

The basic tunnel pressures and the wake pressures were measured with piezoresistive pressure transducers. Measurements of the pressures on the model were made by an automatic pressure-scanning system. Data were obtained and recorded by an electronic dataacquisition system.

\section{METHODS}

The pressures measured on the model were reduced to standard pressure coefficients and numerically integrated to obtain section normal- and chord-force coefficients and section pitching-moment coefficients about the quarter-chord point. Section profile-drag coefficients were computed from the wake total and static pressures by the method of reference 7 .

Standard, low-speed, wind-tunnel boundary corrections (ref. 13) have been applied to the data. The total-pressure-tube displacement correction (ref. 7) has not been taken into account in order that the data be directly comparable to previously published airfoil data.

At angles of attack beyond stall, the unsteadiness of the flow and the large width of the wake made wake surveys impractical. Accordingly, at these angles of attack, the uncorrected profile-drag coefficient was set to $c_{d, \text { last }}+\Delta c_{d}\left(\alpha-\alpha_{\text {last }}\right)$, where $\Delta c_{d}$ was determined from data presented in reference 14 . Typically, the value of $c_{\mathrm{d} \text {,last }}$ was about 0.1 .

\section{TESTS}

All the models were tested at Reynolds numbers based on airfoil chord of $0.7 \times 10^{6}$, $1.0 \times 10^{6}$, and $1.5 \times 10^{6}$ with transition free (smooth) and with transition fixed by roughness at 2 -percent chord on the upper surface and 7-percent chord on the lower surface. The grit roughness was sized using the method of reference 15 and sparsely distributed along 3-mm (0.1-in.) wide strips applied to the model with lacquer. (See table IV.) Each model was also tested with a roughness equivalent to NACA standard roughness (ref. 16), which consisted of grit roughness having a nominal size of $0.211 \mathrm{~mm}(0.0083 \mathrm{in}$.) applied to the model with lacquer and sparsely distributed from the leading edge to an arc length of 8-percent chord on the upper and lower surfaces. (The grit size was scaled from the NACA standard-roughness grit size by the ratio of the model chords used in the two wind tunnels: $457.2 \mathrm{~mm}$ (18.00 in.) in 
the present investigation and $609.6 \mathrm{~mm}(24.00 \mathrm{in}$.) in the NACA tests.)

Starting from $0^{\circ}$, the angle of attack was increased and then decreased to determine hysteresis. The same procedure was followed for negative angles of attack.

For several test runs, the model surfaces were coated with oil to determine the location, as well as the nature, of the boundary-layer transition from laminar to turbulent flow (ref. 17). Transition was also located using a stethoscope connected to a probe that was moved slowly downstream along the model surface. The beginning of the turbulent boundary layer was detected as an increase in noise level over that for the laminar boundary layer which was essentially silent. (See ref. 18.) Tufts were used to check the two-dimensionality of the flow at high angles of attack and to visualize the turbulent-separation patterns.

\section{DISCUSSION OF RESULTS}

\section{EXPERIMENTAL RESULTS}

\section{Pressure Distributions}

The pressure distributions for the S901 airfoil at various angles of attack for a Reynolds number of $1.0 \times 10^{6}$ and a Mach number of 0.10 with transition free are shown in figure 5. At an angle of attack of $-0.01^{\circ}$ (fig. 5(a)), a short laminar separation bubble is evident on the upper surface around 65-percent chord and on the lower surface around 50-percent chord. As the angle of attack is increased, the bubble on the upper surface moves forward whereas the bubble on the lower surface moves aft. At an angle of attack of $5.08^{\circ}$ (fig. 5(a)), which corresponds approximately to the upper limit of the low-drag, lift-coefficient range, the bubble on the upper surface has almost disappeared. As the angle of attack is increased further, transition moves rapidly forward and turbulent, trailing-edge separation occurs on the upper surface. The amount of separation increases with increasing angle of attack (figs. 5(b) and 5(c)). The maximum lift coefficient occurs at an angle of attack just beyond $11.17^{\circ}$ (fig. 5(c)). As the angle of attack is increased further, the separation point continues to move forward until almost the entire upper surface is separated (fig. 5(d)).

As the angle of attack is decreased from $20.06^{\circ}$, the pressure distributions (figs. 5(e) and 5(f)) are essentially identical to the ones that occur with increasing angle of attack (figs. 5(c) and 5(d)). Thus, no hysteresis occurs with respect to separation on the upper surface.

As the angle of attack is decreased from $-1.03^{\circ}$ (fig. $5(\mathrm{~g})$ ), the laminar separation bubble on the lower surface moves forward whereas the bubble on the upper surface moves aft. At an angle of attack of $-6.12^{\circ}$ (fig. 5(h)), which corresponds approximately to the lower limit of the low-drag range, the bubble on the lower surface has almost disappeared. As the angle of attack is decreased further, transition moves rapidly forward and turbulent, trailing-edge separation occurs on the lower surface. The separation point moves rapidly forward to about the midchord (fig. 5(h)). The minimum lift coefficient occurs at an angle of attack of $-13.15^{\circ}$ 
(fig. 5(i)). As the angle of attack is decreased further, the separation point jumps forward, then the leading-edge pressure peak collapses at an angle of attack of $-18.06^{\circ}$, and finally the entire lower surface is separated (fig. 5(j)).

As the angle of attack is increased from $-19.07^{\circ}$, the pressure distributions (fig. $5(\mathrm{k})$ ) are essentially identical to the ones that occur with decreasing angle of attack (figs. 5(i) and 5(j)). Thus, no hysteresis occurs with respect to separation on the lower surface.

The pressure distributions for the S902 airfoil at various angles of attack for a Reynolds number of $1.0 \times 10^{6}$ and a Mach number of 0.10 with transition free are shown in figure 6. At an angle of attack of $0.01^{\circ}$ (fig. 6(a)), which corresponds to the lower limit of the low-drag range, a short laminar separation bubble is evident on the upper surface around 70 percent chord and on the lower surface around 85-percent chord. As the angle of attack is increased, the bubble on the upper surface moves forward whereas the bubble on the lower surface moves aft. At an angle of attack of $5.10^{\circ}$ (fig. 6(a)), which corresponds approximately to the upper limit of the low-drag range, the bubble on the upper surface has almost disappeared. As the angle of attack is increased further, transition moves rapidly forward and turbulent, trailing-edge separation occurs on the upper surface. The amount of separation increases with increasing angle of attack (figs. 6(b) and 6(c)). The maximum lift coefficient occurs at an angle of attack of $13.19^{\circ}$ (fig. 6(c)). As the angle of attack is increased further, the separation point continues to move forward until almost the entire upper surface is separated (fig. 6(d)).

As the angle of attack is decreased from $20.13^{\circ}$, the pressure distributions (figs. 6(e) and 6(f)) are essentially identical to the ones that occur with increasing angle of attack (figs. 6(c) and 6(d)). Thus, no hysteresis occurs with respect to separation on the upper surface.

As the angle of attack is decreased from $-1.01^{\circ}$ (fig. 6(g)), transition moves rapidly forward on the lower surface. At an angle of attack of $-3.04^{\circ}$ (fig. 6(g)), a long laminar separation bubble forms near the leading edge on the lower surface. As the angle of attack is decreased further, the long bubble increases in length (figs. 6(g) and 6(h)). The minimum lift coefficient occurs at an angle of attack of $-8.06^{\circ}$ (fig. 6(h)). As the angle of attack is decreased further, the long bubble continues to increase in length until it extends over the entire lower surface (figs. 6(i) and 6(j)).

As the angle of attack is increased from $-19.06^{\circ}$, the long bubble on the lower surface decreases in length (figs. $6(\mathrm{k})-6(\mathrm{~m})$ ). The pressure distributions are essentially identical to the ones that occur with decreasing angle of attack (figs. 6(h)-6(j)). Thus, no hysteresis occurs with respect to separation on the lower surface.

The pressure distributions for the S903 airfoil at various angles of attack for a Reynolds number of $1.0 \times 10^{6}$ and a Mach number of 0.10 with transition free are shown in figure 7. At an angle of attack of $0.01^{\circ}$ (fig. 7(a)), a short laminar separation bubble is evident on the upper surface around 70-percent chord and on the lower surface around 90-percent chord. As the angle of attack is increased, the bubble on the upper surface moves forward 
whereas the bubble on the lower surface moves aft. At an angle of attack of $4.08^{\circ}$ (fig. 7 (a)), which corresponds to the upper limit of the low-drag range, the bubble on the upper surface has essentially disappeared. As the angle of attack is increased further, transition moves rapidly forward and turbulent, trailing-edge separation occurs on the upper surface. The amount of separation increases with increasing angle of attack (figs. 7(b) and 7(c)). The maximum lift coefficient occurs at an angle of attack just beyond $13.20^{\circ}$ (fig. 7(c)). As the angle of attack is increased further, the separation point continues to move forward until essentially the entire upper surface is separated (fig. 7(d)).

As the angle of attack is decreased from $20.07^{\circ}$, the pressure distributions (figs. 7(e) and $7(f))$ are essentially identical to the ones that occur with increasing angle of attack (figs. 7(c) and 7(d)). Thus, no hysteresis occurs with respect to separation on the upper surface.

At an angle of attack of $-1.01^{\circ}$ (fig. $7(\mathrm{~g})$ ), which corresponds approximately to the lower limit of the low-drag range, the bubble on the lower surface has almost disappeared. As the angle of attack is decreased, transition moves rapidly forward on the lower surface. At an angle of attack of $-7.11^{\circ}$ (fig. 7(h)), a long laminar separation bubble forms near the leading edge on the lower surface. As the angle of attack is decreased further, the long bubble increases in length (fig. 7(h)). The minimum lift coefficient occurs at an angle of attack just beyond $-10.08^{\circ}$ (fig. 7(h)). As the angle of attack is decreased further, the long bubble continues to increase in length until it extends over the entire lower surface (figs. 7(i) and 7(j)).

As the angle of attack is increased from $-20.05^{\circ}$, the long bubble on the lower surface decreases in length (figs. 7(k) and 7(l)). The pressure distributions are essentially identical to the ones that occur with decreasing angle of attack (figs. 7(h)-7(j)). Thus, no hysteresis occurs with respect to separation on the lower surface.

\section{Transition Location}

The variation of transition location with lift coefficient, as determined by stethoscope measurements, for the $\mathrm{S} 901$ airfoil is shown in figure 8 and the effects of Reynolds number on transition location are summarized in figure 9. It should be noted that laminar separation cannot be detected using the stethoscope technique. Thus, for lift coefficients that exhibit laminar separation bubbles, the "transition location" measured corresponds to the turbulentreattachment point. If transition occurred over some length, an average value was taken. Cursory checks indicated that the model orifices generally had little influence on the transition location. The variation of transition location with lift coefficient for the S902 airfoil is shown in figure 10 and the effects of Reynolds number on transition location are summarized in figure 11. The variation of transition location with lift coefficient for the $\$ 903$ airfoil is shown in figure 12 and the effects of Reynolds number on transition location are summarized in figure 13. 


\section{Section Characteristics}

Reynolds number effects.- The section characteristics of the S901 airfoil with transition free, transition fixed, and the scaled, NACA standard roughness ("rough") are shown in figure 8. For a Reynolds number of $1.0 \times 10^{6}$ and a Mach number of 0.10 with transition free (fig. 8(b)), the maximum lift coefficient is 1.26 , which is 3 -percent below the design objective of $c_{l, \max }=1.30$. The airfoil exhibits a turbulent, trailing-edge stall. No hysteresis occurs for angles of attack beyond stall. Low profile-drag coefficients are exhibited over the range of lift coefficients from -0.26 to 1.00 . Thus, the lower limit of the low-drag, lift-coefficient range is well below the design objective of $c_{l, 11}=0.50$ although the upper limit of the low-drag range is also below the design objective of $\mathrm{c}_{l, \mathrm{ul}}=1.10$, primarily to meet other, more important goals. The zero-lift pitching-moment coefficient is -0.12 , which satisfies the design constraint of $\mathrm{c}_{\mathrm{m}, 0} \geq-0.15$.

The effects of Reynolds number on the section characteristics of the S901 airfoil with transition free, transition fixed, and rough are summarized in figure 9. The zero-lift angle of attack, approximately $-4.1^{\circ}$ with transition free, is relatively unaffected by Reynolds number. In general, with transition free (fig. 9(a)), the lift-curve slope, the maximum lift coefficient, and the magnitude of the pitching-moment coefficients increase with increasing Reynolds number; the drag coefficients and the upper limit of the low-drag range decrease. Because the Mach number increases proportionally with the Reynolds number in an atmospheric wind tunnel, part of the increase in lift-curve slope and magnitude of the pitching-moment coefficients is probably due to compressibility effects.

The section characteristics of the S902 airfoil with transition free, transition fixed, and rough are shown in figure 10. For a Reynolds number of $1.0 \times 10^{6}$ and a Mach number of 0.10 with transition free (fig. 10(b)), the maximum lift coefficient is 1.30 , which meets the design objective. The airfoil exhibits a turbulent, trailing-edge stall. No hysteresis occurs for angles of attack beyond stall. Low drag coefficients are exhibited over the range of lift coefficients from 0.51 to 1.04 . Thus, the lower limit of the low-drag range is slightly above the design objective of $c_{l, 11}=0.50$ and the upper limit is below the design objective of $\mathrm{c}_{l, \mathrm{ul}}=1.10$, primarily to meet other, more important goals. The zero-lift pitching-moment coefficient is -0.11 , which satisfies the design constraint of $c_{\mathrm{m}, 0} \geq-0.15$.

The effects of Reynolds number on the section characteristics of the S902 airfoil with transition free, transition fixed, and rough are summarized in figure 11. The zero-lift angle of attack, approximately $-4.8^{\circ}$ with transition free, is relatively unaffected by Reynolds number. In general, with transition free (fig. 11(a)), the lift-curve slope, the maximum lift coefficient, the lower limit of the low-drag range, and the magnitude of the pitching-moment coefficients increase with increasing Reynolds number; the drag coefficients and the upper limit of the low-drag range decrease. Because the Mach number increases proportionally with the Reynolds number, part of the increase in lift-curve slope and magnitude of the pitching-moment coefficients is probably due to compressibility effects.

The section characteristics of the S903 airfoil with transition free, transition fixed, and rough are shown in figure 12. For a Reynolds number of $1.0 \times 10^{6}$ and a Mach number of 
0.10 with transition free (fig. 12(b)), the maximum lift coefficient is 1.13 , which is 26 percent above the design objective of $\mathrm{c}_{l, \max }=0.90$. The airfoil exhibits a turbulent, trailing-edge stall. No hysteresis occurs for angles of attack beyond stall. Low drag coefficients are exhibited over the range of lift coefficients from 0.05 to 0.63 . Thus, the lower limit of the low-drag range is below the design objective of $c_{l, 11}=0.10$ although the upper limit is also below the design objective of $\mathrm{c}_{l, \mathrm{ul}}=0.70$, primarily to meet other, more important goals. The zero-lift pitching-moment coefficient is -0.04 , which satisfies the design constraint of $\mathrm{c}_{\mathrm{m}, 0} \geq-0.07$.

The effects of Reynolds number on the section characteristics of the S903 airfoil with transition free, transition fixed, and rough are summarized in figure 13. The zero-lift angle of attack, approximately $-2.0^{\circ}$ with transition free, is relatively unaffected by Reynolds number. In general, with transition free (fig. 13(a)), the lift-curve slope, the maximum lift coefficient, the lower limit of the low-drag range, and the magnitude of the pitching-moment coefficients increase with increasing Reynolds number; the drag coefficients and the upper limit of the low-drag range decrease. Because the Mach number increases proportionally with the Reynolds number, part of the increase in lift-curve slope and magnitude of the pitching-moment coefficients is probably due to compressibility effects.

Effect of roughness.- The effect of fixing transition on the section characteristics of the S901 airfoil is shown in figure 8. In general, the lift-curve slope, the maximum lift coefficient, and the magnitudes of the zero-lift angle of attack and the pitching-moment coefficients decrease with transition fixed. These results are primarily a consequence of the boundarylayer displacement effect which decambers the airfoil, the displacement thickness being greater with transition fixed than with transition free. In addition, the lift-curve slope and the maximum lift coefficient decrease with transition fixed because the roughness induces earlier trailing-edge separation, particularly at higher angles of attack. The maximum lift coefficient for a Reynolds number of $1.0 \times 10^{6}$ and a Mach number of 0.10 (fig. $8(\mathrm{~b})$ ) is 1.25 , a reduction of 1 percent from that with transition free. Thus, one of the most important design goals has been achieved. The drag coefficients are, of course, adversely affected by the roughness. For many conditions, the Reynolds number, based on local velocity and boundary-layer momentum thickness, at the roughness location is too low to support turbulent flow. Accordingly, to force transition, the roughness must be so large that it increases the momentum thickness, which abnormally decreases the lift coefficients and the magnitude of the pitching-moment coefficients and increases the drag coefficients. Conversely, at low lift coefficients, the roughness on the upper surface, which was sized for higher lift coefficients, was frequently too small to force transition, resulting in inappropriately low drag coefficients.

The effect of the scaled, NACA standard roughness on the section characteristics of the S901 airfoil is shown in figure 8. The effect is more severe than that of fixing transition. The maximum lift coefficient for a Reynolds number of $1.0 \times 10^{6}$ and a Mach number of 0.10 (fig. 8(b)) is 1.07, a reduction of 15 percent from that with transition free. It should be remembered that the effect of roughness is proportional to the ratio of the roughness height to the boundary-layer thickness. Because the height of the scaled, NACA standard roughness and the airfoil chord are constant, the effect of this roughness generally increases with increasing Reynolds number (because increasing Reynolds number results in decreasing boundary-layer thickness). 
The effect of fixing transition on the section characteristics of the S902 airfoil is shown in figure 10. The zero-lift angle of attack is relatively unaffected by fixing transition. In general, the lift-curve slope, the maximum lift coefficient, and the magnitude of the pitching-moment coefficients decrease with transition fixed. The maximum lift coefficient for a Reynolds number of $1.0 \times 10^{6}$ and a Mach number of 0.10 (fig. $10(\mathrm{~b})$ ) is 1.28 , a reduction of 2 percent from that with transition free. Thus, one of the most important design goals has been achieved. The drag coefficients are, of course, adversely affected by the roughness. For many conditions, the abnormal roughness effects previously discussed also occurred for the S902 airfoil.

The effect of the scaled, NACA standard roughness on the section characteristics of the $\mathrm{S} 902$ airfoil is shown in figure 10. The effect is more severe than that of fixing transition. The maximum lift coefficient for a Reynolds number of $1.0 \times 10^{6}$ and a Mach number of 0.10 (fig. $10(\mathrm{~b})$ ) is 1.16 , a reduction of approximately 11 percent from that with transition free. The effect of roughness generally increases with increasing Reynolds number, as discussed previously.

The effect of fixing transition on the section characteristics of the S903 airfoil is shown in figure 12. The zero-lift angle of attack and the pitching-moment coefficients are relatively unaffected by fixing transition. In general, the lift-curve slope and the maximum lift coefficient decrease with transition fixed. The maximum lift coefficient for a Reynolds number of $1.0 \times 10^{6}$ and a Mach number of 0.10 (fig. 12(b)) is 1.11 , a reduction of 2 percent from that with transition free. Thus, one of the most important design goals has been achieved. The drag coefficients are, of course, adversely affected by the roughness. For many conditions, the abnormal roughness effects previously discussed also occurred for the S903 airfoil.

The effect of the scaled, NACA standard roughness on the section characteristics of the $\mathrm{S} 903$ airfoil is shown in figure 12. The effect is more severe than that of fixing transition. The maximum lift coefficient for a Reynolds number of $1.0 \times 10^{6}$ and a Mach number of 0.10 (fig. 12(b)) is 1.01, a reduction of 11 percent from that with transition free. The effect of roughness generally increases with increasing Reynolds number, as discussed previously.

The variation of the maximum lift coefficient of the S901, S902, and S903 airfoils with Reynolds number is shown in figure 14. The maximum lift coefficient generally increases with increasing Reynolds number. The rate of increase is similar with transition free and transition fixed but lower with the scaled, NACA standard roughness.

The variation of the minimum profile-drag coefficient of the S901, S902, and S903 airfoils with Reynolds number is shown in figure 15. The minimum drag coefficient with transition free decreases with increasing Reynolds number. The minimum drag coefficient with transition fixed varies erratically with Reynolds number because of the abnormal roughness effects previously discussed. The trend of the minimum drag coefficient with the scaled, NACA standard roughness is upward with increasing Reynolds number, as discussed previously. 
The variation of the change in maximum lift coefficient due to roughness with Reynolds number for the S901, S902, and S903 airfoils is shown in figure 16. The change due to fixing transition is relatively small and exhibits no definite trend with Reynolds number. The change due to the scaled, NACA standard roughness is an order of magnitude larger and generally increases with increasing Reynolds number.

Effect of airfoil thickness.- The effect of airfoil thickness on the change in maximum lift coefficient due to roughness is shown in figure 17. Because the change due to fixing transition is small and essentially the same for all the airfoils, only the change due to the scaled, NACA standard roughness is shown. For all three Reynolds numbers, the change in maximum lift coefficient due to roughness increases with increasing airfoil thickness.

Effect of maximum lift coefficient.- The effect of maximum lift coefficient on the change in maximum lift coefficient due to roughness is shown in figure 18. Because the change due to fixing transition is small and essentially the same for all the airfoils, only the change due to the scaled, NACA standard roughness is shown. Except for a Reynolds number

of $0.7 \times 10^{6}$, the change in maximum lift coefficient due to roughness decreases slightly with increasing maximum lift coefficient.

\section{COMPARISON OF THEORETICAL AND EXPERIMENTAL RESULTS}

\section{Pressure Distributions}

The comparison of the theoretical and experimental pressure distributions for the S901, S902, and S903 airfoils is shown in figures 19, 20, and 21, respectively. The theoretical pressure distributions are inviscid and incompressible; the experimental pressure distributions were obtained for a Reynolds number of $1.0 \times 10^{6}$ and a Mach number of 0.10 with transition free. Although the pressure coefficients at the lift coefficient that corresponds to the lower limit of the low-drag range (figs. 19(a), 20(a), and 21(a)) do not match exactly, the pressure gradients agree well except where laminar separation bubbles are present and near the trailing edge. The bubbles are not modeled in the pressure distributions predicted by the method of references 5 and 6 . At the lift coefficient that corresponds to the upper limit of the low-drag range (figs. 19(b), 20(b), and 21(b)), the decambering viscous effects are more apparent and the disparities include small differences in the pressure gradients. Near the maximum lift coefficient (figs. 19(c), 20(c), and 21(c)), the agreement is poor primarily because the effect of the upper-surface, trailing-edge separation on the pressure distribution is not modeled in the theory.

\section{Transition Location}

The predicted and measured transition locations for the S901, S902, and S903 airfoils are compared in figures 22,23 , and 24 , respectively. The theory consistently predicts transition forward of the locations measured in the wind tunnel. This result is obtained because the method of references 5 and 6 defines the "transition location" as the end of the laminar bound- 
ary layer whether due to natural transition or laminar separation. As previously discussed, transition was confirmed in the wind tunnel only by the observation of attached turbulent flow. Thus, the majority of the disparity between the predicted and measured transition locations results from the difference between the laminar-separation and turbulent-reattachment points. Therefore, the agreement between theory and experiment is better for conditions that produce shorter laminar separation bubbles (higher lift coefficients for the upper surface, lower lift coefficients for the lower surface, and higher Reynolds numbers).

\section{Section Characteristics}

The comparison of the theoretical and experimental section characteristics of the S901, S902, and S903 airfoils with transition free is shown in figures 22, 23, and 24, respectively. In general, the magnitude of the zero-lift angle of attack is overpredicted, except for the S903 airfoil (fig. 24). Part of the disparity is probably due to uncertainty in establishing the zero angle-of-attack position during model installation in the wind tunnel. The lift-curve slope is predicted relatively accurately. The maximum lift coefficient is slightly $(\sim 5 \%)$ overpredicted for the $\mathrm{S} 901$ airfoil (fig. 22), relatively accurately predicted for the $\mathrm{S} 902$ airfoil (fig. 23), and greatly underpredicted ( $20 \%$ ) for the S903 airfoil (fig. 24). It should be noted that the maximum lift coefficient computed by the method of references 5 and 6 is not always realistic. Accordingly, an empirical criterion has been applied to the computed results. This criterion assumes that the maximum lift coefficient has been reached if the drag coefficient of the upper surface is greater than $0.0160\left(2 \times 10^{6} / \mathrm{R}\right)^{1 / 7}$ or if the length of turbulent separation on the upper surface is greater than $0.1000 \mathrm{c}$. The magnitude of the minimum lift coefficient is greatly underpredicted. The profile-drag coefficients of the S901 airfoil are relatively accurately predicted for a Reynolds number of $0.7 \times 10^{6}$ (fig. 22(a)) whereas the drag coefficients of the S902 and S903 airfoils are underpredicted (figs. 23(a) and 24(a)). The drag coefficients of all three airfoils are relatively accurately predicted for a Reynolds number of $1.0 \times 10^{6}$ (figs. 22(b), 23(b), and 24(b)). The drag coefficients of the S901 airfoil are overpredicted for a Reynolds number of $1.5 \times 10^{6}$ (fig. 22(c)) whereas the drag coefficients of the $\mathrm{S} 902$ and S903 airfoils are relatively accurately predicted (figs. 23(c) and 24(c)). The lower limit of the low-drag range is relatively accurately predicted whereas the upper limit is generally overpredicted. The pitching-moment coefficients are generally overpredicted.

The comparison of the theoretical and experimental section characteristics of the S901, S902, and S903 airfoils with transition fixed is shown in figures 25, 26, and 27, respectively. In general, the magnitude of the zero-lift angle of attack is again overpredicted, except for the S903 airfoil (fig. 27). The lift-curve slope is again predicted relatively accurately. The maximum lift coefficient is again slightly ( 5\%) overpredicted for the S901 airfoil (fig. 25$)$, relatively accurately predicted for the S902 airfoil (fig. 26), and greatly underpredicted $(\sim 20 \%)$ for the $\$ 903$ airfoil (fig. 27). The magnitude of the minimum lift coefficient is again greatly underpredicted. The agreement between the predicted and measured drag coefficients is poor probably because of the abnormal roughness effects previously discussed. The pitching-moment coefficients are again generally overpredicted. 


\section{CONCLUDING REMARKS}

A matrix of airfoils has been developed to determine quantitatively the effects of airfoil thickness and maximum lift coefficient on the sensitivity of the maximum lift coefficient to leading-edge roughness. The matrix consists of three natural-laminar-flow airfoils, the S901, S902, and S903, for wind-turbine applications. The airfoils have been designed and analyzed theoretically and verified experimentally in The Pennsylvania State University lowspeed, low-turbulence wind tunnel. The effect of roughness on the maximum lift coefficient increases with increasing airfoil thickness and decreases slightly with increasing maximum

lift coefficient. Comparisons of the theoretical and experimental results generally show good agreement.

\section{ACKNOWLEDGMENTS}

The assistance of the staff of The Pennsylvania State University Department of Aerospace Engineering is gratefully acknowledged. In particular, the efforts of Mark D. Maughmer are sincerely appreciated. In addition, the contributions of Cris K. Bosetti are recognized. 


\section{REFERENCES}

1. Somers, Dan M.: Design and Experimental Results for the S805 Airfoil. NREL/SR440-6917, Jan. 1997.

2. Somers, Dan M.: Design and Experimental Results for the S809 Airfoil. NREL/SR440-6918, Jan. 1997.

3. Somers, Dan M.: Design and Experimental Results for the S814 Airfoil. NREL/SR440-6919, Jan. 1997.

4. Brophy, Christopher M.: Turbulence Management and Flow Qualification of The Pennsylvania State University Low Turbulence, Low Speed, Closed Circuit Wind Tunnel. M. S. Thesis, Pennsylvania State Univ., 1993.

5. Eppler, Richard: Airfoil Design and Data. Springer-Verlag (Berlin), 1990.

6. Eppler, Richard: Airfoil Program System "PROFIL98." User's Guide. Richard Eppler, c. 1998 .

7. Pankhurst, R. C.; and Holder, D. W.: Wind-Tunnel Technique. Sir Isaac Pitman \& Sons, Ltd. (London), 1965.

8. Wortmann, F. X.: Experimental Investigations on New Laminar Profiles for Gliders and Helicopters. TIL/T.4906, British Minist. Aviat., Mar. 1960. (Translated from Z. Flugwissenschaften, Bd. 5, Heft 8, Aug. 1957, S. 228-243.)

9. Eppler, Richard; and Somers, Dan M.: Airfoil Design for Reynolds Numbers Between 50,000 and 500,000. Proceedings of the Conference on Low Reynolds Number Airfoil Aerodynamics, UNDAS-CP-77B123, Univ. of Notre Dame, June 1985, pp. 1-14.

10. Maughmer, Mark D.; and Somers, Dan M.: Design and Experimental Results for a HighAltitude, Long-Endurance Airfoil. J. Aircr., vol. 26, no. 2, Feb. 1989, pp. 148-153.

11. Eppler, R.: Laminar Airfoils for Reynolds Numbers Greater Than $4 \times 10^{6}$. B-819-35, Apr. 1969. (Available from NTIS as N69-28178; translated from Ingenieur-Archiv, Bd. 38, Heft 4/5, 1969, S. 232-240.)

12. Somers, Dan M.: Subsonic Natural-Laminar-Flow Airfoils. Natural Laminar Flow and Laminar Flow Control, R. W. Barnwell and M. Y. Hussaini, eds., Springer-Verlag New York, Inc., 1992, pp. 143-176.

13. Allen, H. Julian; and Vincenti, Walter G.: Wall Interference in a Two-Dimensional-Flow Wind Tunnel, With Consideration of the Effect of Compressibility. NACA Rep. 782, 1944. (Supersedes NACA WR A-63.) 
14. Critzos, Chris C.; Heyson, Harry H.; and Boswinkle, Robert W., Jr.: Aerodynamic Characteristics of NACA 0012 Airfoil Section at Angles of Attack From $0^{\circ}$ to $180^{\circ}$. NACA TN 3361, 1955.

15. Braslow, Albert L.; and Knox, Eugene C.: Simplified Method for Determination of Critical Height of Distributed Roughness Particles for Boundary-Layer Transition at Mach Numbers From 0 to 5. NACA TN 4363, 1958.

16. Abbott, Ira H.; Von Doenhoff, Albert E.; and Stivers, Louis S., Jr.: Summary of Airfoil Data. NACA Rep. 824, 1945. (Supersedes NACA WR L-560.)

17. Loving, Donald L.; and Katzoff, S.: The Fluorescent-Oil Film Method and Other Techniques for Boundary-Layer Flow Visualization. NASA MEMO 3-17-59L, 1959.

18. Pfenninger, Werner: Investigations on Reductions of Friction on Wings, in Particular by Means of Boundary Layer Suction. NACA TM 1181, 1947. (Translated from Mitteilungen aus dem Institut für Aerodynamik an der Eidgenössischen Technischen Hochschule Zürich, Nr. 13, 1946.) 
TABLE I.- AIRFOIL DESIGN SPECIFICATIONS

\begin{tabular}{|l|c|c|c|}
\hline \multicolumn{1}{|c|}{ Airfoil } & S901 & S902 & S903 \\
\hline Parameter & \multicolumn{3}{|c|}{ Objective/Constraint } \\
\hline \hline Reynolds number $\mathrm{R}$ & $1.0 \times 10^{6}$ & $1.0 \times 10^{6}$ & $1.0 \times 10^{6}$ \\
\hline Maximum lift coefficient $\mathrm{c}_{l, \mathrm{max}}$ & 1.30 & 1.30 & 0.90 \\
\hline Lower limit of low-drag, lift-coefficient range $\mathrm{c}_{l, 11}$ & 0.50 & 0.50 & 0.10 \\
\hline Upper limit of low-drag, lift-coefficient range $\mathrm{c}_{l, \mathrm{ul}}$ & 1.10 & 1.10 & 0.70 \\
\hline Zero-lift pitching-moment coefficient $\mathrm{c}_{\mathrm{m}, 0}$ & $\geq-0.15$ & $\geq-0.15$ & $\geq-0.07$ \\
\hline Airfoil thickness $\mathrm{t} / \mathrm{c}$ & $18 \%$ & $12 \%$ & $12 \%$ \\
\hline
\end{tabular}


TABLE II.- AIRFOIL COORDINATES

(a) $\mathrm{S} 901$

\begin{tabular}{cc}
\multicolumn{2}{c}{ Upper Surface } \\
$\mathrm{x} / \mathrm{c}$ & $\mathrm{z} / \mathrm{c}$ \\
0.00001 & 0.00049 \\
.00034 & .00248 \\
.00453 & .01108 \\
.01355 & .02098 \\
.02714 & .03124 \\
.04515 & .04146 \\
.06748 & .05138 \\
.09397 & .06078 \\
.12441 & .06957 \\
.15846 & .07770 \\
.19566 & .08502 \\
.23555 & .09136 \\
.27765 & .09644 \\
.32163 & .09997 \\
.36732 & .10179 \\
.41445 & .10198 \\
.46261 & .10064 \\
.51138 & .09785 \\
.56031 & .09376 \\
.60895 & .08850 \\
.65679 & .08227 \\
.70333 & .07526 \\
.74806 & .06766 \\
.79043 & .05968 \\
.82993 & .05149 \\
.86601 & .04326 \\
.89814 & .03501 \\
.92609 & .02656 \\
.95009 & .01809 \\
.97025 & .01039 \\
.98604 & .00449 \\
.99637 & .00105 \\
1.00000 & .00000
\end{tabular}

\begin{tabular}{|c|c|}
\hline \multicolumn{2}{|c|}{ Lower Surface } \\
\hline$x / c$ & $\mathrm{z} / \mathrm{c}$ \\
\hline 0.00012 & -0.00131 \\
\hline .00076 & -.00303 \\
\hline .00190 & -.00483 \\
\hline .01052 & -.01279 \\
\hline .02434 & -.02082 \\
\hline .04326 & -.02896 \\
\hline .06686 & -.03717 \\
\hline .09465 & -.04528 \\
\hline .12617 & -.05306 \\
\hline 16096 & -.06027 \\
\hline .19856 & -.06668 \\
\hline 23847 & -.07203 \\
\hline .28020 & -.07602 \\
\hline .32320 & -.07825 \\
\hline .36724 & -.07811 \\
\hline .41244 & -.07527 \\
\hline .45892 & -.06978 \\
\hline .50669 & -.06182 \\
\hline .55579 & -.05174 \\
\hline 60617 & -.04017 \\
\hline 65768 & -.02792 \\
\hline 70987 & -.01610 \\
\hline .76174 & -.00586 \\
\hline .81195 & .00201 \\
\hline .85905 & .00698 \\
\hline 90138 & .00879 \\
\hline .93711 & .00788 \\
\hline .96500 & .00544 \\
\hline .98464 & .00275 \\
\hline .99620 & .00074 \\
\hline 1.00000 & .00000 \\
\hline
\end{tabular}


TABLE II.- Continued

(b) $\mathrm{S} 902$

\begin{tabular}{cc}
\multicolumn{2}{c}{ Upper Surface } \\
$\mathrm{x} / \mathrm{c}$ & $\mathrm{z} / \mathrm{c}$ \\
0.00001 & 0.00041 \\
.00224 & .00717 \\
.00856 & .01569 \\
.01903 & .02489 \\
.03372 & .03435 \\
.05264 & .04375 \\
.07573 & .05288 \\
.10287 & .06158 \\
.13387 & .06979 \\
.16841 & .07750 \\
.20603 & .08461 \\
.24627 & .09096 \\
.28868 & .09642 \\
.33277 & .10081 \\
.37806 & .10397 \\
.42409 & .10567 \\
.47051 & .10571 \\
.51703 & .10400 \\
.56335 & .10053 \\
.60921 & .09535 \\
.65431 & .08857 \\
.69839 & .08041 \\
.74116 & .07112 \\
.78234 & .06109 \\
.82155 & .05078 \\
.85824 & .04067 \\
.89179 & .03109 \\
.92166 & .02219 \\
.94760 & .01420 \\
.96923 & .00767 \\
.98581 & .00312 \\
.99636 & .00069 \\
1.00000 & .00000
\end{tabular}

\begin{tabular}{|c|c|}
\hline \multicolumn{2}{|c|}{ Lower Surface } \\
\hline $\mathrm{x} / \mathrm{c}$ & $\mathrm{z} / \mathrm{c}$ \\
\hline 0.00007 & -0.00098 \\
\hline .00046 & -.00208 \\
\hline .00134 & -.00296 \\
\hline .00274 & -.00373 \\
\hline .01286 & -.00627 \\
\hline .02922 & -.00777 \\
\hline . 05180 & -.00876 \\
\hline .08008 & -.00954 \\
\hline .11354 & -.01018 \\
\hline .15169 & -.01077 \\
\hline 19395 & -.01135 \\
\hline 23976 & -.01192 \\
\hline .28852 & -.01249 \\
\hline .33958 & -.01304 \\
\hline 39232 & -.01354 \\
\hline .44607 & -.01397 \\
\hline .50019 & -.01425 \\
\hline .55401 & -.01435 \\
\hline .60688 & -.01416 \\
\hline .65818 & -.01357 \\
\hline .70742 & -.01232 \\
\hline .75434 & -.01032 \\
\hline .79878 & -.00769 \\
\hline .84045 & -.00480 \\
\hline .87892 & -.00210 \\
\hline .91350 & -.00006 \\
\hline .94332 & .00107 \\
\hline .96752 & .00132 \\
\hline .98537 & .00093 \\
\hline .99631 & .00031 \\
\hline 1.00000 & .00000 \\
\hline
\end{tabular}


TABLE II.- Concluded

(c) $\mathrm{S} 903$

\begin{tabular}{cc}
\multicolumn{2}{c}{ Upper Surface } \\
$\mathrm{x} / \mathrm{c}$ & $\mathrm{z} / \mathrm{c}$ \\
0.00001 & 0.00035 \\
.00032 & .00180 \\
.00242 & .00608 \\
.00942 & .01372 \\
.02086 & .02187 \\
.03671 & .03007 \\
.05695 & .03802 \\
.08152 & .04554 \\
.11029 & .05253 \\
.14306 & .05897 \\
.17946 & .06490 \\
.21899 & .07029 \\
.26115 & .07502 \\
.30544 & .07897 \\
.35132 & .08201 \\
.39827 & .08397 \\
.44581 & .08464 \\
.49357 & .08384 \\
.54122 & .08146 \\
.58849 & .07752 \\
.63507 & .07208 \\
.68070 & .06529 \\
.72507 & .05739 \\
.76790 & .04867 \\
.80885 & .03953 \\
.84753 & .03044 \\
.88343 & .02189 \\
.91595 & .01437 \\
.94435 & .00830 \\
.96779 & .00397 \\
.98538 & .00138 \\
.99630 & .00026 \\
1.00000 & .00000
\end{tabular}

\begin{tabular}{|c|c|}
\hline \multicolumn{2}{|c|}{ Lower Surface } \\
\hline$x / c$ & $\mathrm{z} / \mathrm{c}$ \\
\hline 0.00011 & -0.00088 \\
\hline .00072 & -.00201 \\
\hline .00182 & -.00317 \\
\hline .00411 & -.00490 \\
\hline .01420 & -.00970 \\
\hline .02963 & -.01426 \\
\hline 05031 & -.01838 \\
\hline .07601 & -.02209 \\
\hline 10643 & -.02536 \\
\hline .14123 & -.02820 \\
\hline 18001 & -.03057 \\
\hline .22234 & -.03247 \\
\hline 26775 & -.03390 \\
\hline .31573 & -.03486 \\
\hline .36574 & -.03536 \\
\hline .41722 & -.03541 \\
\hline 46959 & -.03502 \\
\hline .52226 & -.03419 \\
\hline .57462 & -.03295 \\
\hline 62607 & -.03129 \\
\hline .67602 & -.02922 \\
\hline .72392 & -.02668 \\
\hline .76934 & -.02360 \\
\hline .81196 & -.02009 \\
\hline .85137 & -.01636 \\
\hline .88711 & -.01255 \\
\hline .91879 & -.00882 \\
\hline .94609 & -.00537 \\
\hline .96860 & -.00261 \\
\hline .98563 & -.00087 \\
\hline .99633 & -.00014 \\
\hline 1.00000 & .00000 \\
\hline
\end{tabular}




\section{TABLE III.- MODEL ORIFICE LOCATIONS}

$$
[\mathrm{c}=457.20 \mathrm{~mm}(18.000 \mathrm{in} .)]
$$

(a) $\mathrm{S} 901$

\begin{tabular}{cc}
\multicolumn{2}{c}{ Upper Surface } \\
$\mathrm{x} / \mathrm{c}$ & $\mathrm{y}, \mathrm{mm}(\mathrm{in})$. \\
0.00000 & $-203.2(-8.000)$ \\
.00167 & $-201.2(-7.920)$ \\
.00511 & $-199.1(-7.839)$ \\
.01028 & $-197.1(-7.761)$ \\
.01539 & $-195.1(-7.682)$ \\
.02056 & $-193.0(-7.597)$ \\
.02544 & $-191.0(-7.521)$ \\
.03111 & $-189.1(-7.445)$ \\
.04061 & $-186.9(-7.358)$ \\
.05122 & $-185.0(-7.283)$ \\
.06056 & $-182.9(-7.199)$ \\
.07461 & $-180.7(-7.116)$ \\
.09089 & $-178.8(-7.038)$ \\
.12094 & $-176.1(-6.934)$ \\
.15094 & $-173.7(-6.837)$ \\
.20144 & $-169.8(-6.687)$ \\
.25111 & $-165.5(-6.514)$ \\
.30039 & $-161.4(-6.354)$ \\
.35139 & $-157.4(-6.196)$ \\
.40067 & $-153.3(-6.037)$ \\
.45139 & $-149.1(-5.869)$ \\
.50100 & $-145.1(-5.711)$ \\
.55128 & $-141.1(-5.555)$ \\
.60072 & $-136.7(-5.382)$ \\
.65089 & $-140.8(-5.542)$ \\
.70094 & $-145.2(-5.718)$ \\
.75106 & $-149.4(-5.882)$ \\
.80061 & $-153.3(-6.037)$ \\
.85128 & $-157.3(-6.193)$ \\
.90072 & $-161.6(-6.361)$ \\
.95089 & $-165.5(-6.515)$ \\
.98267 & $-168.1(-6.618)$ \\
&
\end{tabular}

Lower Surface

$\begin{array}{cc}\mathrm{x} / \mathrm{c} & \mathrm{y}, \mathrm{mm}(\mathrm{in} .) \\ 0.00267 & -139.2(-5.480) \\ .00483 & -141.5(-5.571) \\ .00922 & -143.5(-5.649) \\ .01456 & -145.7(-5.737) \\ .01983 & -147.6(-5.812) \\ .02383 & -150.0(-5.904) \\ .02961 & -151.8(-5.977) \\ .03967 & -153.7(-6.052) \\ .04961 & -155.7(-6.128) \\ .06006 & -157.7(-6.207) \\ .07483 & -159.8(-6.290) \\ .08944 & -161.9(-6.374) \\ .11939 & -164.3(-6.470) \\ .14961 & -166.8(-6.567) \\ .19972 & -170.9(-6.730) \\ .24944 & -174.9(-6.886) \\ .29928 & -179.0(-7.047) \\ .34894 & -183.0(-7.206) \\ .39950 & -187.1(-7.366) \\ .44917 & -191.3(-7.532) \\ .49939 & -195.2(-7.684) \\ .54889 & -199.3(-7.846) \\ .59939 & -203.5(-8.013) \\ .64883 & -199.3(-7.846) \\ .69956 & -194.9(-7.675) \\ .74956 & -191.0(-7.520) \\ .79928 & -186.9(-7.358) \\ .84928 & -182.8(-7.195) \\ .89939 & -178.6(-7.032) \\ .94917 & -174.5(-6.869) \\ .97839 & -172.1(-6.777) \\ 1.00000 & -171.1(-6.737) \\ & \end{array}$


TABLE III.- Continued

(b) $\mathrm{S} 902$

Upper Surface

$\begin{array}{cc}\mathrm{x} / \mathrm{c} & \mathrm{y}, \mathrm{mm}(\mathrm{in} .) \\ 0.00000 & -203.2(-8.000) \\ .00068 & -201.2(-7.920) \\ .00383 & -199.2(-7.841) \\ .00864 & -197.2(-7.763) \\ .01388 & -195.1(-7.680) \\ .01866 & -193.0(-7.598) \\ .02376 & -191.0(-7.518) \\ .02899 & -189.2(-7.447) \\ .03921 & -187.0(-7.363) \\ .04890 & -185.0(-7.282) \\ .05927 & -183.0(-7.205) \\ .07397 & -180.8(-7.118) \\ .08962 & -178.8(-7.041) \\ .11906 & -176.2(-6.936) \\ .14940 & -173.8(-6.843) \\ .20001 & -169.7(-6.680) \\ .25025 & -165.5(-6.515) \\ .30109 & -161.7(-6.368) \\ .35106 & -157.7(-6.209) \\ .40153 & -153.6(-6.049) \\ .45213 & -149.6(-5.891) \\ .50271 & -145.5(-5.729) \\ .55272 & -141.6(-5.573) \\ .60309 & -137.3(-5.407) \\ .65327 & -132.8(-5.227) \\ .70363 & -128.8(-5.070) \\ .75407 & -134.9(-5.309) \\ .80468 & -141.2(-5.560) \\ .85468 & -147.3(-5.799) \\ .90501 & -153.3(-6.034) \\ .95517 & -146.9(-5.785) \\ .98540 & -143.5(-5.650) \\ & \end{array}$

Lower Surface

$\begin{array}{cc}\mathrm{x} / \mathrm{c} & \mathrm{y}, \mathrm{mm}(\mathrm{in} .) \\ 0.00026 & -122.9(-4.840) \\ .00366 & -125.3(-4.935) \\ .00847 & -127.3(-5.011) \\ .01364 & -129.2(-5.088) \\ .01896 & -131.3(-5.170) \\ .02333 & -133.3(-5.249) \\ .02882 & -135.2(-5.324) \\ .03869 & -138.3(-5.443) \\ .04863 & -139.4(-5.489) \\ .05846 & -141.4(-5.568) \\ .07405 & -143.5(-5.650) \\ .08907 & -145.6(-5.732) \\ .11909 & -148.1(-5.832) \\ .14890 & -150.5(-5.926) \\ .19943 & -154.6(-6.088) \\ .24969 & -158.8(-6.252) \\ .30041 & -162.8(-6.407) \\ .35074 & -167.1(-6.577) \\ .40154 & -171.0(-6.733) \\ .45154 & -175.0(-6.892) \\ .50217 & -179.1(-7.049) \\ .55214 & -182.9(-7.202) \\ .60254 & -187.0(-7.363) \\ .65274 & -191.3(-7.531) \\ .70286 & -195.2(-7.686) \\ .75273 & -199.3(-7.846) \\ .80316 & -203.6(-8.014) \\ .85386 & -207.5(-8.170) \\ .90367 & -211.6(-8.332) \\ .95408 & -188.9(-7.436) \\ .98448 & -175.5(-6.909) \\ 1.00000 & -166.1(-6.540)\end{array}$


TABLE III.- Concluded

(c) $\mathrm{S} 903$

Upper Surface

$\begin{array}{cc}\mathrm{x} / \mathrm{c} & \mathrm{y}, \mathrm{mm} \text { (in.) } \\ 0.00000 & -203.2(-8.000) \\ .00203 & -201.2(-7.920) \\ .00453 & -199.0(-7.836) \\ .00985 & -197.0(-7.755) \\ .01487 & -195.1(-7.681) \\ .02012 & -193.2(-7.607) \\ .02525 & -191.1(-7.523) \\ .03044 & -189.0(-7.441) \\ .04044 & -187.1(-7.367) \\ .05024 & -185.1(-7.287) \\ .06035 & -183.2(-7.211) \\ .07506 & -181.0(-7.128) \\ .09007 & -179.0(-7.049) \\ .11987 & -176.4(-6.946) \\ .15012 & -173.9(-6.846) \\ .19991 & -170.1(-6.696) \\ .25059 & -166.0(-6.536) \\ .29993 & -162.0(-6.378) \\ .35028 & -157.9(-6.216) \\ .40029 & -154.0(-6.062) \\ .45017 & -149.8(-5.896) \\ .50031 & -145.9(-5.745) \\ .55065 & -141.7(-5.578) \\ .60043 & -137.7(-5.421) \\ .64985 & -133.7(-5.264) \\ .70076 & -129.6(-5.104) \\ .75021 & -125.5(-4.942) \\ .80019 & -133.2(-5.244) \\ .84998 & -141.3(-5.563) \\ .89978 & -148.8(-5.859) \\ .94963 & -141.3(-5.562) \\ .97933 & -136.0(-5.354) \\ & \end{array}$

Lower Surface

$\begin{array}{cc}\mathrm{x} / \mathrm{c} & \mathrm{y}, \mathrm{mm} \text { (in.) } \\ 0.00094 & -119.1(-4.688) \\ .00409 & -120.9(-4.760) \\ .00903 & -123.0(-4.841) \\ .01354 & -124.9(-4.916) \\ .01853 & -126.9(-4.996) \\ .02410 & -129.0(-5.078) \\ .02891 & -130.8(-5.152) \\ .03903 & -132.9(-5.234) \\ .04861 & -134.9(-5.313) \\ .05861 & -136.9(-5.390) \\ .07380 & -139.1(-5.478) \\ .08883 & -141.0(-5.552) \\ .11876 & -143.6(-5.655) \\ .14835 & -145.9(-5.742) \\ .19826 & -149.9(-5.903) \\ .24831 & -153.9(-6.059) \\ .29863 & -158.2(-6.229) \\ .34910 & -162.2(-6.386) \\ .39899 & -166.3(-6.548) \\ .44908 & -170.3(-6.707) \\ .49949 & -174.4(-6.864) \\ .54903 & -178.5(-7.029) \\ .59903 & -182.5(-7.186) \\ .64848 & -186.7(-7.351) \\ .69821 & -190.7(-7.510) \\ .74712 & -195.1(-7.680) \\ .79757 & -199.1(-7.839) \\ .84790 & -203.3(-8.003) \\ .89762 & -207.4(-8.164) \\ .94755 & -211.5(-8.326) \\ .97755 & -183.2(-7.215) \\ 1.00000 & -163.7(-6.444)\end{array}$


TABLE IV.- ROUGHNESS LOCATION AND SIZE

\begin{tabular}{|c|c|c|c|c|c|c|}
\hline \multirow{2}{*}{$\begin{array}{c}\text { Reynolds } \\
\text { Number }\end{array}$} & \multicolumn{3}{|c|}{ Upper Surface } & \multicolumn{3}{|c|}{ Lower Surface } \\
\cline { 2 - 4 } & $\mathrm{x} / \mathrm{c}$ & $\begin{array}{c}\text { Grit } \\
\text { Number }\end{array}$ & $\begin{array}{c}\text { Nominal } \\
\text { Size, mm } \\
\text { (in.) }\end{array}$ & $\mathrm{x} / \mathrm{c}$ & $\begin{array}{c}\text { Grit } \\
\text { Number }\end{array}$ & $\begin{array}{c}\text { Nominal } \\
\text { Size, mm } \\
\text { (in.) }\end{array}$ \\
\hline \hline \multirow{2}{*}{$0.7 \times 10^{6}$} & \multirow{2}{*}{0.02} & 90 & $\begin{array}{c}0.211 \\
(0.0083)\end{array}$ & & 36 & $\begin{array}{c}0.589 \\
(0.0232)\end{array}$ \\
\cline { 3 - 4 } $1.0 \times 10^{6}$ & 90 & $\begin{array}{c}0.178 \\
(0.0070)\end{array}$ & \multirow{2}{*}{0.07} & 54 & $\begin{array}{c}0.351 \\
(0.0138)\end{array}$ \\
\cline { 3 - 4 } $1.5 \times 10^{6}$ & 120 & $\begin{array}{c}0.124 \\
(0.0049)\end{array}$ & & 70 & $\begin{array}{c}0.249 \\
(0.0098)\end{array}$ \\
\hline
\end{tabular}




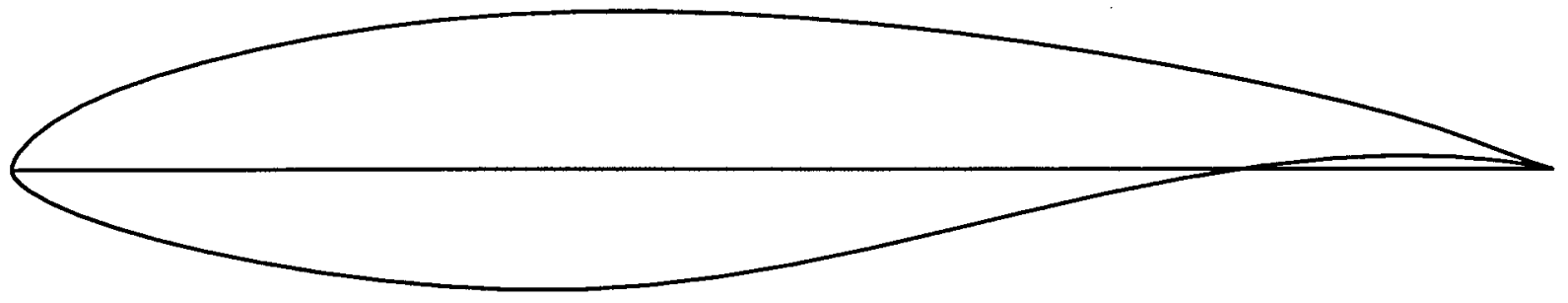

(a) $\mathrm{S} 901$.

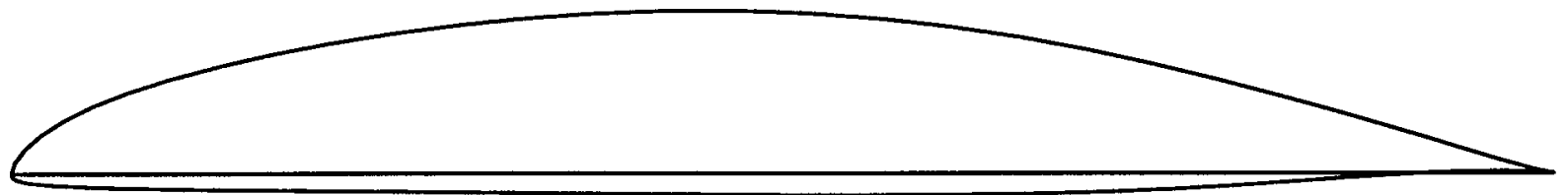

(b) $\mathrm{S} 902$.

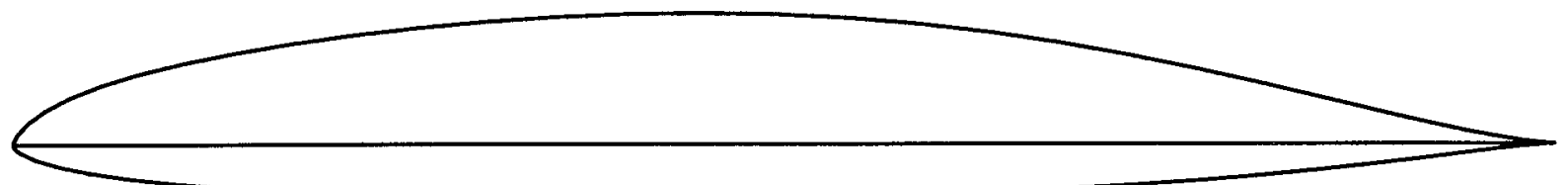

(c) $\mathrm{S} 903$.

Figure 1.- Airfoil shapes. 


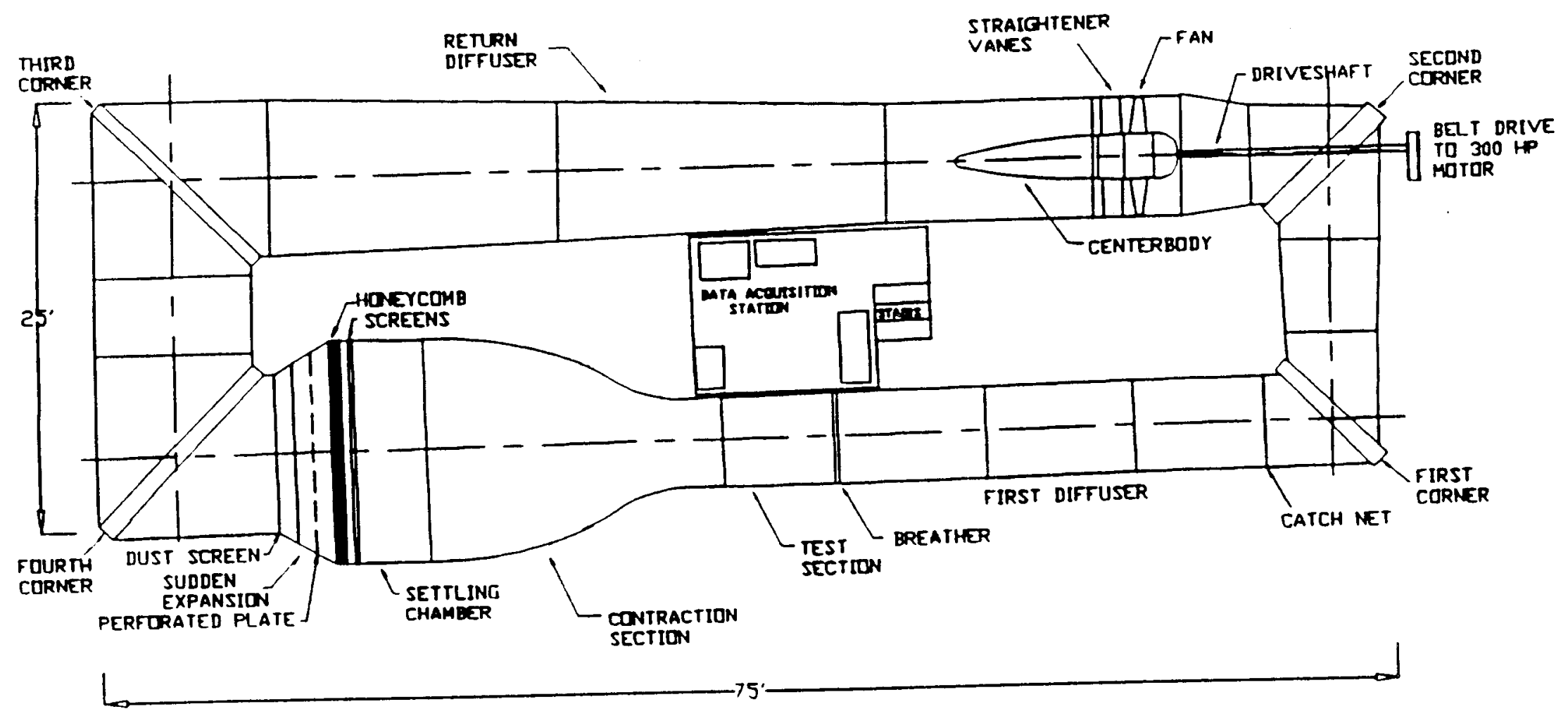

Figure 2.- The Pennsylvania State University low-speed, low-turbulence wind tunnel. 


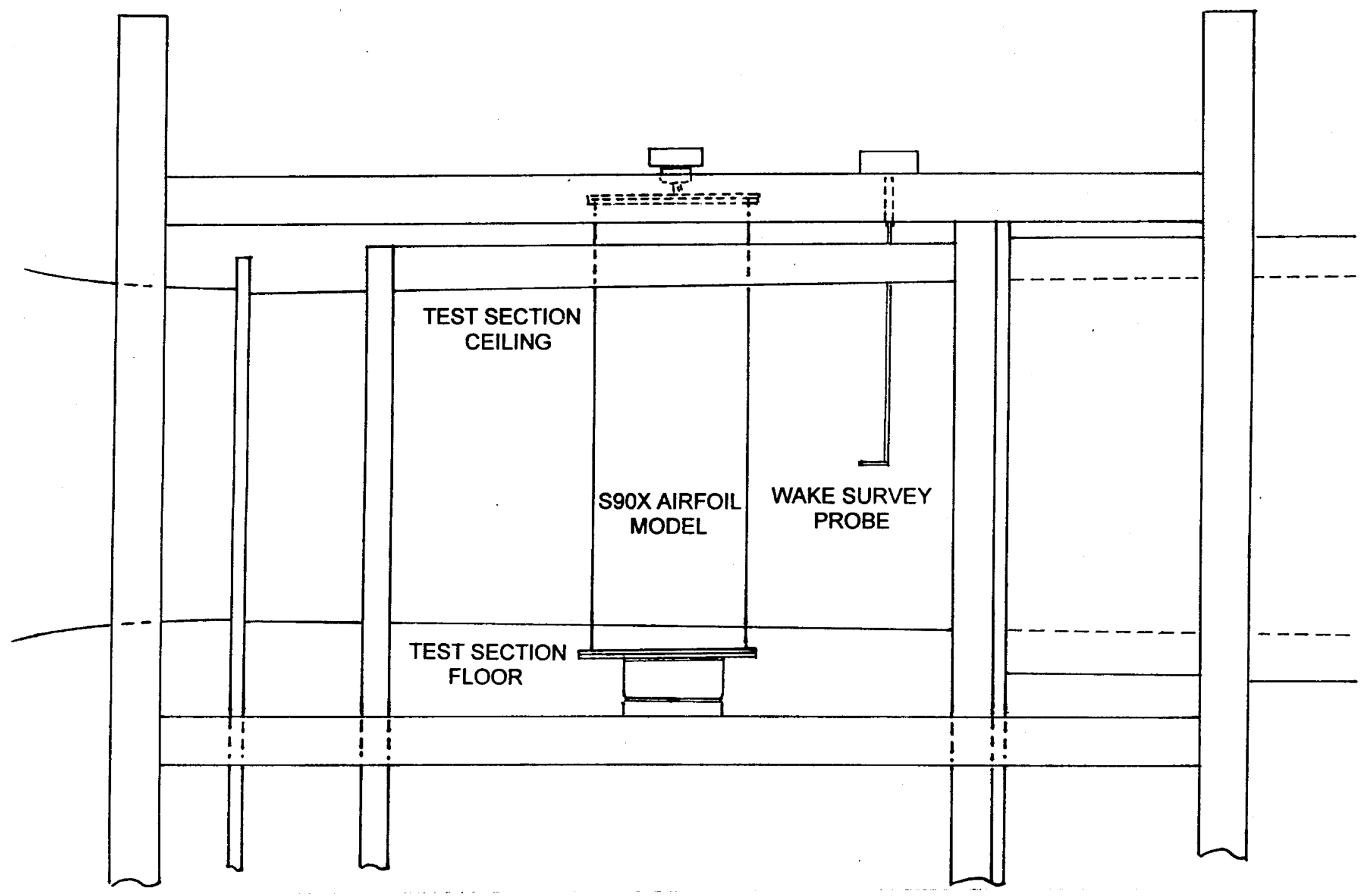

Figure 3.- Model and wake-survey probe mounted in test section. 


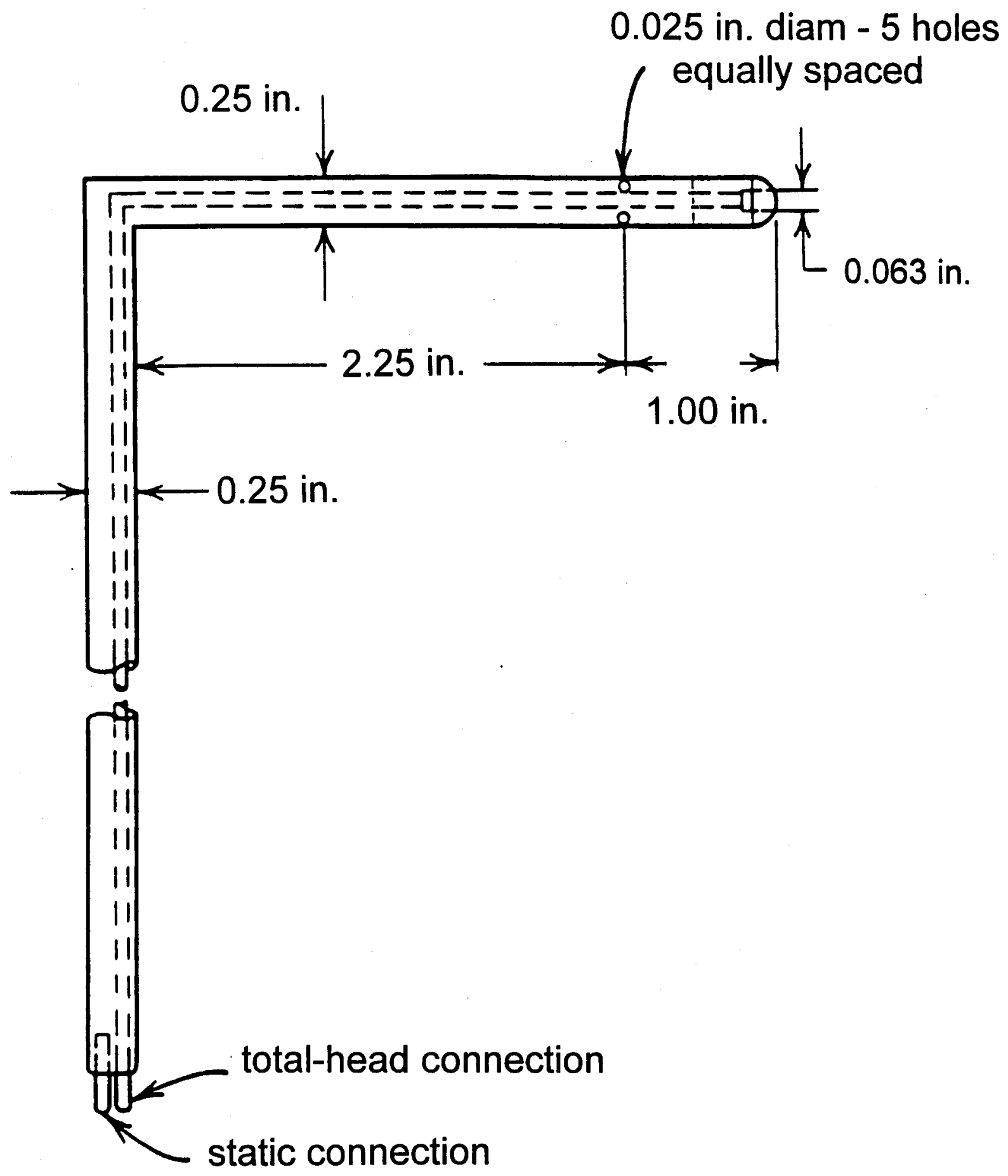

Figure 4.- Wake-survey probe. 


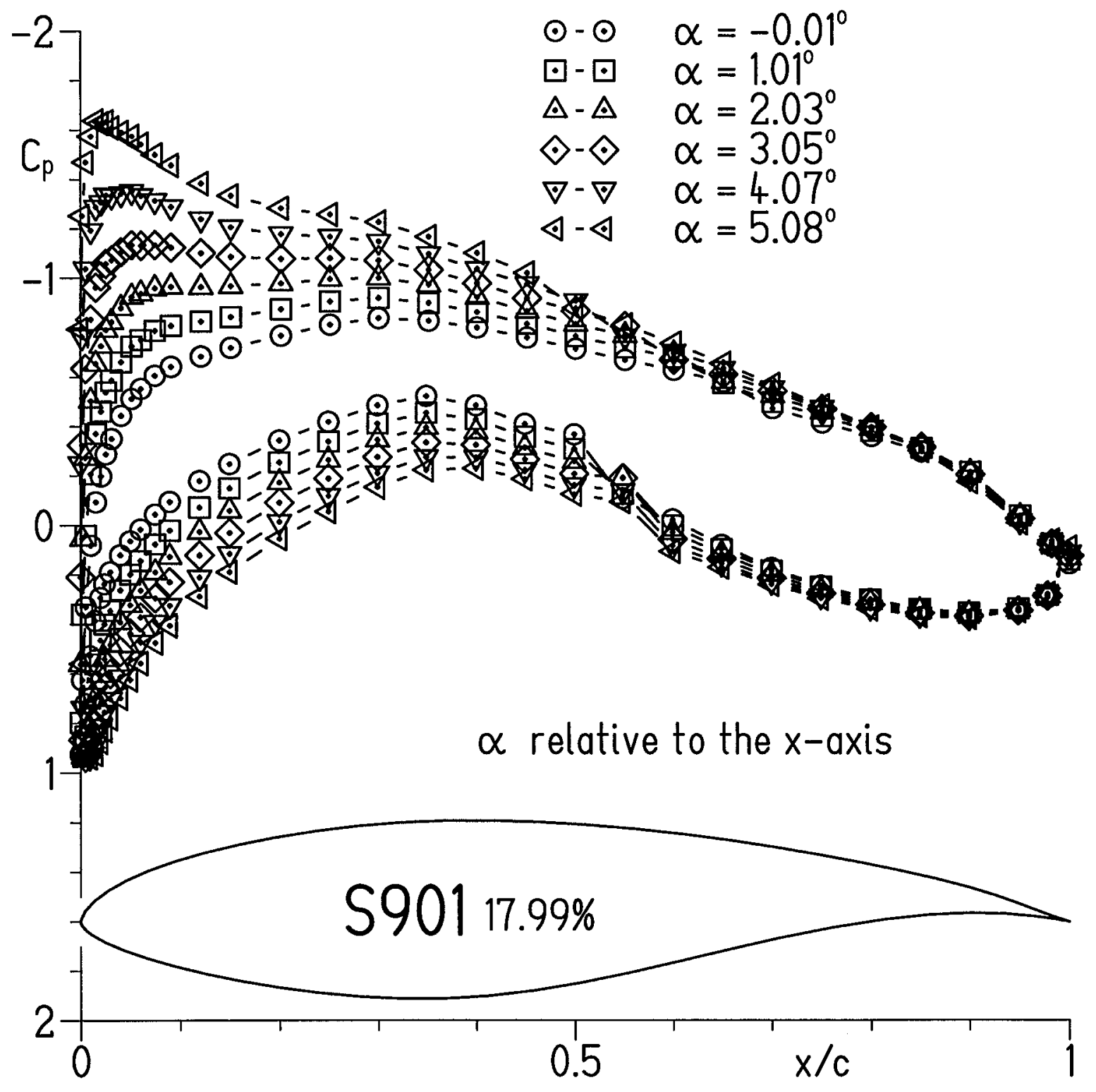

(a) $\alpha=-0.01^{\circ}, 1.01^{\circ}, 2.03^{\circ}, 3.05^{\circ}, 4.07^{\circ}$, and $5.08^{\circ}$.

Figure 5.- Pressure distributions for $\mathrm{S} 901$ airfoil for $\mathrm{R}=1.0 \times 10^{6}$ and $\mathrm{M}=0.10$ with transition free. 


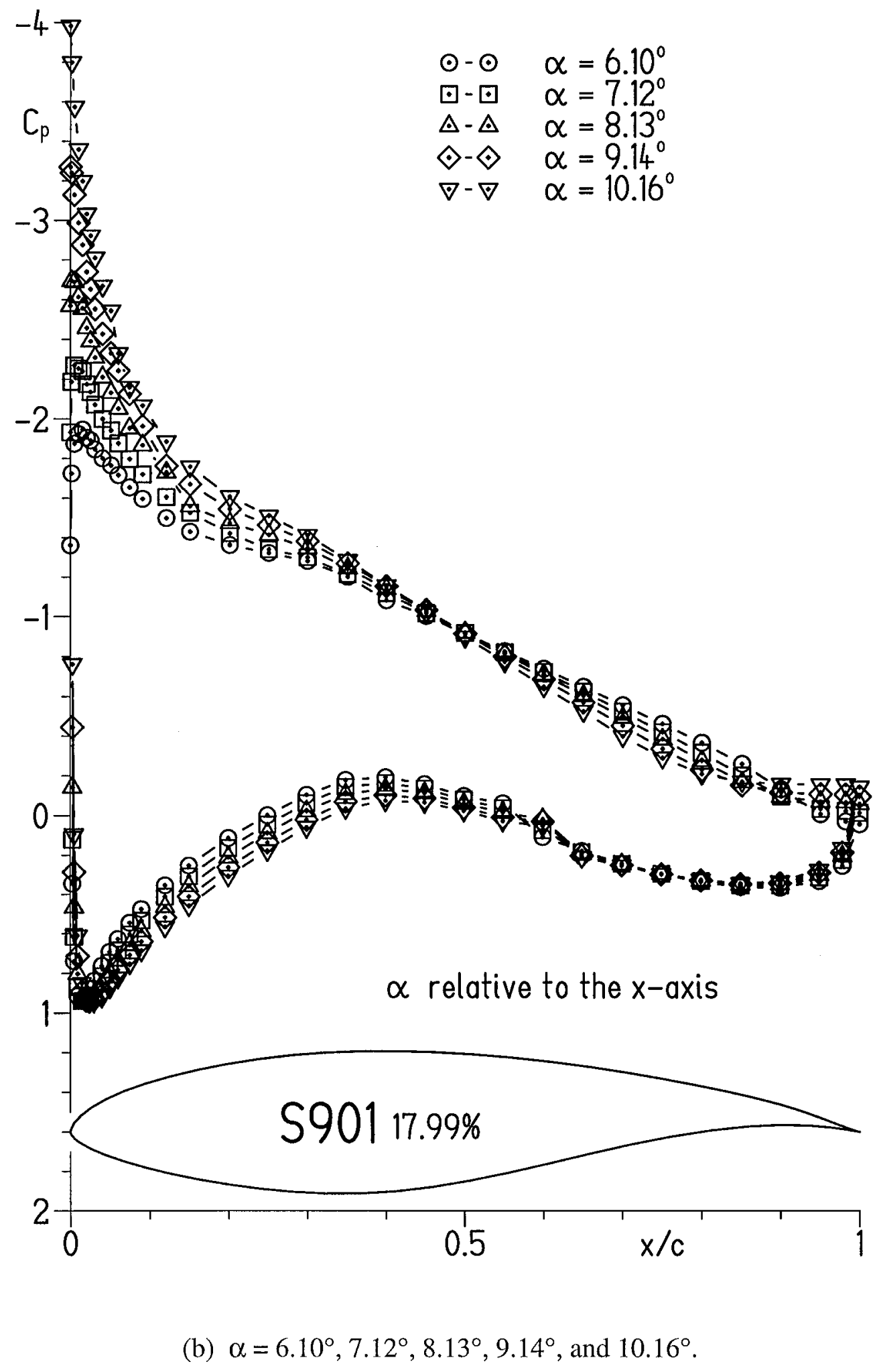

Figure 5.- Continued. 


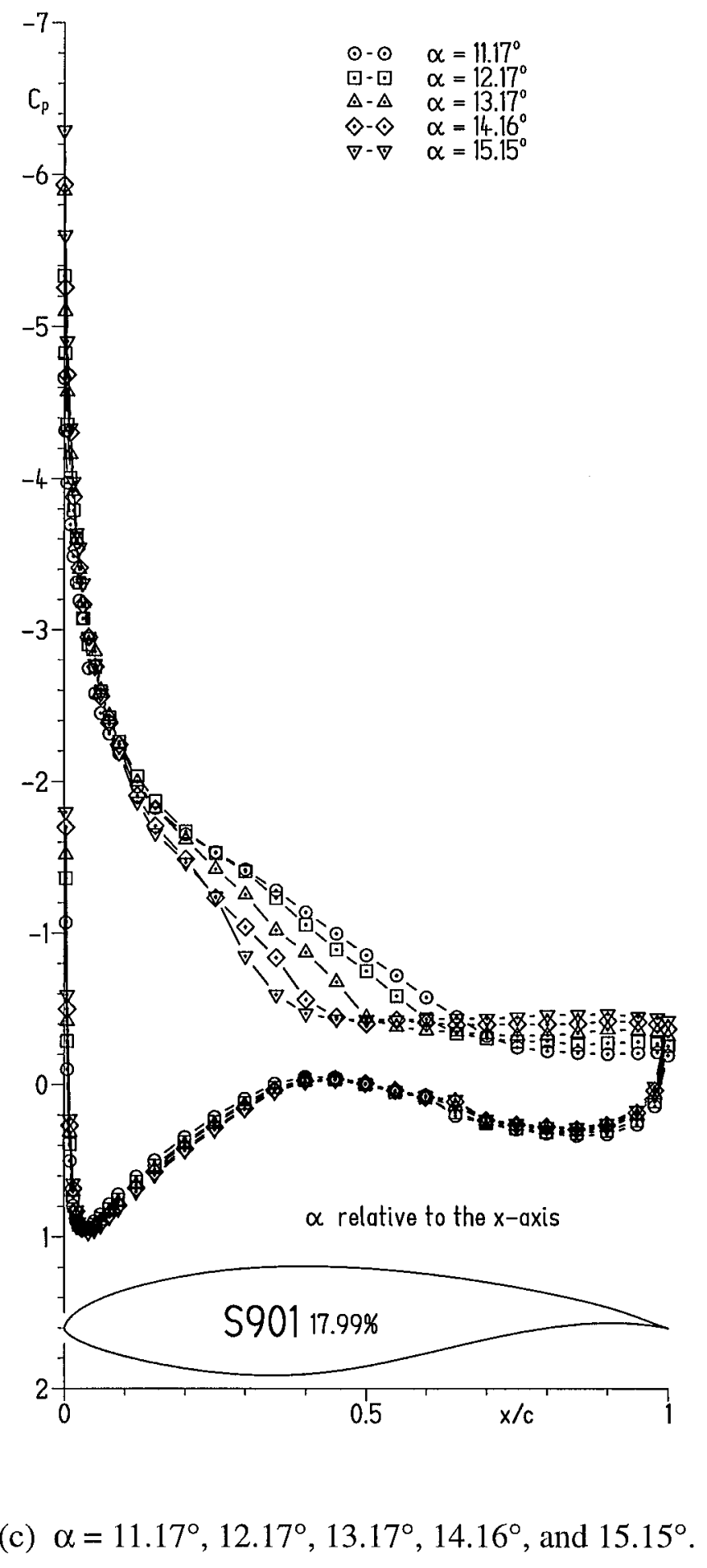

Figure 5.- Continued. 


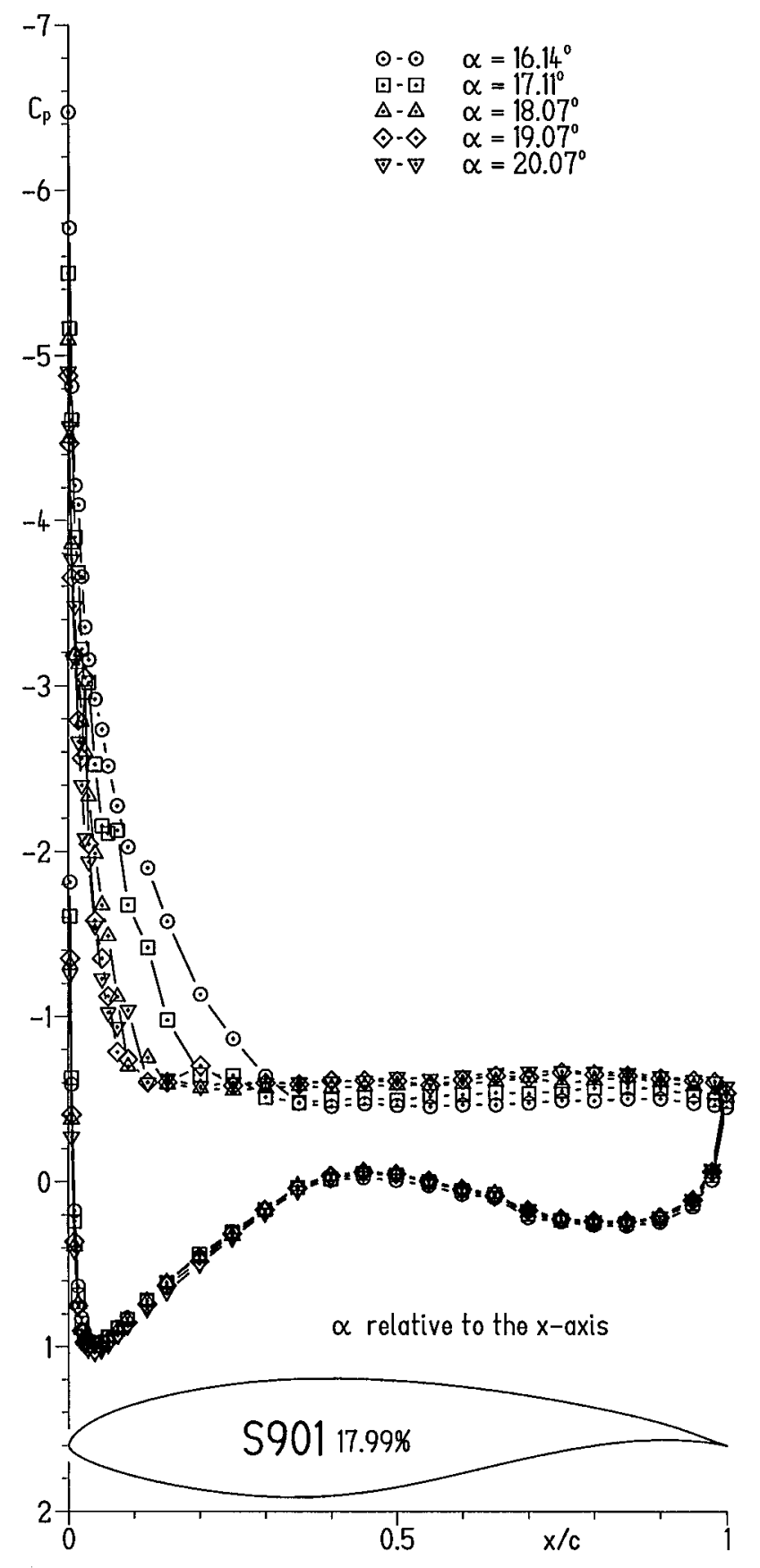

(d) $\alpha=16.14^{\circ}, 17.11^{\circ}, 18.07^{\circ}, 19.07^{\circ}$, and $20.07^{\circ}$.

Figure 5.- Continued. 


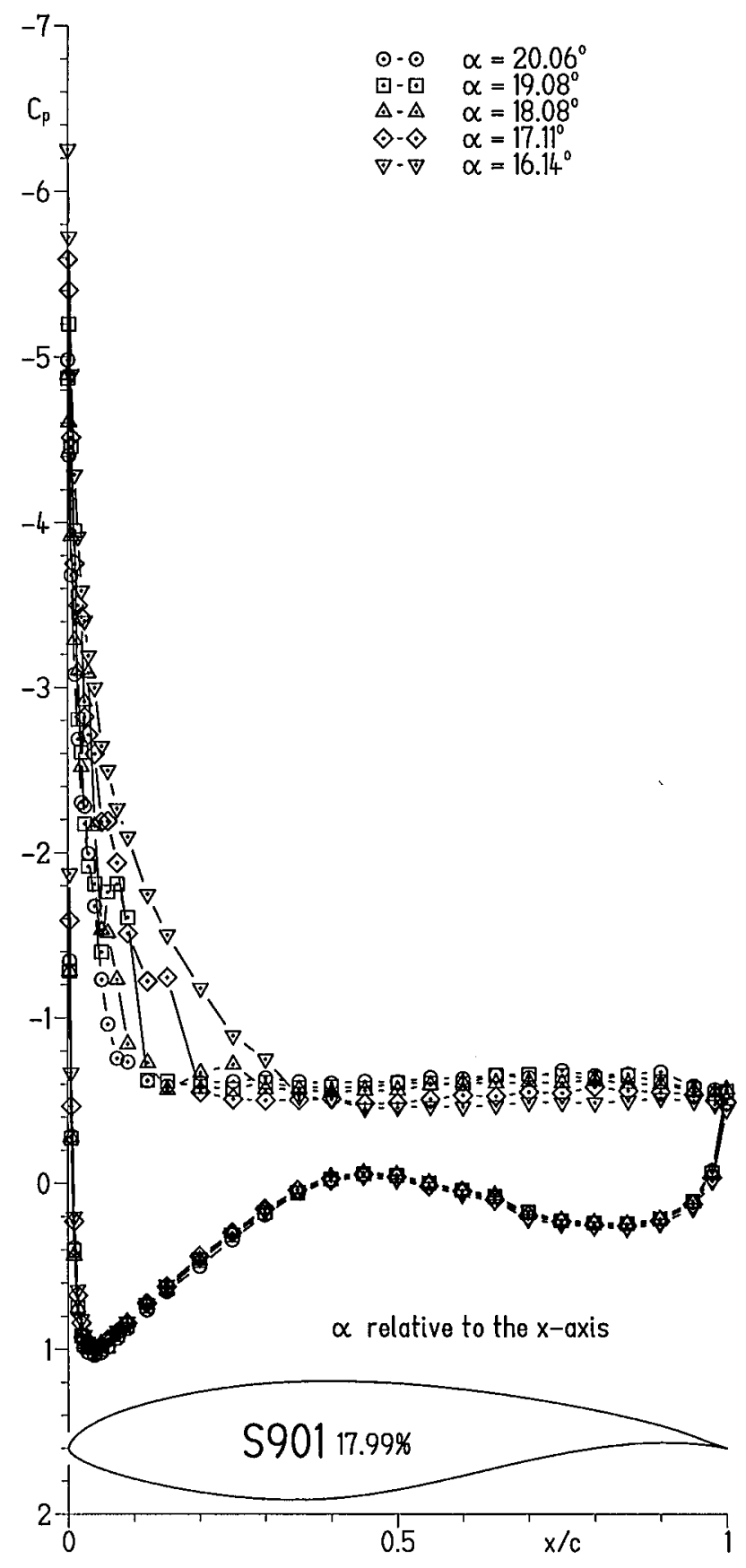

(e) $\alpha=20.06^{\circ}, 19.08^{\circ}, 18.08^{\circ}, 17.11^{\circ}$, and $16.14^{\circ}$.

Figure 5.- Continued. 


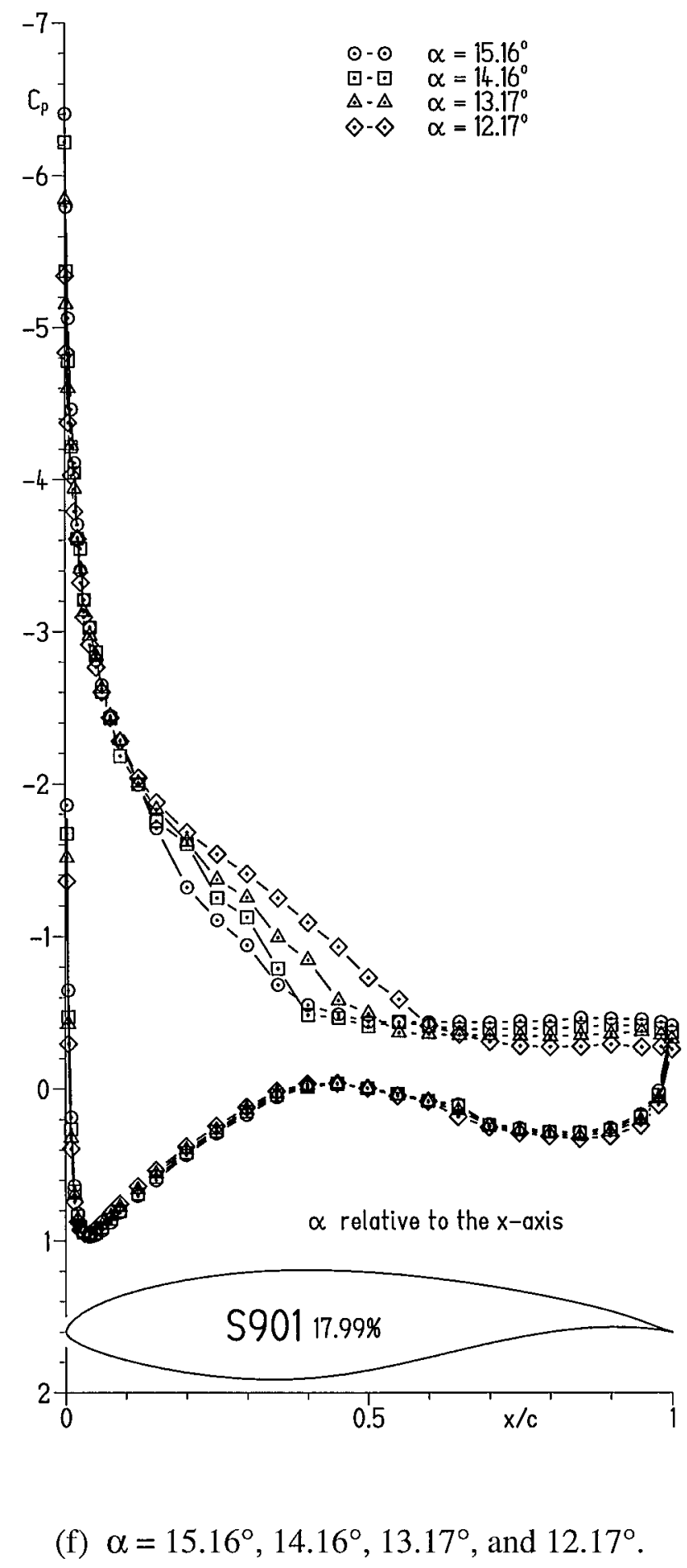

Figure 5.- Continued. 


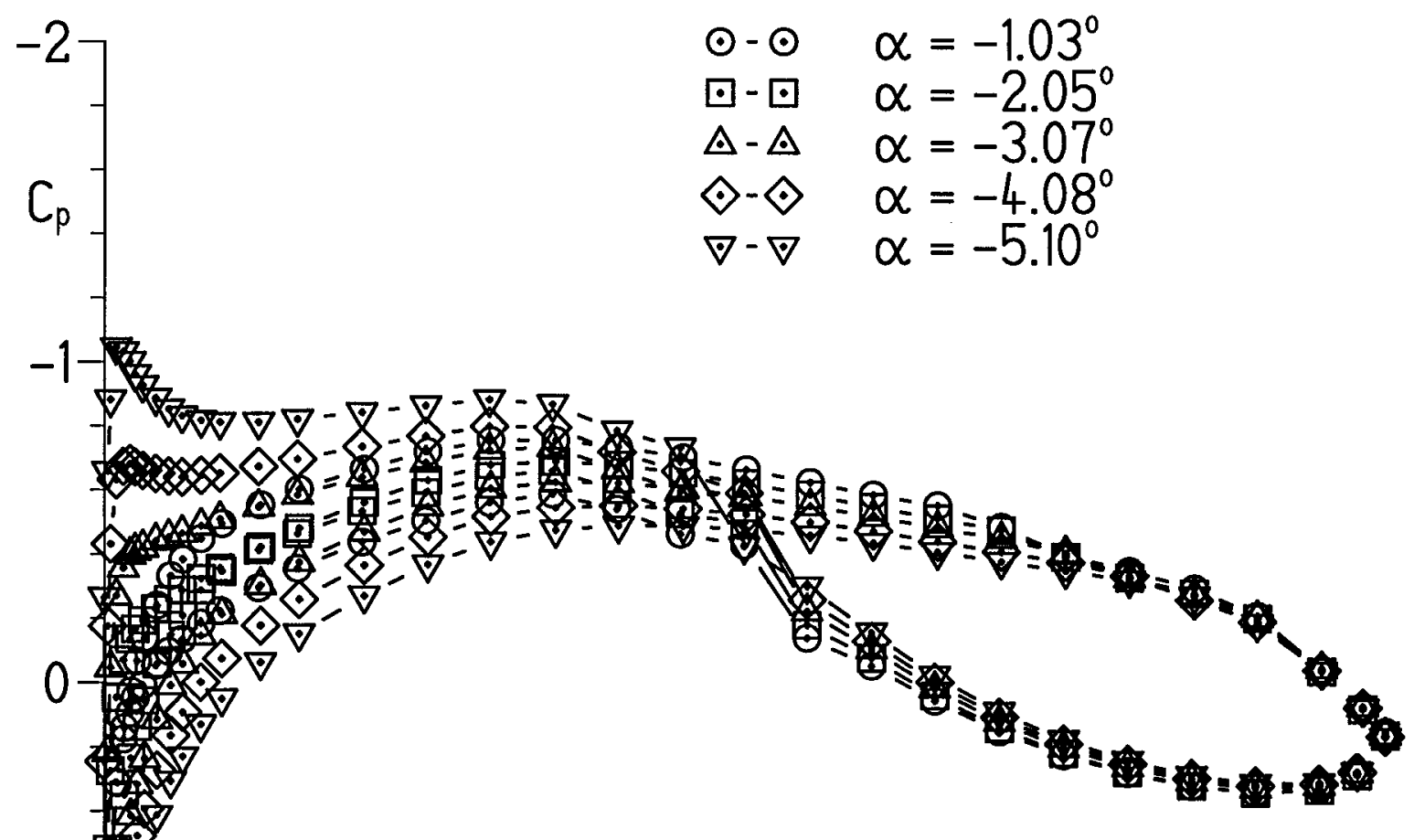

$\alpha$ relative to the $x$-axis

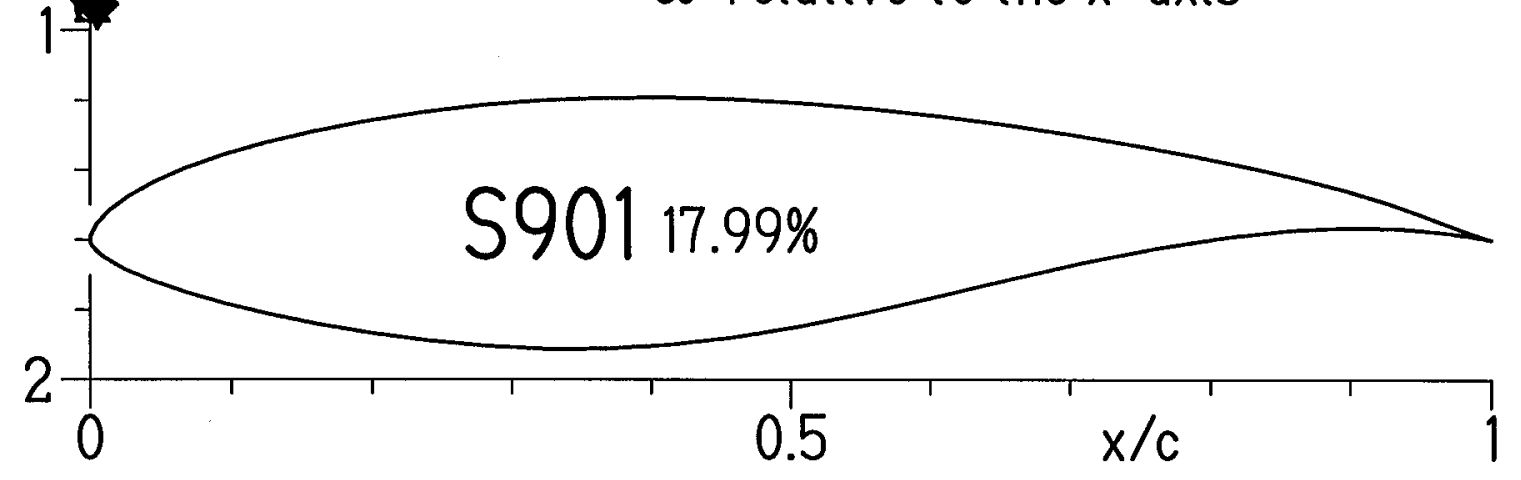

(g) $\alpha=-1.03^{\circ},-2.05^{\circ},-3.07^{\circ},-4.08^{\circ}$, and $-5.10^{\circ}$.

Figure 5.- Continued. 


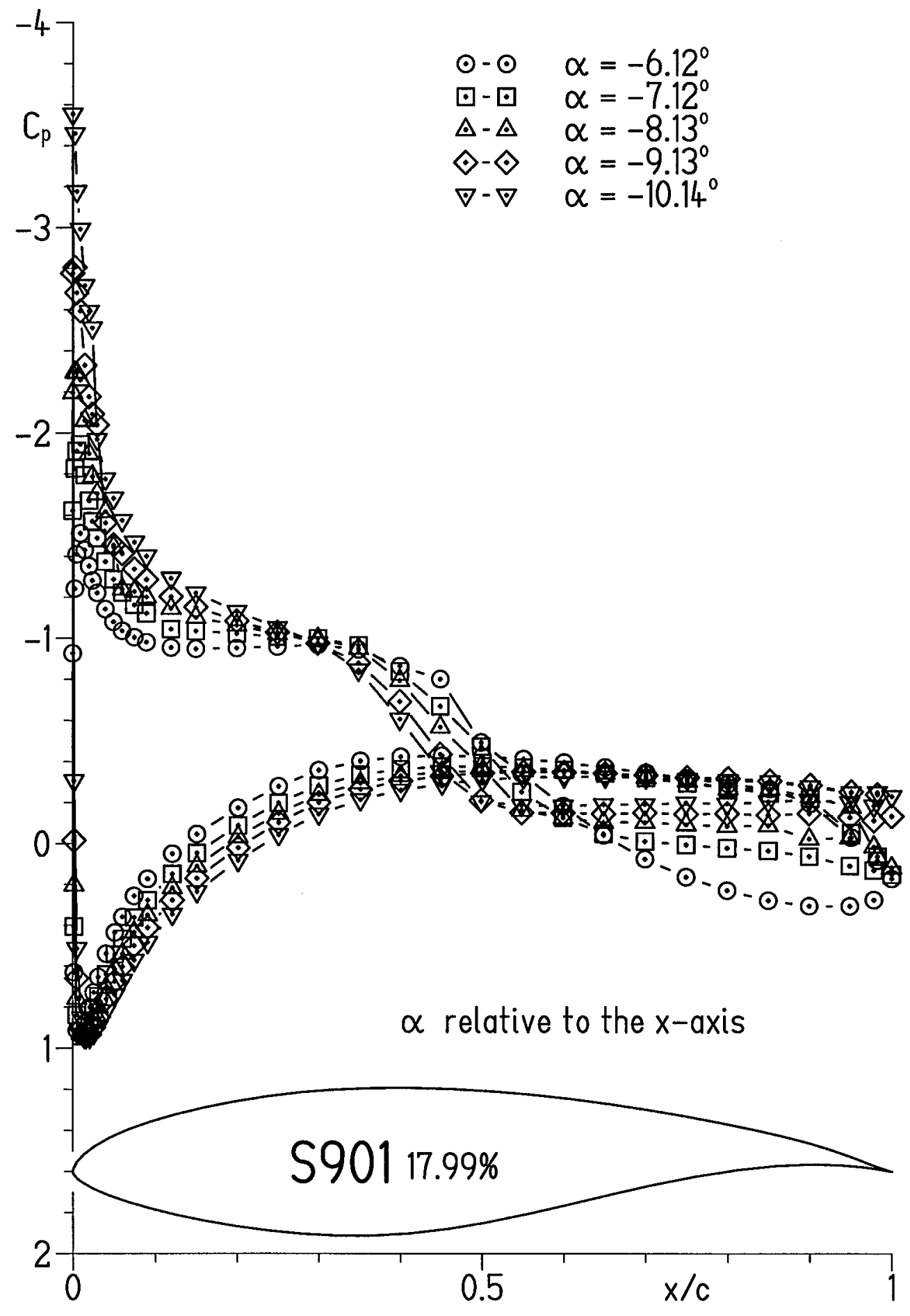

(h) $\alpha=-6.12^{\circ},-7.12^{\circ},-8.13^{\circ},-9.13^{\circ}$, and $-10.14^{\circ}$.

Figure 5.- Continued. 


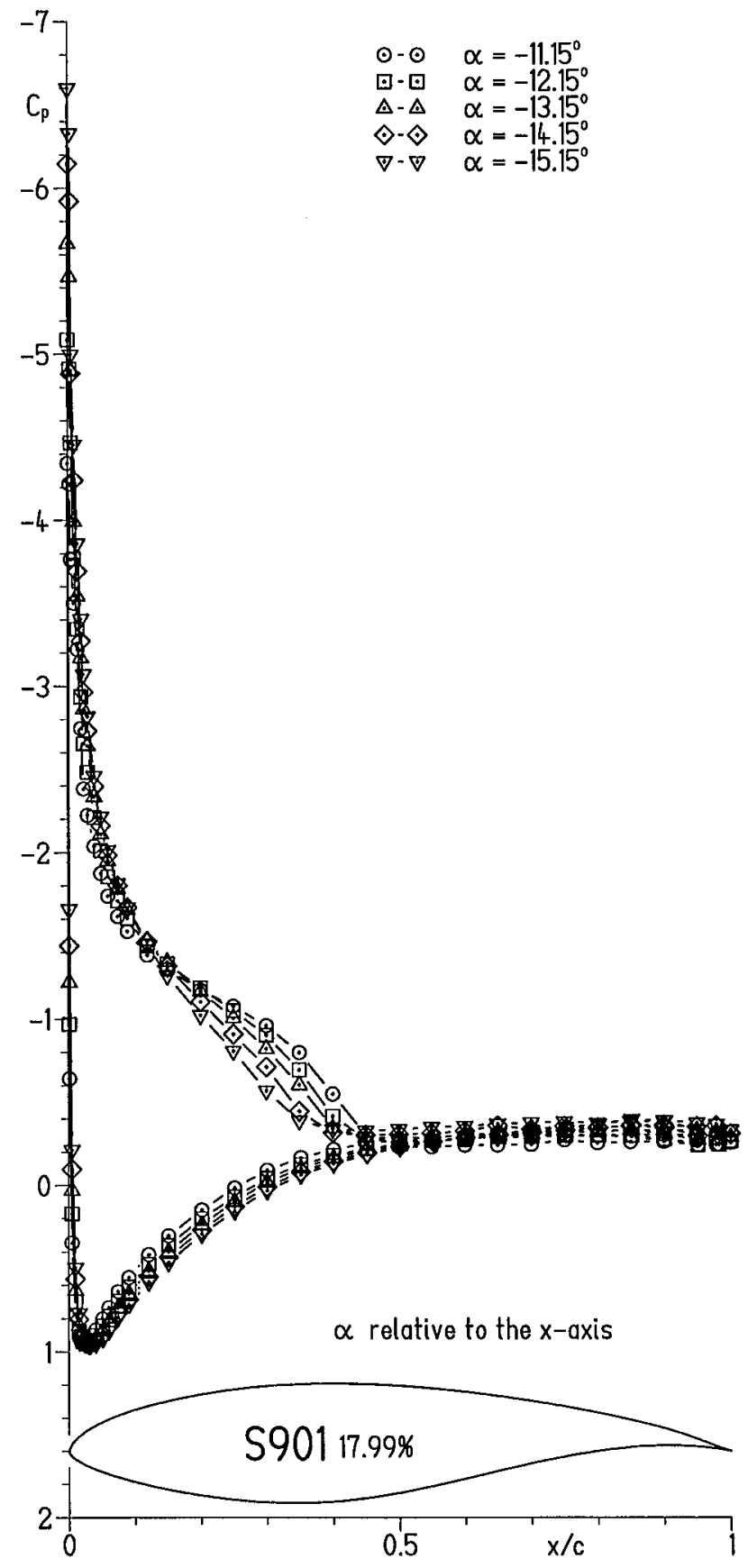

(i) $\alpha=-11.15^{\circ},-12.15^{\circ},-13.15^{\circ},-14.15^{\circ}$, and $-15.15^{\circ}$.

Figure 5.- Continued. 


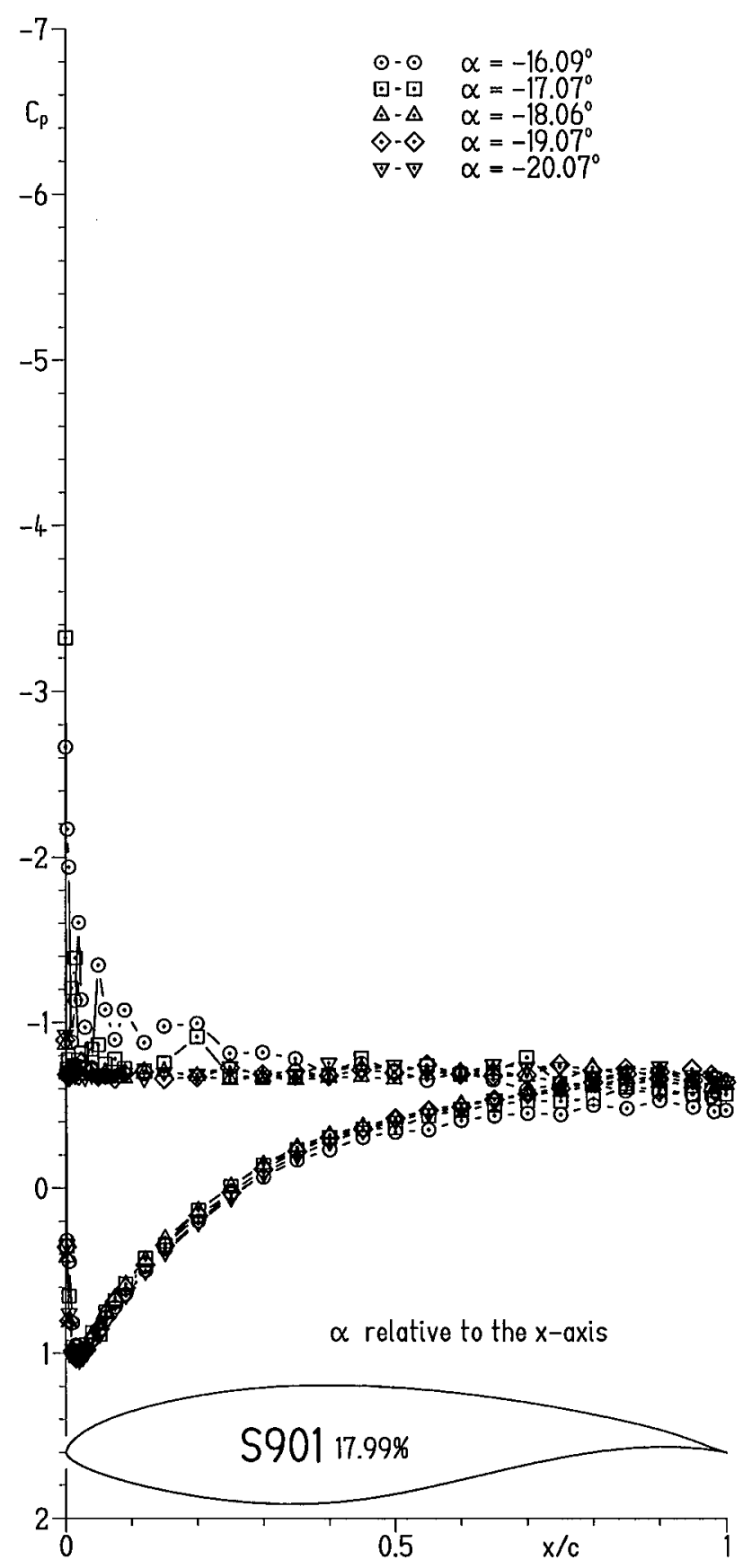

(j) $\alpha=-16.09^{\circ},-17.07^{\circ},-18.06^{\circ},-19.07^{\circ}$, and $-20.07^{\circ}$.

Figure 5.- Continued. 


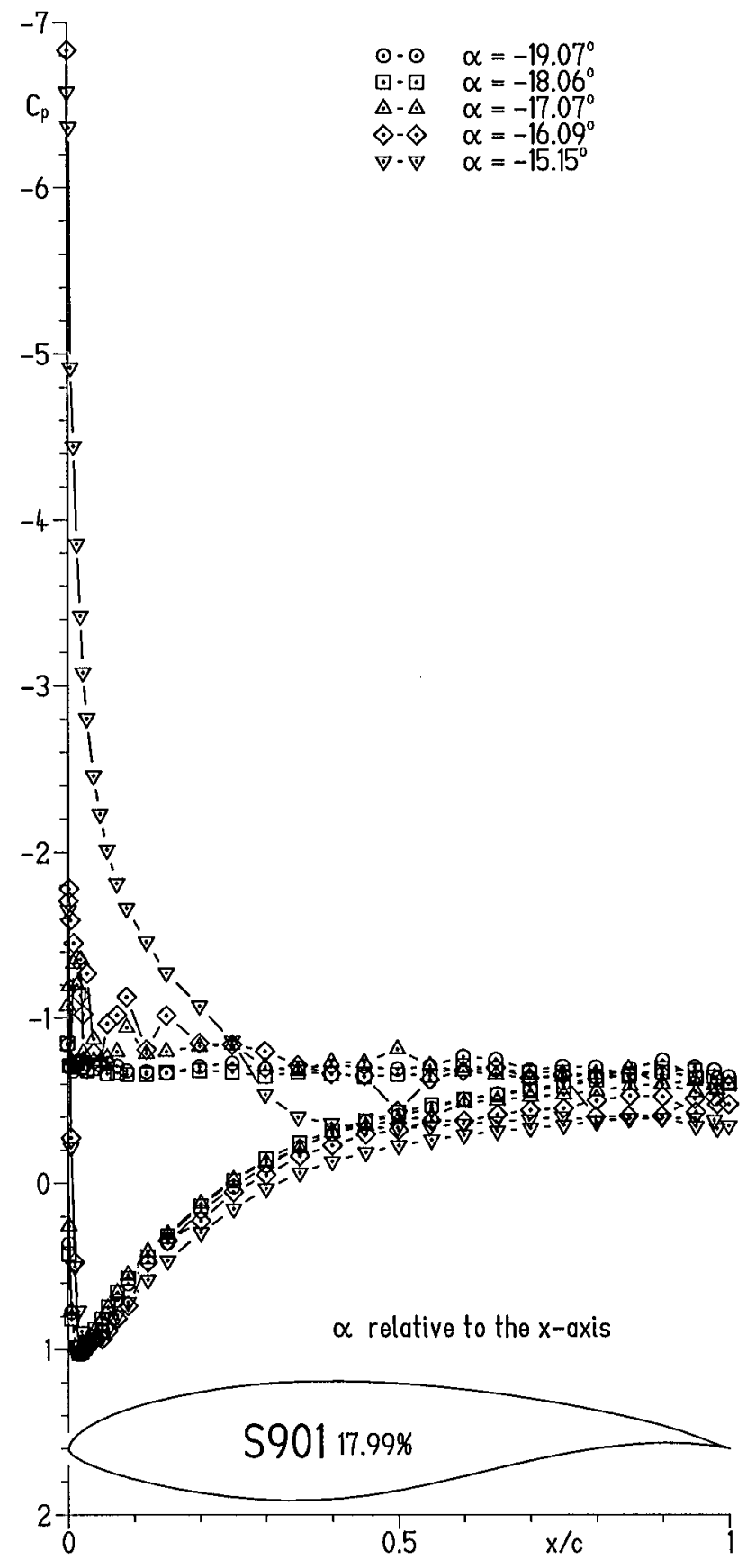

(k) $\alpha=-19.07^{\circ},-18.06^{\circ},-17.07^{\circ},-16.09^{\circ}$, and $-15.15^{\circ}$.

Figure 5.- Concluded. 


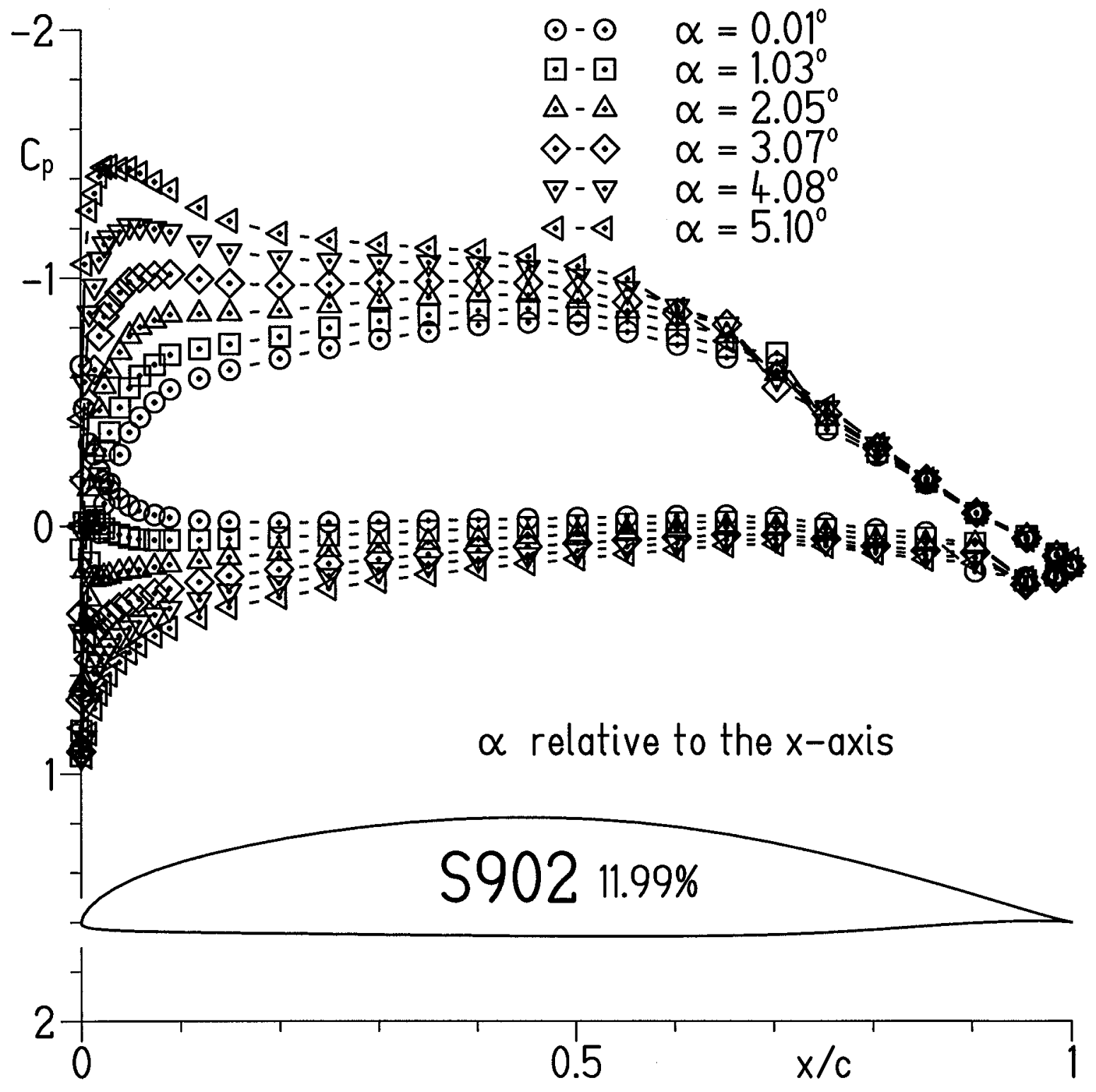

(a) $\alpha=0.01^{\circ}, 1.03^{\circ}, 2.05^{\circ}, 3.07^{\circ}, 4.08^{\circ}$, and $5.10^{\circ}$.

Figure 6.- Pressure distributions for $\mathrm{S} 902$ airfoil for $\mathrm{R}=1.0 \times 10^{6}$ and $\mathrm{M}=0.10$ with transition free. 


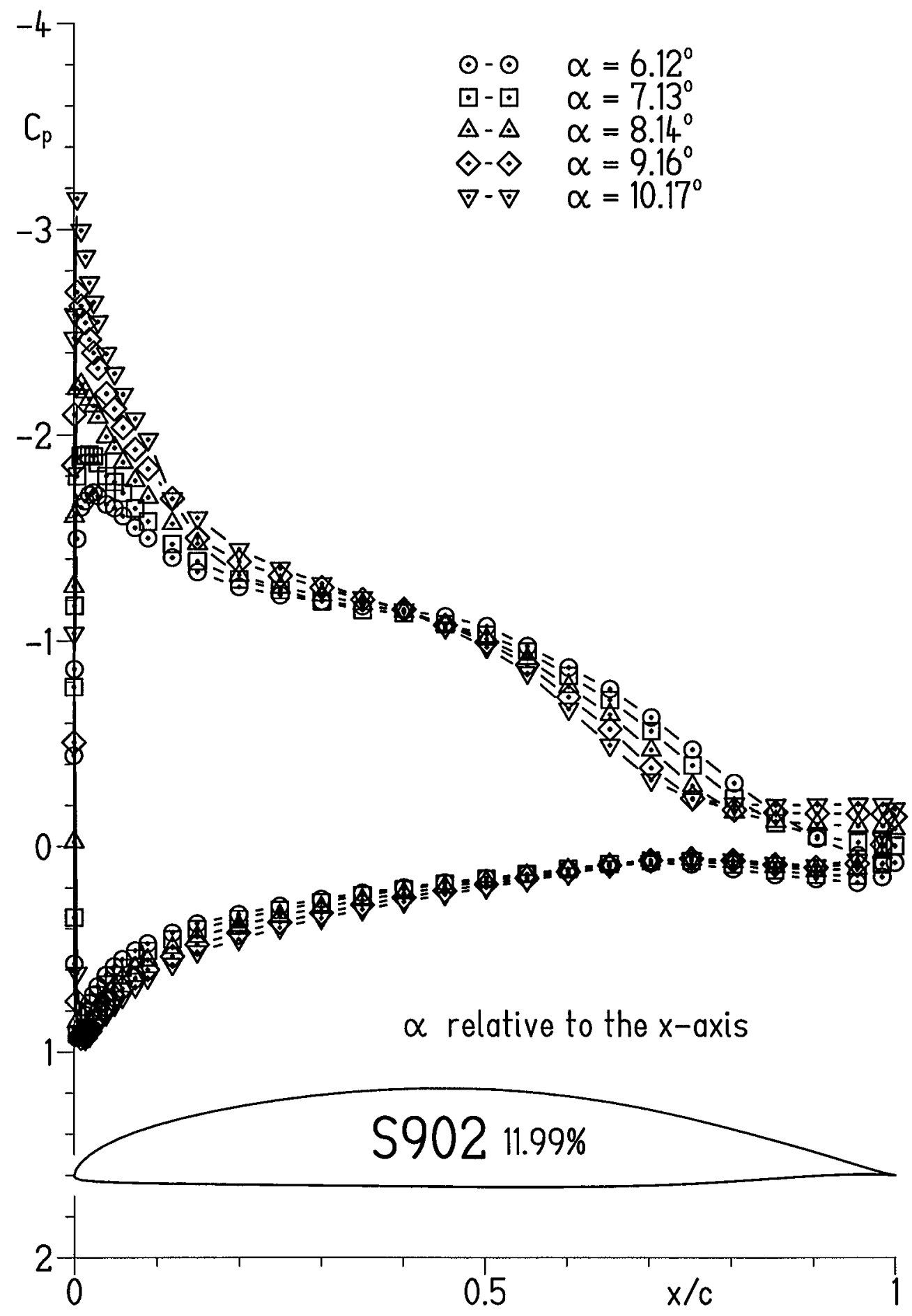

(b) $\alpha=6.12^{\circ}, 7.13^{\circ}, 8.14^{\circ}, 9.16^{\circ}$, and $10.17^{\circ}$.

Figure 6.- Continued. 


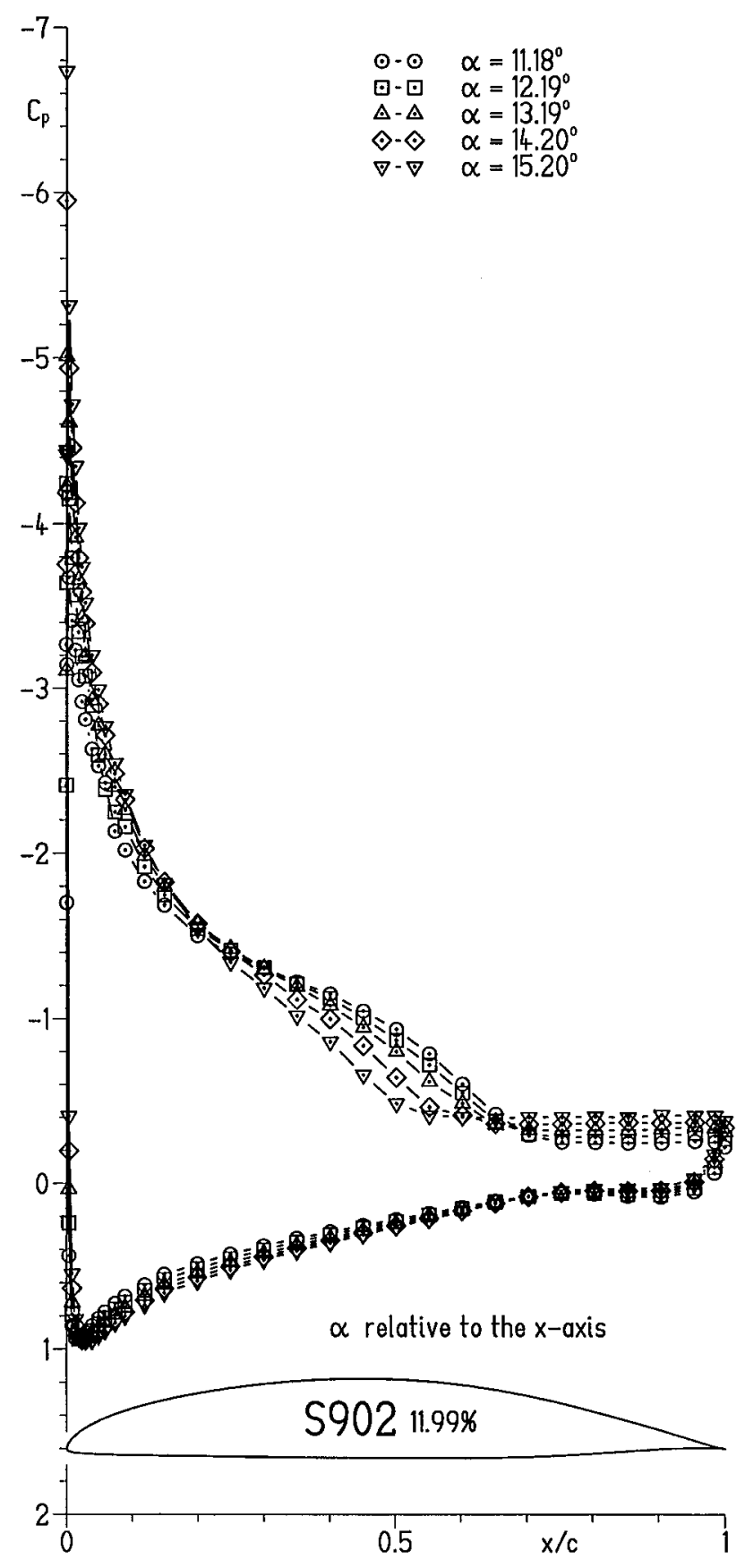

(c) $\alpha=11.18^{\circ}, 12.19^{\circ}, 13.19^{\circ}, 14.20^{\circ}$, and $15.20^{\circ}$.

Figure 6.- Continued. 


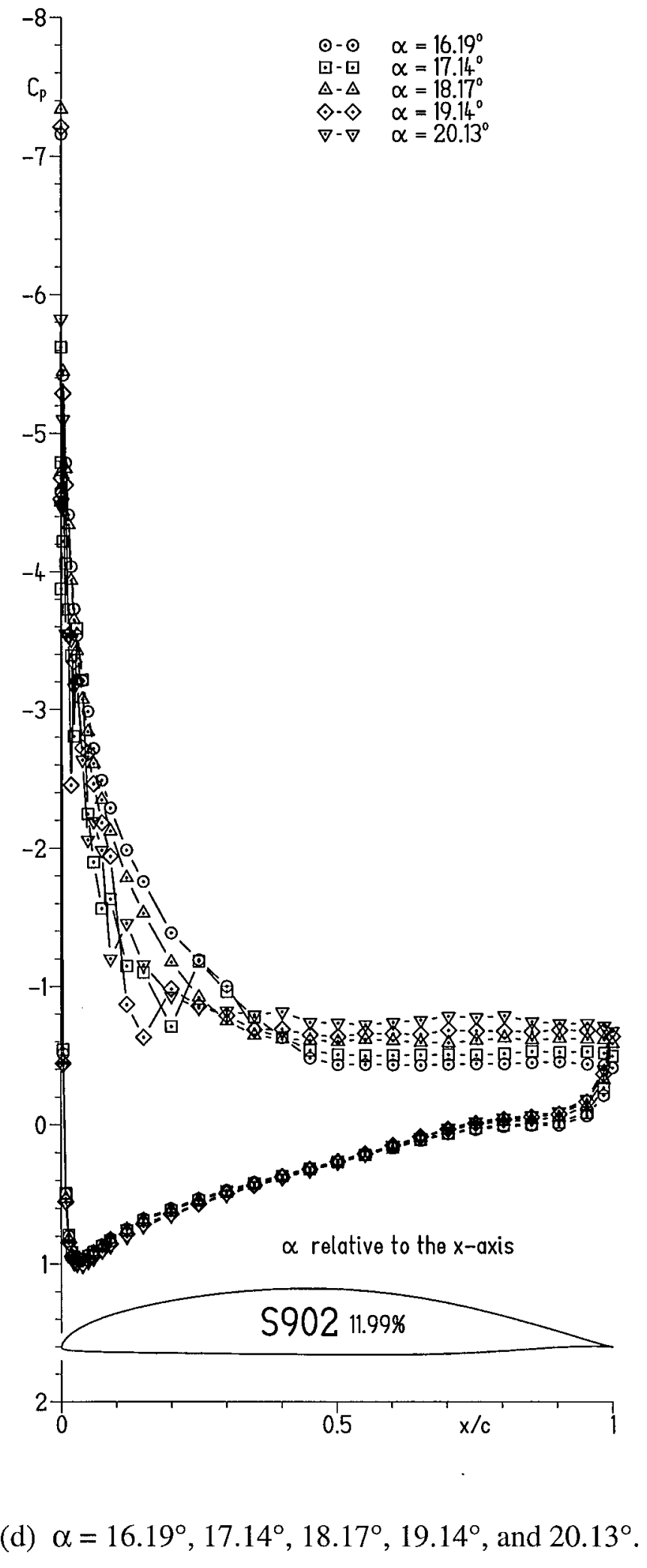

Figure 6.- Continued. 


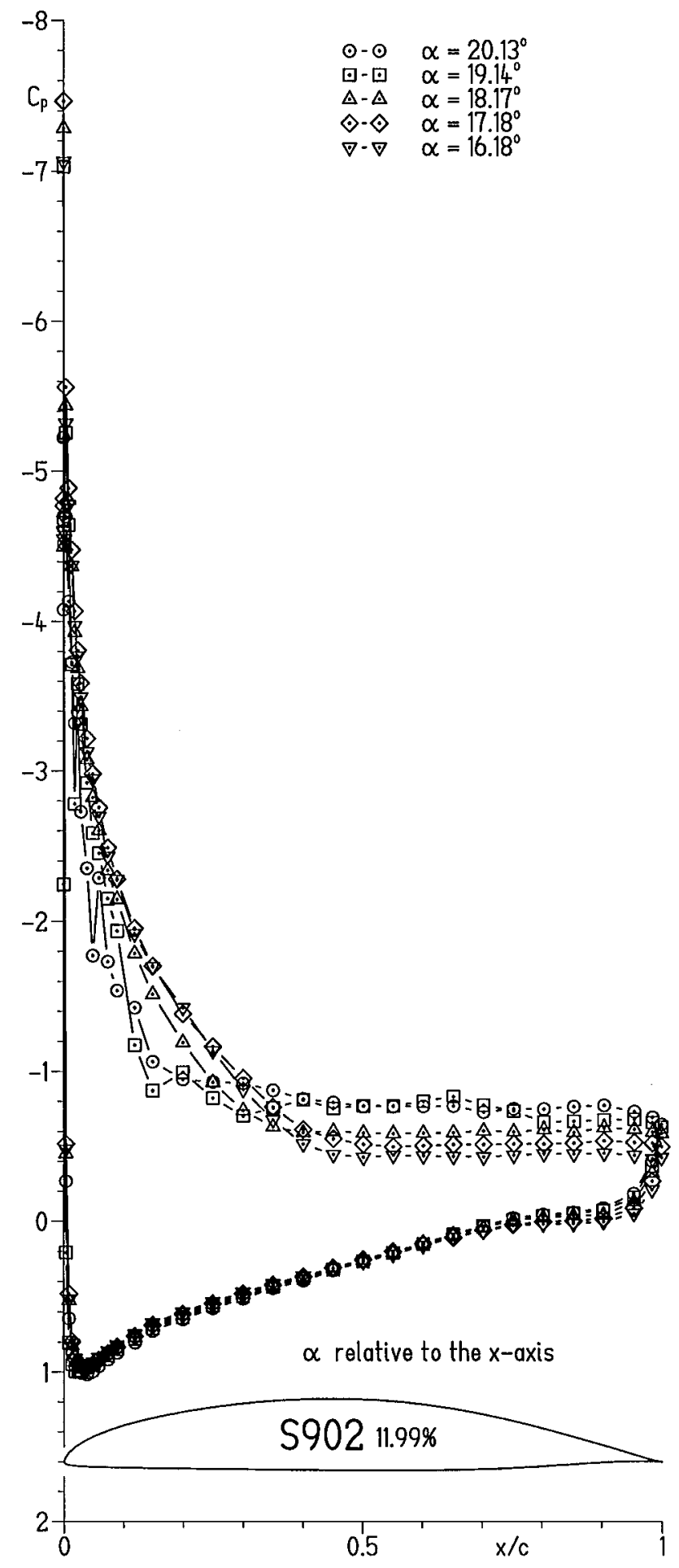

(e) $\alpha=20.13^{\circ}, 19.14^{\circ}, 18.17^{\circ}, 17.18^{\circ}$, and $16.18^{\circ}$.

Figure 6.- Continued. 


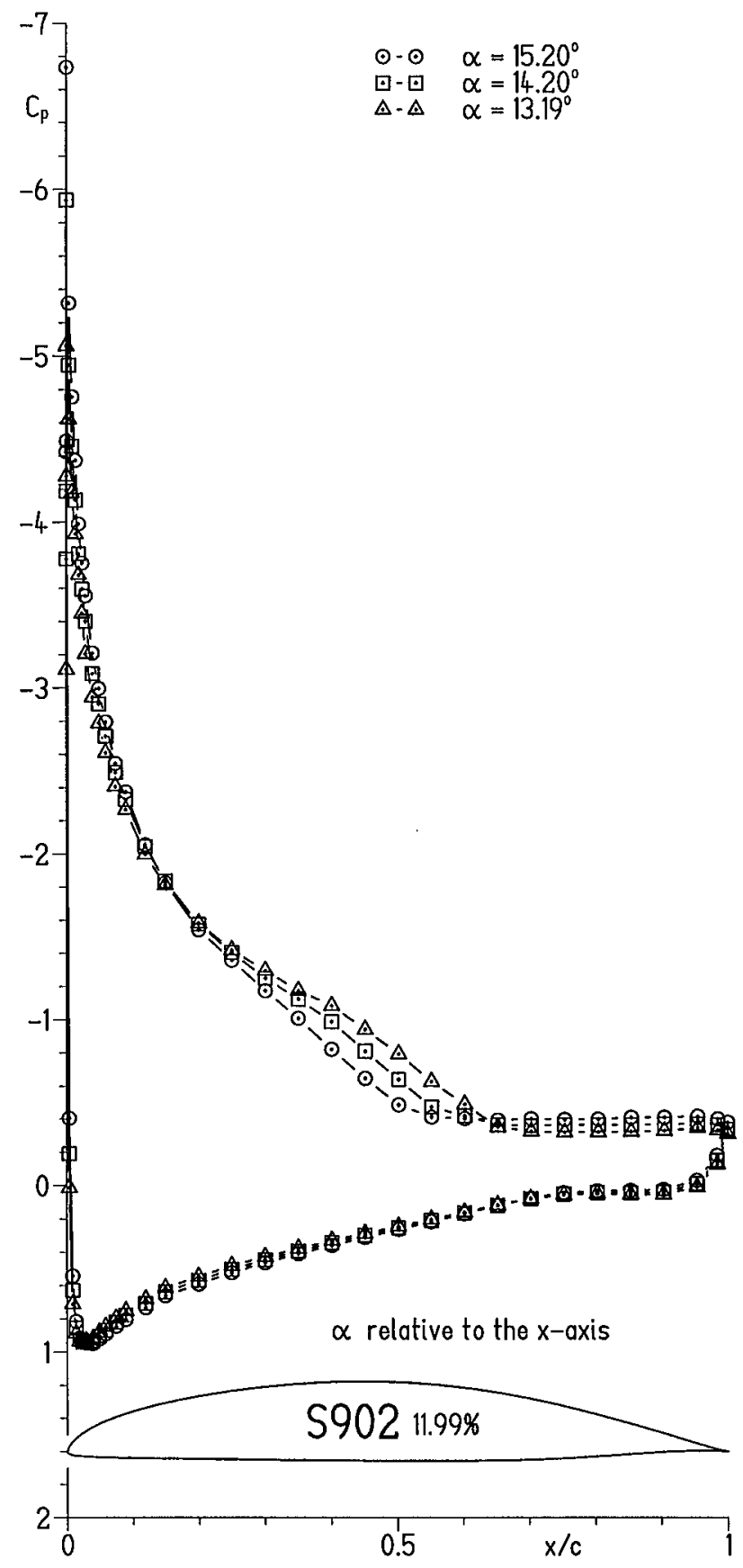

(f) $\alpha=15.20^{\circ}, 14.20^{\circ}$, and $13.19^{\circ}$.

Figure 6.- Continued. 


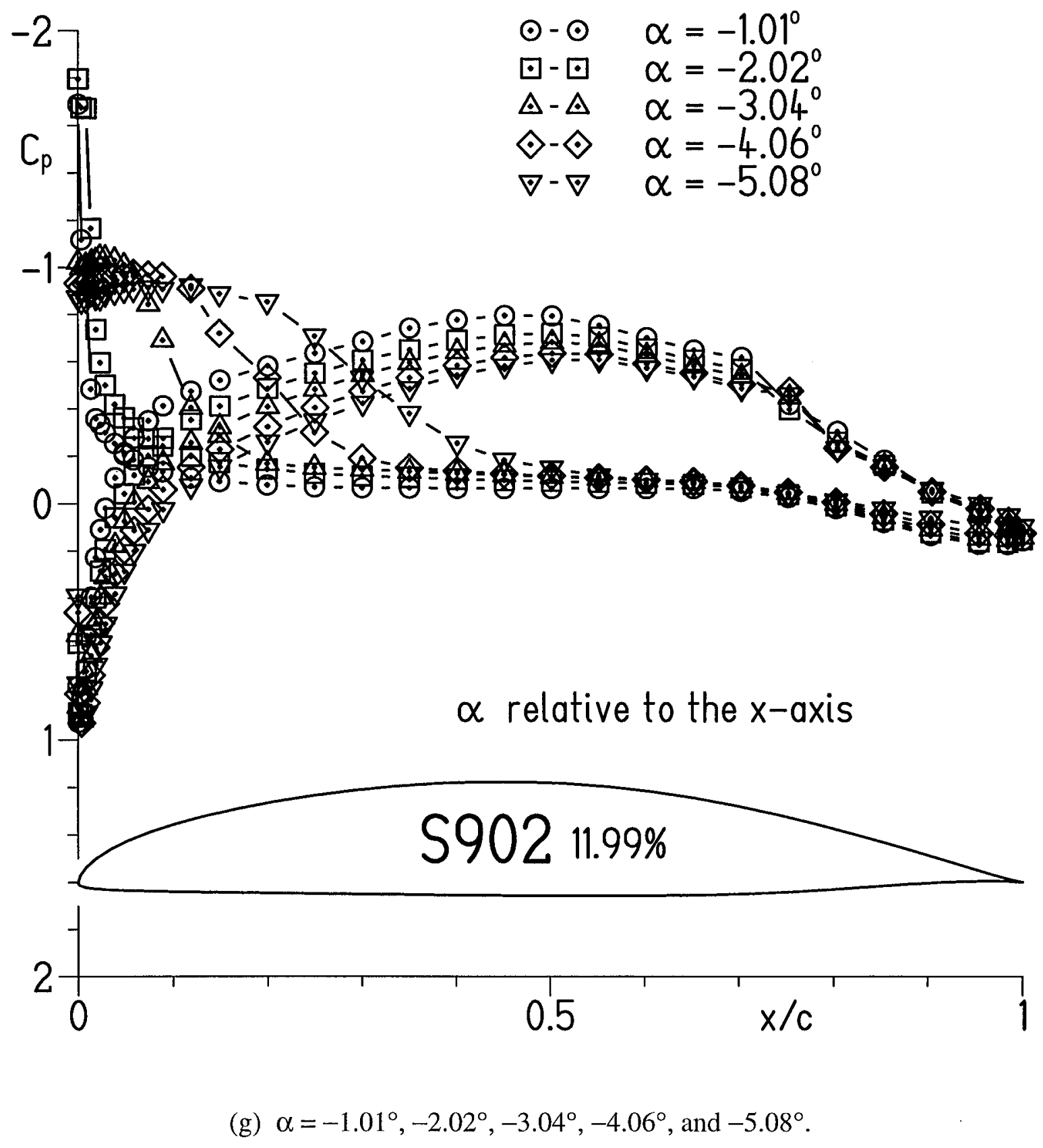

Figure 6.- Continued. 


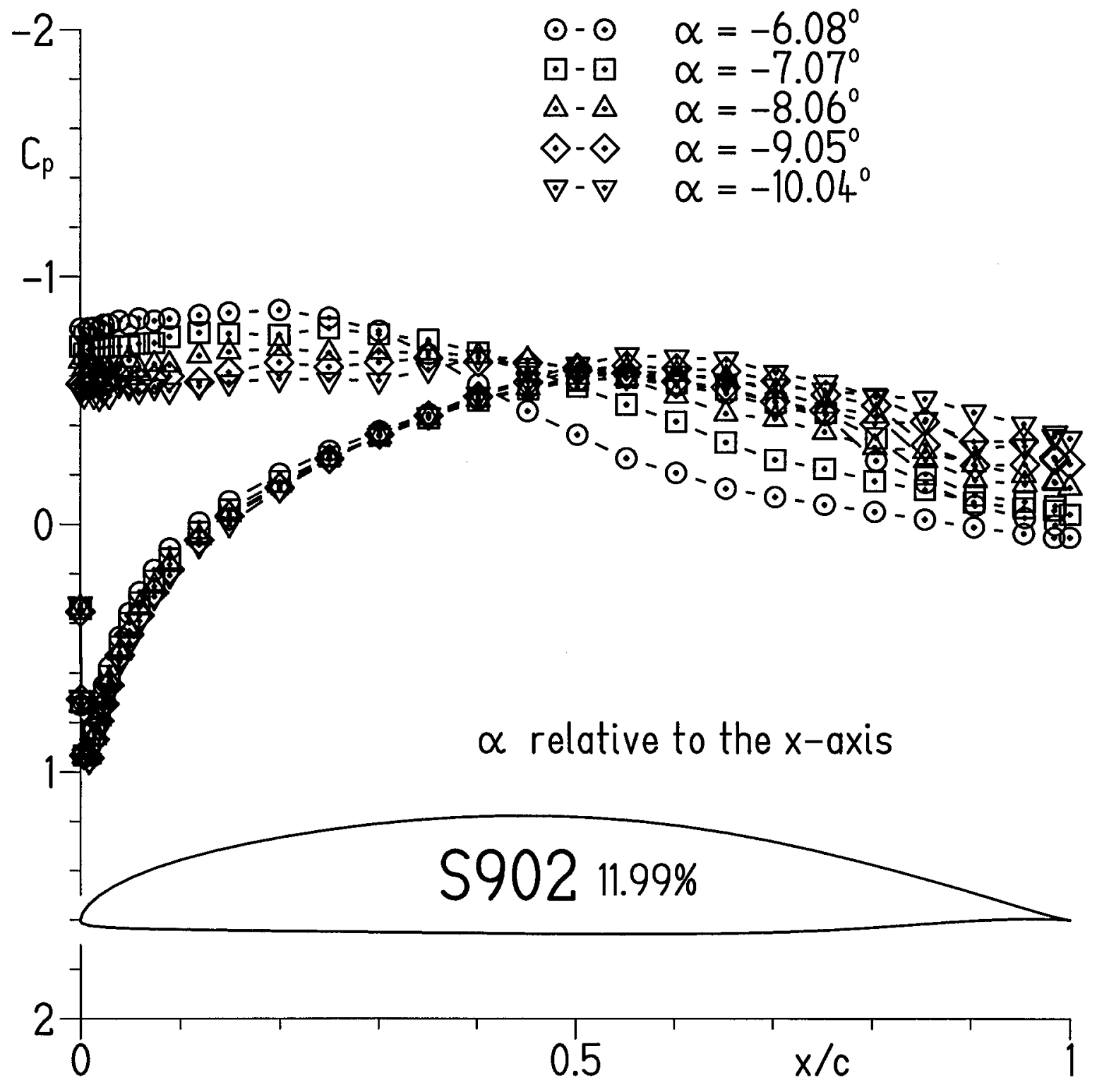

(h) $\alpha=-6.08^{\circ},-7.07^{\circ},-8.06^{\circ},-9.05^{\circ}$, and $-10.04^{\circ}$.

Figure 6.- Continued. 


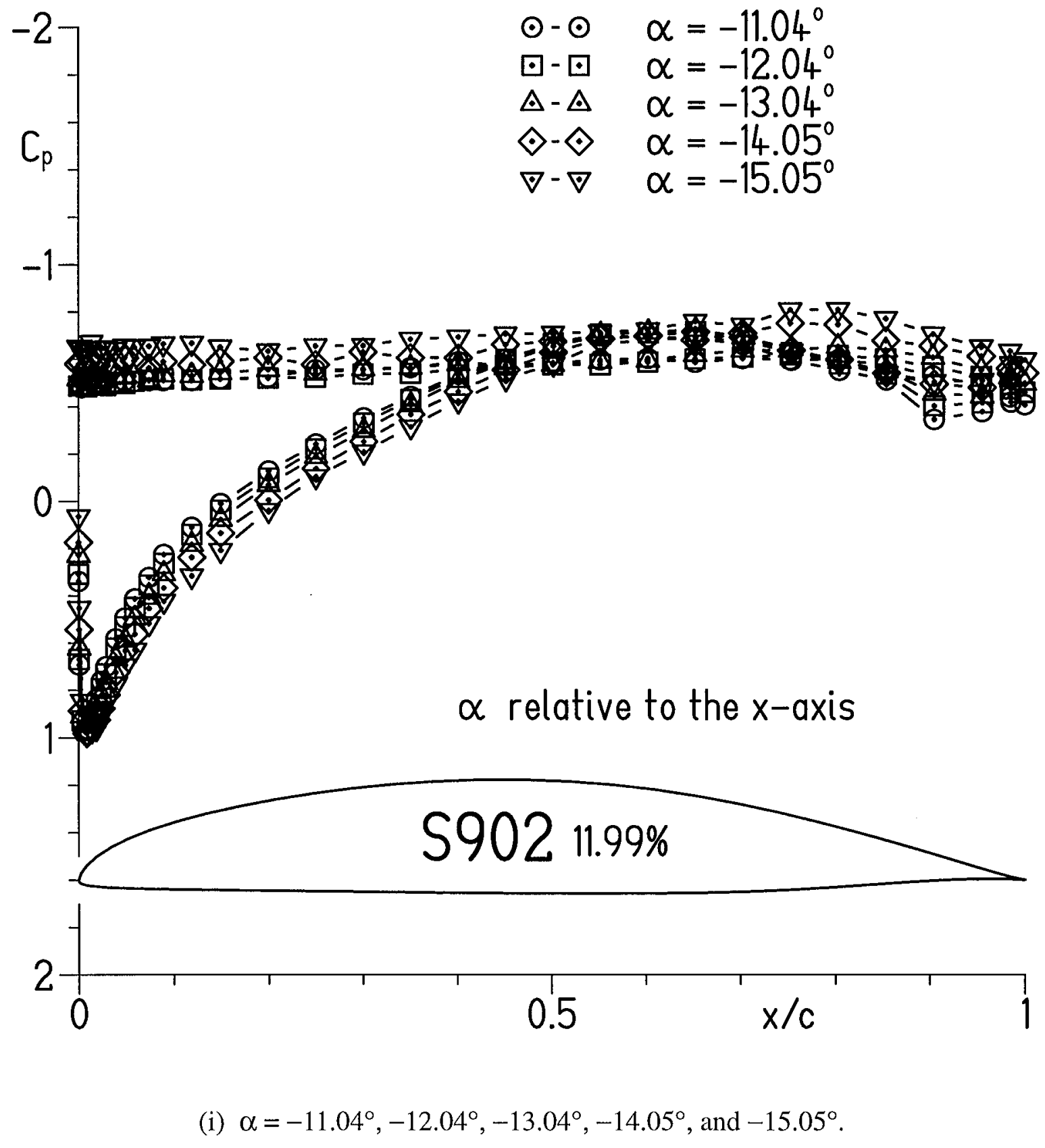

Figure 6.- Continued. 


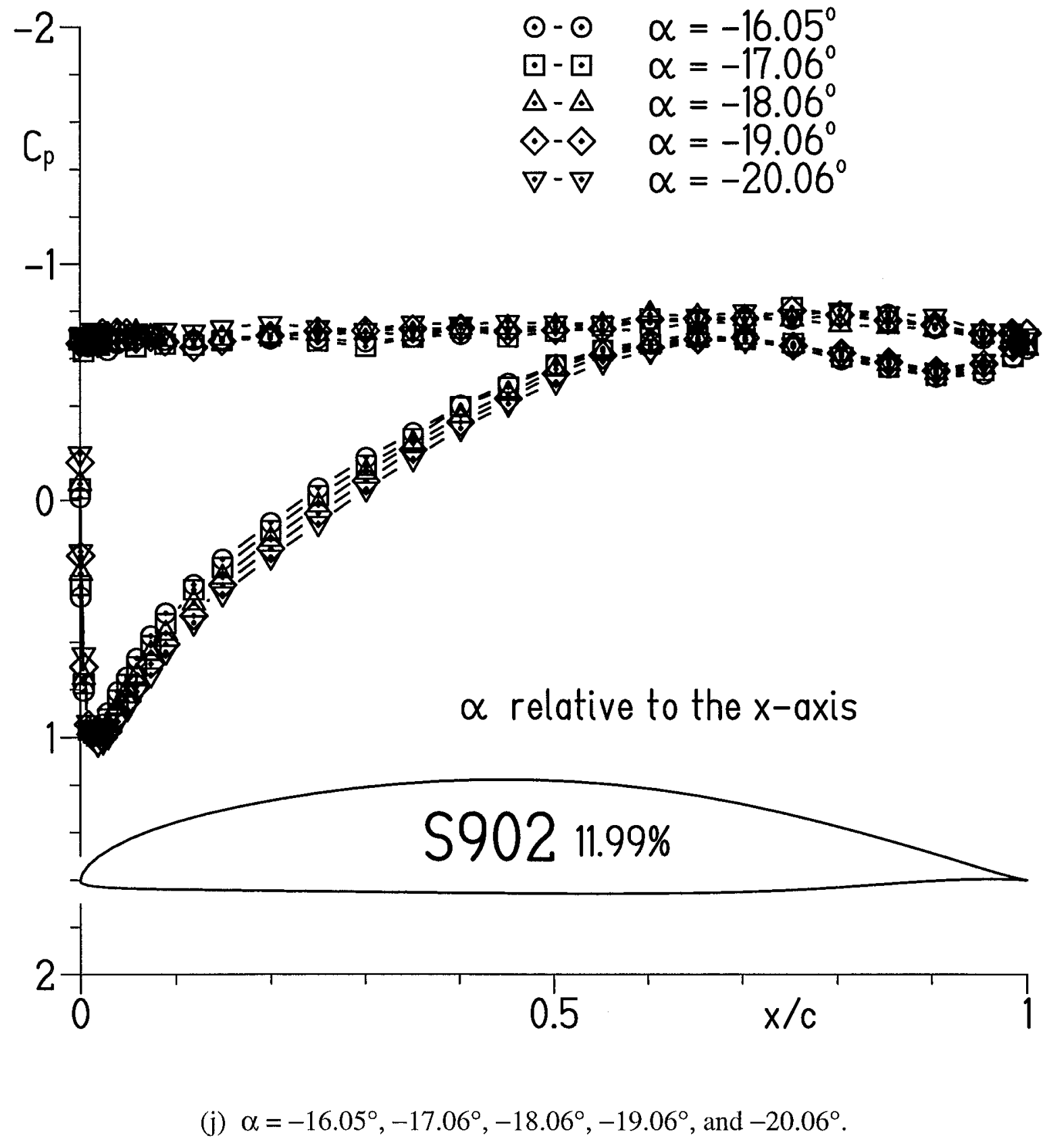

Figure 6.- Continued. 


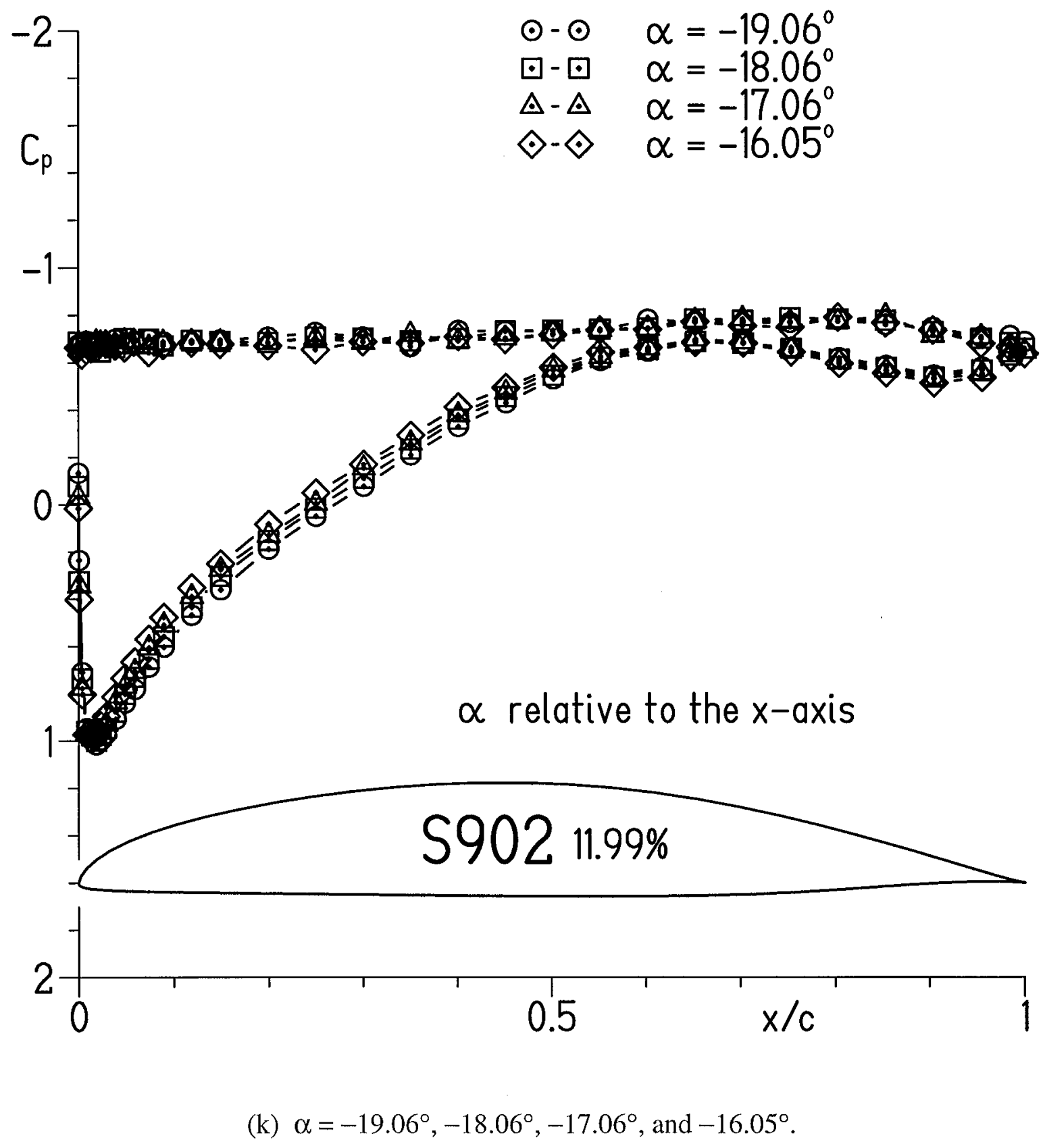

Figure 6.- Continued. 


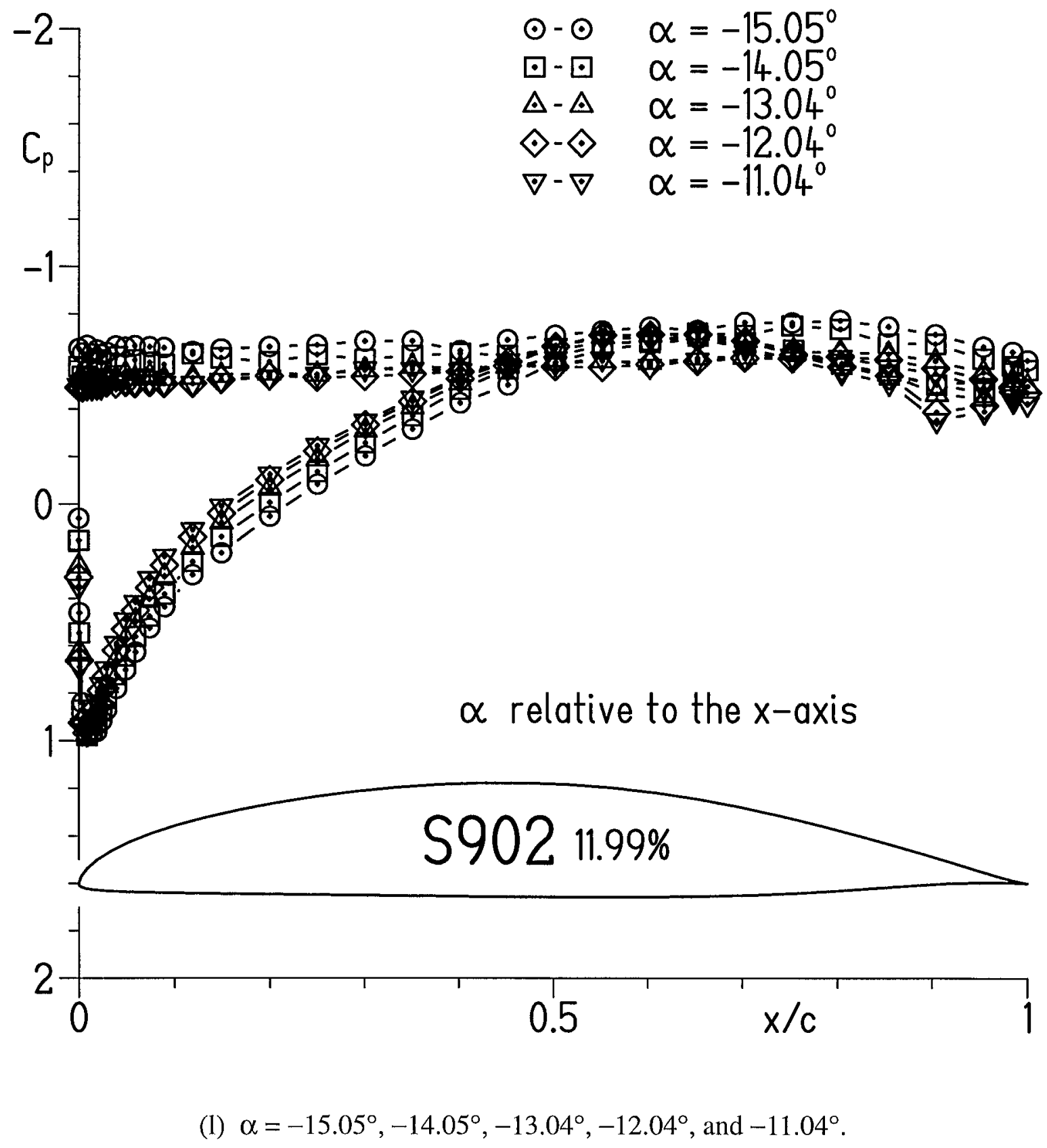

Figure 6.- Continued. 


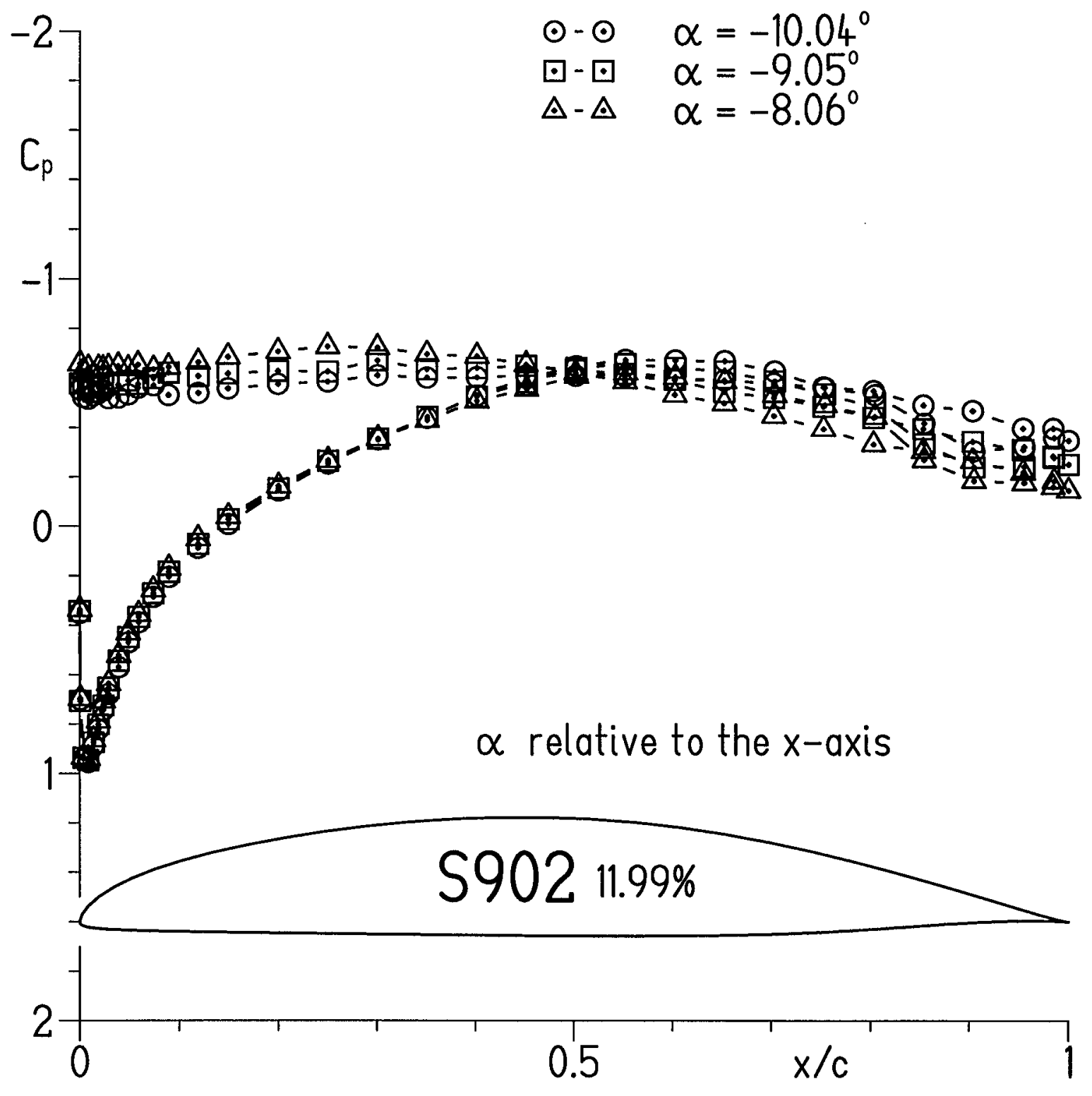

(m) $\alpha=-10.04^{\circ},-9.05^{\circ}$, and $-8.06^{\circ}$.

Figure 6.- Concluded. 


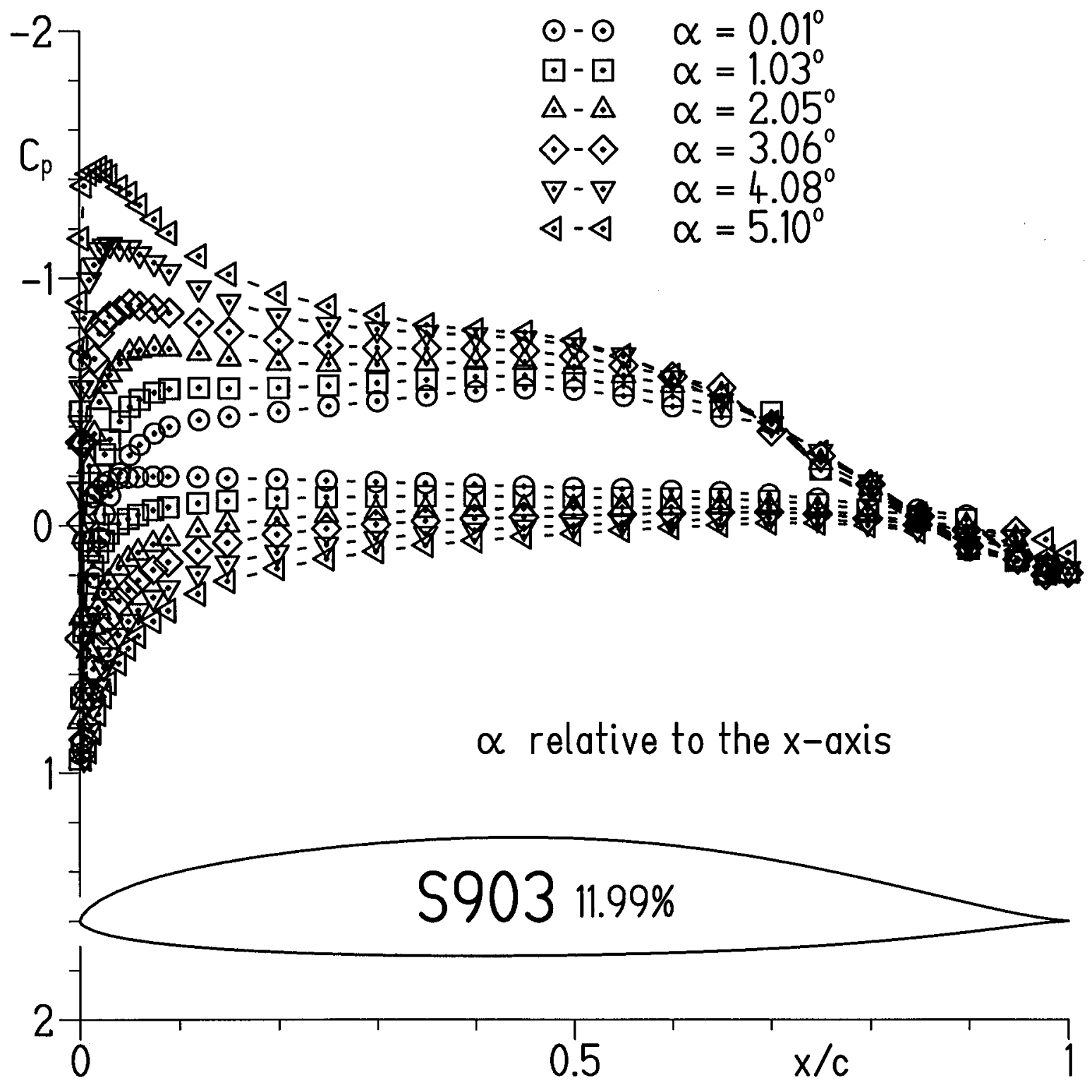

(a) $\alpha=0.01^{\circ}, 1.03^{\circ}, 2.05^{\circ}, 3.06^{\circ}, 4.08^{\circ}$, and $5.10^{\circ}$.

Figure 7.- Pressure distributions for $\mathrm{S} 903$ airfoil for $\mathrm{R}=1.0 \times 10^{6}$ and $\mathrm{M}=0.10$ with transition free. 


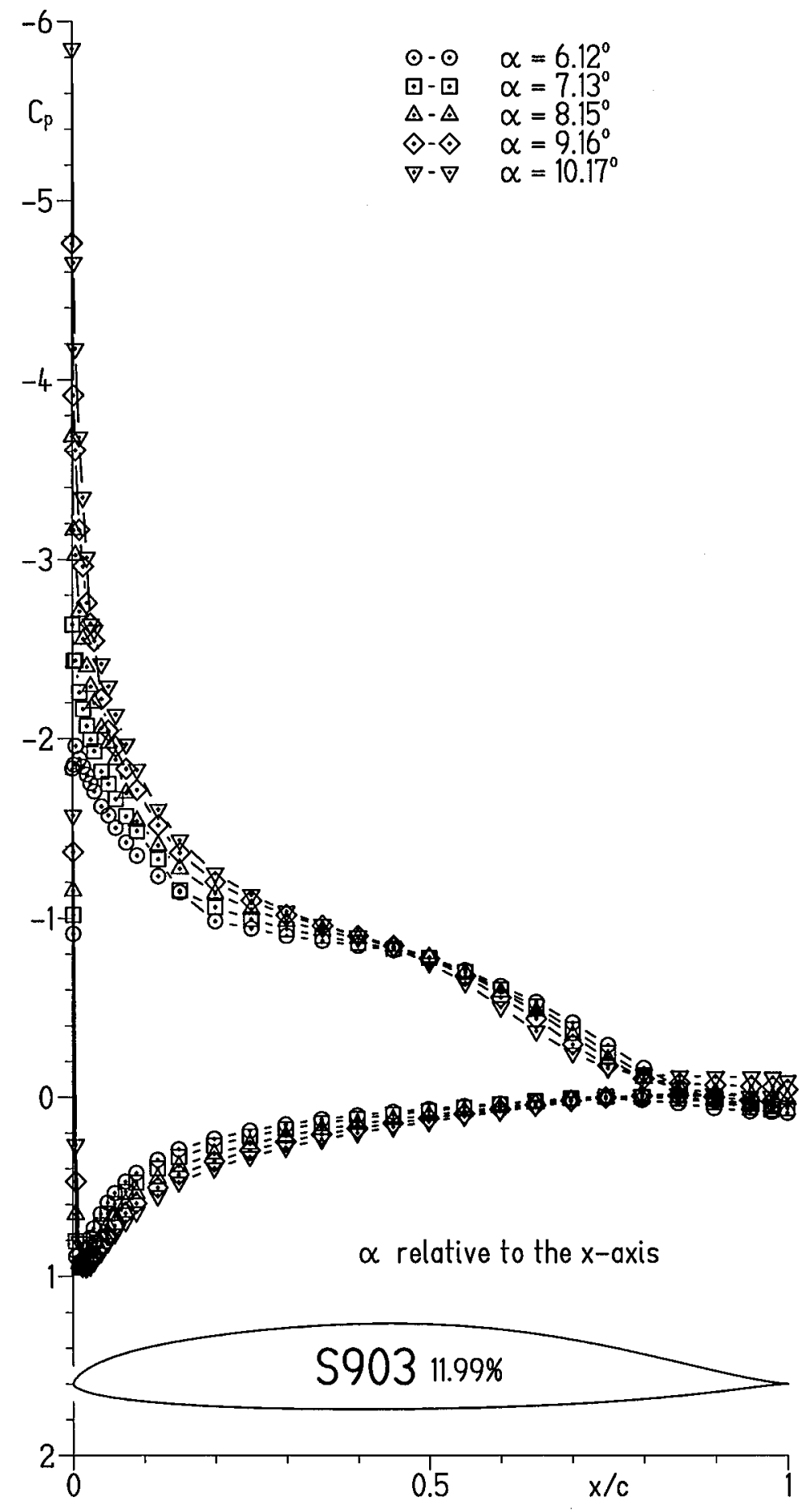

(b) $\alpha=6.12^{\circ}, 7.13^{\circ}, 8.15^{\circ}, 9.16^{\circ}$, and $10.17^{\circ}$.

Figure 7.- Continued. 


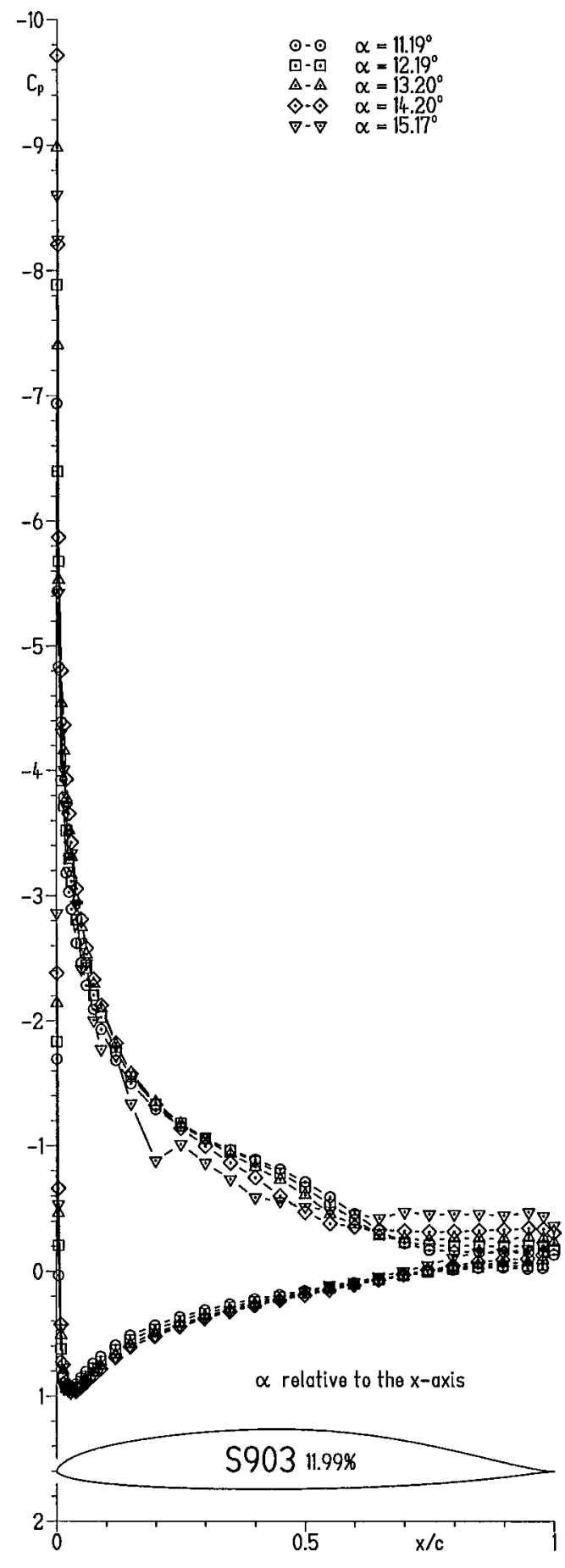

(c) $\alpha=11.19^{\circ}, 12.19^{\circ}, 13.20^{\circ}, 14.20^{\circ}$, and $15.17^{\circ}$.

Figure 7.- Continued. 


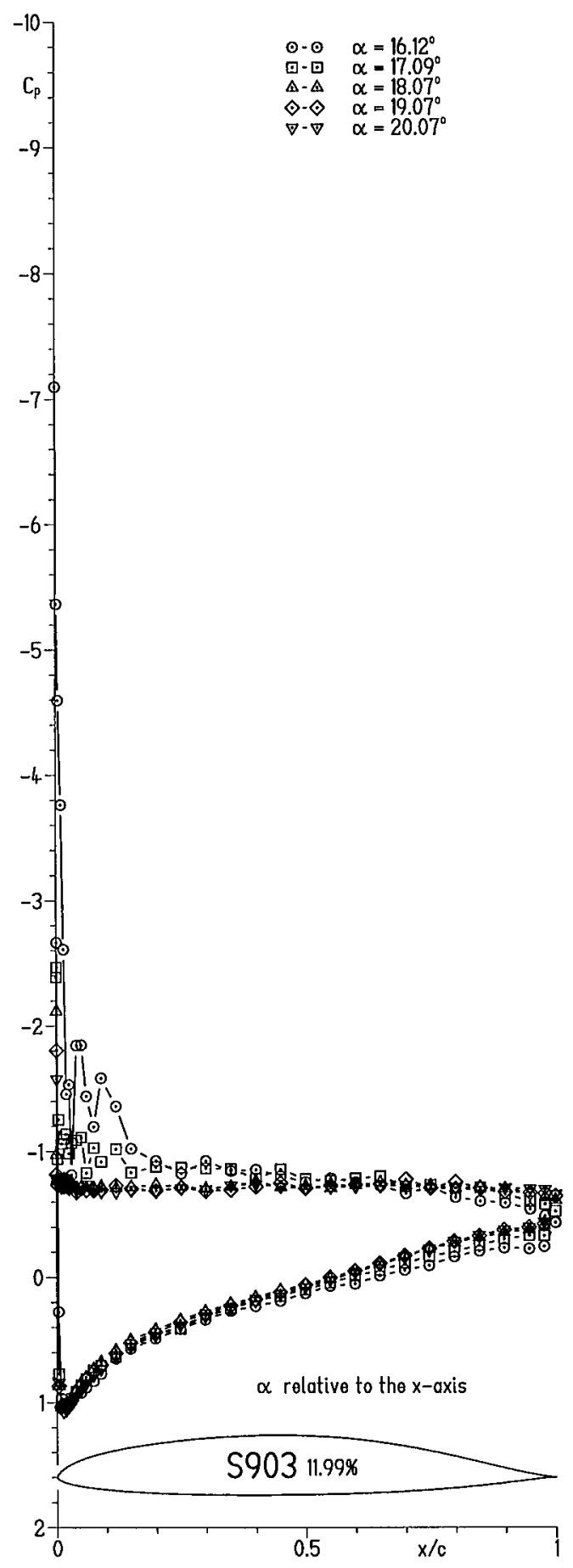

(d) $\alpha=16.12^{\circ}, 17.09^{\circ}, 18.07^{\circ}, 19.07^{\circ}$, and $20.07^{\circ}$.

Figure 7.- Continued. 


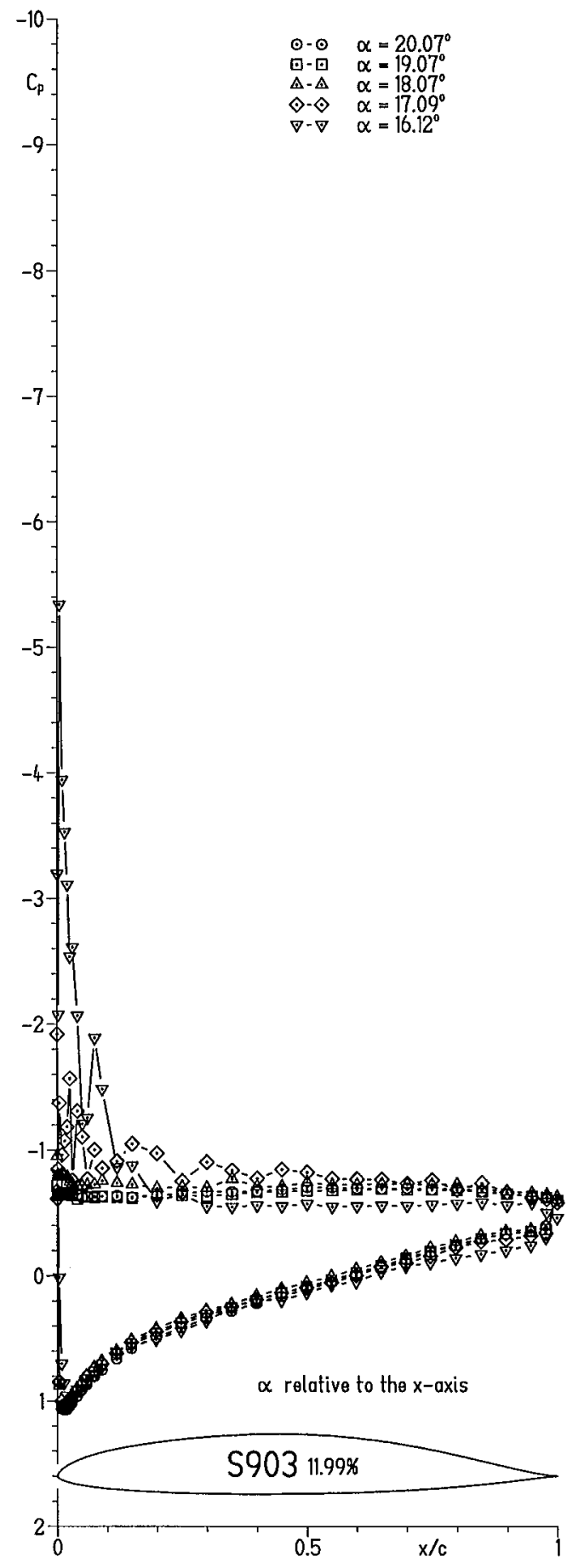

(e) $\alpha=20.07^{\circ}, 19.07^{\circ}, 18.07^{\circ}, 17.09^{\circ}$, and $16.12^{\circ}$.

Figure 7.- Continued. 


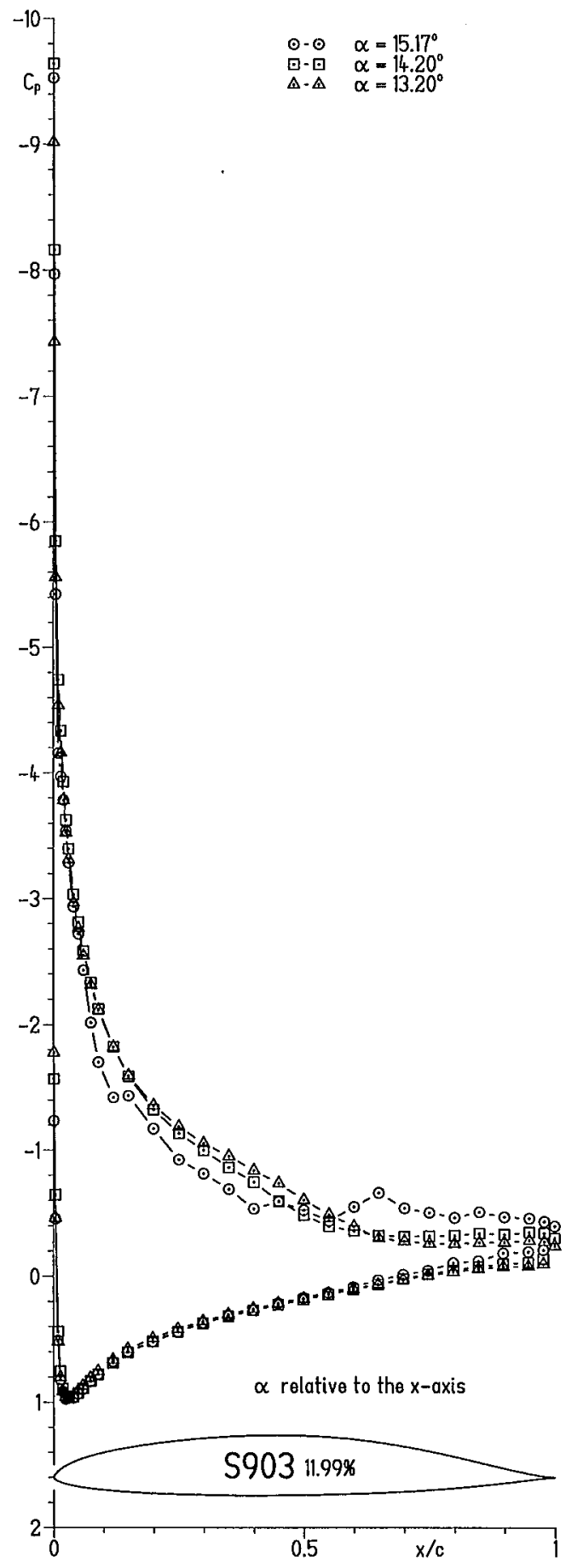

(f) $\alpha=15.17^{\circ}, 14.20^{\circ}$, and $13.20^{\circ}$.

Figure 7.- Continued. 


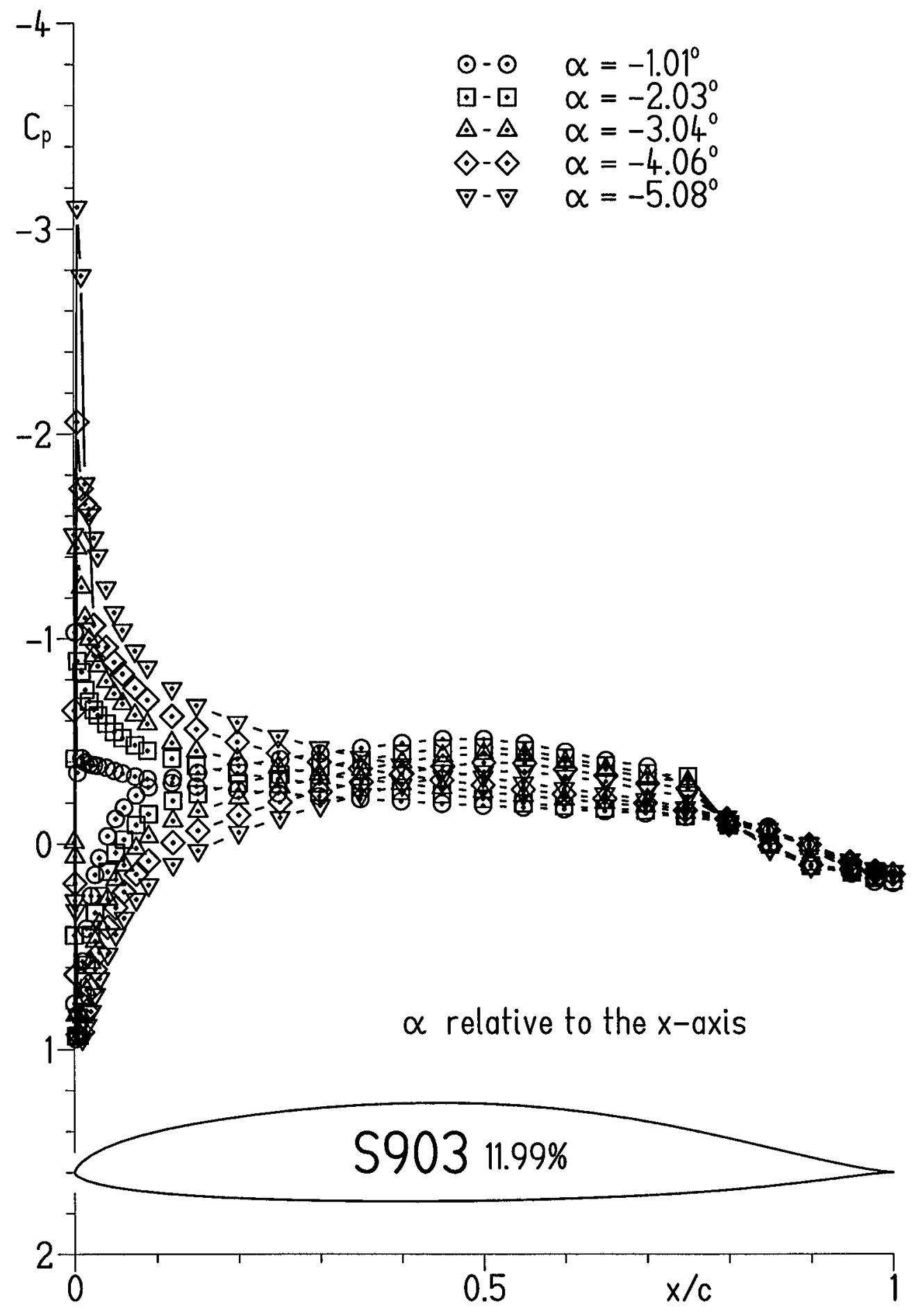

(g) $\alpha=-1.01^{\circ},-2.03^{\circ},-3.04^{\circ},-4.06^{\circ}$, and $-5.08^{\circ}$.

Figure 7.- Continued. 


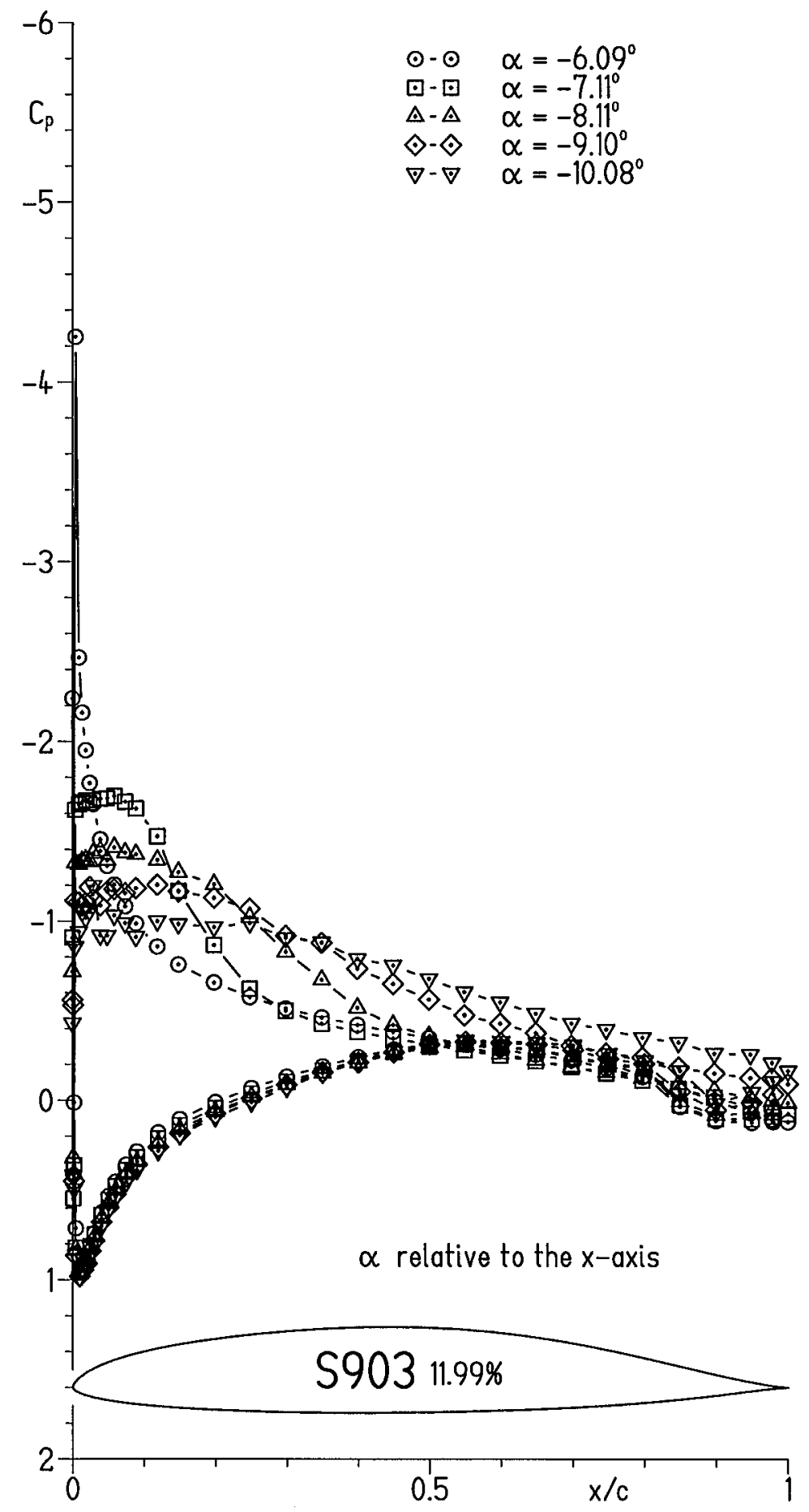

(h) $\alpha=-6.09^{\circ},-7.11^{\circ},-8.11^{\circ},-9.10^{\circ}$, and $-10.08^{\circ}$.

Figure 7.- Continued. 

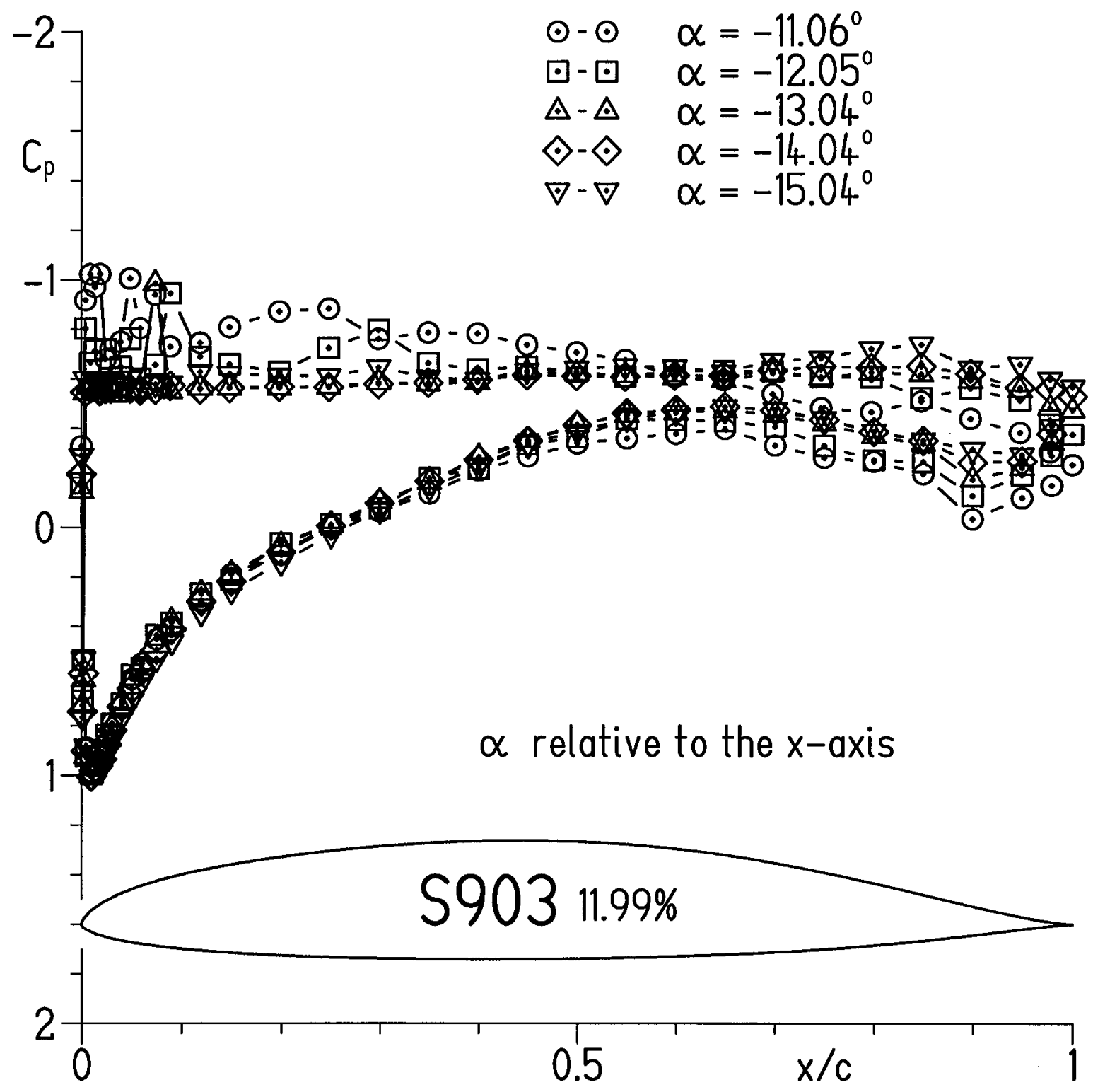

(i) $\alpha=-11.06^{\circ},-12.05^{\circ},-13.04^{\circ},-14.04^{\circ}$, and $-15.04^{\circ}$.

Figure 7.- Continued. 


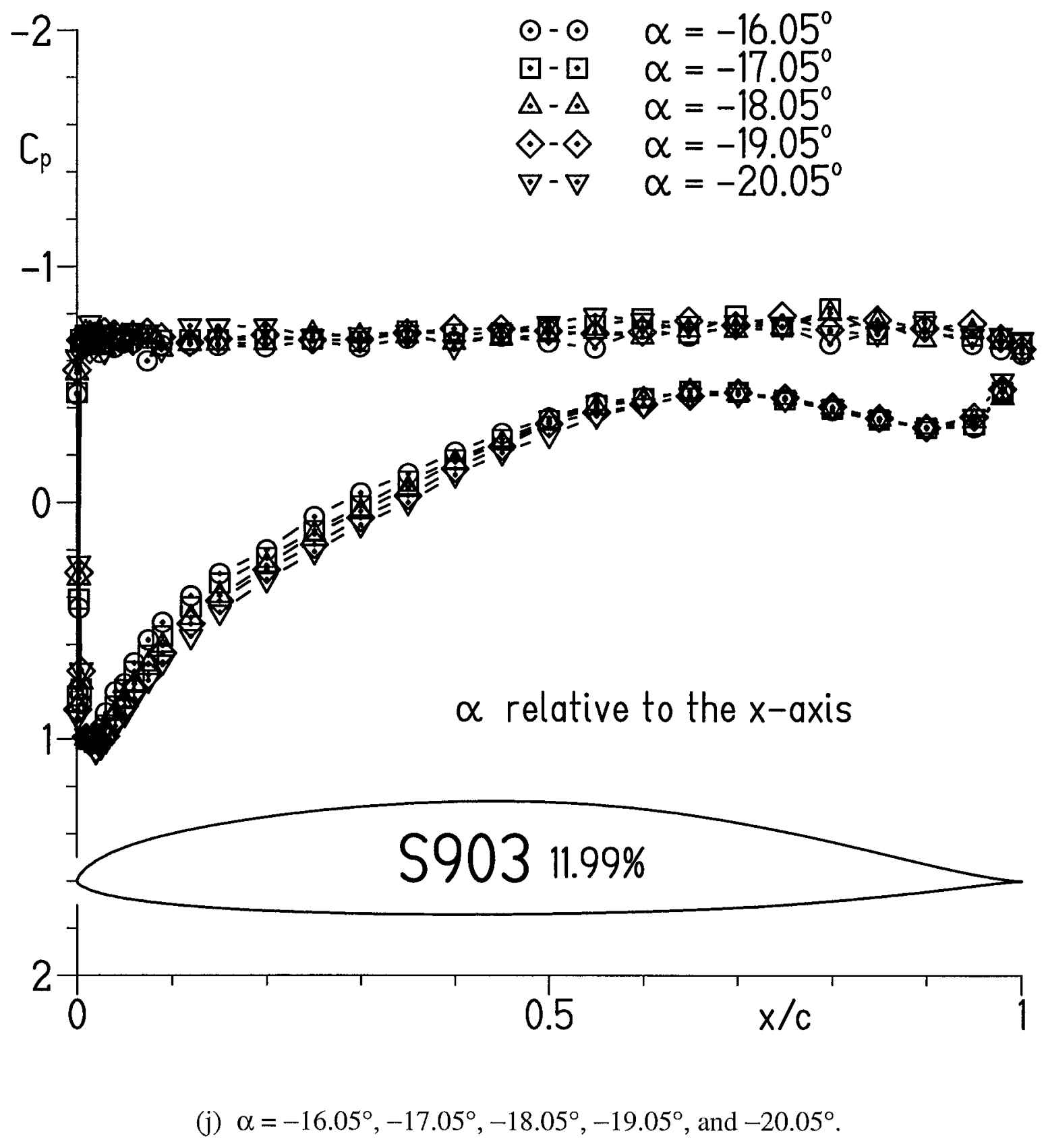

Figure 7.- Continued. 


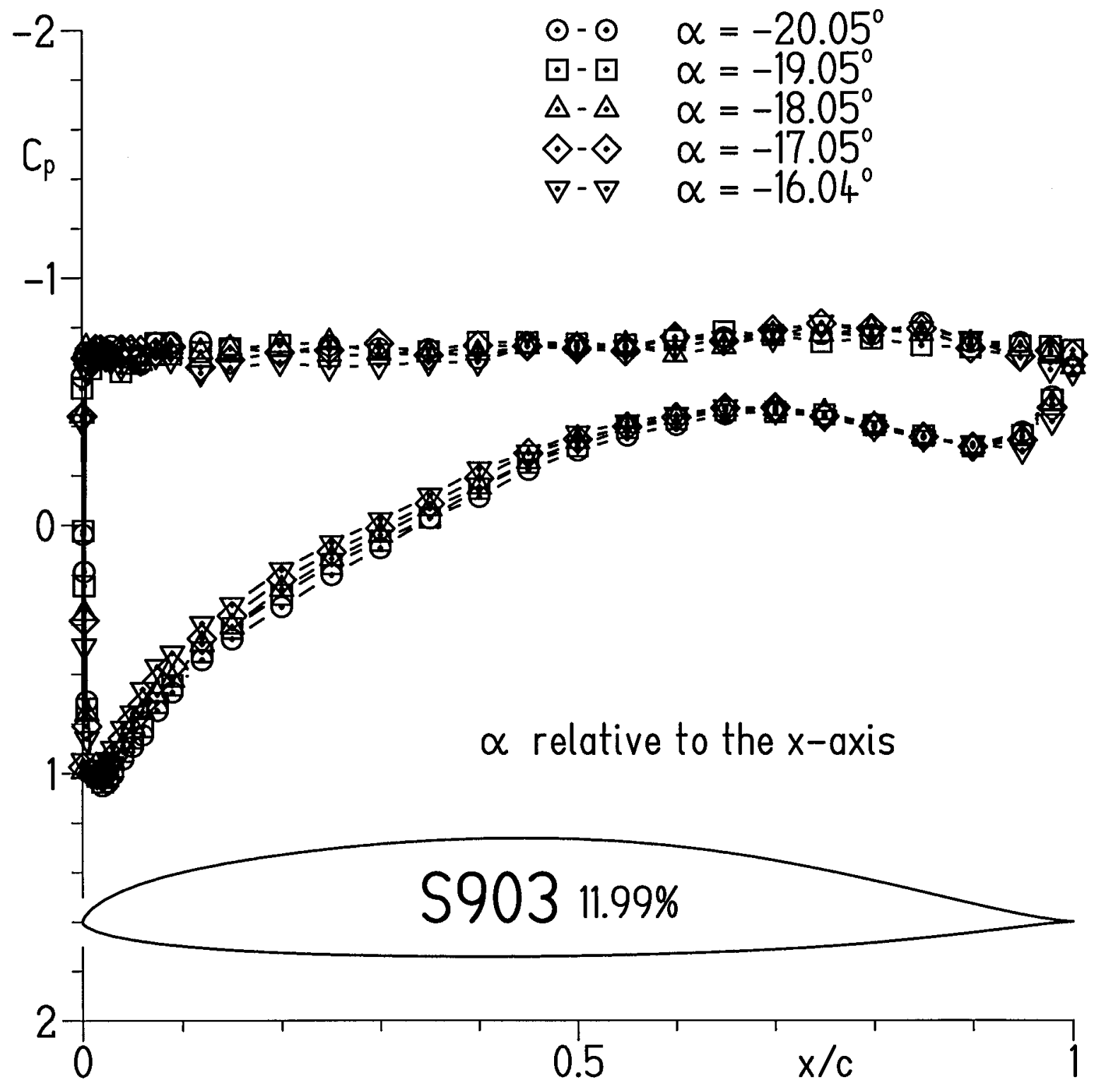

(k) $\alpha=-20.05^{\circ},-19.05^{\circ},-18.05^{\circ},-17.05^{\circ}$, and $-16.04^{\circ}$.

Figure 7.- Continued. 

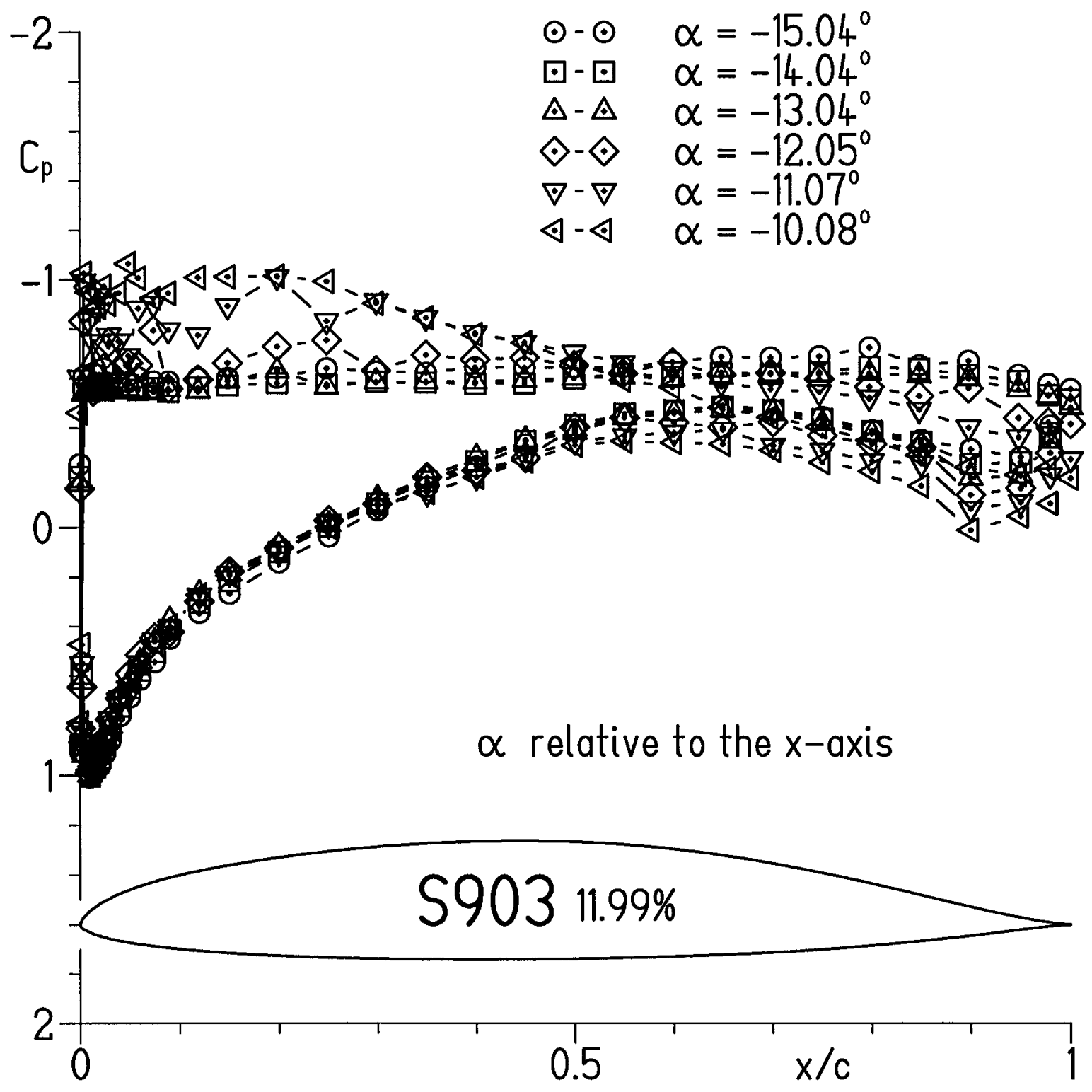

(l) $\alpha=-15.04^{\circ},-14.04^{\circ},-13.04^{\circ},-12.05^{\circ},-11.07^{\circ}$, and $-10.08^{\circ}$.

Figure 7.- Concluded. 


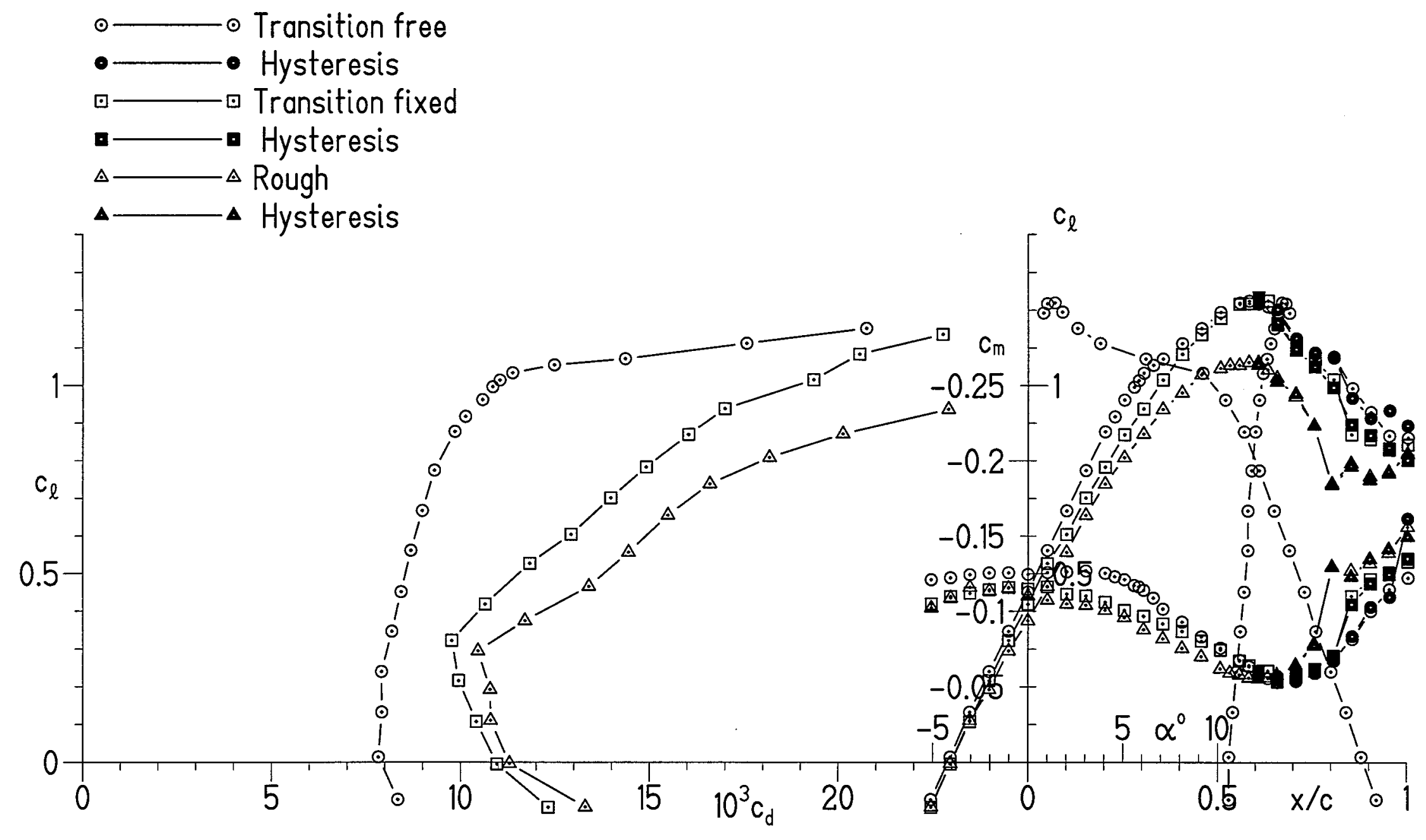

(a) $\mathrm{R}=0.7 \times 10^{6} ; \mathrm{M}=0.07$.

Figure 8.- Section characteristics of S901 airfoil with transition free, transition fixed, and rough. 


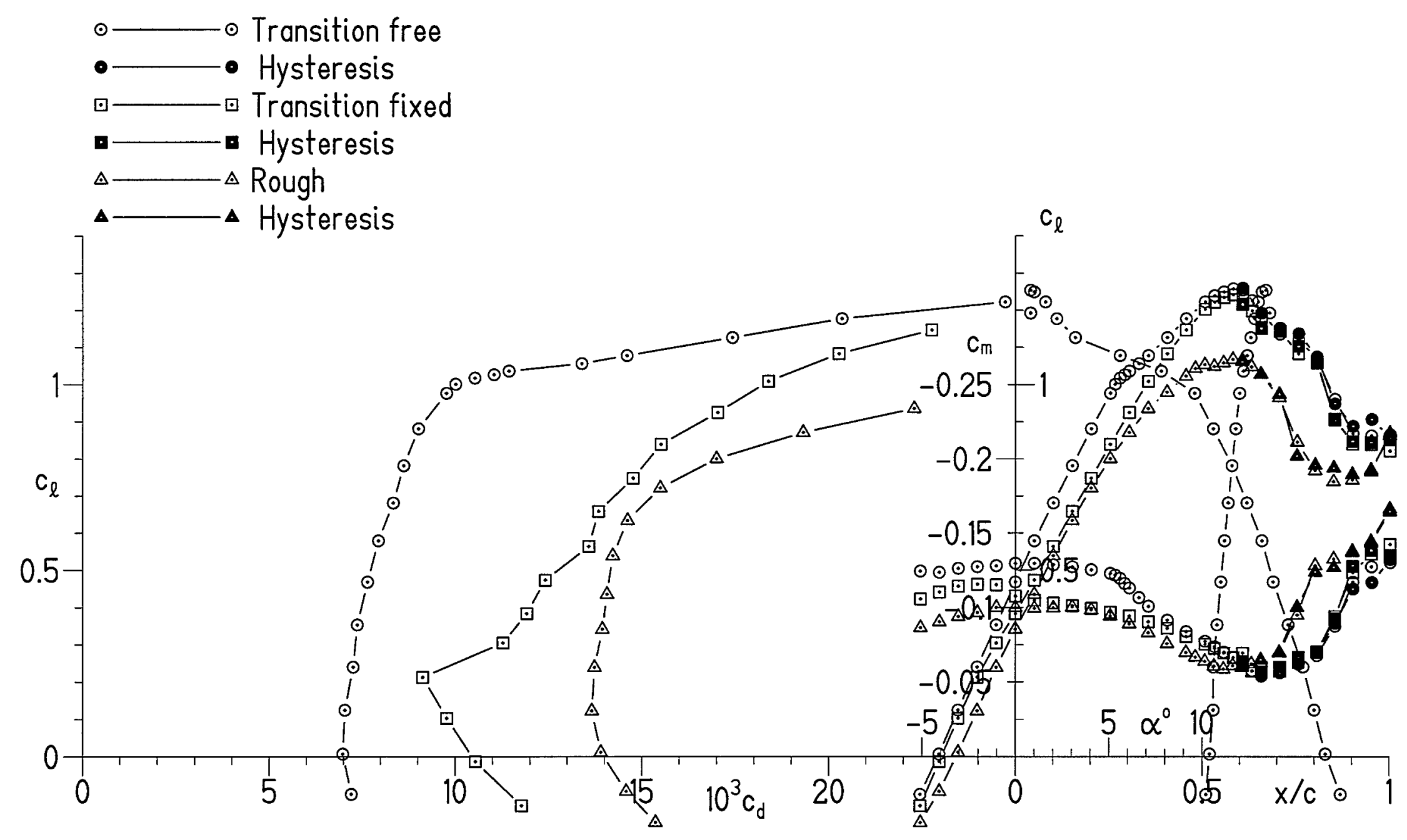

(b) $\mathrm{R}=1.0 \times 10^{6} ; \mathrm{M}=0.10$. 


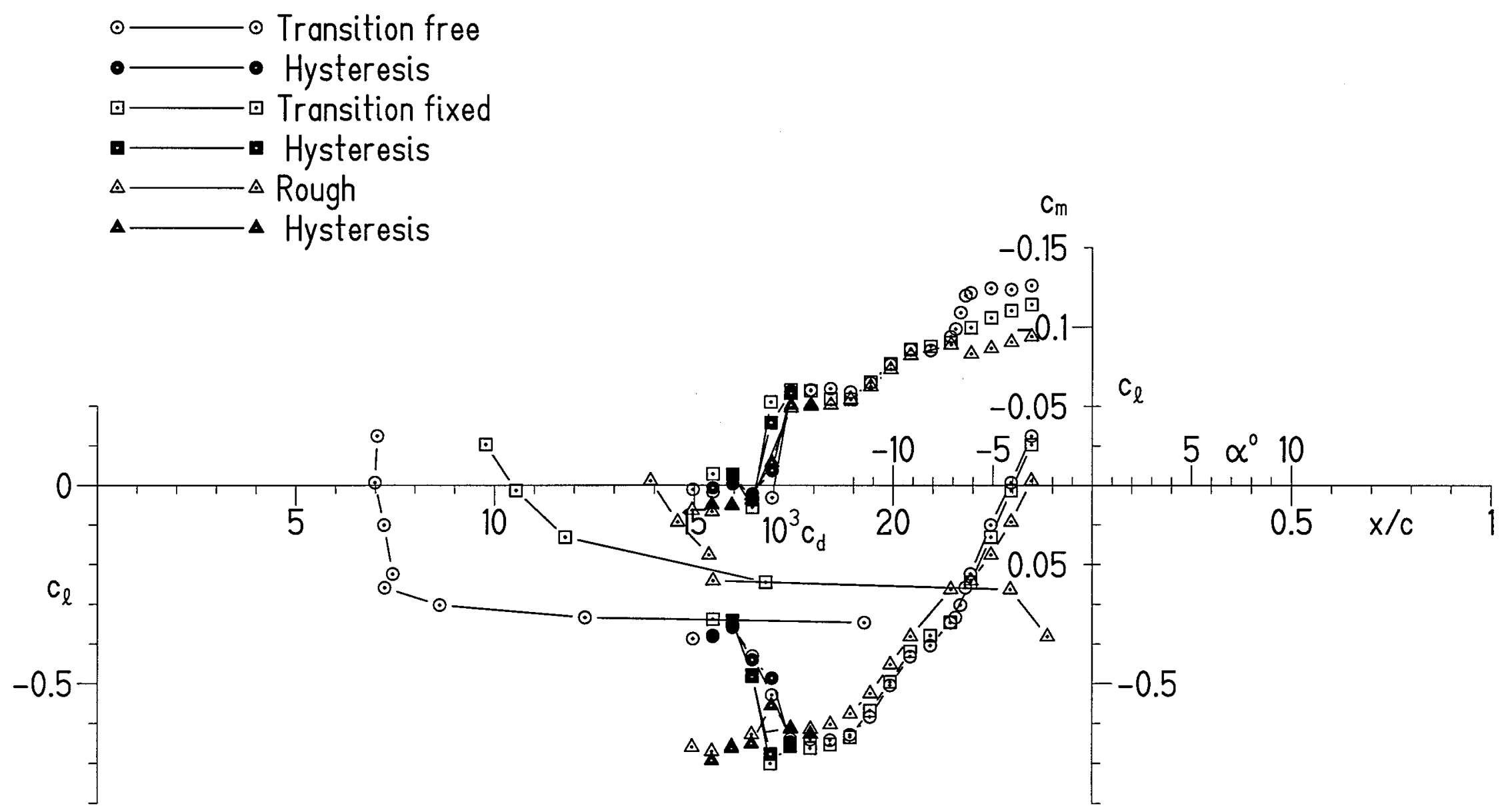

(b) Concluded.

Figure 8.- Continued. 


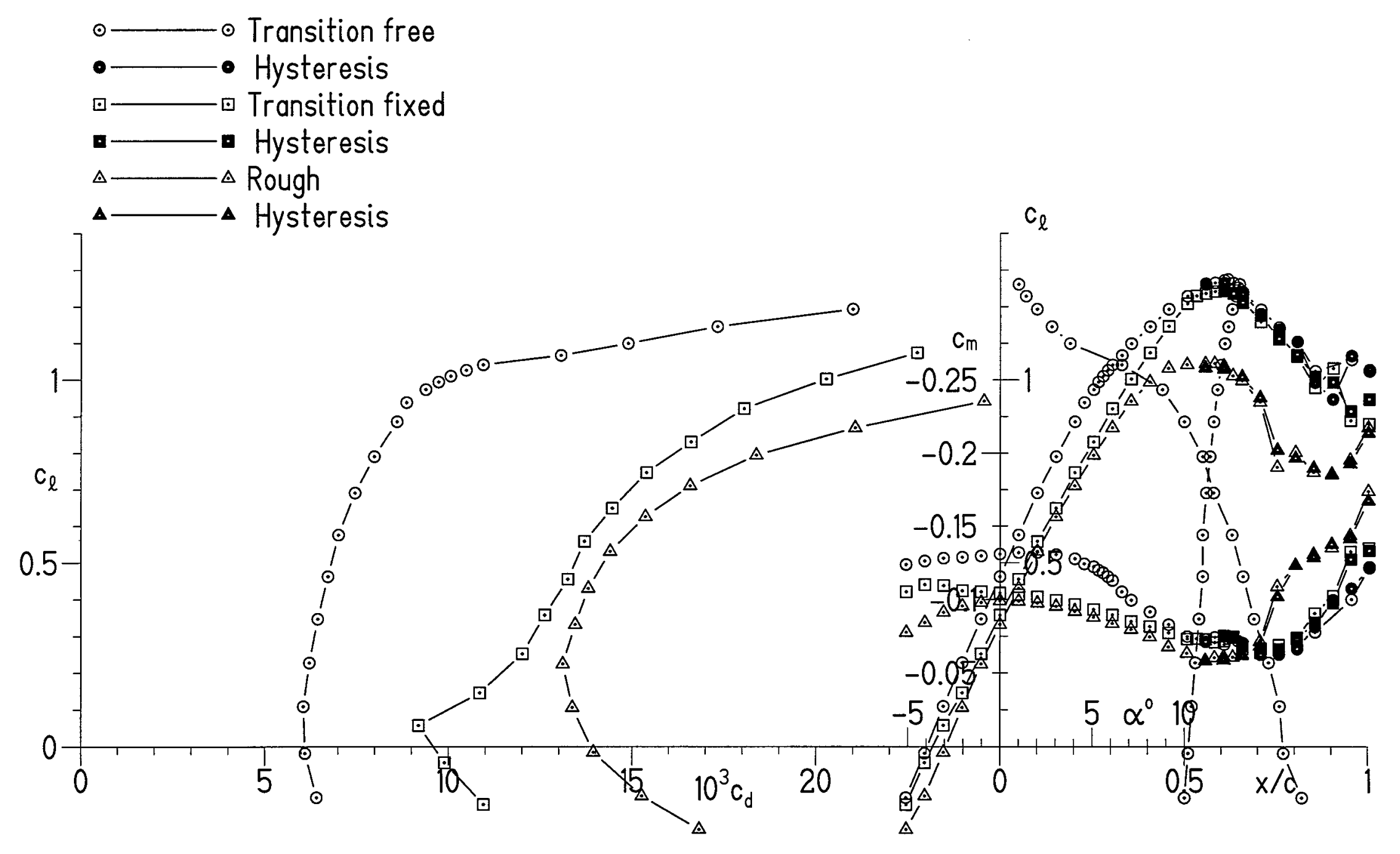

(c) $\mathrm{R}=1.5 \times 10^{6} ; \mathrm{M}=0.16$.

Figure 8.- Concluded. 


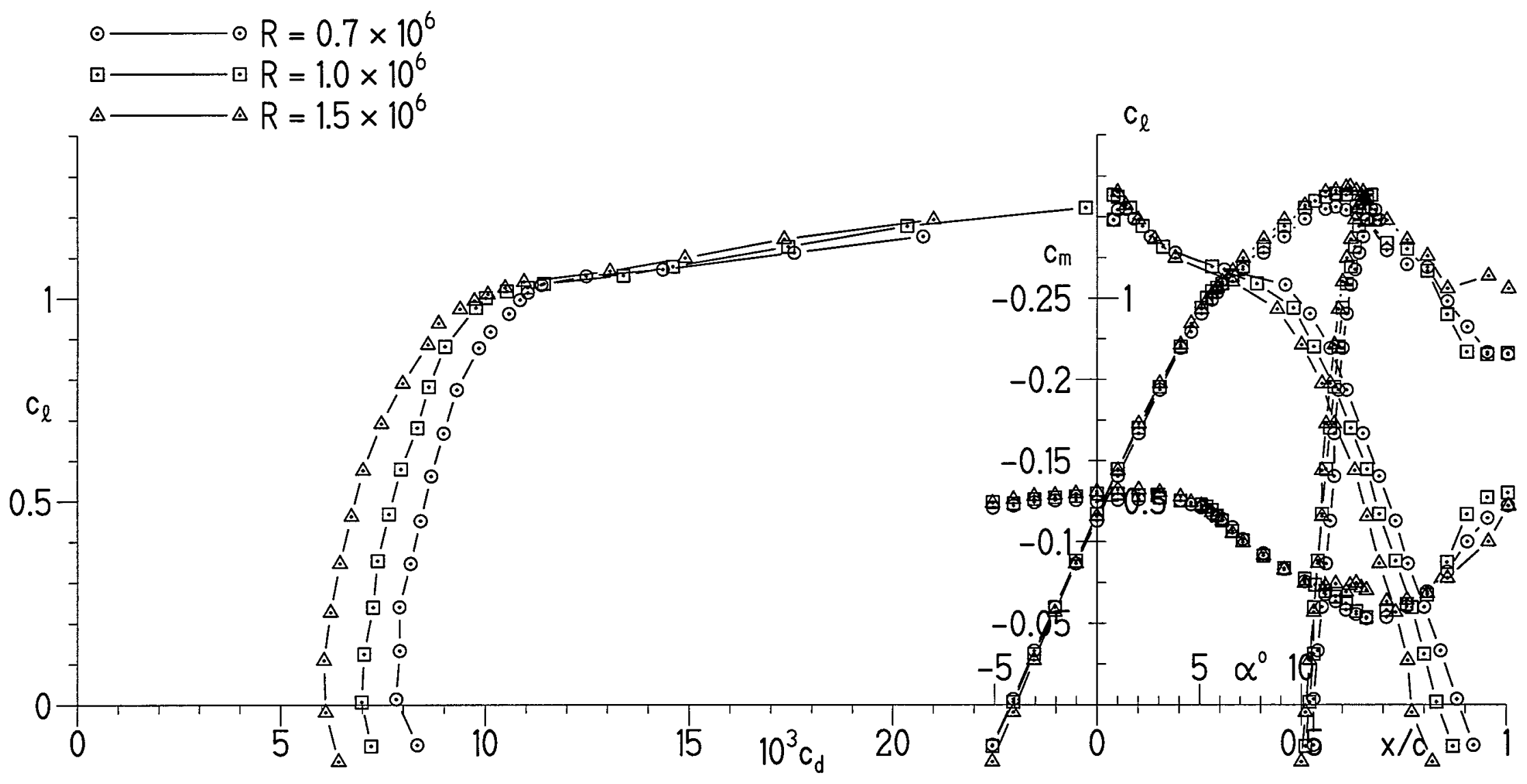

(a) Transition free.

Figure 9.- Effects of Reynolds number on section characteristics of S901 airfoil. 


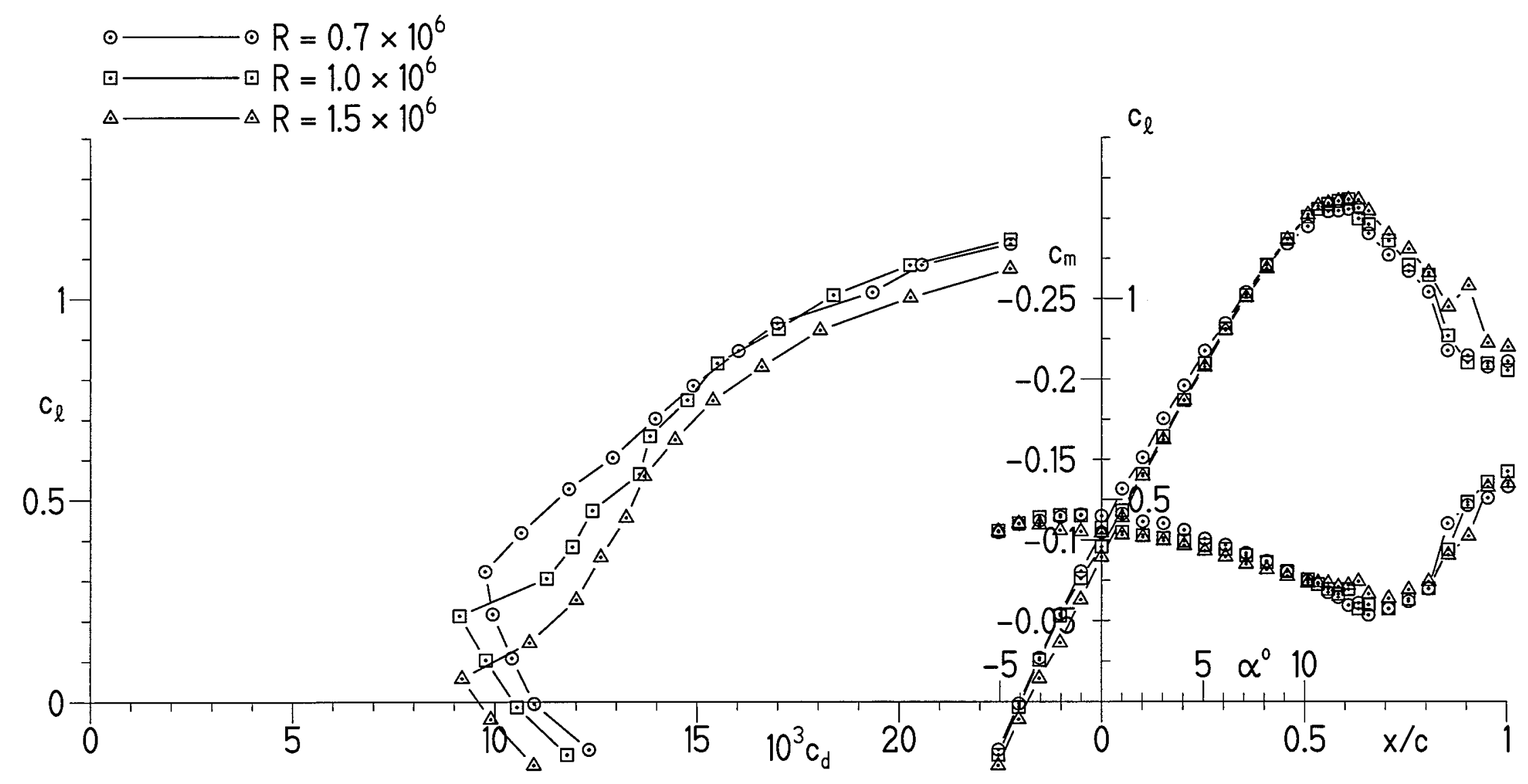

(b) Transition fixed.

Figure 9.- Continued. 


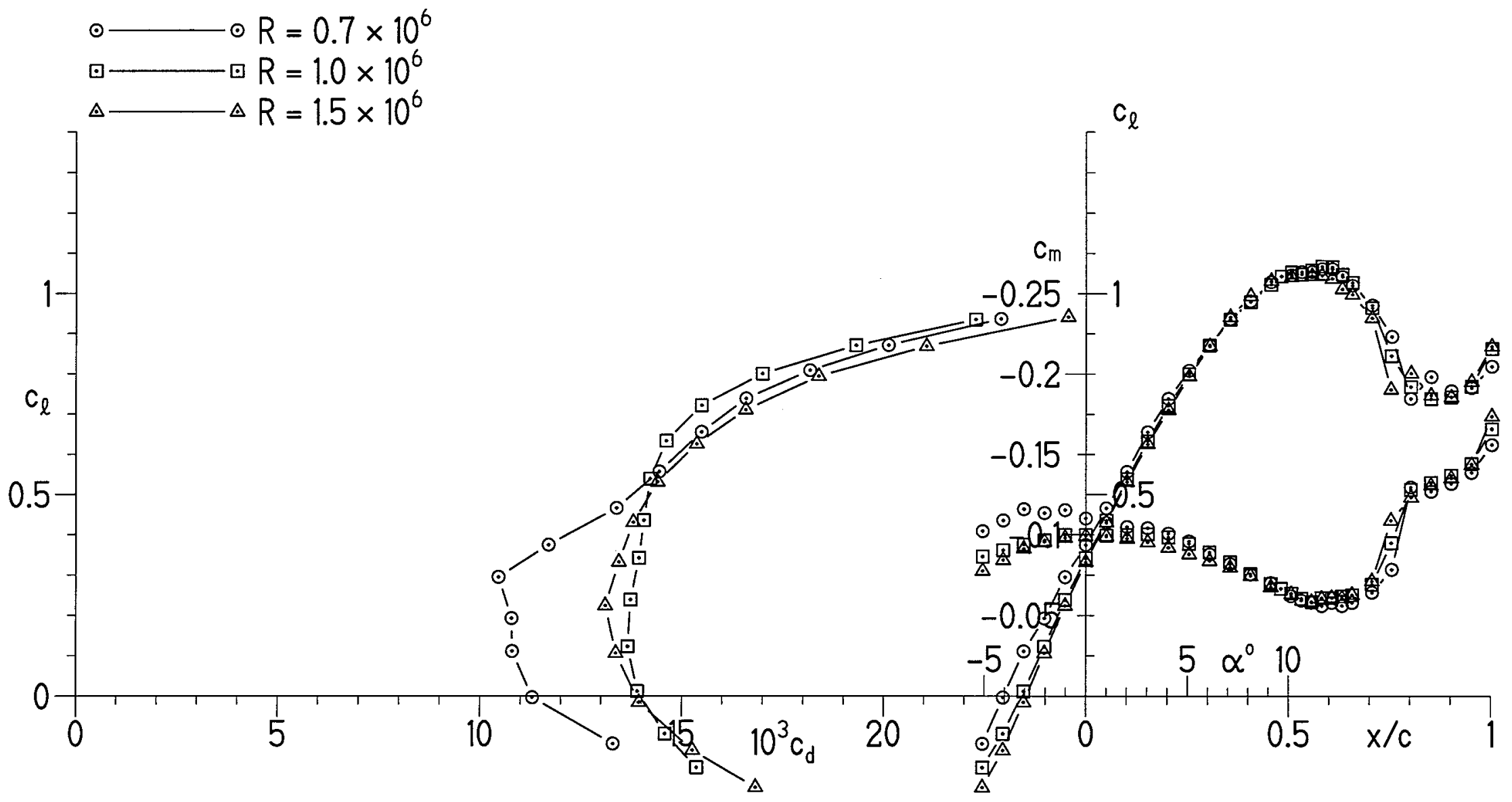

(c) Rough.

Figure 9.- Concluded. 


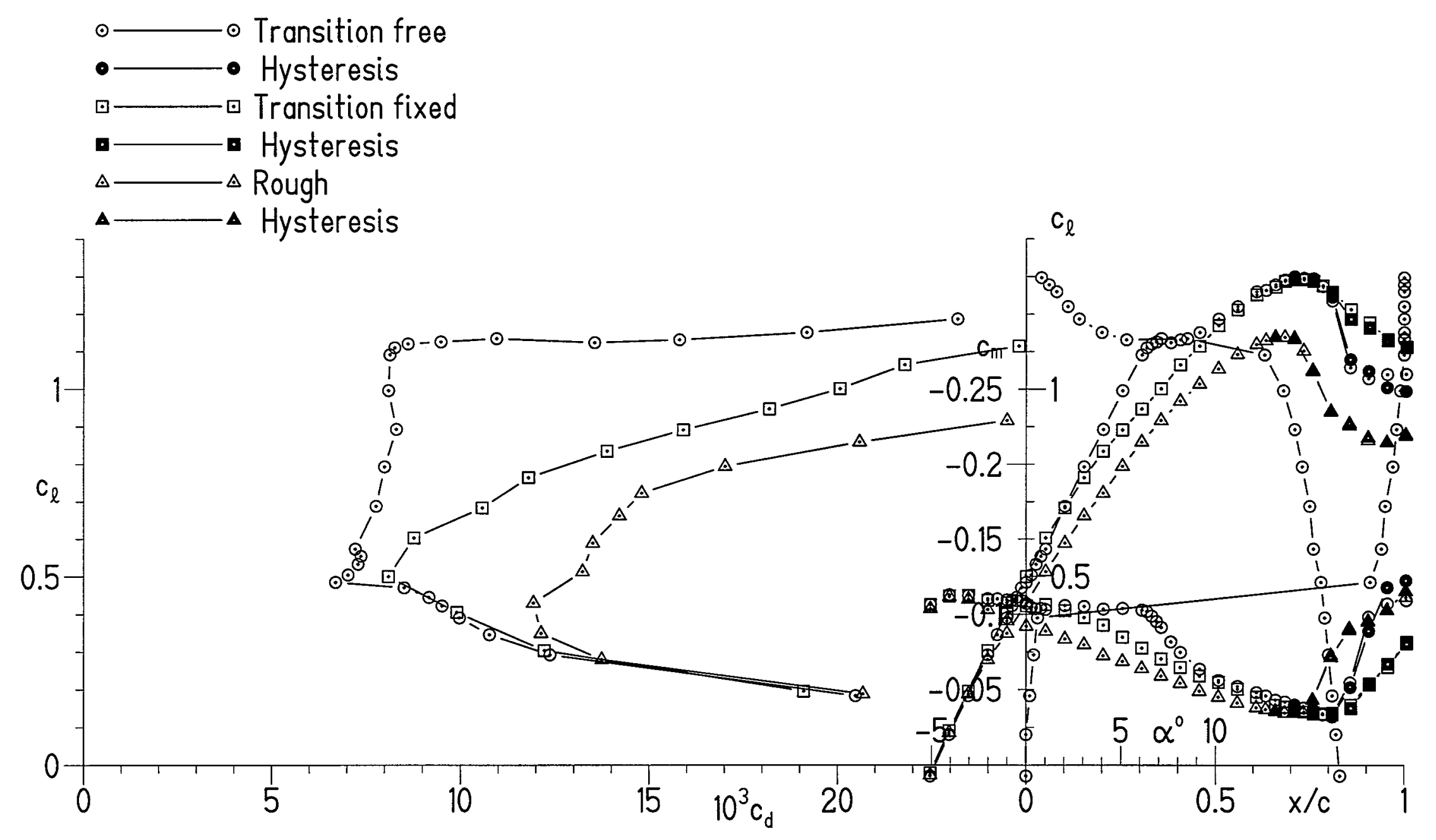

(a) $\mathrm{R}=0.7 \times 10^{6} ; \mathrm{M}=0.07$.

Figure 10.- Section characteristics of S902 airfoil with transition free, transition fixed, and rough. 


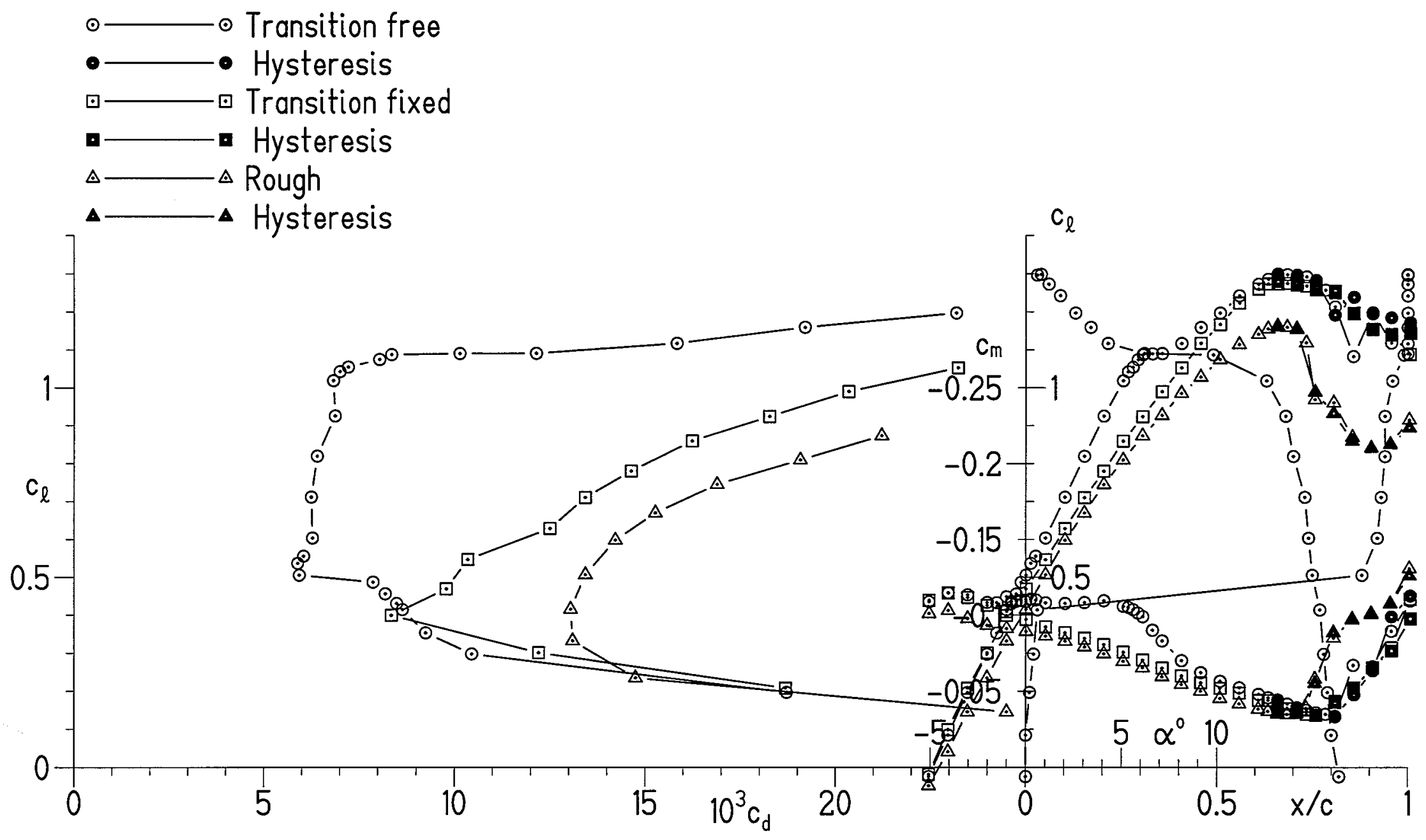

(b) $\mathrm{R}=1.0 \times 10^{6} ; \mathrm{M}=0.10$.

Figure 10.- Continued. 


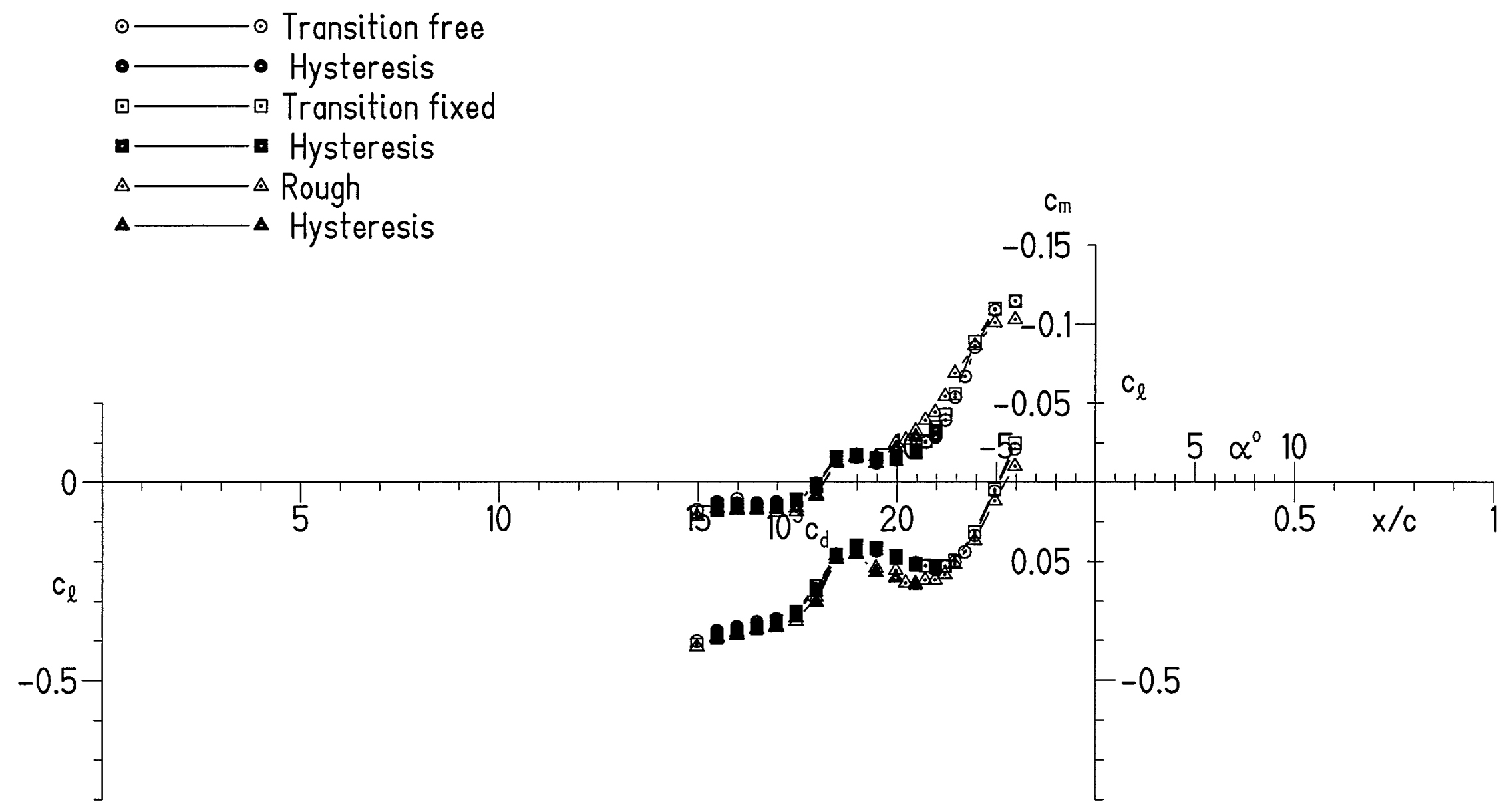

(b) Concluded. 


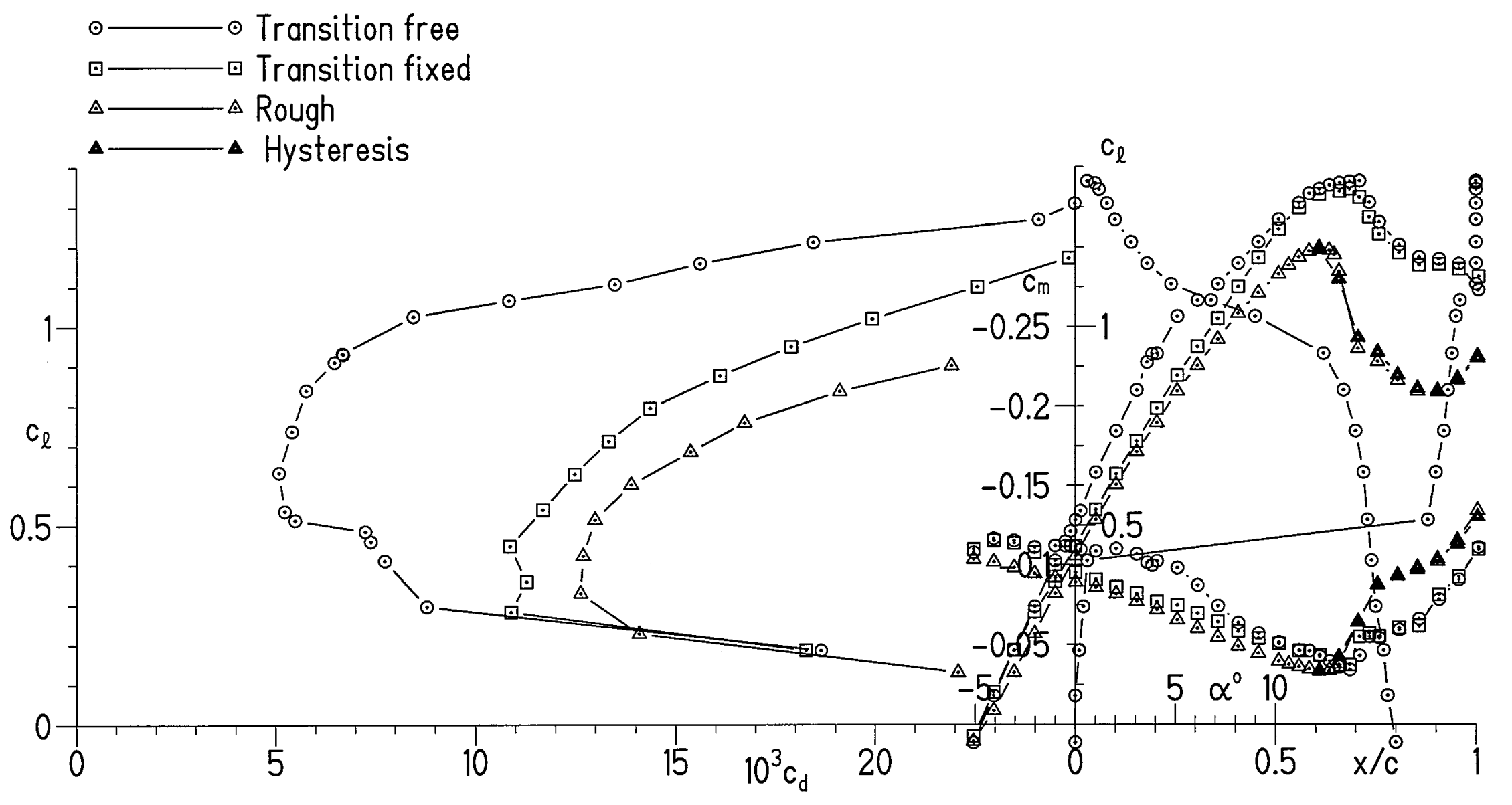

(c) $\mathrm{R}=1.5 \times 10^{6} ; \mathrm{M}=0.16$.

Figure 10.- Concluded. 


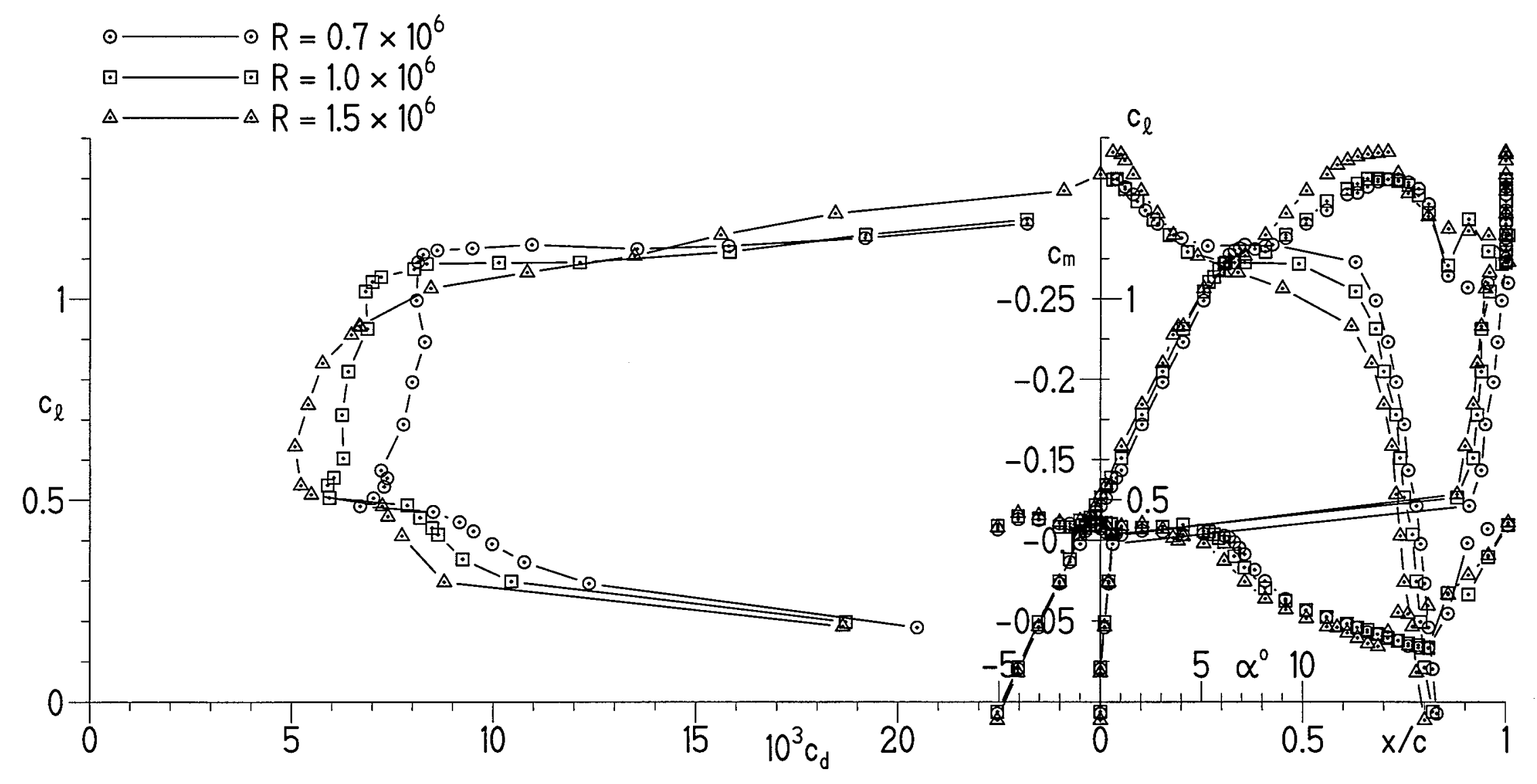

(a) Transition free.

Figure 11.- Effects of Reynolds number on section characteristics of S902 airfoil. 


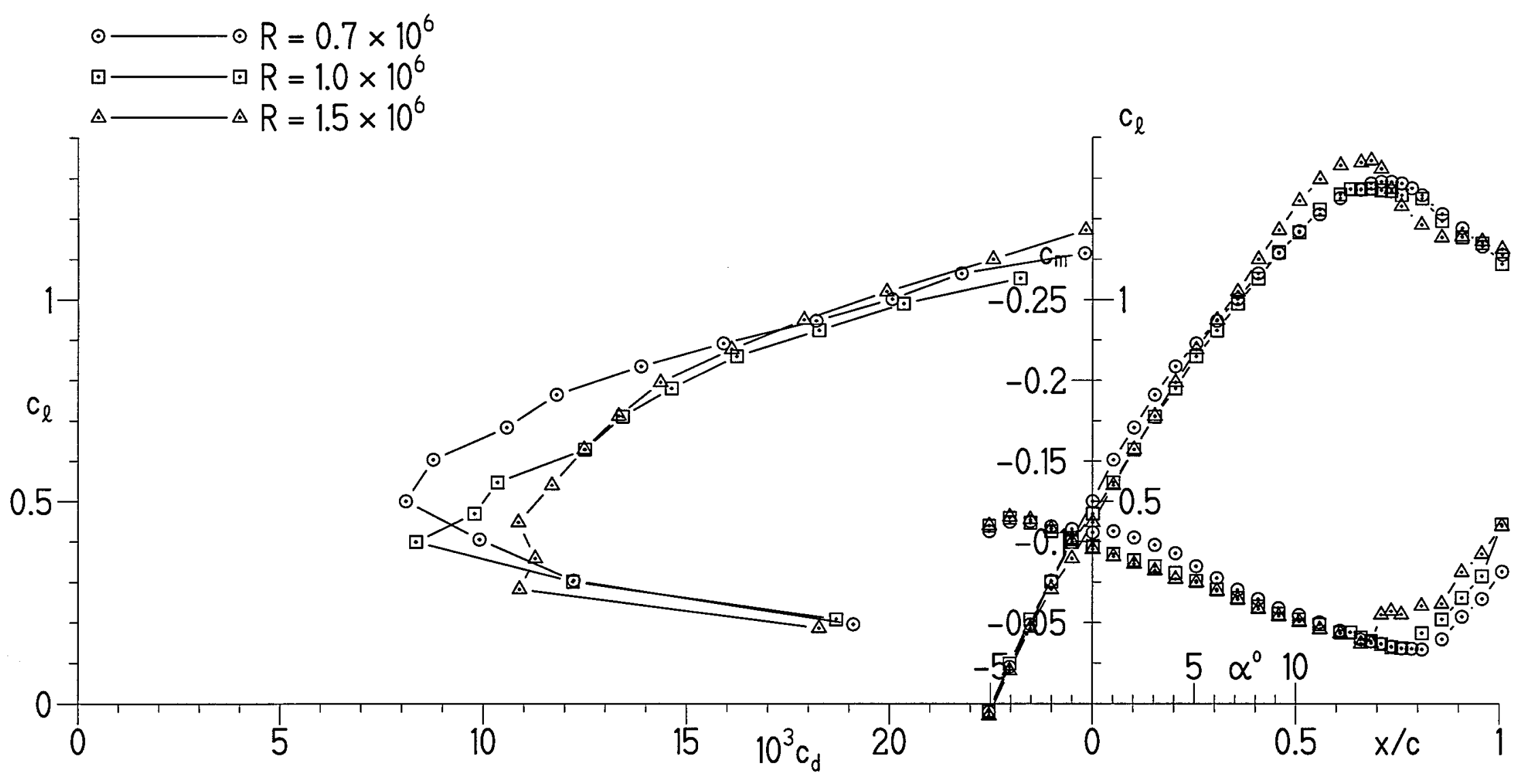

(b) Transition fixed.

Figure 11.- Continued. 


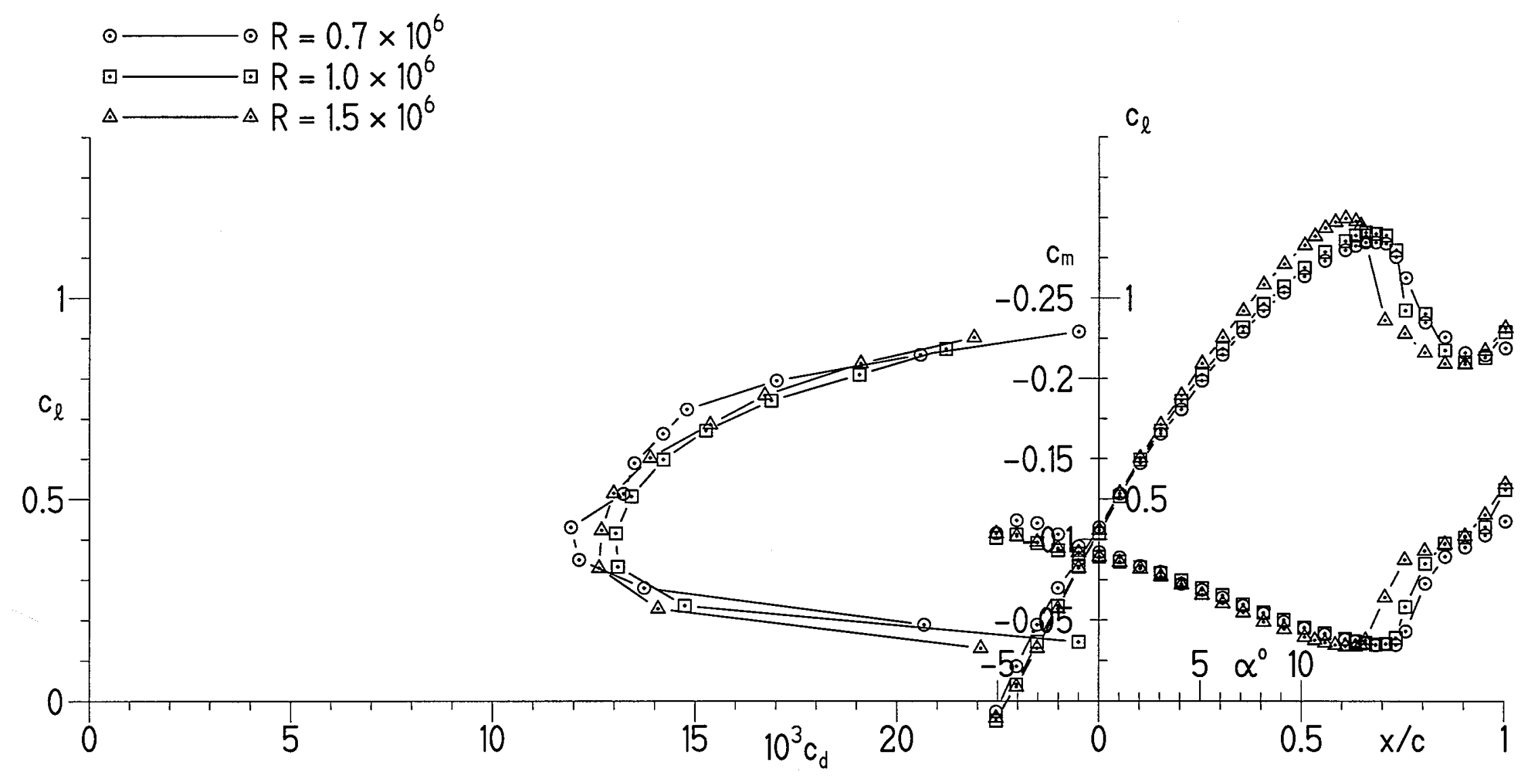

(c) Rough. 


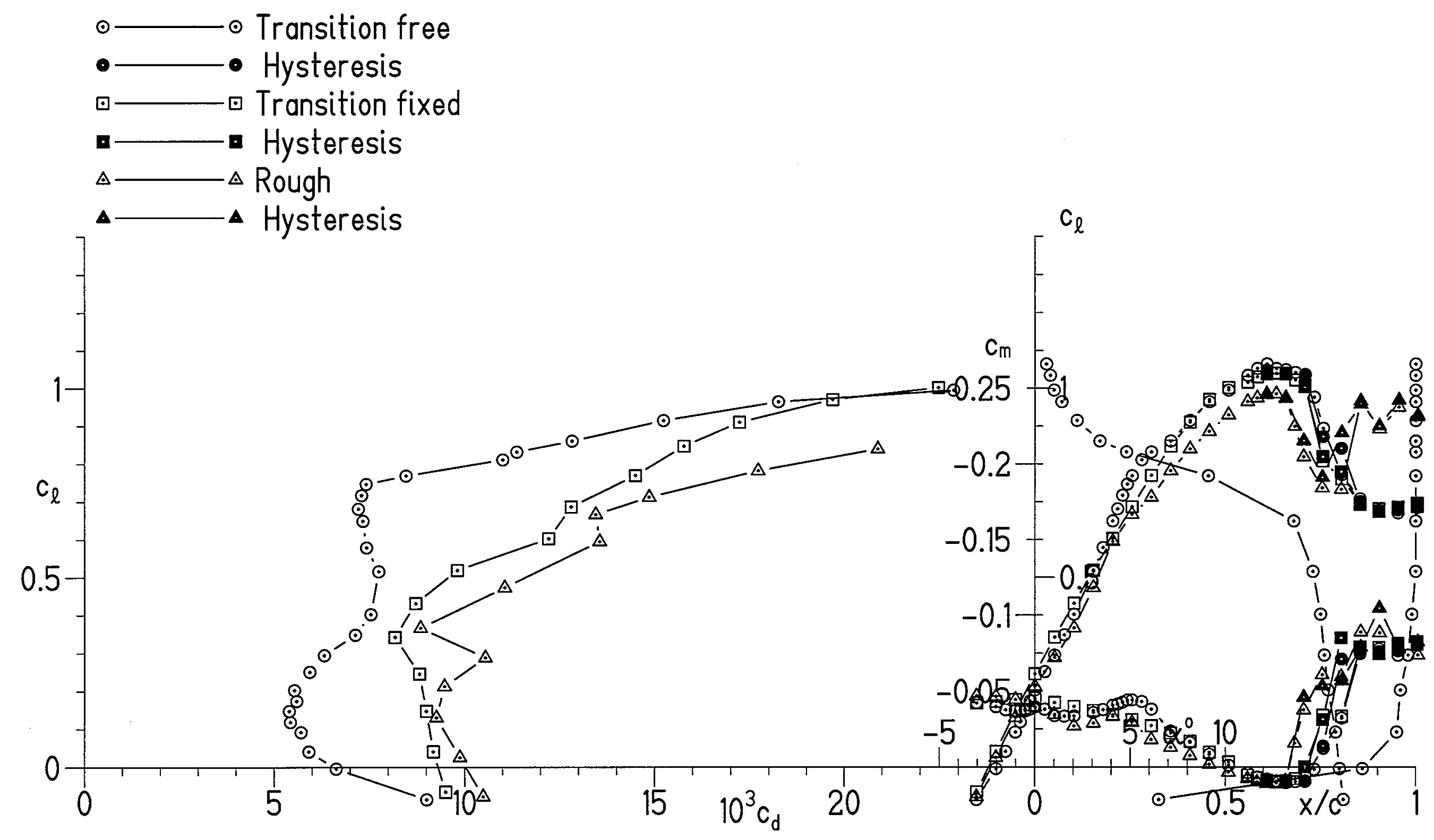

(a) $\mathrm{R}=0.7 \times 10^{6} ; \mathrm{M}=0.07$.

Figure 12.- Section characteristics of S903 airfoil with transition free, transition fixed, and rough. 


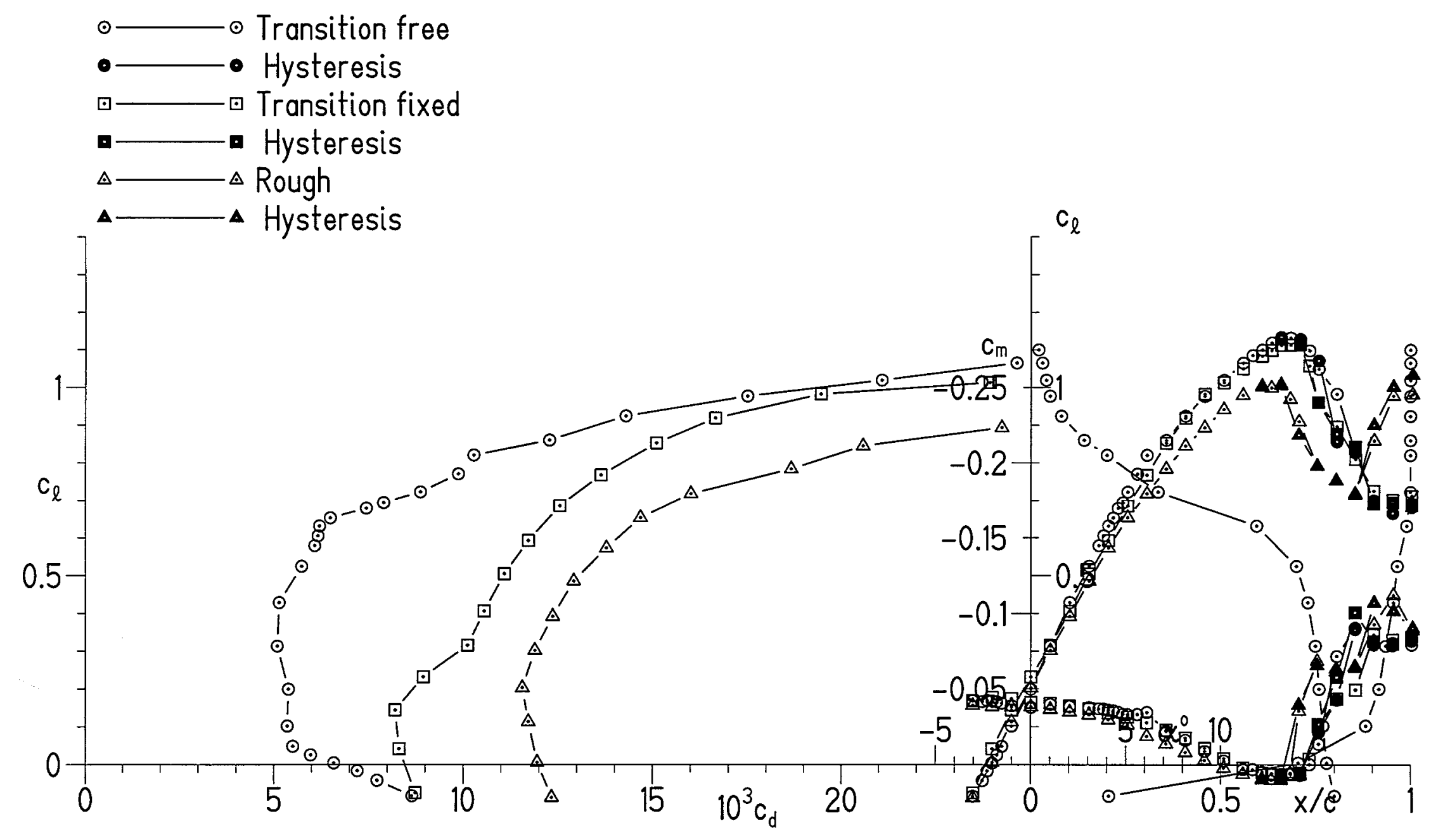

(b) $\mathrm{R}=1.0 \times 10^{6} ; \mathrm{M}=0.10$. 


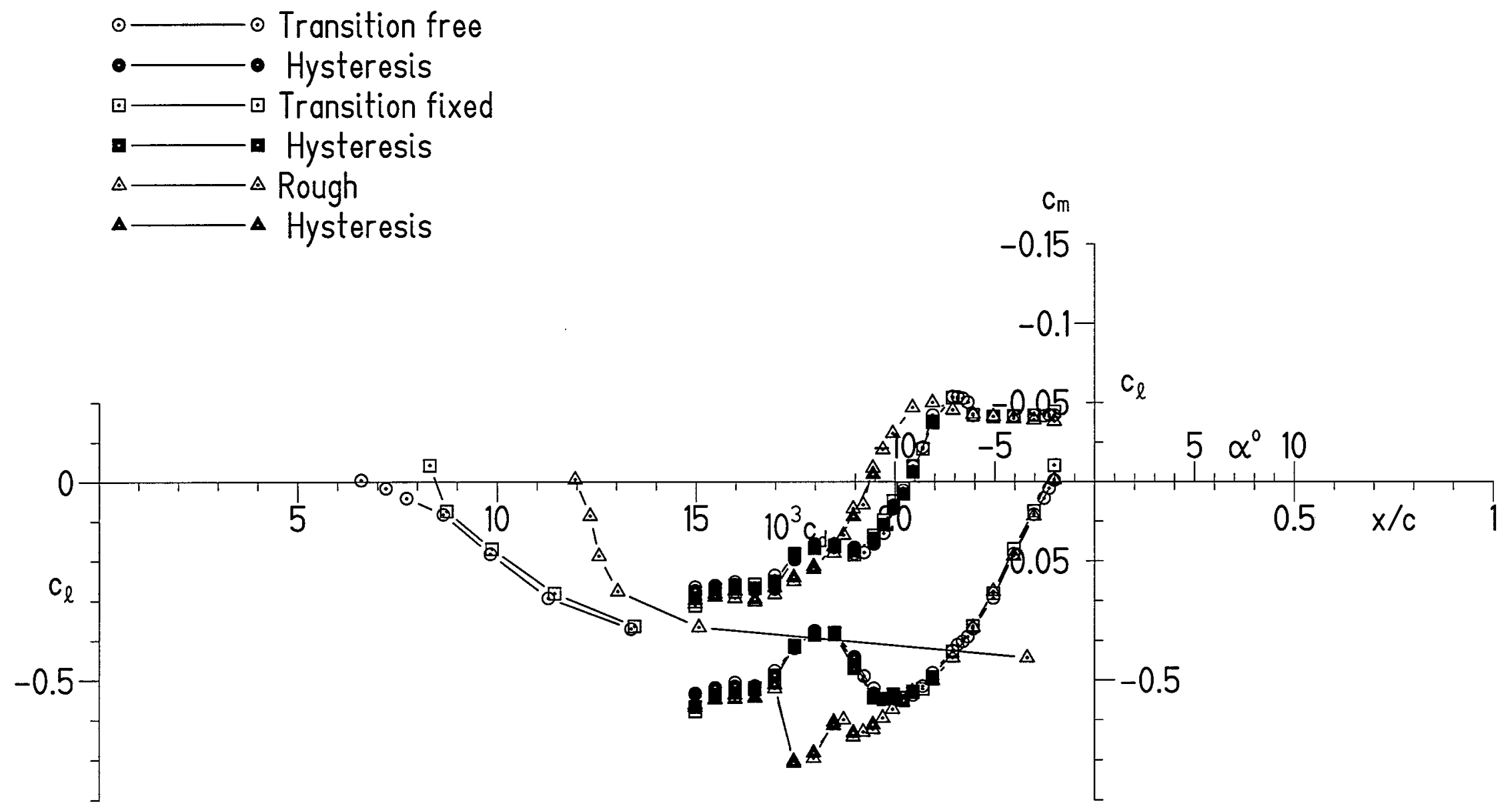

(b) Concluded.

Figure 12.- Continued. 


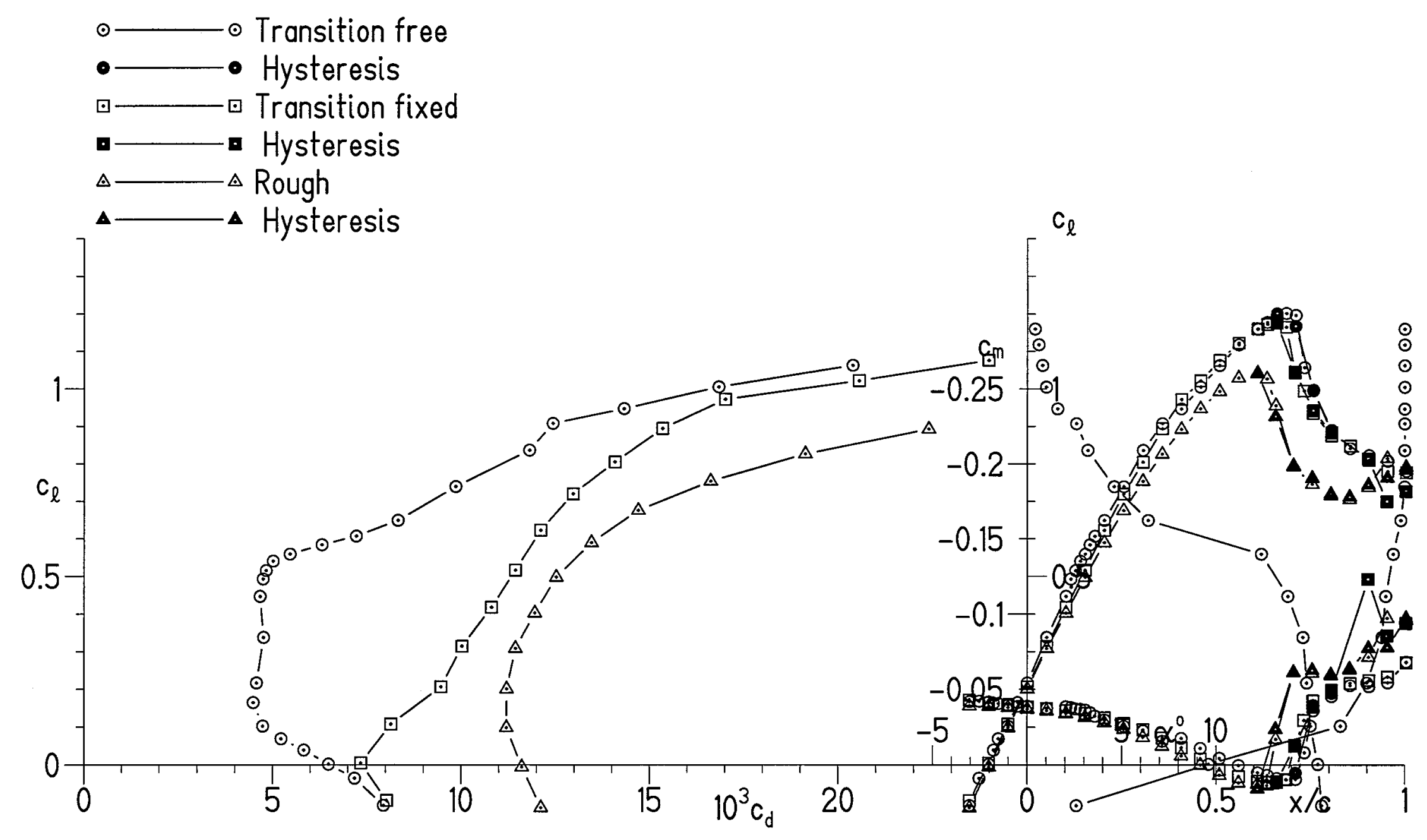

(c) $\mathrm{R}=1.5 \times 10^{6} ; \mathrm{M}=0.16$.

Figure 12.- Concluded. 


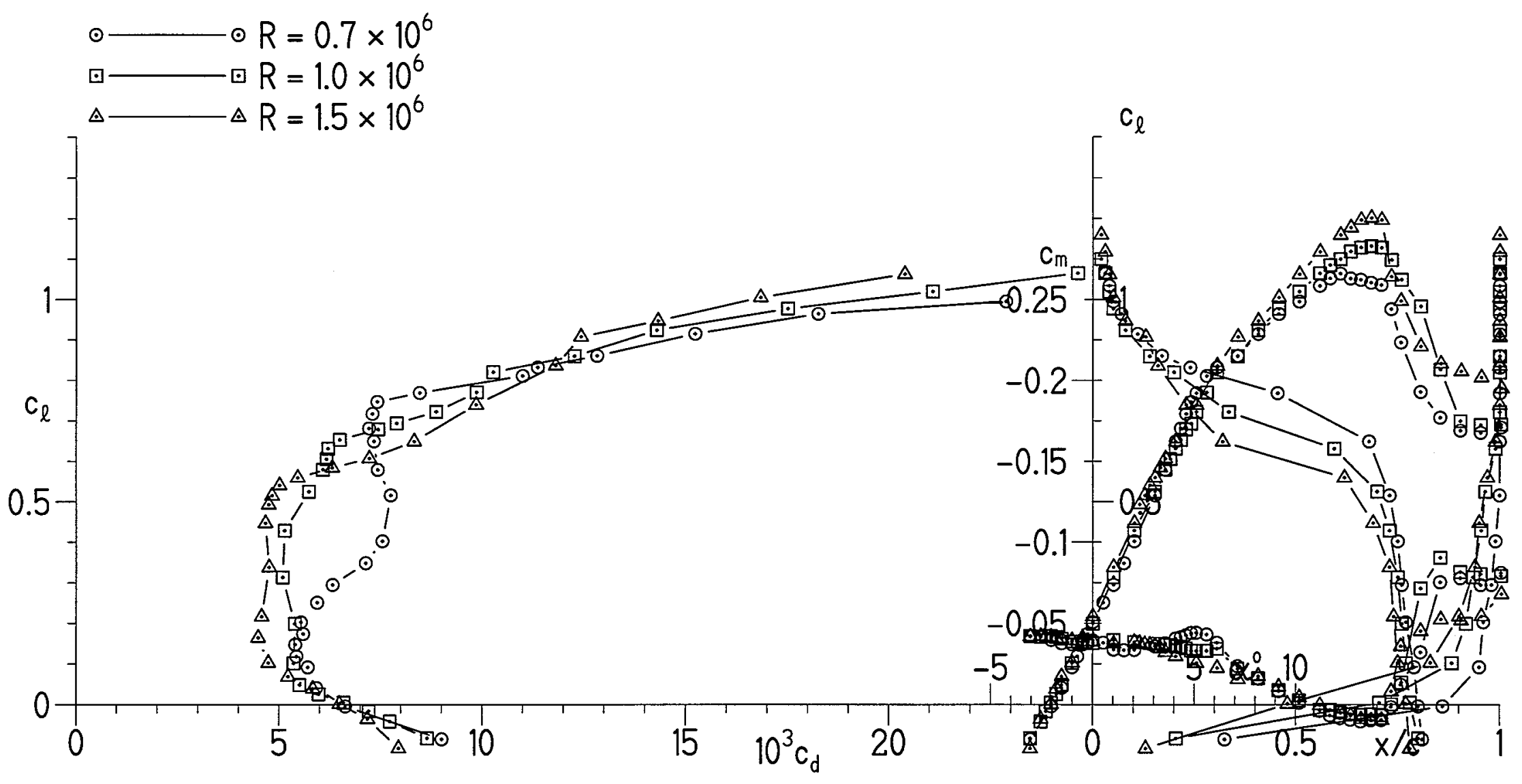

(a) Transition free.

Figure 13.- Effects of Reynolds number on section characteristics of S903 airfoil. 


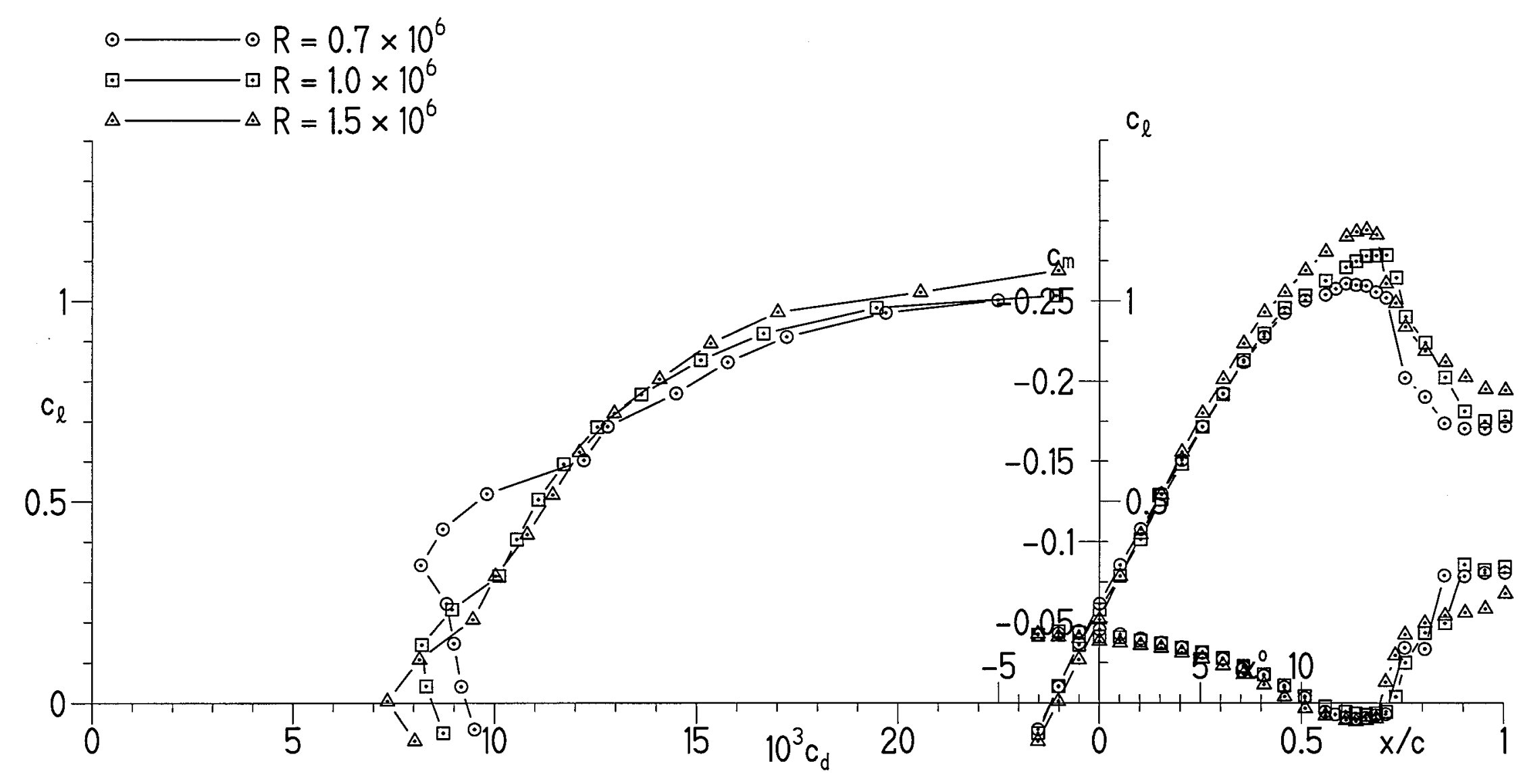

(b) Transition fixed.

Figure 13.- Continued. 


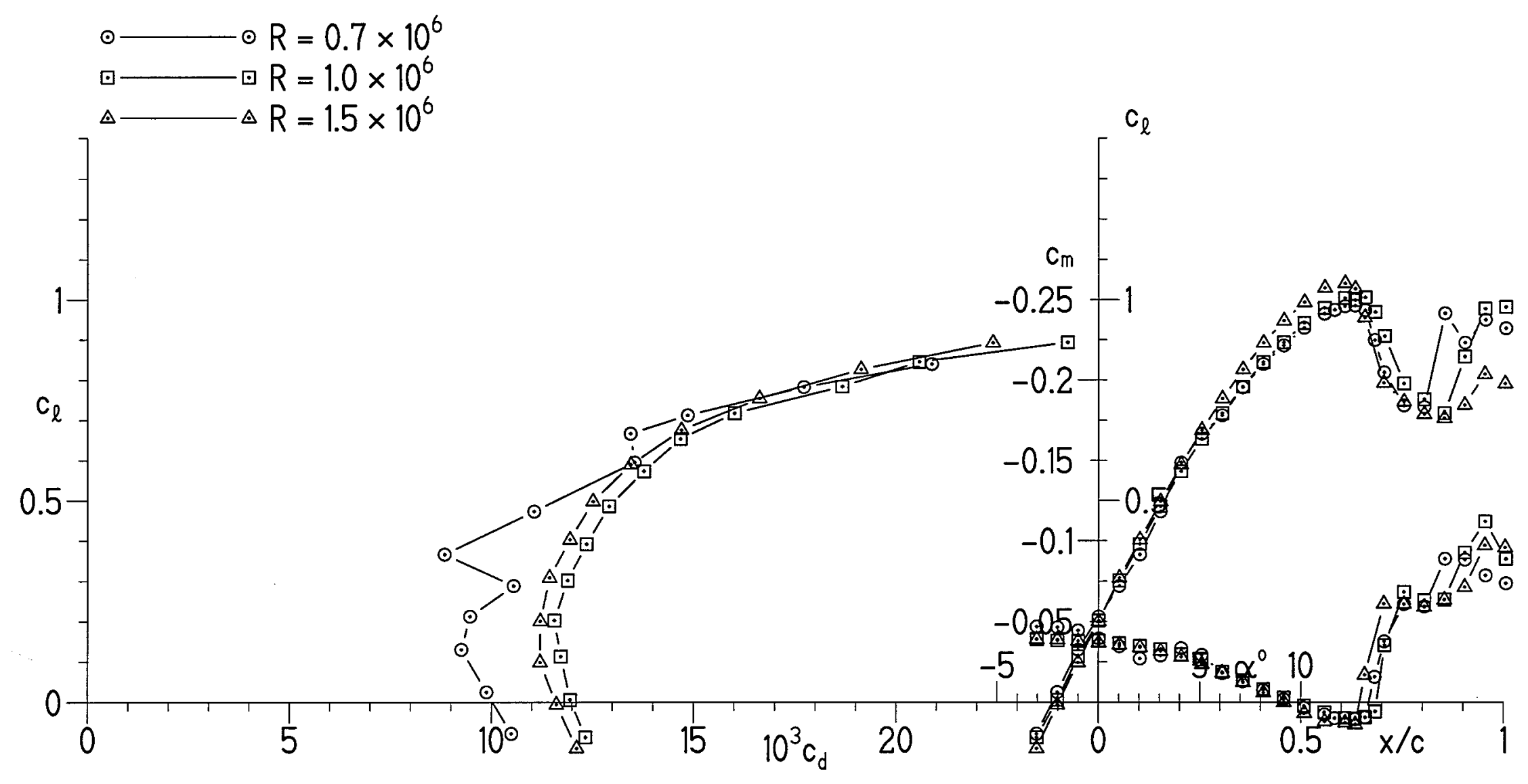

(c) Rough.

Figure 13.- Concluded. 


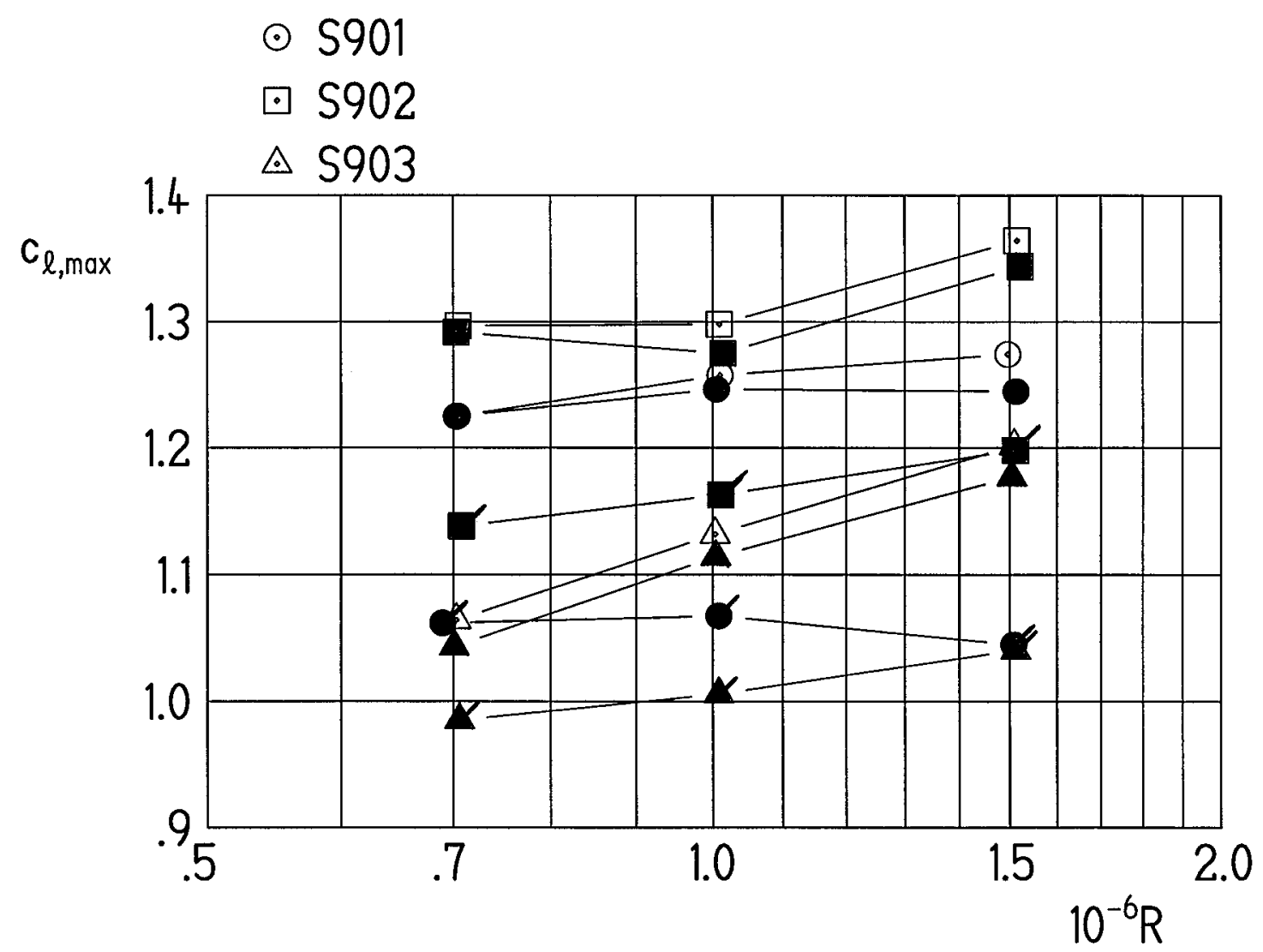

Figure 14.- Variation of maximum lift coefficient of S901, S902, and S903 airfoils with Reynolds number. Open symbols represent data with transition free; solid symbols, data with transition fixed; and flagged, solid symbols, data with scaled, NACA standard roughness. 


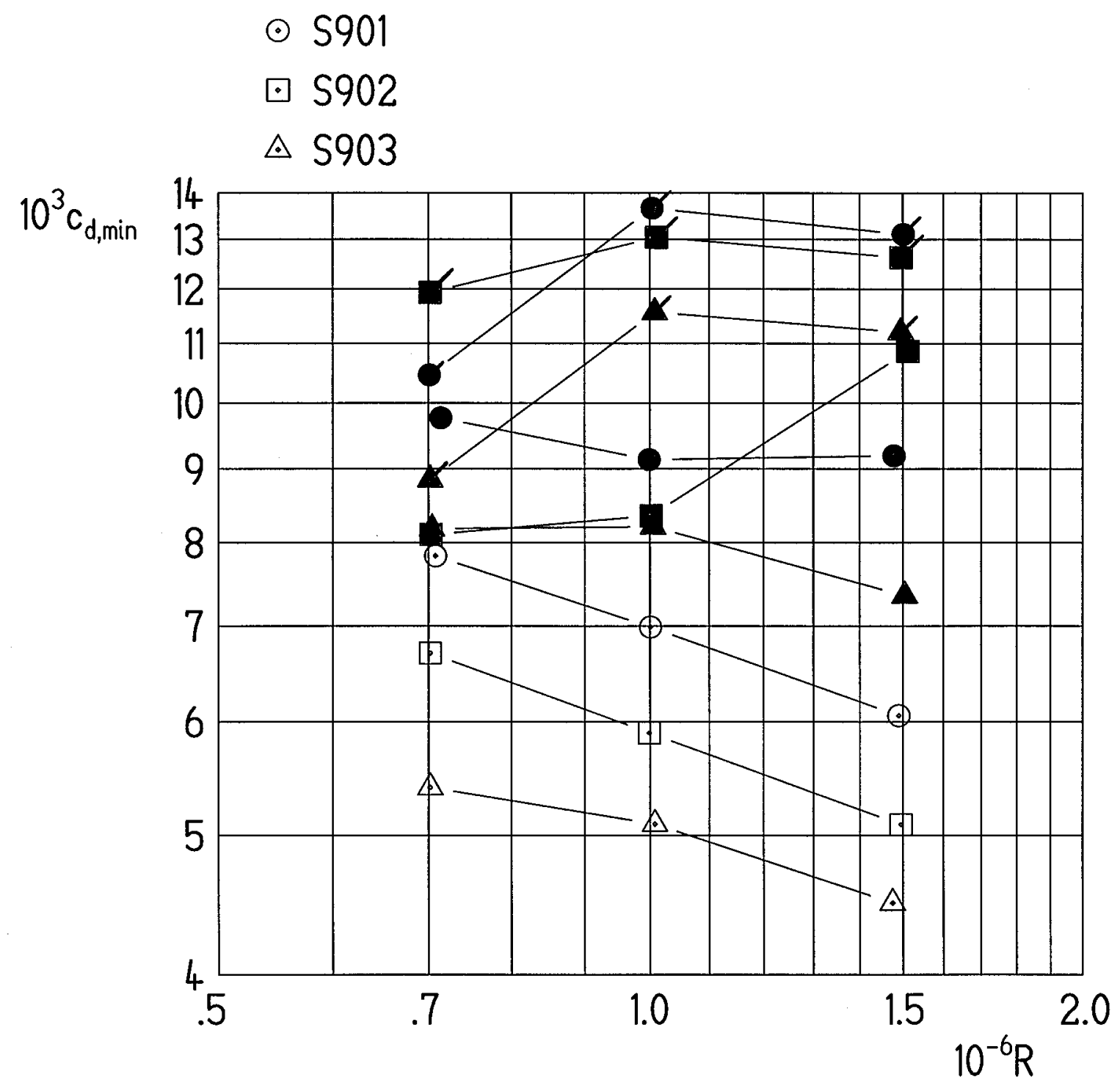

Figure 15.- Variation of minimum profile-drag coefficient of S901, S902, and S903 airfoils with Reynolds number. Open symbols represent data with transition free; solid symbols, data with transition fixed; and flagged, solid symbols, data with scaled, NACA standard roughness. 


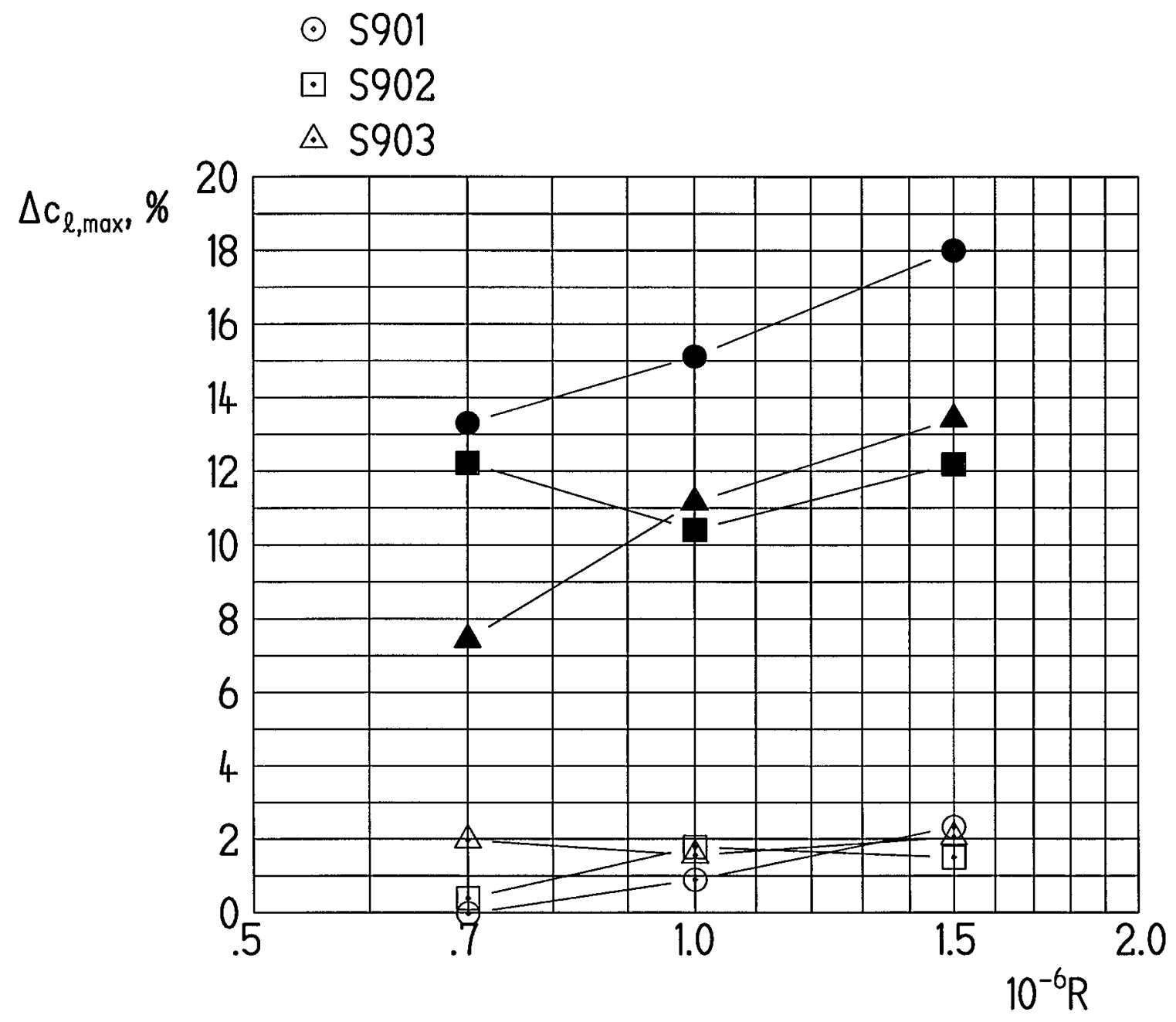

Figure 16.- Variation of change in maximum lift coefficient due to roughness with Reynolds number for S901, S902, and S903 airfoils. Open symbols represent data with transition fixed; solid symbols, data with scaled, NACA standard roughness. 


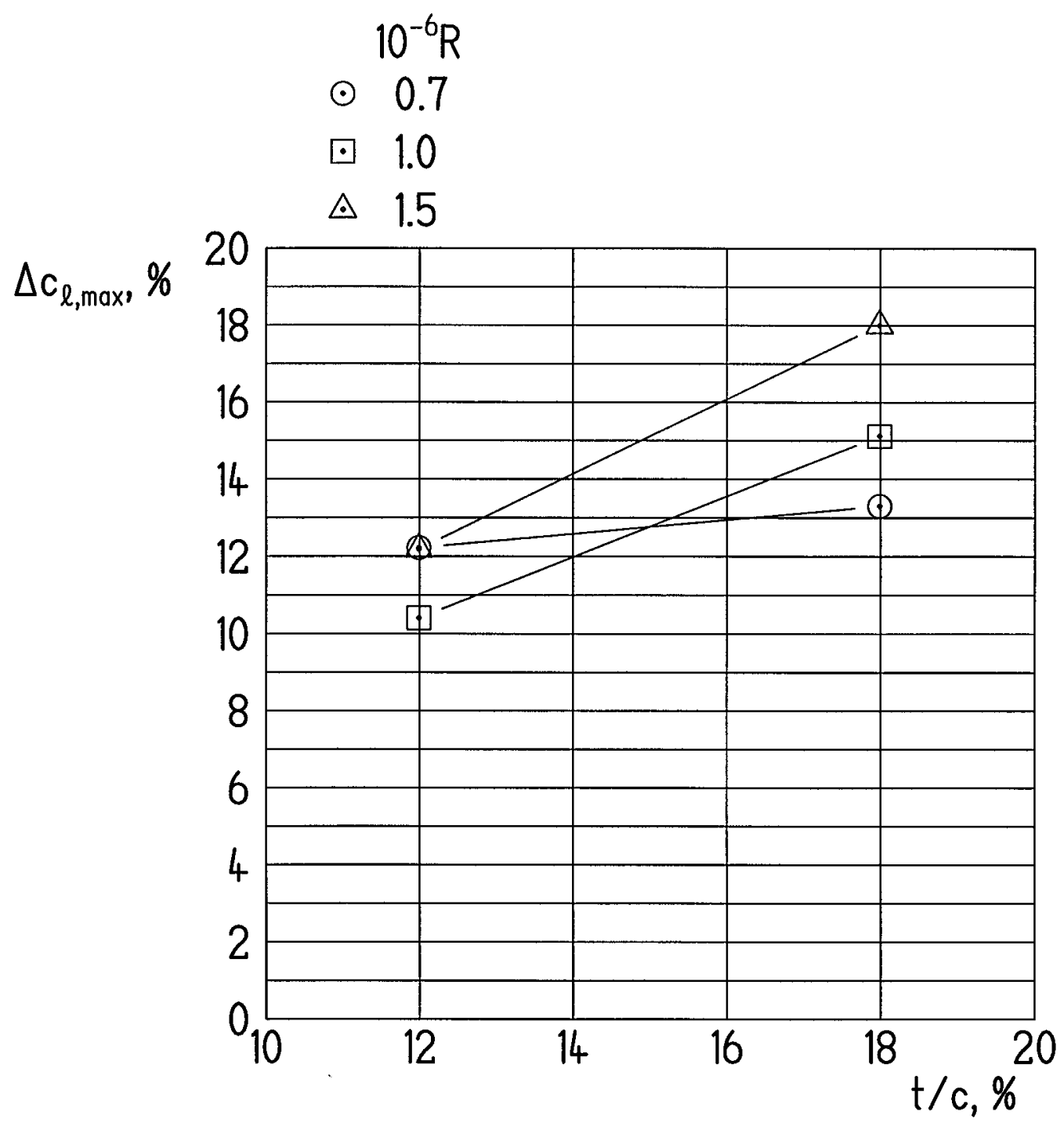

Figure 17.- Effect of airfoil thickness on change in maximum lift coefficient due to scaled, NACA standard roughness. 


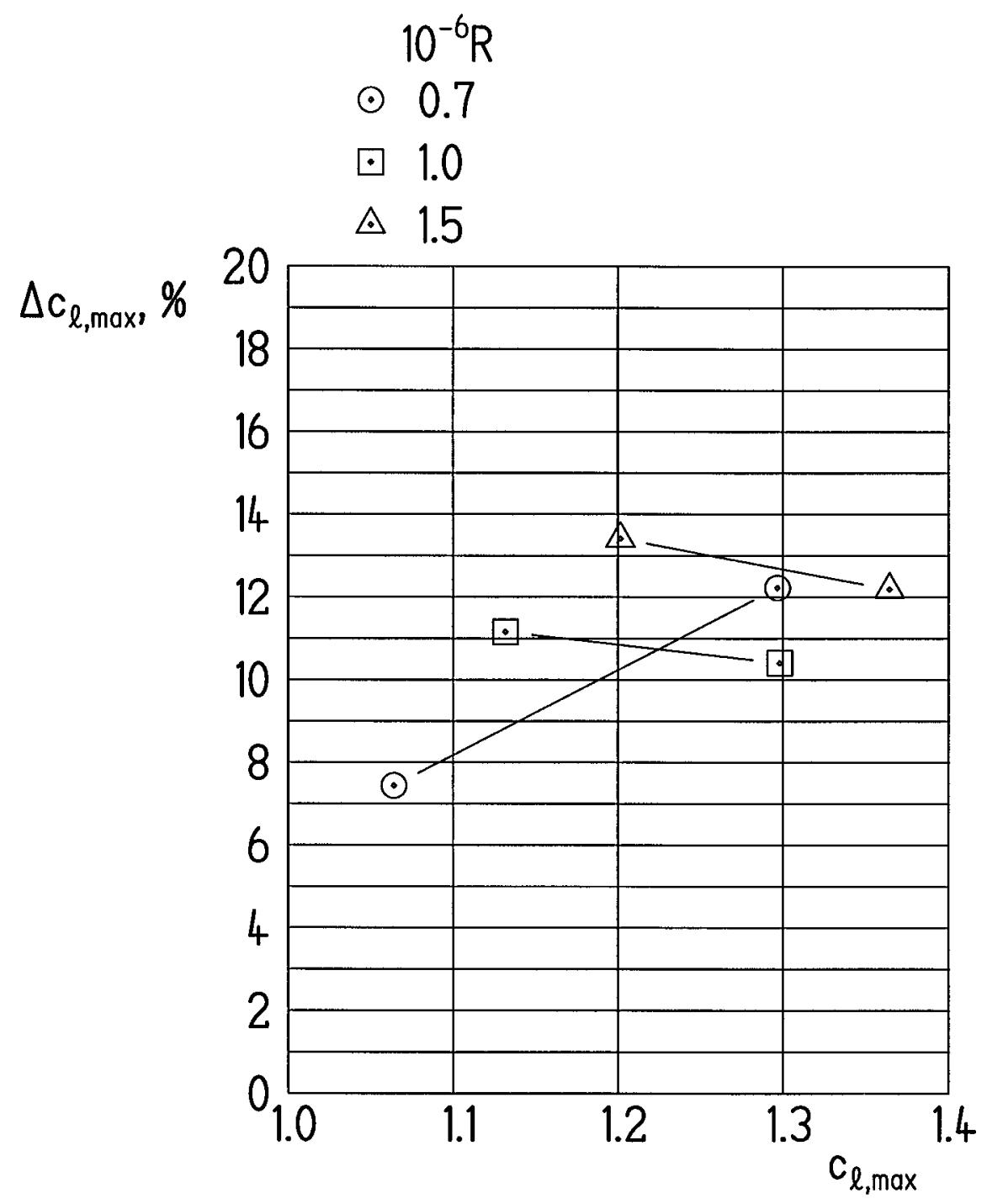

Figure 18.- Effect of maximum lift coefficient on change in maximum lift coefficient due to scaled, NACA standard roughness. 


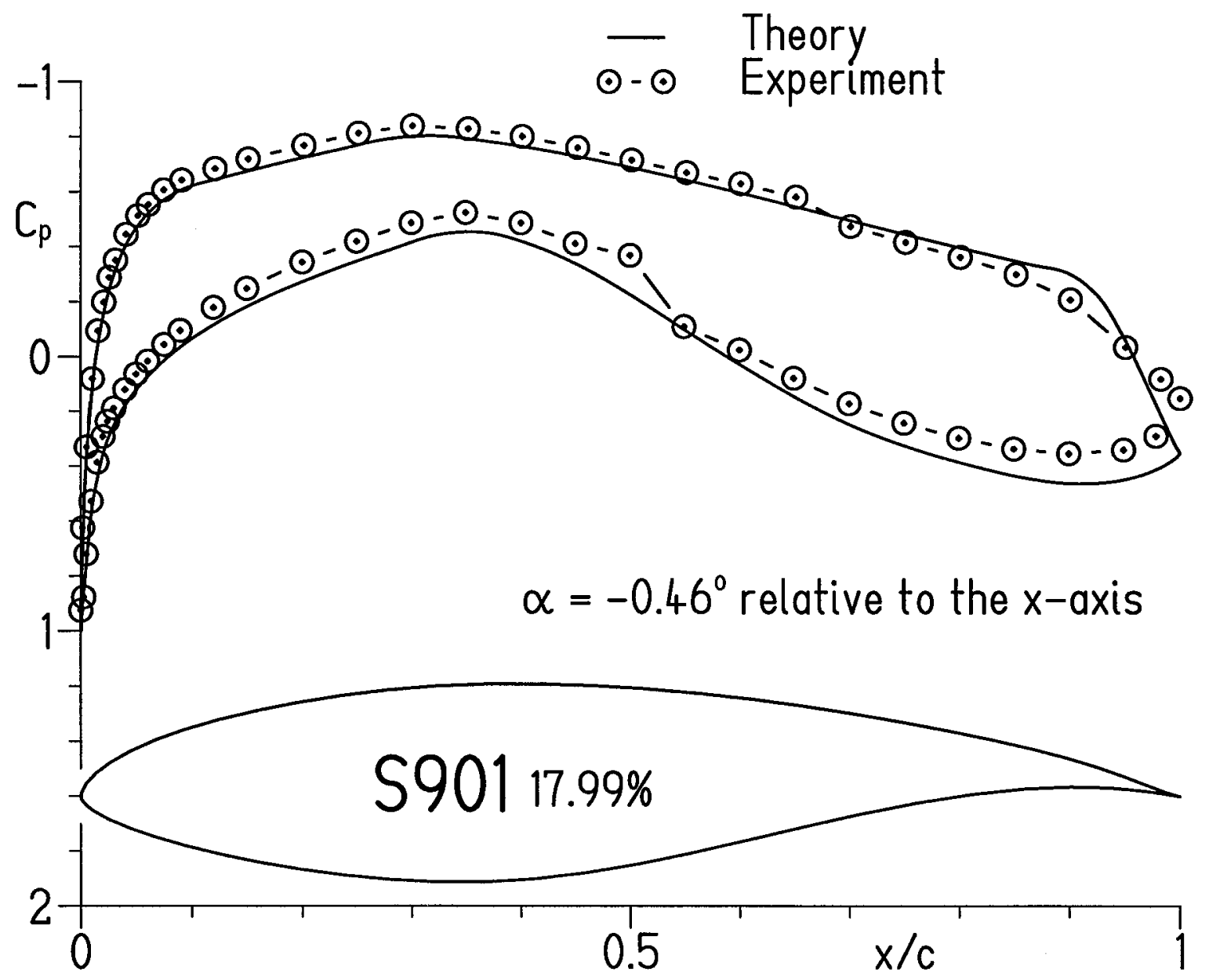

(a) $\mathrm{c}_{l}=0.47$

Figure 19.- Comparison of theoretical and experimental pressure distributions for S901 airfoil. 


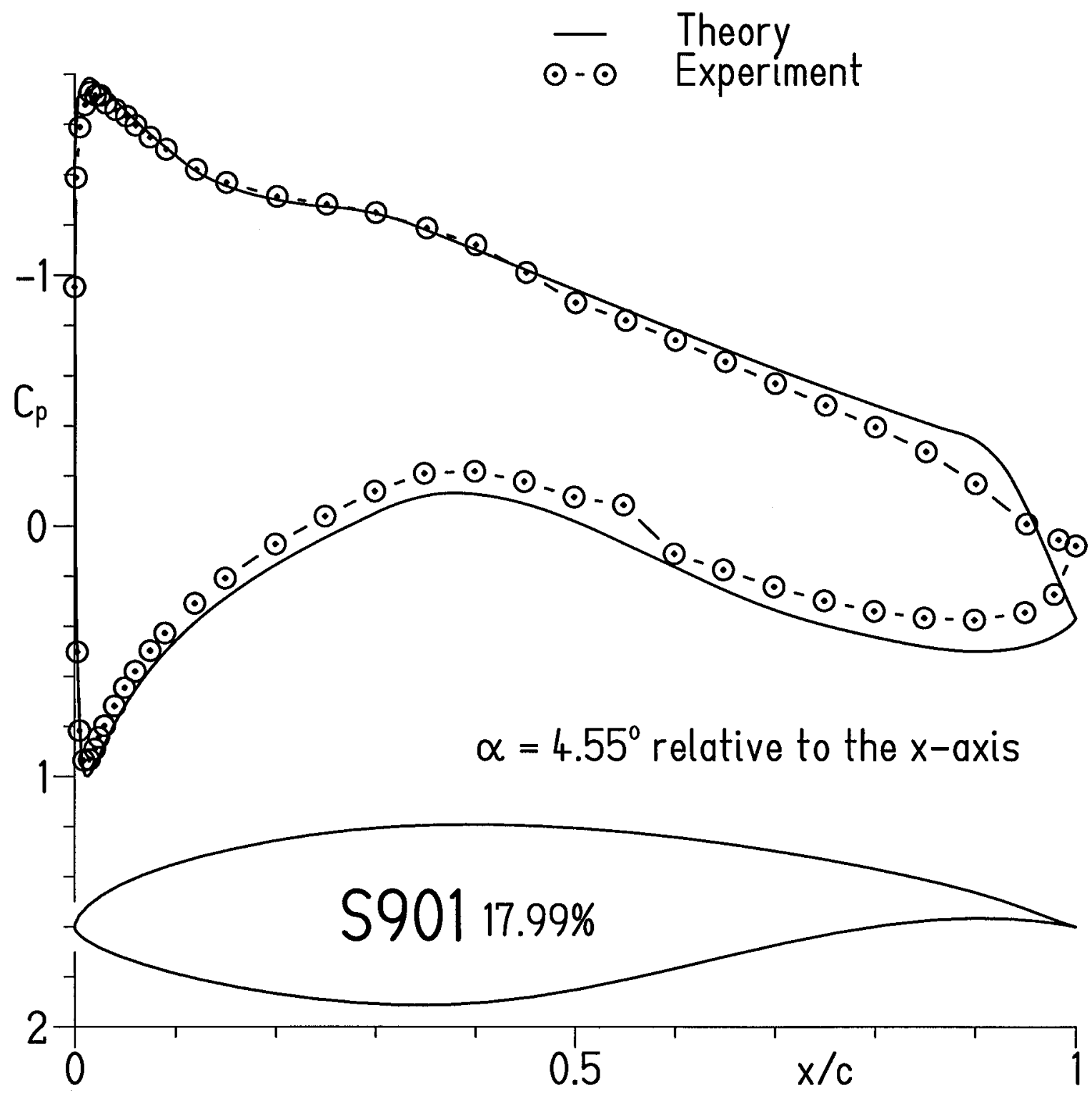

(b) $\mathrm{c}_{l}=1.00$.

Figure 19.- Continued. 


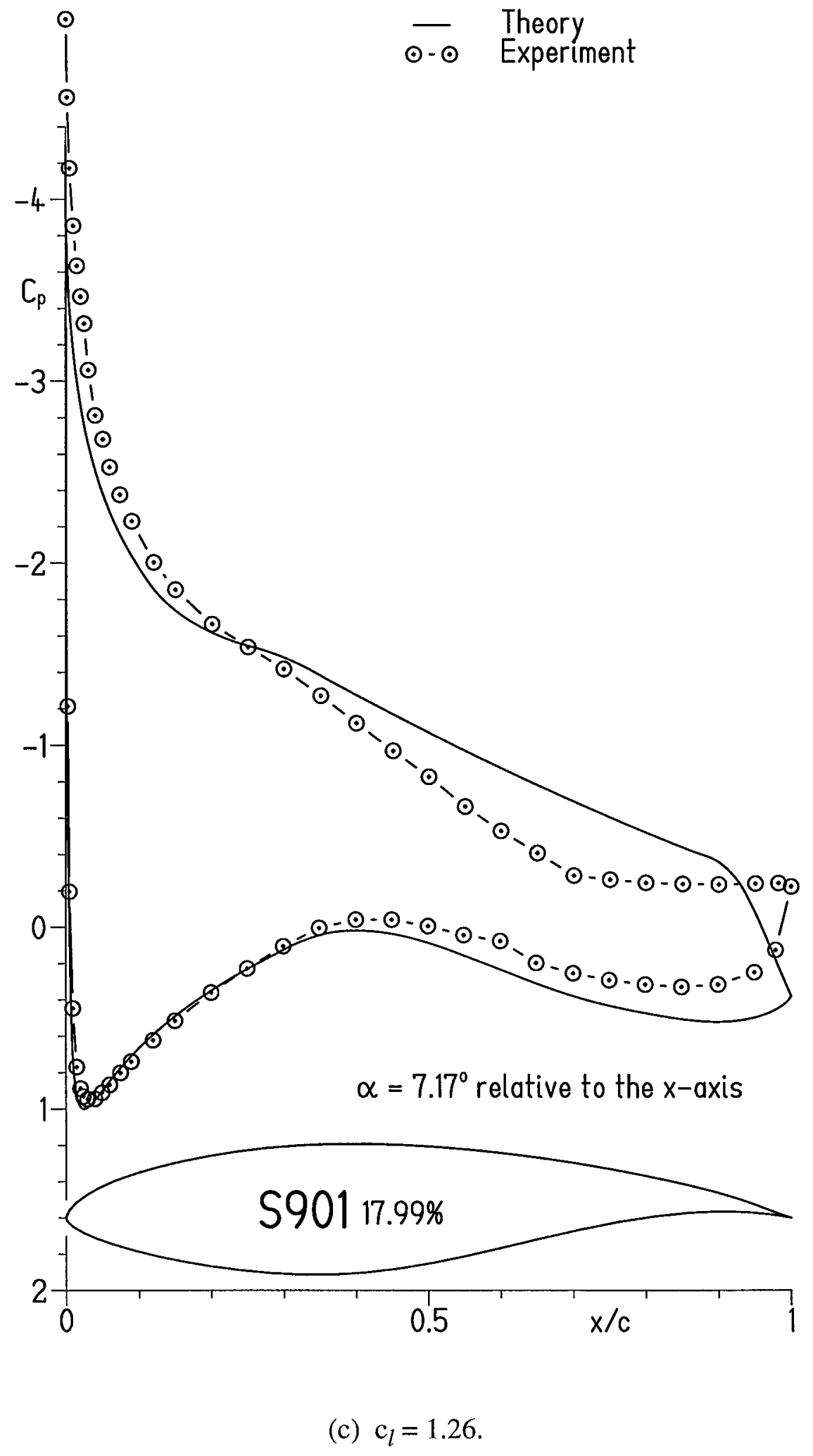

Figure 19.- Concluded. 


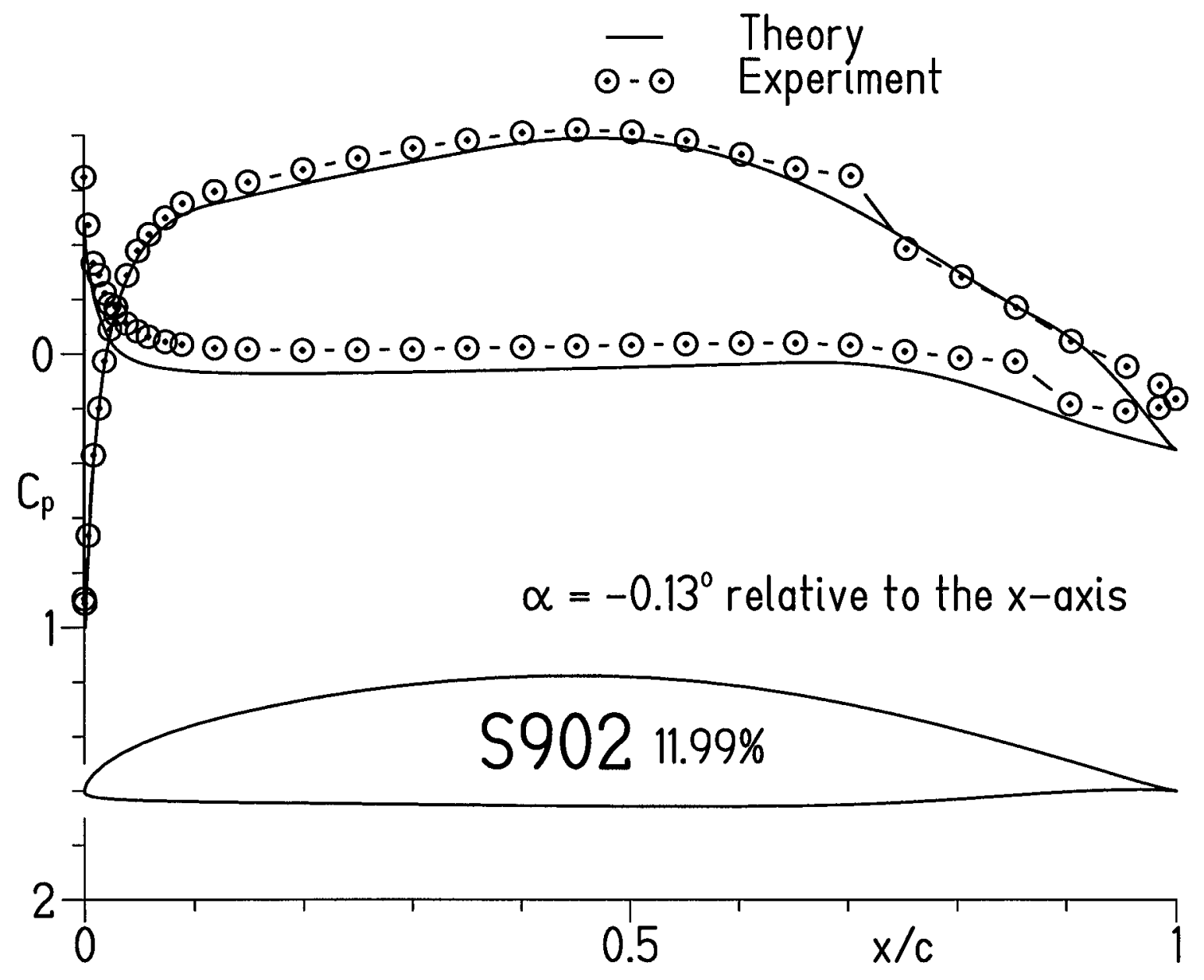

(a) $\mathrm{c}_{l}=0.51$.

Figure 20.- Comparison of theoretical and experimental pressure distributions for S902 airfoil. 


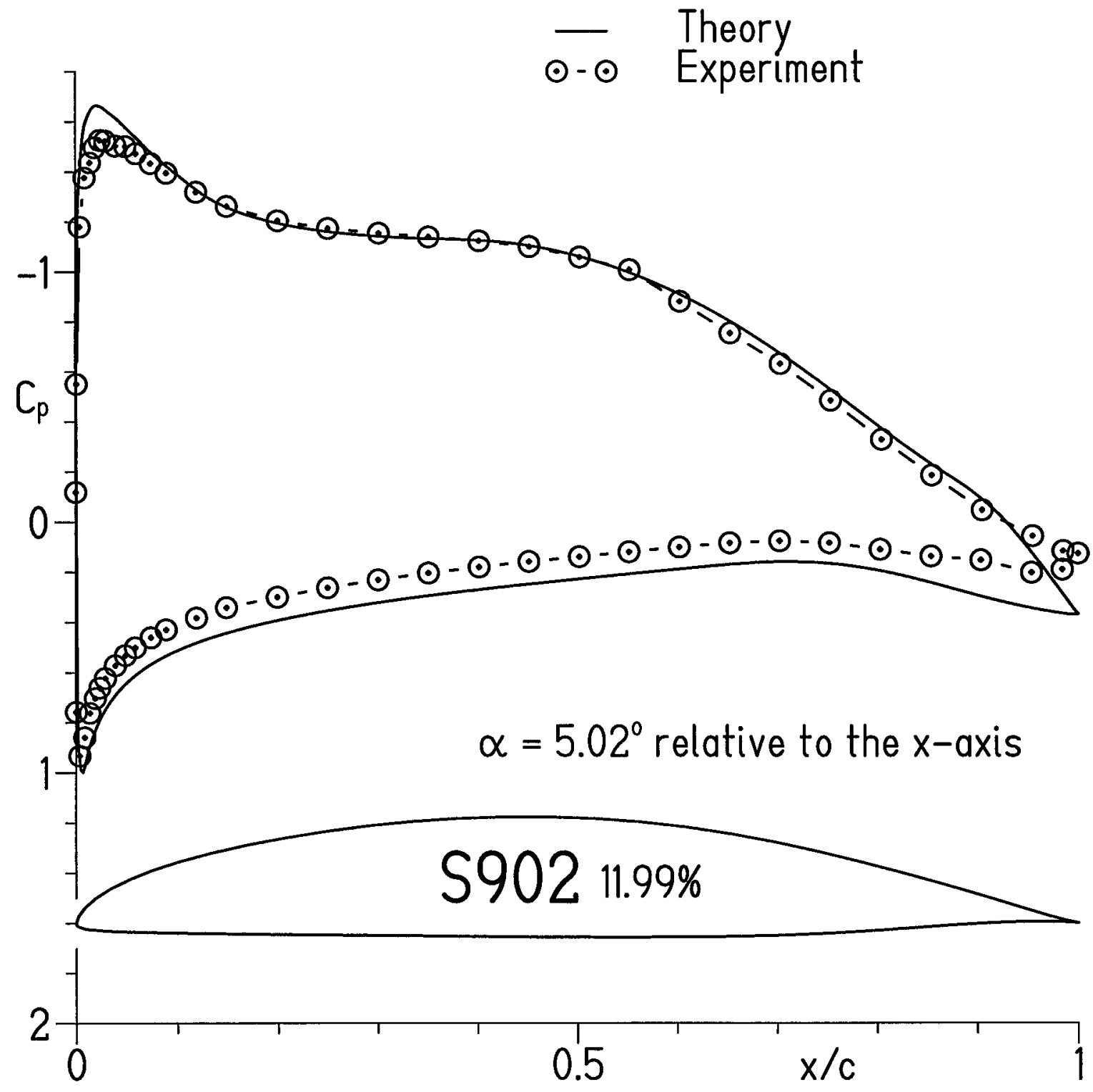

(b) $\mathrm{c}_{l}=1.04$.

Figure 20.- Continued. 


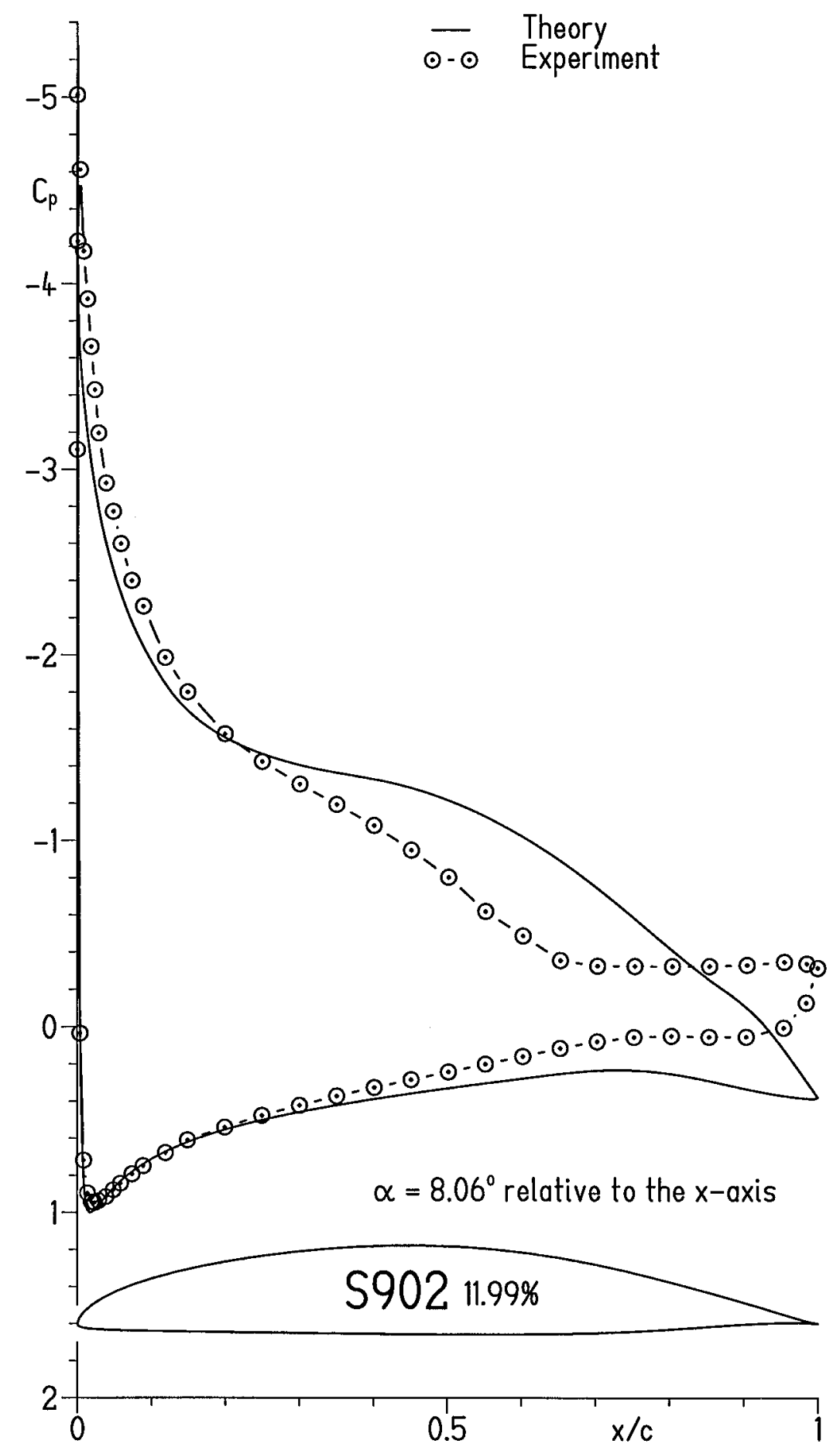

(c) $\mathrm{c}_{l}=1.30$.

Figure 20.- Concluded. 


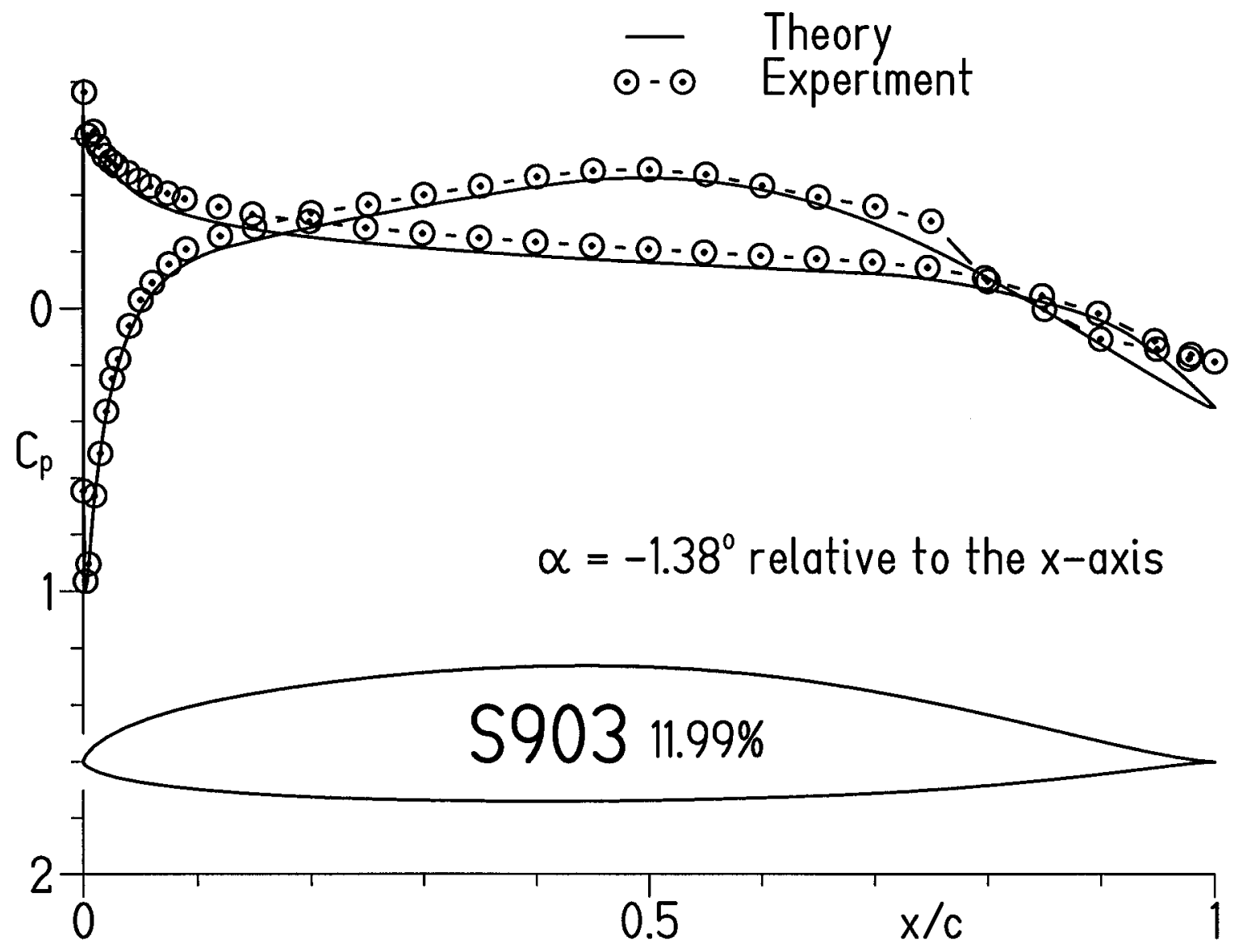

(a) $\mathrm{c}_{l}=0.05$.

Figure 21.- Comparison of theoretical and experimental pressure distributions for S903 airfoil. 


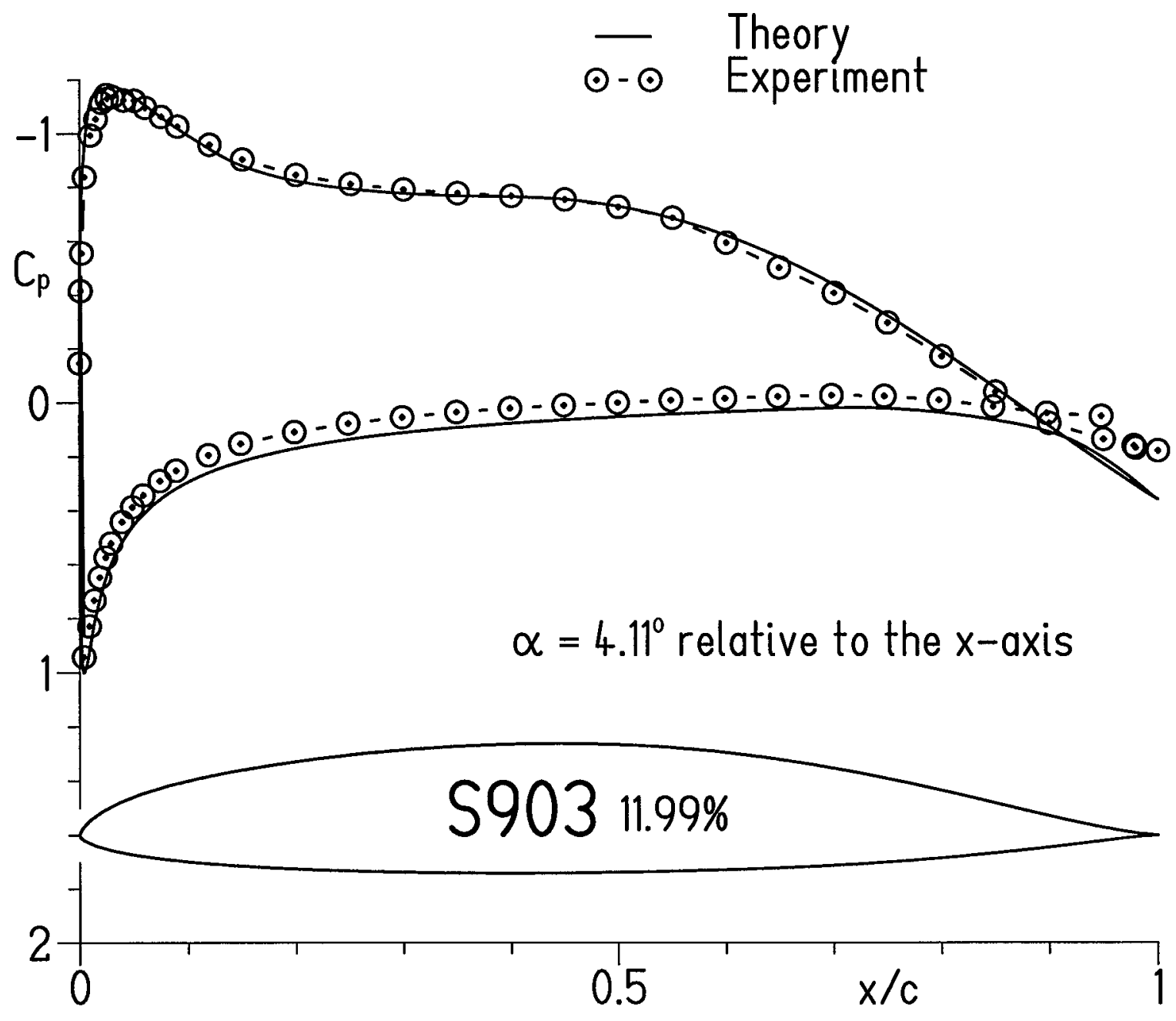

(b) $\mathrm{c}_{l}=0.63$.

Figure 21.- Continued. 


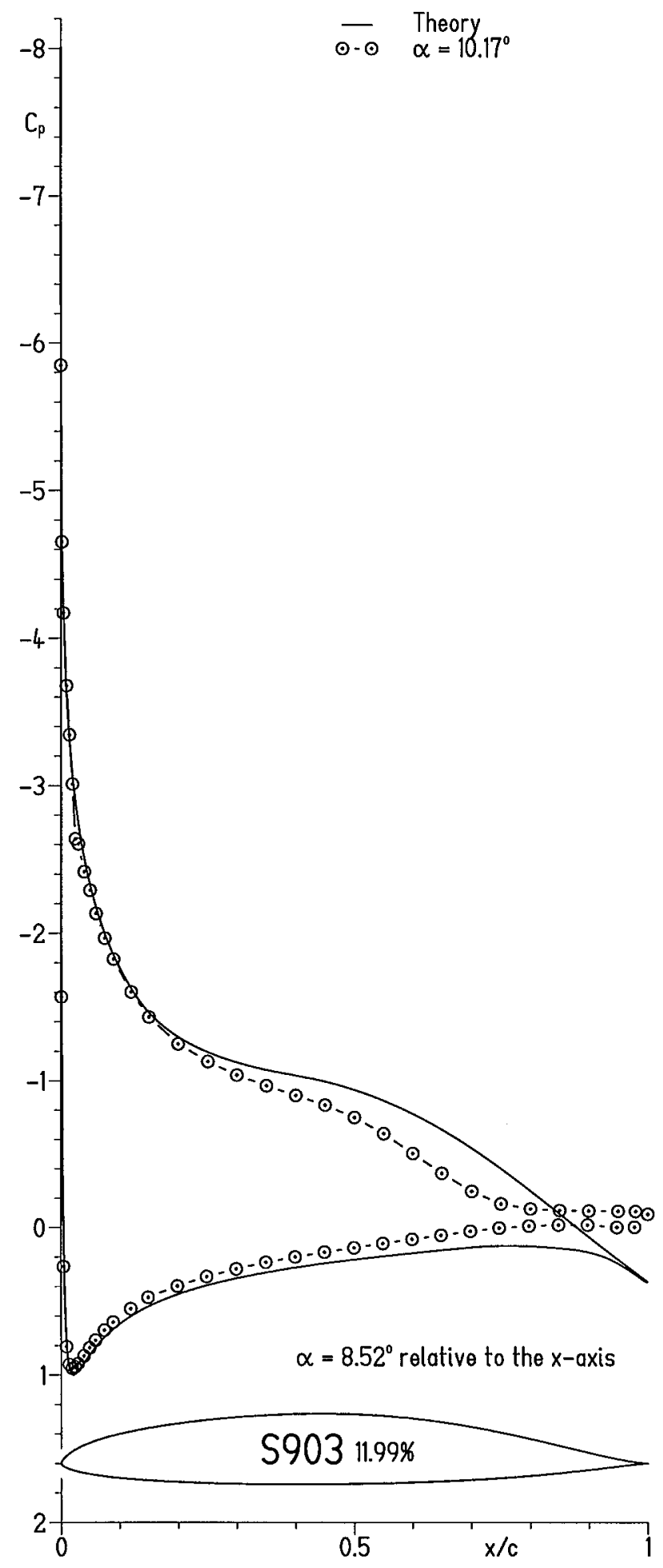

(c) $\mathrm{c}_{l}=1.02$.

Figure 21.- Concluded. 


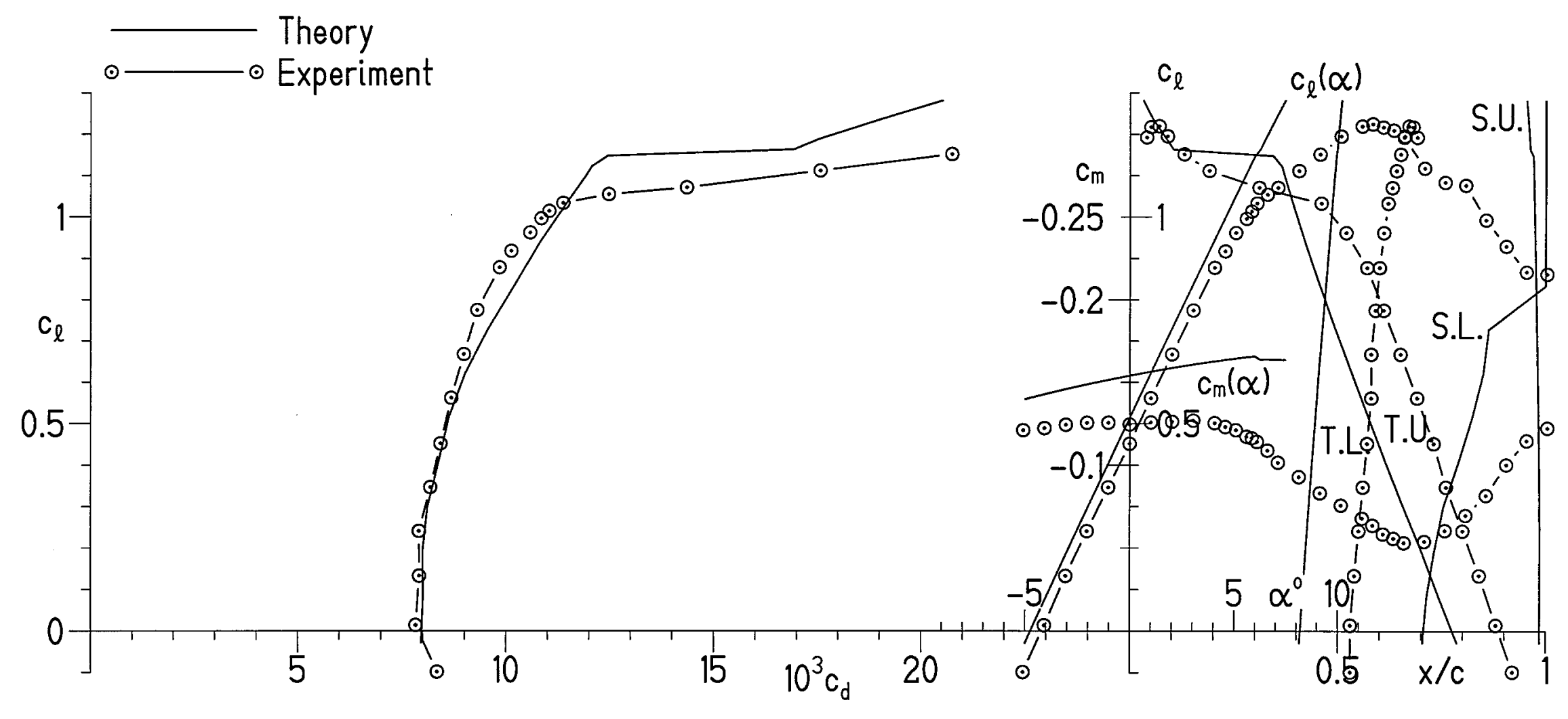

(a) $\mathrm{R}=0.7 \times 10^{6}$.

Figure 22.- Comparison of theoretical and experimental section characteristics of S901 airfoil with transition free. 


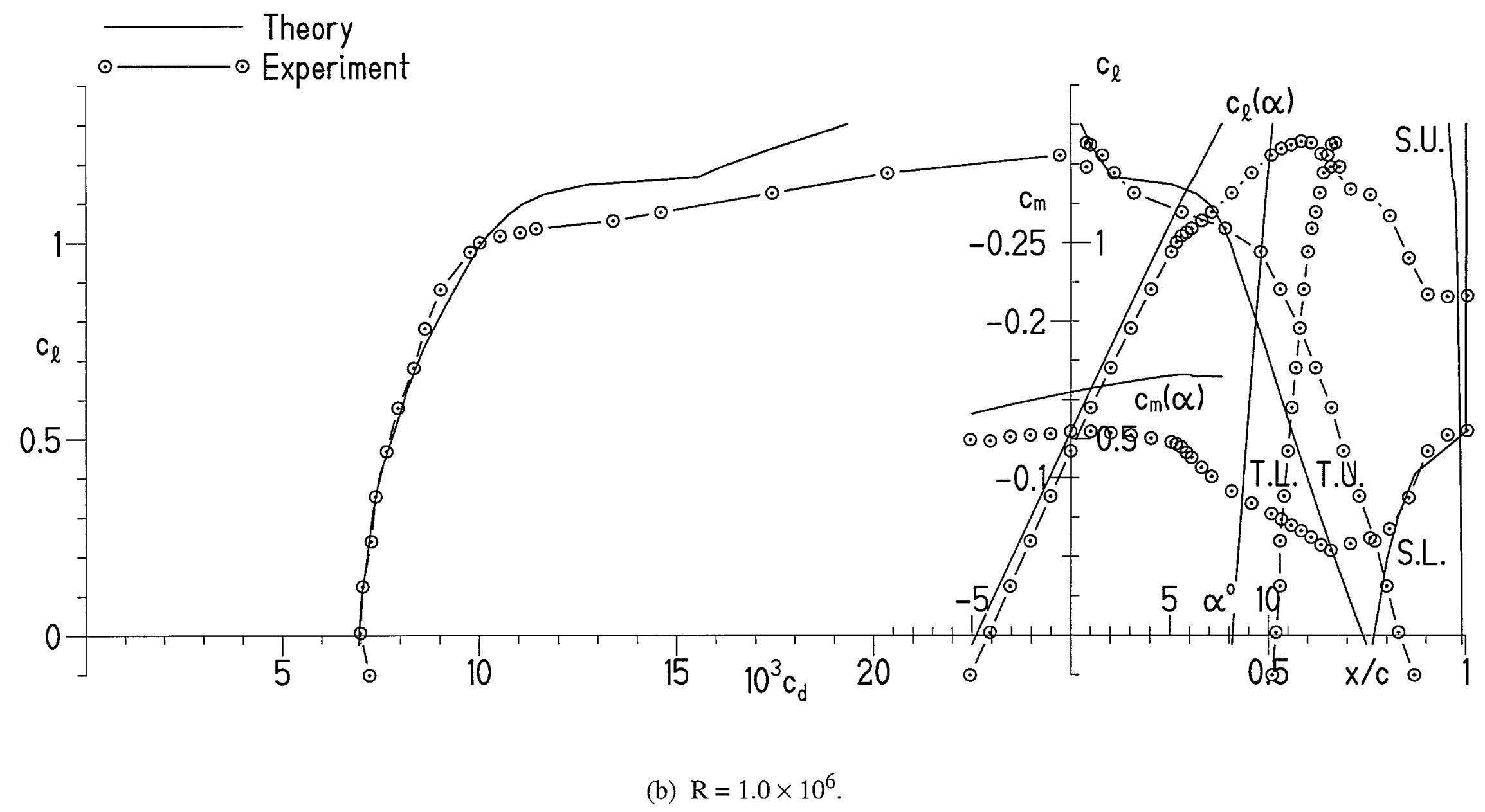

Figure 22.- Continued. 


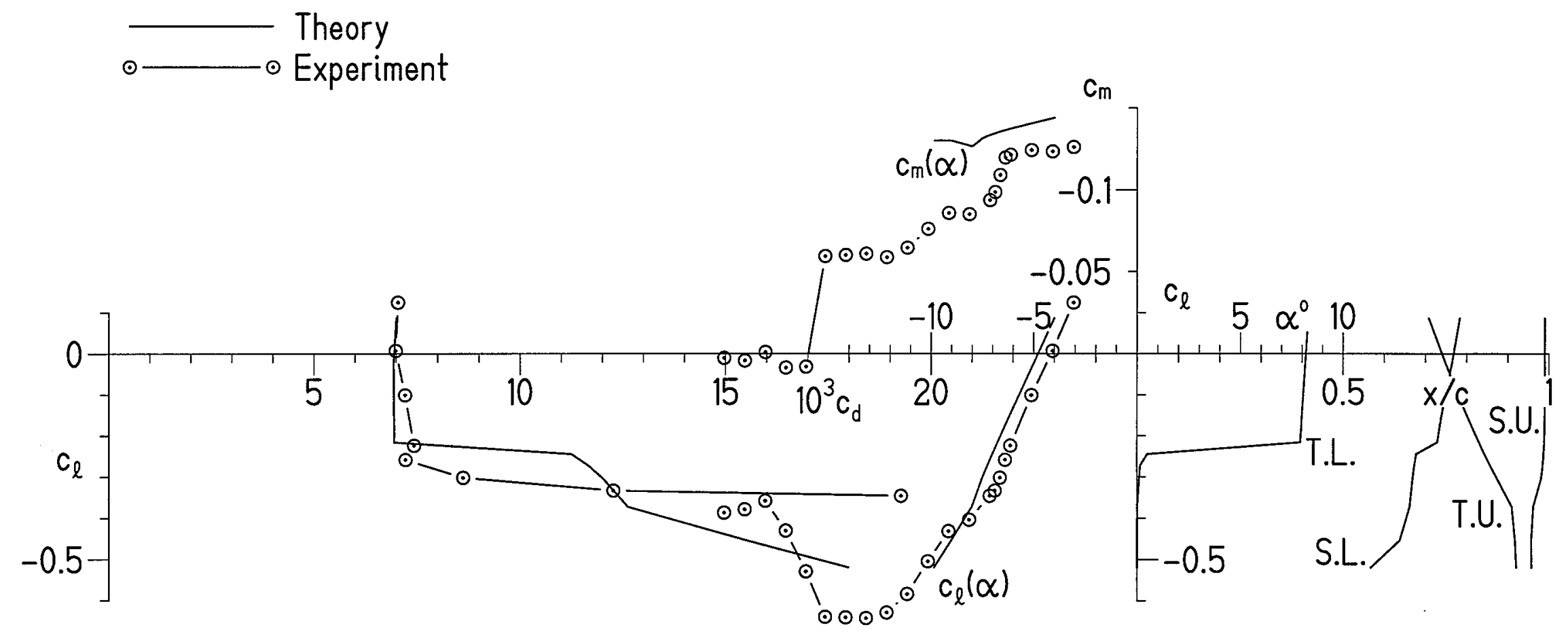

(b) Concluded.

Figure 22.- Continued. 


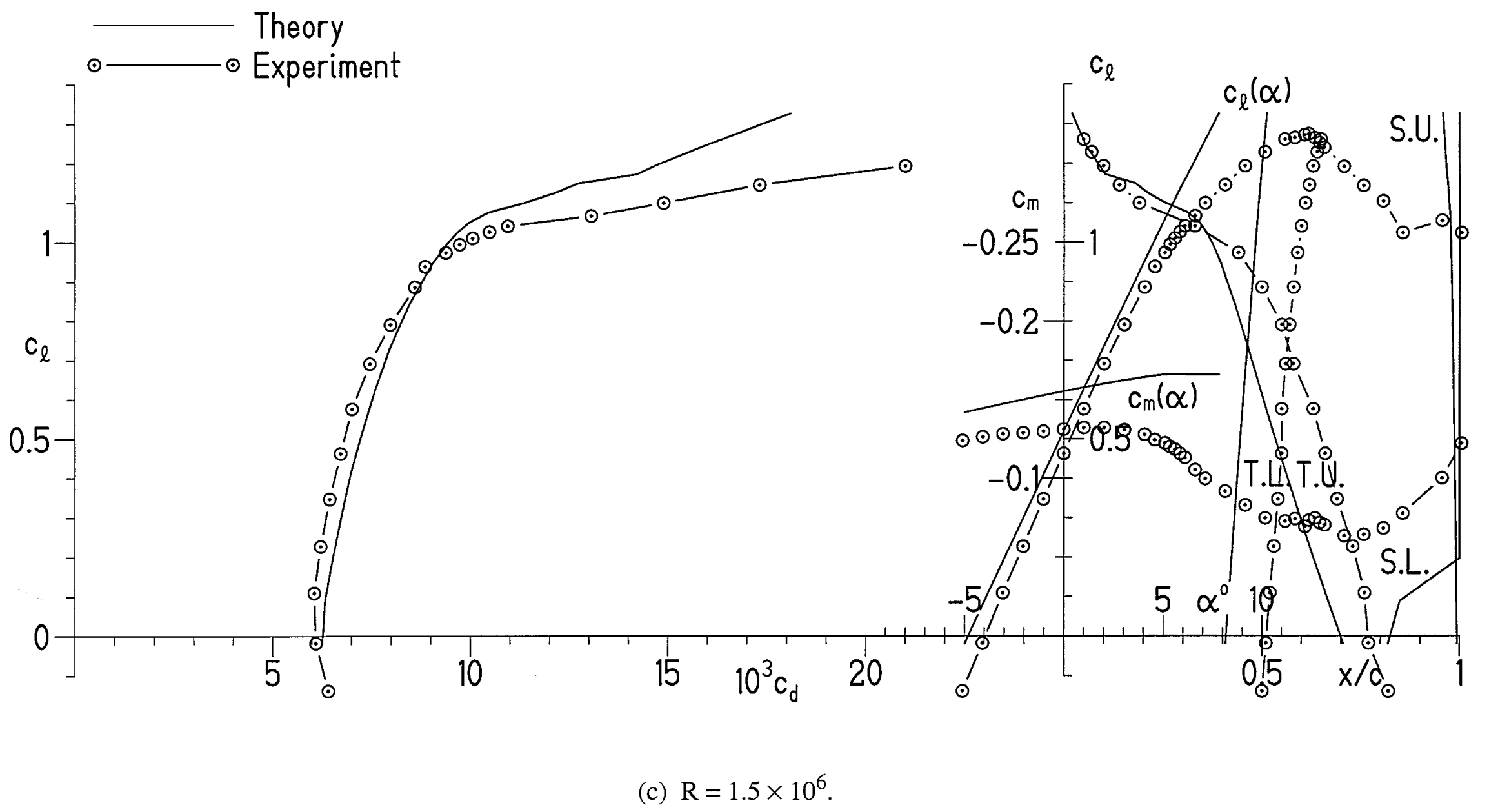

Figure 22.- Concluded. 


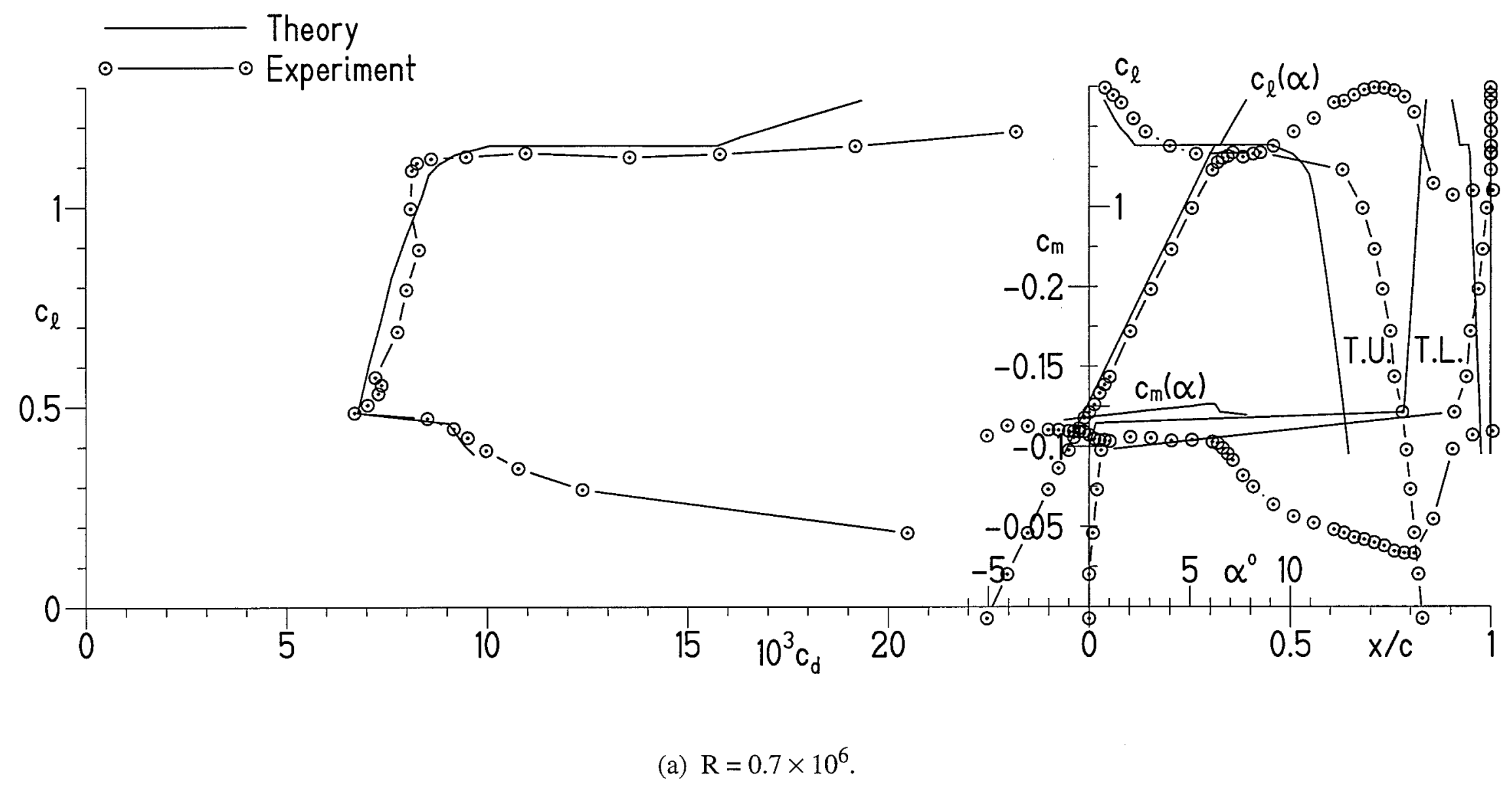

Figure 23.- Comparison of theoretical and experimental section characteristics of S902 airfoil with transition free. 


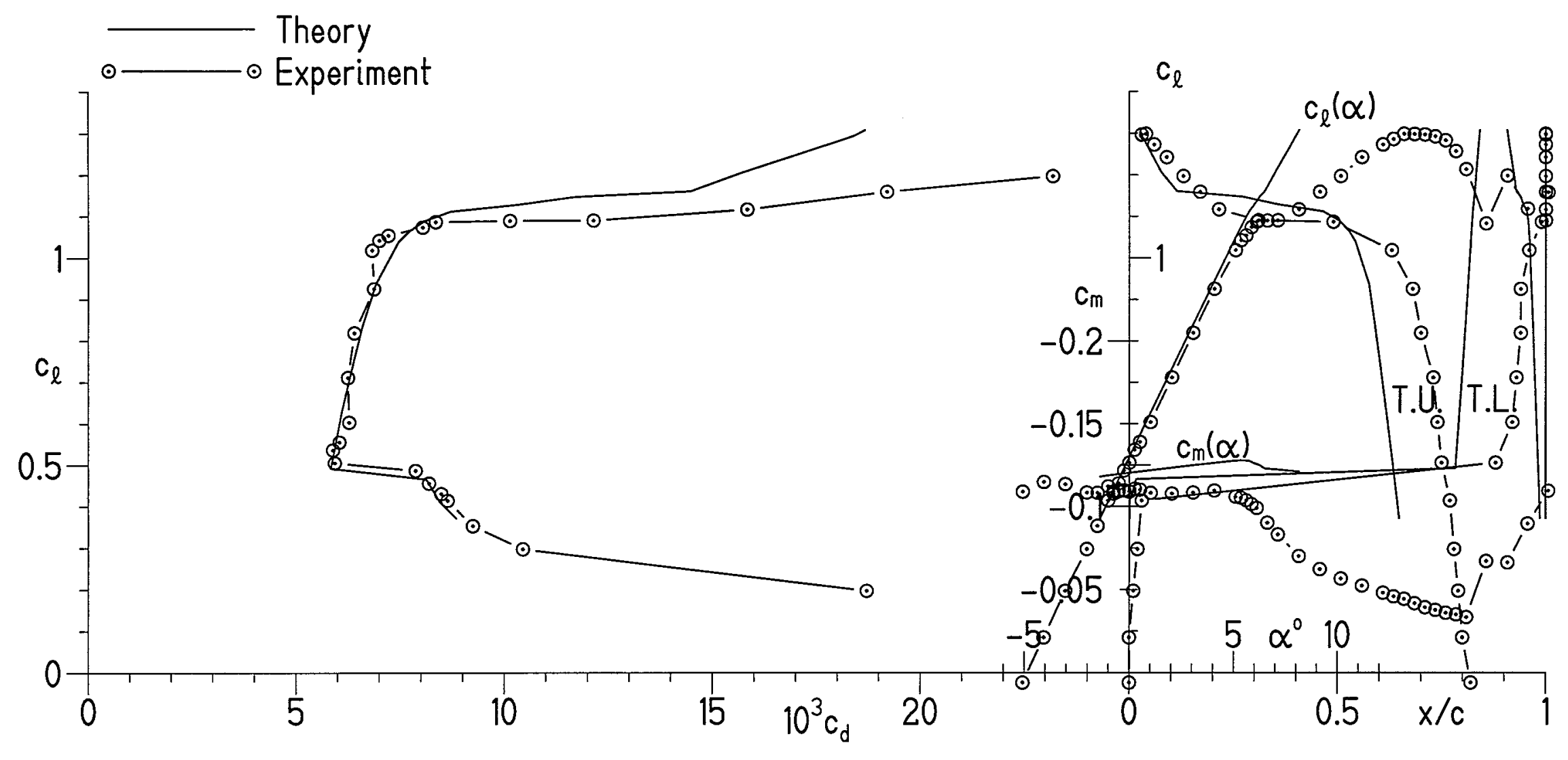

(b) $\mathrm{R}=1.0 \times 10^{6}$.

Figure 23.- Continued. 


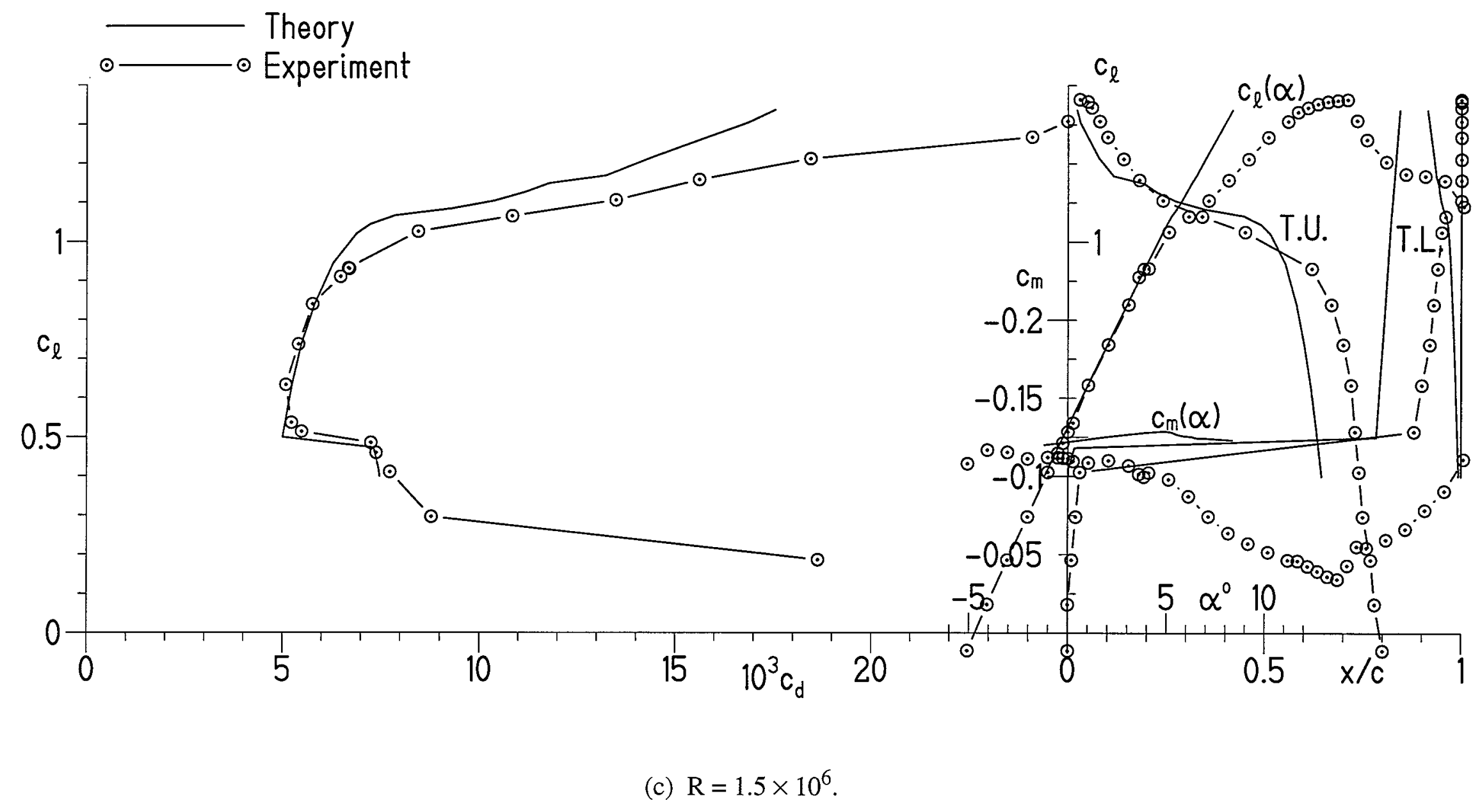

Figure 23.- Concluded. 


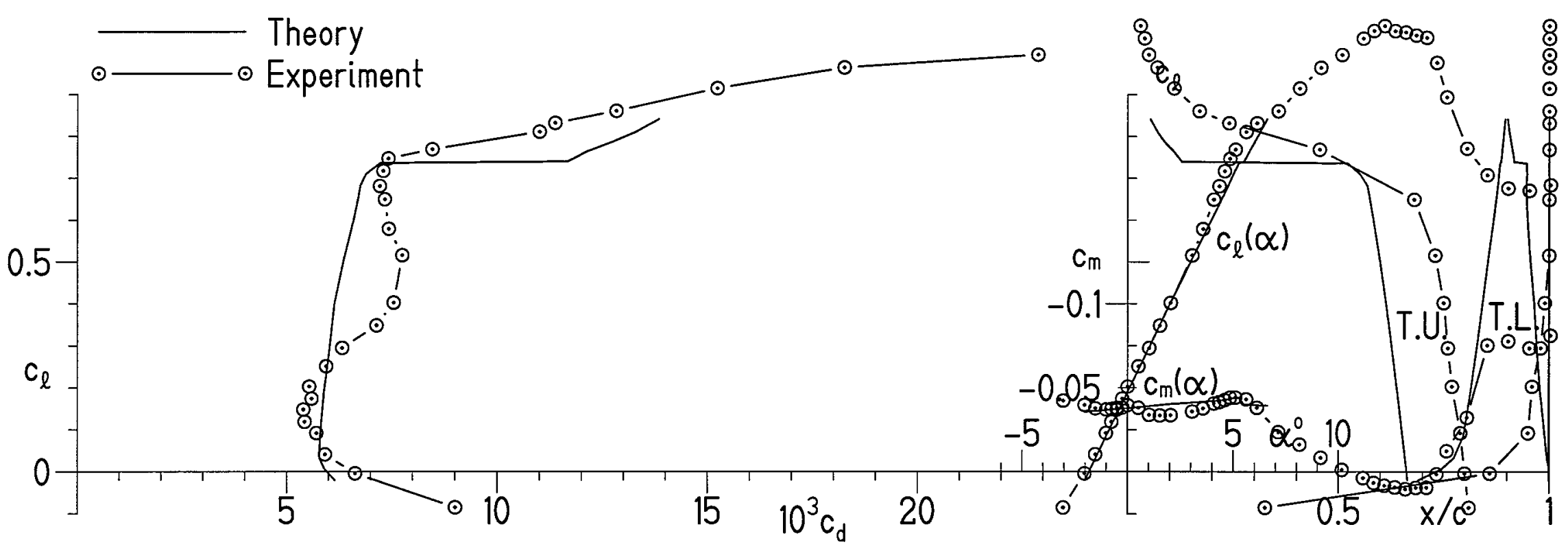

(a) $\mathrm{R}=0.7 \times 10^{6}$.

Figure 24.- Comparison of theoretical and experimental section characteristics of S903 airfoil with transition free. 


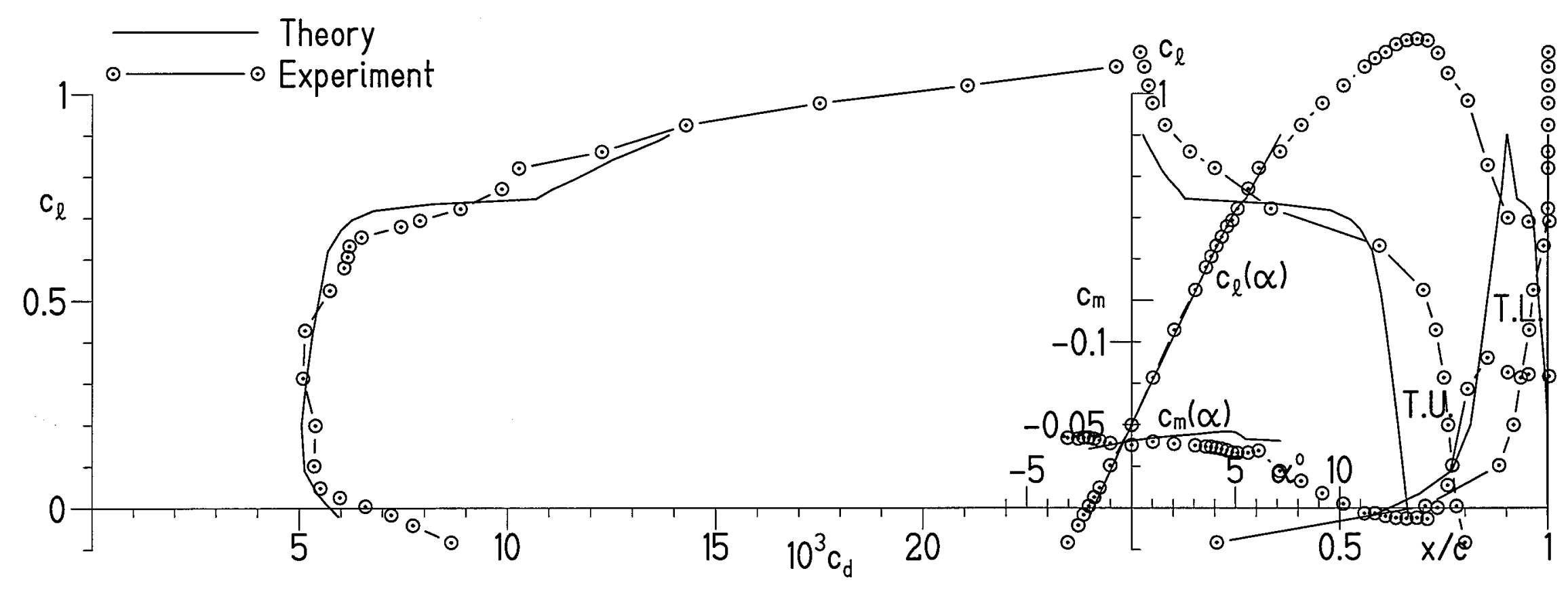

(b) $\mathrm{R}=1.0 \times 10^{6}$.

Figure 24.- Continued. 


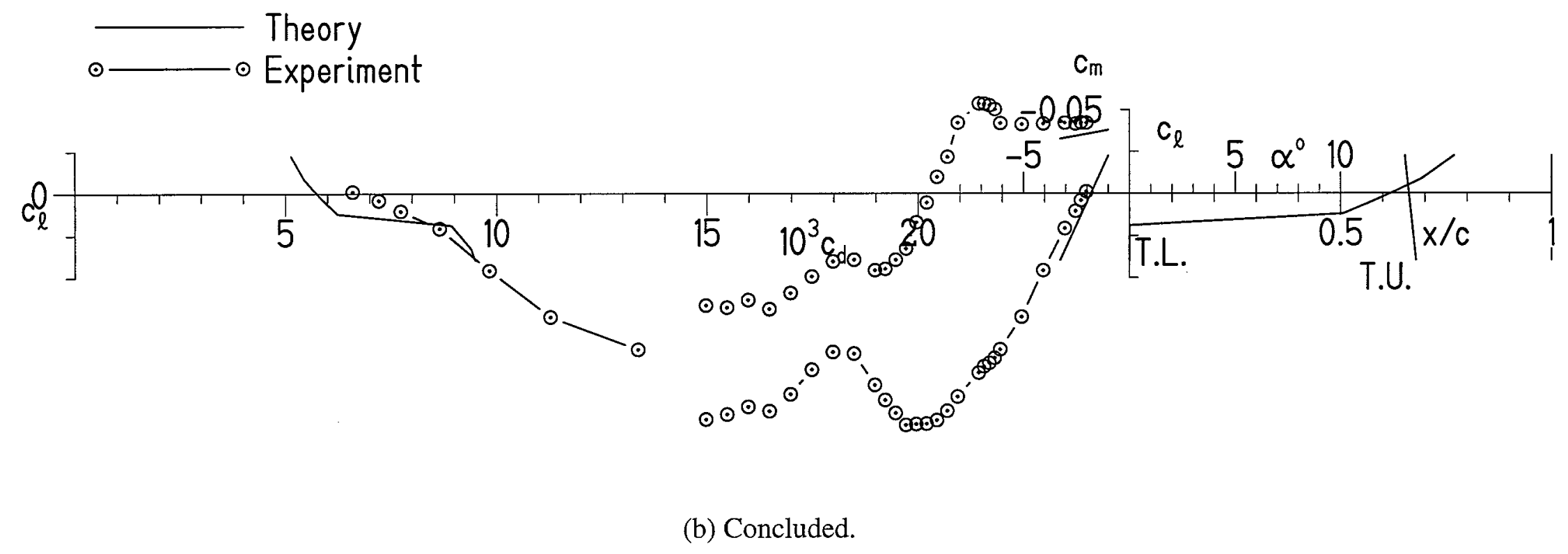

Figure 24.- Continued. 


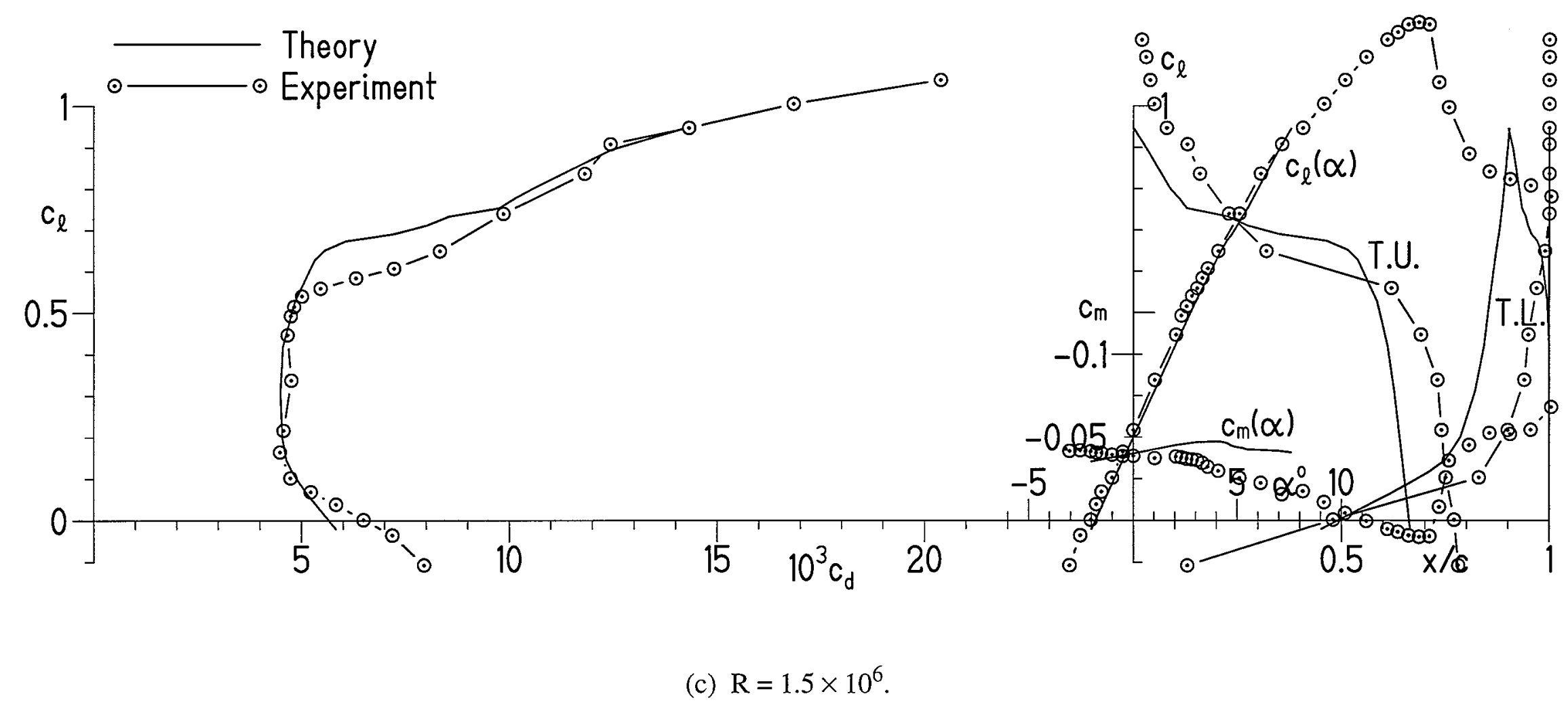

Figure 24.- Concluded. 


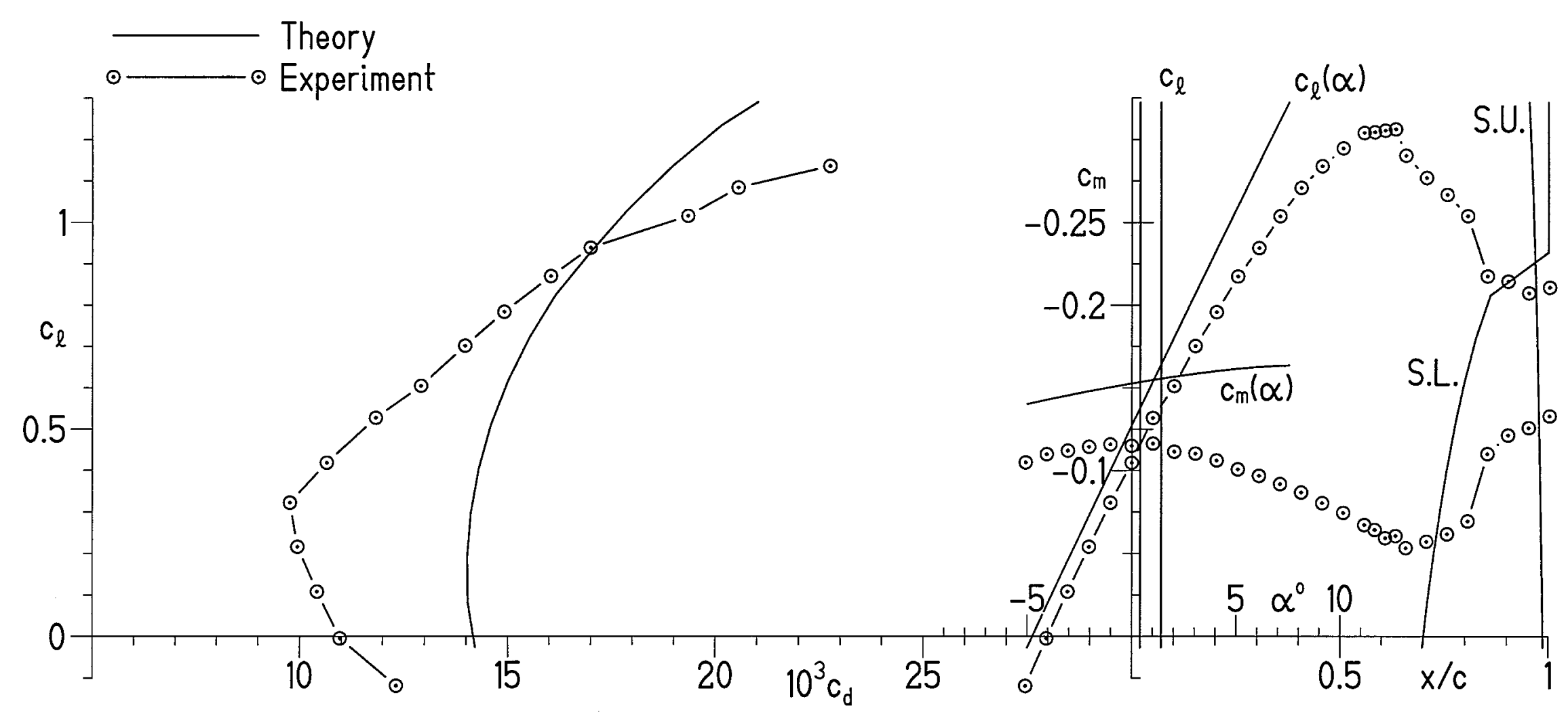

(a) $\mathrm{R}=0.7 \times 10^{6}$.

Figure 25.- Comparison of theoretical and experimental section characteristics of S901 airfoil with transition fixed. 


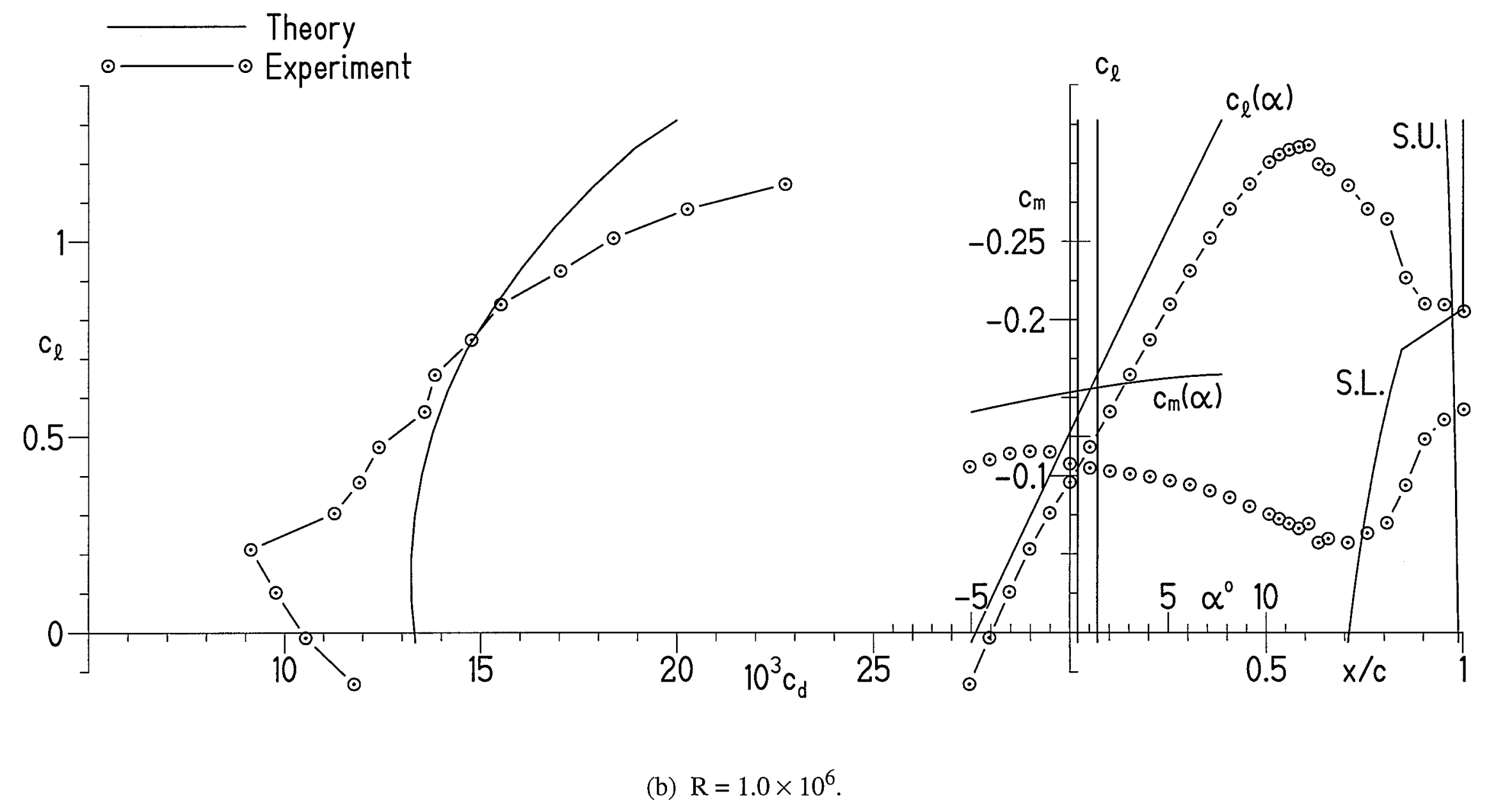

Figure 25.- Continued. 


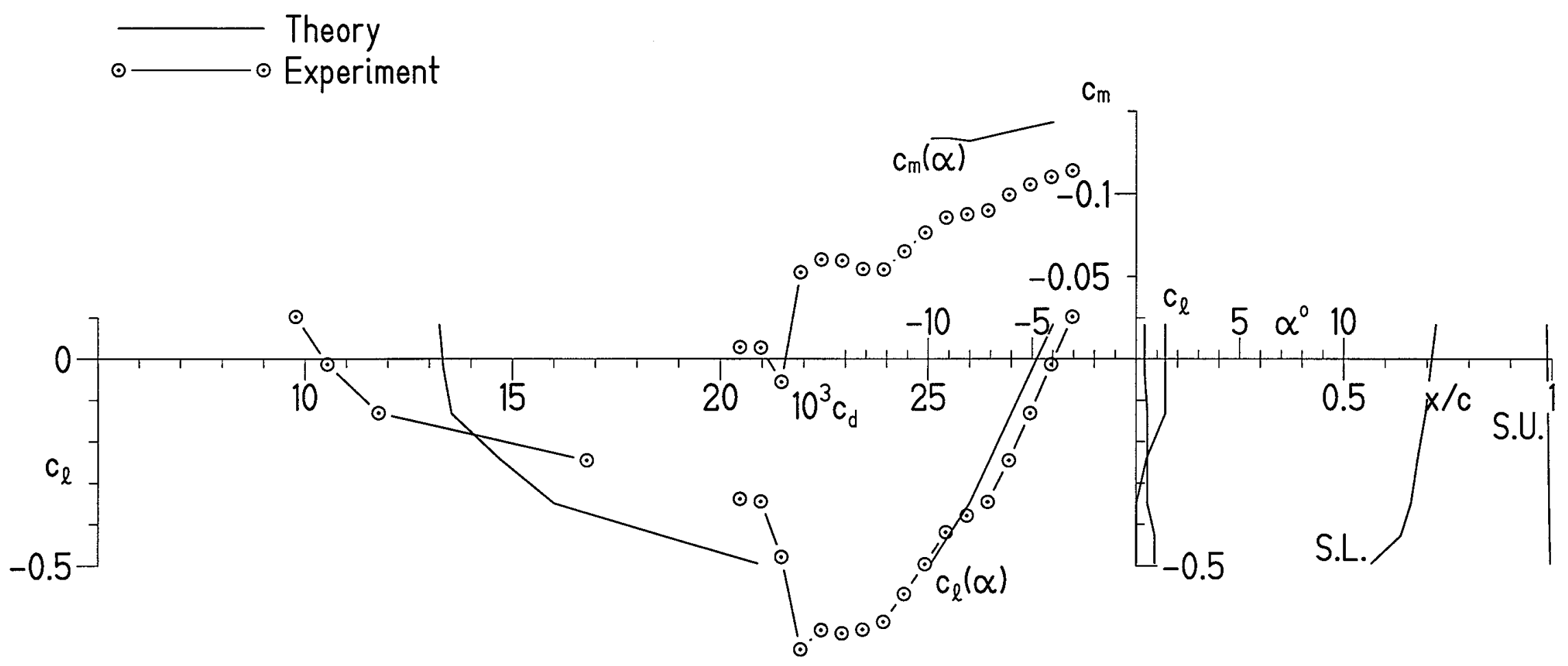

(b) Concluded.

Figure 25.- Continued. 


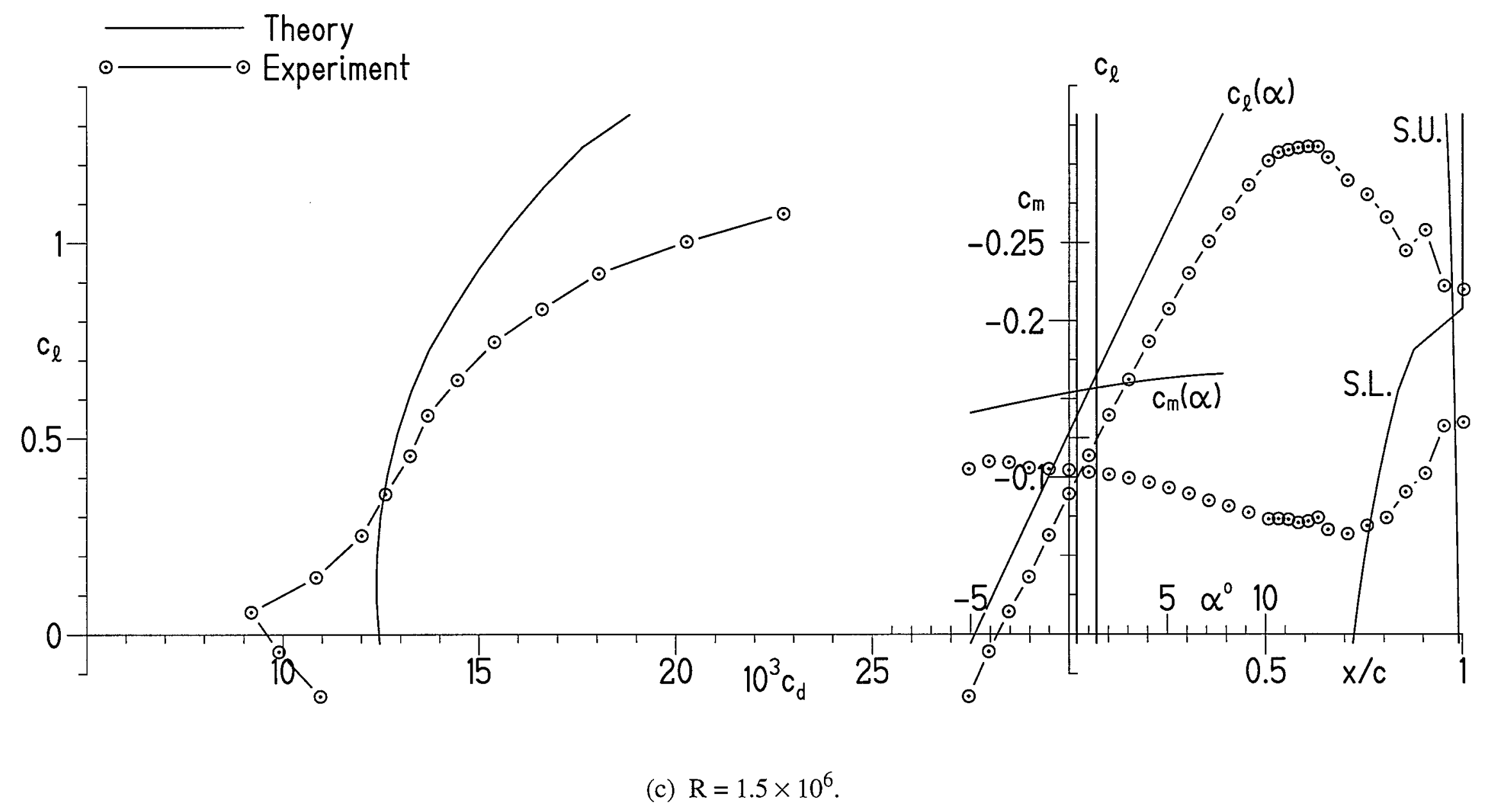

Figure 25.- Concluded. 


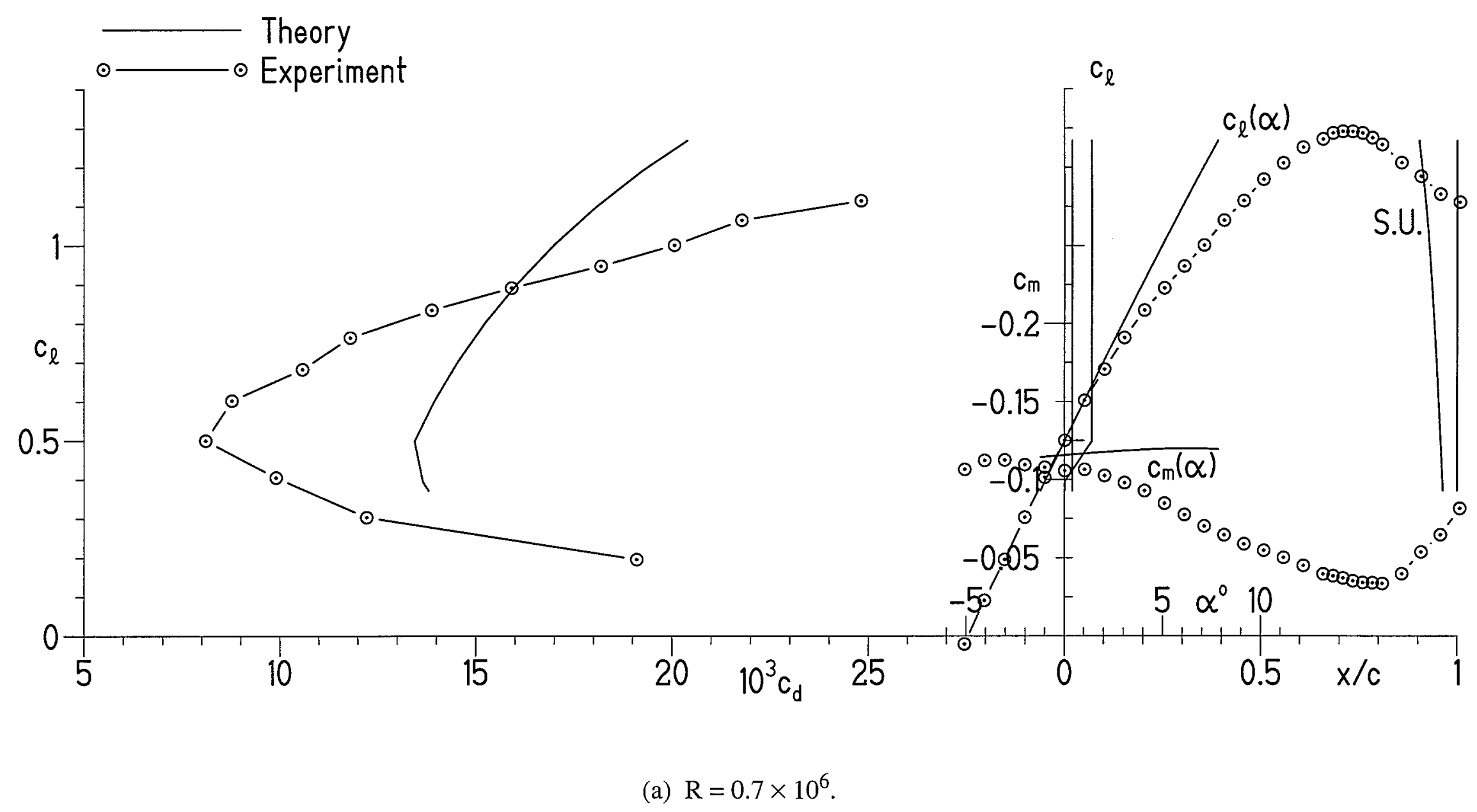

Figure 26.- Comparison of theoretical and experimental section characteristics of S902 airfoil with transition fixed. 


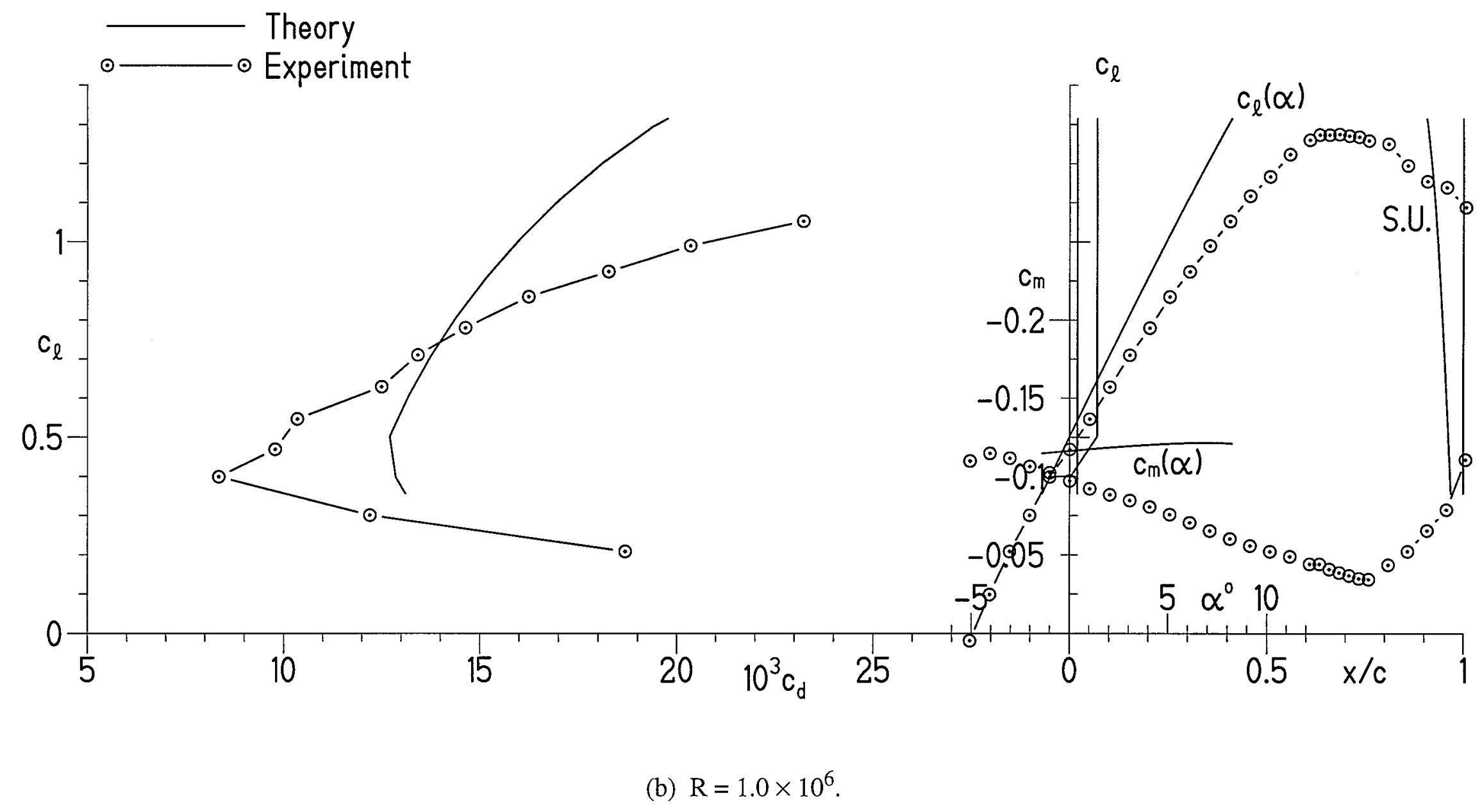

Figure 26.- Continued. 


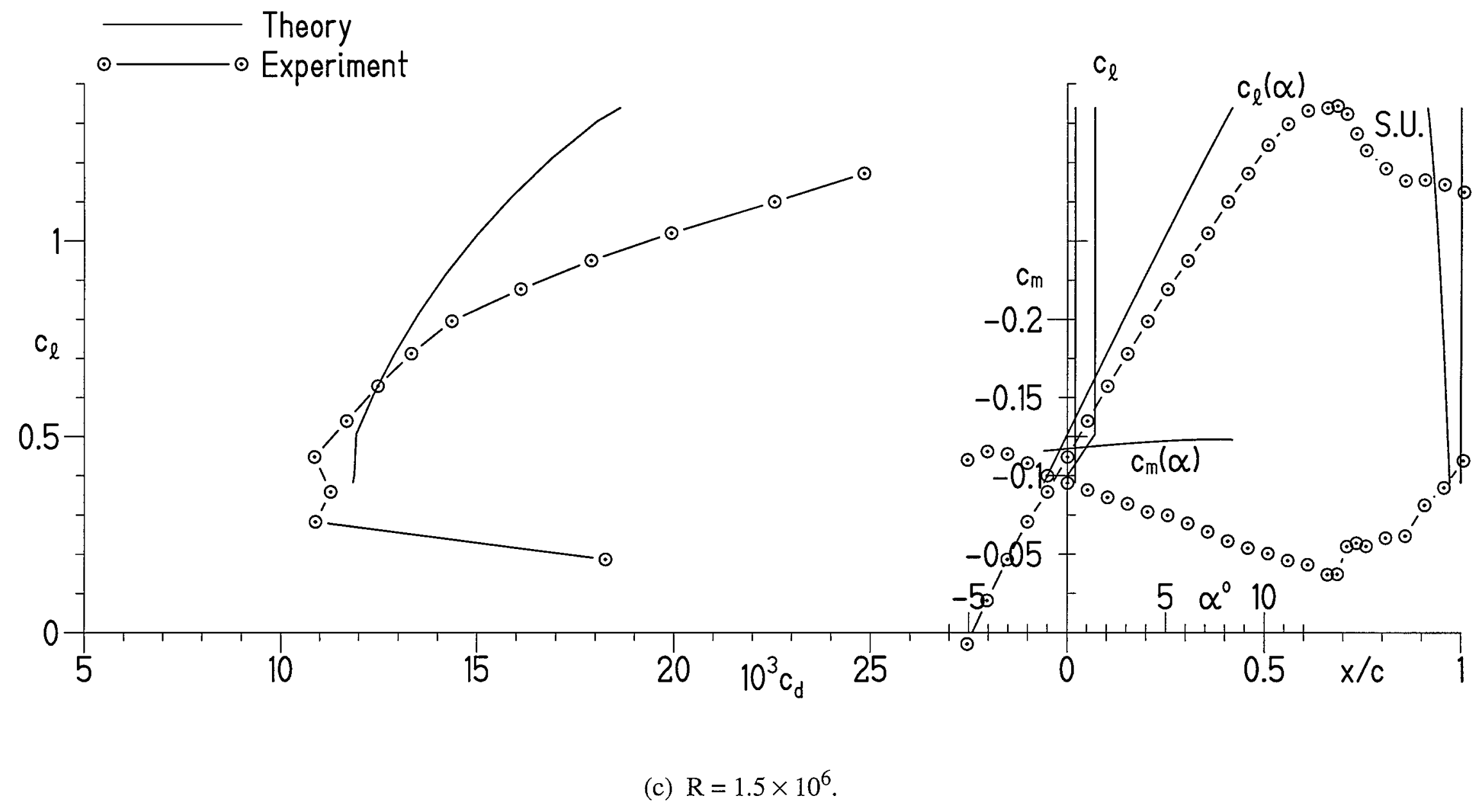

Figure 26.- Concluded. 


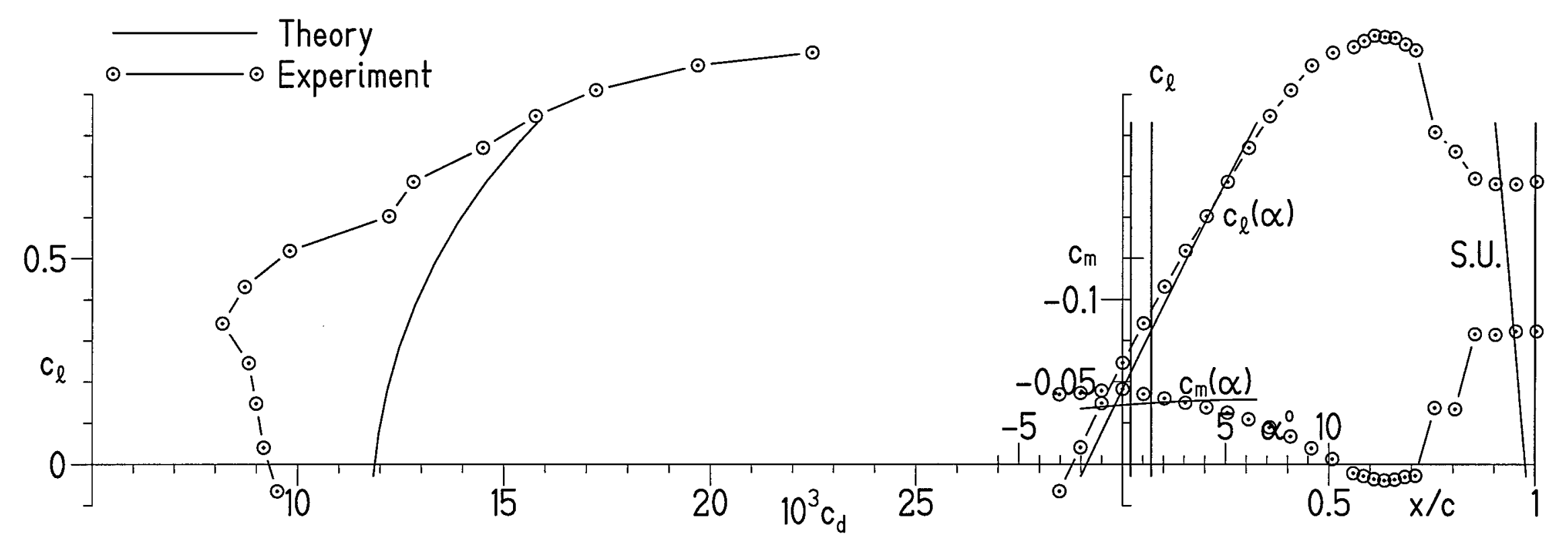

(a) $\mathrm{R}=0.7 \times 10^{6}$. 


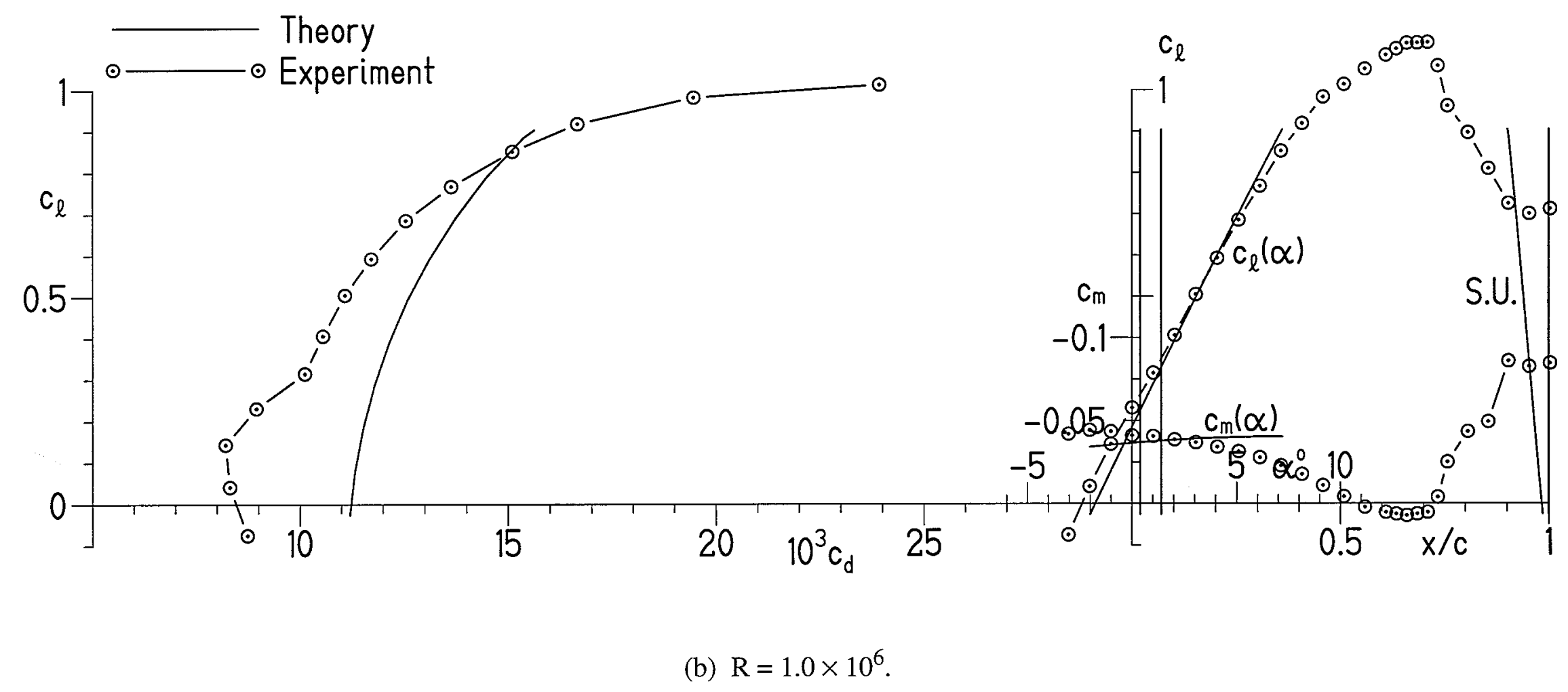

Figure 27.- Continued. 


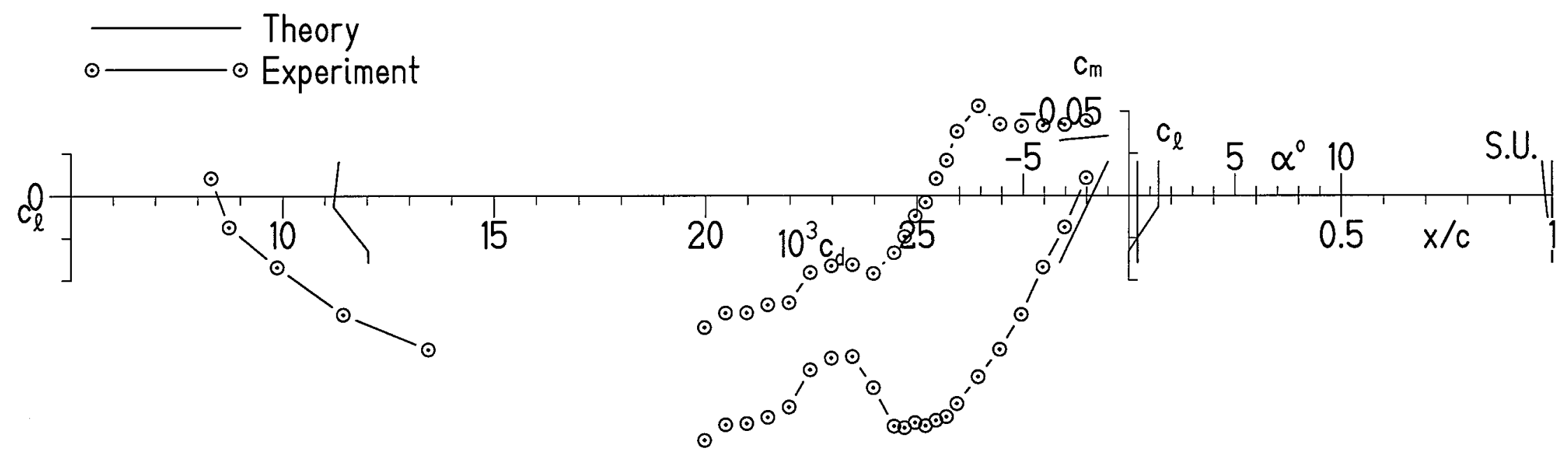

(b) Concluded.

Figure 27.- Continued. 


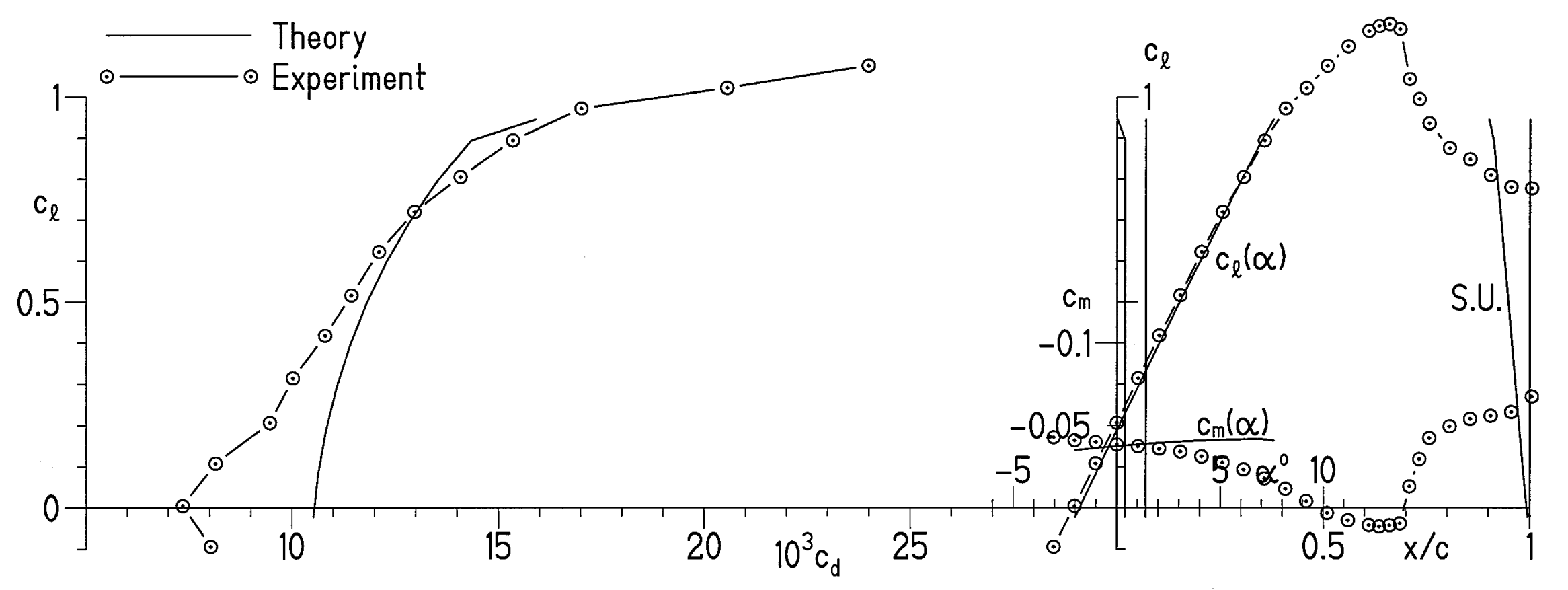

(c) $\mathrm{R}=1.5 \times 10^{6}$.

Figure 27.- Concluded. 


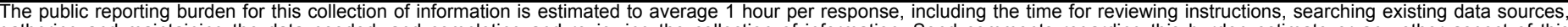

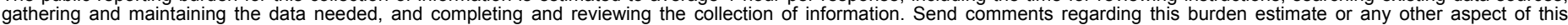

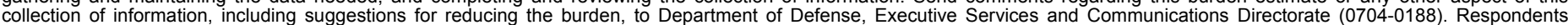

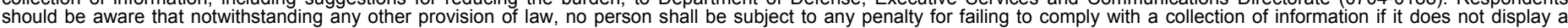

should be aware that notwithstanding

PLEASE DO NOT RETURN YOUR FORM TO THE ABOVE ORGANIZATION.

\section{REPORT DATE (DD-MM-YYYY) January 2005 \\ 2. REPORT TYPE \\ Subcontract report}

4. TITLE AND SUBTITLE

Effects of Airfoil Thickness and Maximum Lift Coefficient on

Roughness Sensitivity
3. DATES COVERED (From - To)

1997 - 1998

5a. CONTRACT NUMBER

DE-AC36-99-GO10337

5b. GRANT NUMBER

5c. PROGRAM ELEMENT NUMBER

5d. PROJECT NUMBER

NREL/SR-500-36336

5e. TASK NUMBER

WER4.3110

5f. WORK UNIT NUMBER

7. PERFORMING ORGANIZATION NAME(S) AND ADDRESS(ES)

Airfoils, Inc.

601 Cricklewood Drive

8. PERFORMING ORGANIZATION REPORT NUMBER

State College, PA 16083

AAM-7-16479-01

9. SPONSORING/MONITORING AGENCY NAME(S) AND ADDRESS(ES)

National Renewable Energy Laboratory

1617 Cole Blvd.

Golden, CO 80401-3393

10. SPONSOR/MONITOR'S ACRONYM(S)

NREL

11. SPONSORING/MONITORING AGENCY REPORT NUMBER NREL/SR-500-36336

12. DISTRIBUTION AVAILABILITY STATEMENT

National Technical Information Service

U.S. Department of Commerce

5285 Port Royal Road

Springfield, VA 22161

13. SUPPLEMENTARY NOTES

NREL Technical Monitor: J. Tangler

14. ABSTRACT (Maximum 200 Words)

A matrix of airfoils has been developed to determine the effects of airfoil thickness and the maximum lift to leadingedge roughness. The matrix consists of three natural-laminar-flow airfoils, the S901, S902, and S903, for wind turbine applications. The airfoils have been designed and analyzed theoretically and verified experimentally in the The Pennsylvania State University low-speed, low-turbulence wind tunnel. The effect of roughness on the maximum life increases with increasing airfoil thickness and decreases slightly with increasing maximum lift. Comparisons of the theoretical and experimental results generally show good agreement.

15. SUBJECT TERMS

airfoils; wind turbine; airfoil design; Pennsylvania State University; wind energy

\begin{tabular}{l}
\hline 16. SECURITY CLASSIFICATION OF: \\
\begin{tabular}{|l|l|l|}
\hline a. REPORT & b. ABSTRACT & c. THIS PAGE \\
Unclassified & Unclassified & Unclassified \\
& & \\
\hline
\end{tabular} \\
\hline
\end{tabular}

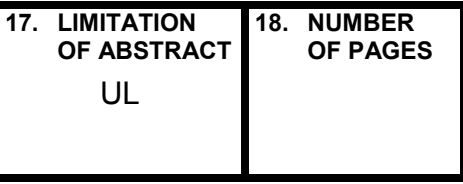

19a. NAME OF RESPONSIBLE PERSON

19b. TELEPONE NUMBER (Include area code) 